Beiträge zum

ausländischen öffentlichen Recht und Völkerrecht

Armin von Bogdandy | Reinhard Mehring (Hrsg.)

\title{
Heinrich Triepel - Parteienstaat und Staatsgerichtshof
}

Gesammelte verfassungspolitische Schriften zur Weimarer Republik 


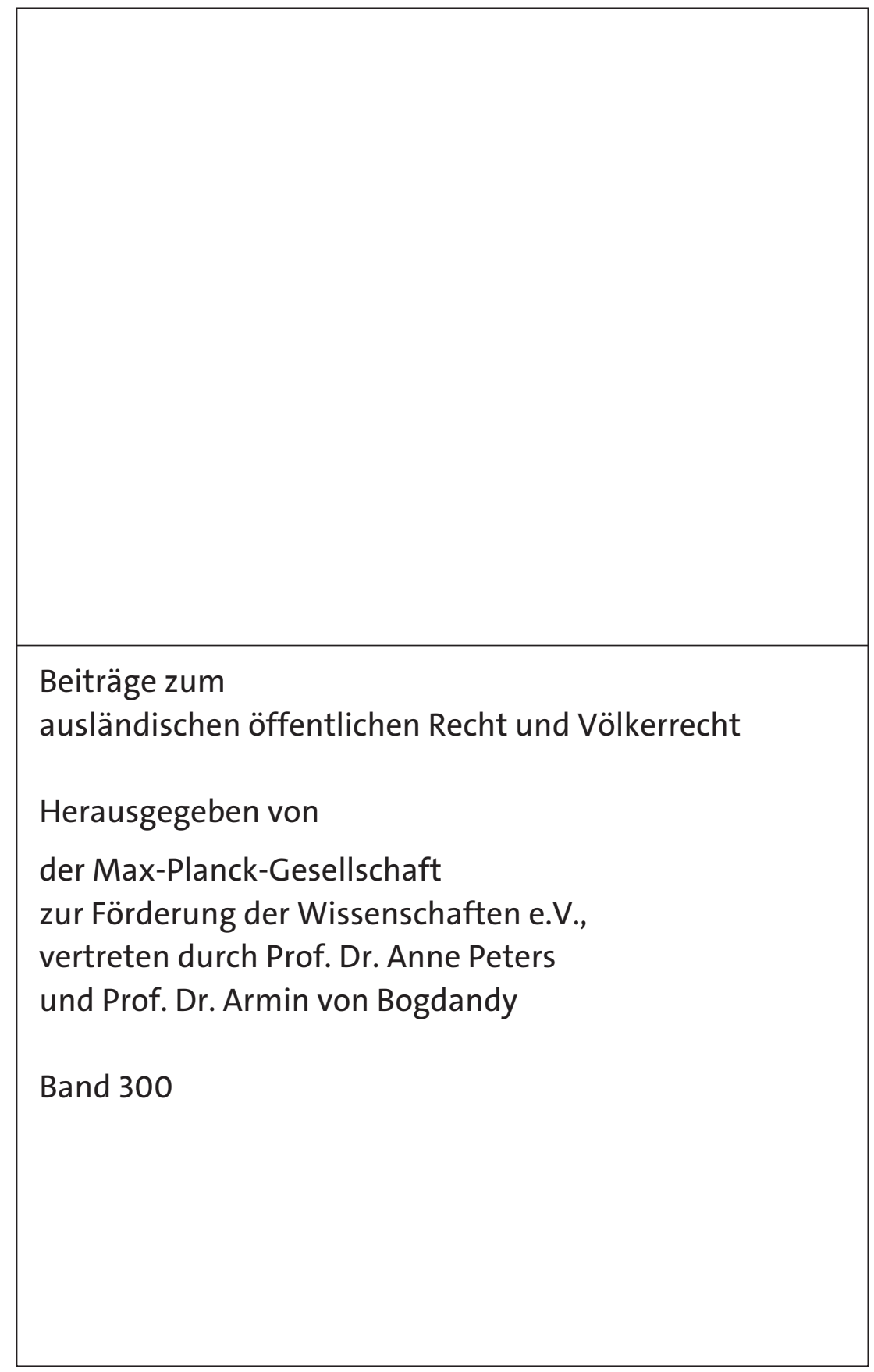


Armin von Bogdandy | Reinhard Mehring

\section{Heinrich Triepel - Parteienstaat und Staatsgerichtshof}

Gesammelte verfassungspolitische Schriften zur Weimarer Republik 
Die Deutsche Nationalbibliothek verzeichnet diese Publikation in der Deutschen Nationalbibliografie; detaillierte bibliografische Daten sind im Internet über http://dnb.d-nb.de abrufbar.

1. Auflage 2021

() Armin von Bogdandy | Reinhard Mehring

Publiziert von

Nomos Verlagsgesellschaft $\mathrm{mbH} \& \mathrm{Co}$. KG

Waldseestraße 3-5 | 76530 Baden-Baden

www.nomos.de

Gesamtherstellung:

Nomos Verlagsgesellschaft $\mathrm{mbH} \& \mathrm{Co}$. KG

Waldseestraße 3-5 | 76530 Baden-Baden

ISBN (Print): 978-3-8487-7736-5

ISBN (ePDF): 978-3-7489-2132-5

DOI: https://doi.org/10.5771/9783748921325

\section{(9) $(\Theta \Theta \Theta$}

Dieses Werk ist lizenziert unter einer Creative Commons Namensnennung - Nicht kommerziell - Keine Bearbeitungen 4.0 International Lizenz. 
Im Gedenken an Michael Stolleis (1941-2021), dem Lehrer und Gelehrten

dem großen Historiker des öffentlichen Rechts in Deutschland 


\section{Vorwort}

Die Geschichte der Weimarer Republik war stets ein Lehrstück: Laboratorium, Spiegel und Mahnung. Während die alte Bundesrepublik sie lange zur Negativfolie erhob, ${ }^{1}$ wurden in den letzten Jahren verstärkt auch offene Möglichkeiten diskutiert. ${ }^{2}$ Der Untergang der Republik blieb gleichwohl eine negative historische Parallele. 2017/18 wurde sie bei der schwierigen Regierungsbildung erneut mahnend beschworen.

Die Historisierung der Weimarer Republik ist inzwischen fortgeschritten. ${ }^{3}$ Wenige andere Epochen der deutschen Geschichte sind so detailliert erforscht. Auch ihre Rechtsgeschichte und Rechtswissenschaftsgeschichte ist inzwischen intensiv erschlossen. ${ }^{4}$ Mit der Gründung der Bundesrepublik musste eine liberale und demokratische Rechtswissenschaft rekonstru-

1 Beginnend mit Karl-Dietrich Bracher, Die Auflösung der Weimarer Republik. Eine Studie zum Problem des Machtzerfalls in der Demokratie, Stuttgart 1955; Fritz René Allemann, Bonn ist nicht Weimar, Köln 1956; Kurt Sontheimer, Antidemokratisches Denken in der Weimarer Republik. Die politischen Ideen des deutschen Nationalismus zwischen 1918 und 1933, München 1962; Friedrich Karl Fromme, Von der Weimarer Verfassung zum Bonner Grundgesetz, Tübingen 1962.

2 Horst Dreier / Christian Waldhoff (Hg.), Das Wagnis der Demokratie. Eine Anatomie der Weimarer Reichsverfassung, München 2018; dies. (Hg.), Weimars Verfassung. Eine Bilanz nach 100 Jahren, Göttingen 2020; Rüdiger Voigt (Hg.), Aufbruch zur Demokratie. Die Weimarer Reichsverfassung als Bauplan für eine demokratische Republik, Baden-Baden 2020.

3 Heinrich August Winkler, Weimar 1918-1933. Die Geschichte der ersten deutschen Demokratie, München 2005; Ulrich Herbert, Geschichte Deutschlands im 20.Jahrhundert, München 2014; detaillierte verfassungsgeschichtliche Darstellung bei Ernst Rudolf Huber, Deutsche Verfassungsgeschichte seit 1789. Bd. VI: Die Weimarer Reichsverfassung, Stuttgart 1981; ders., Deutsche Verfassungsgeschichte seit 1789. Bd. VII: Aufbau, Schutz und Untergang der Weimarer Republik, Stuttgart 1984; Christoph Gusy, Die Weimarer Reichsverfassung, Tübingen 1997; jetzt: Udo Di Fabio, Die Weimarer Verfassung. Aufbruch und Scheitern, München 2018.

4 Michael Stolleis, Geschichte des öffentlichen Rechts in Deutschland. Dritter Band: Staats- und Verwaltungsrechtswissenschaft in Demokratie und Diktatur 1914-1945, München 1999; Christoph Gusy (Hg.), Demokratisches Denken in der Weimarer Republik, Baden-Baden 2000; Katrin Groh, Deutsche Staatsrechtslehrer in der Weimarer Republik. Von der konstitutionellen Staatslehre zur Theorie des modernen demokratischen Verfassungsstaats, Tübingen 2010; Horst Dreier, Staatsrecht in Demokratie und Diktatur, hrsg. Matthias Jestaedt / Stanley L. Paulson, Tübingen 
iert werden. Das Scheitern Weimars wurde dabei auch am „Richtungsstreit ${ }^{\text {“5 }}$ der Weimarer Staatsrechtslehre festgemacht und die rivalisierenden und teils antipodischen Autoren des Streites wurden erneut gelesen. Die Stunde der Staatsrechtswissenschaft schien wieder gekommen, weil Recht und Gerechtigkeit neu bedacht und die Rechtspraxis erneuert werden mussten.

Da eine Generation nationalsozialistisch belasteter Hochschullehrer für große Karrieren aber damals mehr oder weniger ausfiel, übernahmen ältere Weimarer Vertreter erneut wichtige Funktionen im Fach. Die grundlegenden Publikationen des Richtungsstreites wurden seit den 1950er Jahren deshalb auch neu zugänglich gemacht. Rudolf Smend (1955), Erich Kaufmann (1960) und auch Carl Schmitt (1958) bündelten ihre Schriften in Auswahleditionen. Eine dreibändige Ausgabe der Schriften Hermann Hellers folgte. Erst nach 1989 entstanden große Gesamtausgaben der Schriften von Gustav Radbruch, Hans Kelsen und auch Hugo Preuß. Horst Dreier besorgte einen Auswahlband der Schriften Richard Thomas. ${ }^{6}$ Eine Sammlung der Weimarer Schriften Heinrich Triepels (1868-1946), des Begründers der Staatsrechtslehrervereinigung, gab es aber bislang nicht. Dabei ist dessen Position im „Richtungsstreit“ zwischen den Alternativen extremer Politisierung oder Juridifizierung, Schmitt und Kelsen, eigentlich recht gut vertretbar. So schreibt Michael Stolleis in seiner schon im Titel an Triepel anklingenden Programmschrift Staatsrechtslehre und Politik, die Staatsrechtslehre sei „- wenn wir nationalistische und idealistische Obertöne überhören - etwa wieder beim methodischen Eklektizismus Heinrich Triepels angekommen. Seine Position möchte wissenschaftstheoretisch mangelhaft gewesen sein. Jedenfalls barg sie doch ein gewisses Maß an praktischer Klugheit." "7

2016; ders., Kelsen im Kontext. Beiträge zum Werk Hans Kelsens und geistesverwandter Vertreter, hrsg. Matthias Jestaedt / Stanley L. Paulson, Tübingen 2019; Jens Hacke, Existenzkrise der Demokratie. Zur politischen Theorie des Liberalismus in der Zwischenkriegszeit, Berlin 2018.

5 Aus der umfangreichen Literatur hier neben dem grundlegenden Werk von Stolleis nur die rückblickenden Akteursberichte: Ulrich Scheuner, 50 Jahre deutsche Staatsrechtswissenschaft im Spiegel der Verhandlungen der vereinigung der Deutschen Staatsrechtslehrer, in: Archiv des öffentlichen Rechts 97 (1972), S. 349-374; Rudolf Smend, Die Vereinigung der Deutschen Staatsrechtslehrer und der Richtungsstreit, in: Festschrift für Ulrich Scheuner zum 70. Geburtstag, Berlin 1973, S. 575-589.

6 Horst Dreier (Hg.), Richard Thoma. Rechtsstaat - Demokratie - Grundrechte. Ausgewählte Abhandlungen aus fünf Jahrzehnten, Tübingen 2008.

7 Michael Stolleis, Staatsrechtslehre und Politik, Heidelberg 1996, S. 20. 
Trifft dies zu, so fehlt ein Auswahlband seiner wichtigsten Weimarer Schriften. Der vorliegende möchte diese Lücke schließen. Anders als in seinen Monographien verzichtete Triepel in seinen kleinen Weimarer Schriften weitgehend auf bibliographische Nachweise. Um der Zugänglichkeit willen wurden einige (in [...]) nachgetragen, prägnante Hinweise auf neuere deutsche Staatslehrer möglichst identifiziert, kleinere Erläuterungen gelegentlich hinzugefügt. Triepels Rechtsschreibung wurde weitgehend beibehalten, eindeutige Setzfehler wurden korrigiert. Die mühevolle Transkription der Texte übernahm Isa Weyknecht-Diehl.

In seiner wegweisenden Geschichte des öffentlichen Rechts in Deutschland schreibt Stolleis: „Nach Vorgesprächen auf dem Deutschen Juristentag 1921 in Bamberg und bei der Deutschen Gesellschaft für Völkerrecht regte Heinrich Triepel die Gründung einer Vereinigung der Staatsrechtslehrer an. [...] Mit Rundschreiben vom 13. September 1922 lud Triepel auf [den] 13./14. Oktober 1922 nach Berlin ein. Er hatte auch die erste Fassung der am 13. Oktober 1922 beschlossenen Satzung entworfen. Die rasche und allgemeine Zustimmung zu dieser Initiative beweist, daß das Bedürfnis nach einem organisatorischen Zentrum verbreitet war." 8

Der vorliegende Band empfiehlt sich der deutschen Staatsrechtslehre zum 100. Geburtstag ihrer Vereinigung und sollte Michael Stolleis zum 80. Geburtstag gewidmet sein, der die Widmung auch freundlich annahm. Der große Lehrer und Gelehrte, die prägende Gestalt der neueren Rechtsgeschichtsforschung, verstarb leider am 18. März 2021 in Frankfurt nach kurzer, schwerer Krankheit, sodass der vorliegende Band nur noch seiner Erinnerung gewidmet sein kann.

8 Michael Stolleis, Geschichte des öffentlichen Rechts in Deutschland. Dritter Band: Staats- und Verwaltungsrechtswissenschaft in Demokratie und Diktatur 1914-1945, München 1999, S. $186 \mathrm{f}$. 


\section{Inhaltsverzeichnis}

Einleitung von Reinhard Mehring

Teil I: Ausgangslage 1918/19

Text 1 Der Völkerbund

Text 2 Der Zusammenschluß des Deutschen Reichs und des Staates Deutsch-Österreich

Text 3 Das Frankfurter Parlament und die künftige

Nationalversammlung

Text 4 Die Auslieferung des Kaisers

Text 5 Der Entwurf des Reichsgesetzes über die Errichtung eines Staatsgerichtshofs

Text 6 Die Entwürfe zur neuen Reichsverfassung

\section{Teil II: Krisenbefund 1923/24}

Text 7 Die Krisis des Parlamentarismus in der Welt

Text 8 Die Ermächtigungsgesetze

Text 9 Der Föderalismus und die Revision der Weimarer Reichsverfassung 


\section{Teil III: Grundauffassung 1927/1929}

Text 10 Staatsrecht und Politik. Rede beim Antritte des Rektorats

Text 11 Die Staatsverfassung und die politischen Parteien. Rektoratsrede

Text 12 Wesen und Entwicklung der Staatsgerichtsbarkeit

Teil IV: Übergang zur „nationalen Revolution“?

Text 13 Die Entscheidung des Staatsgerichtshofs im Verfassungsstreite zwischen Preußen und dem Reiche

Text 14 Die nationale Revolution und die deutsche Verfassung

Text 15 Im Namen der Schriftleitung

\section{Teil V: Letzte Texte}

Text 16 [Nachruf] Viktor Bruns †

Text 17 [Vom Stil des Rechts. Schlusskapitel]

Text 18 Zweierlei Föderalismus

Bibliographische Nachweise 


\section{Einleitung \\ von Reinhard Mehring}

Es hat zunächst einen sehr einfachen, äußerlichen Grund, dass Triepels Weimarer Schriften nach 1949 nicht wieder aufgelegt wurden: Triepel verstarb bald nach Kriegsende 1946; anders als Smend und Kaufmann, Schmitt oder Kelsen konnte er die weitere Rezeption seines Werkes nicht mehr steuern. Sachliche Gründe sind seine stärkere Orientierung am Völkerrecht, die verfassungshistorisch vergleichende Argumentation sowie der Verzicht auf eine eigene systematische Theorieanstrengung. Durchgängig, nüchtern und konsequent analysierte Triepel aber die Verfassungsgeschichte Weimars, vom Anfang bis Ende, Oktober 1918 bis April 1933, und hob dabei grundlegende Entwicklungen hervor, die wir auch heute noch diskutieren: Ausgangsfragen, Probleme der föderalen Struktur und Entwicklungstendenzen zur Ausnahmegesetzgebung, zum Parteienstaat und zur Verfassungsgerichtsbarkeit. Triepel formulierte seine Auffassung des Staatsrechts auch bündig in seiner bekannten Berliner Rektoratsrede Staatsrecht und Politik von 1927, die hier mit bibliographischen Nachweisen erneut abgedruckt ist. Seine ambivalente oder auch zwiespältige Haltung zur Weimarer Republik zeigte sich 1933/34 dann deutlich in der anfänglichen nationalistischen Bejahung der „legalen Revolution“ des Nationalsozialismus, die bald jedoch dezidierter Ablehnung wich.

Triepel war durch den Wilhelminismus geprägt. Bei der Gründung der Weimarer Republik war er bereits 50 Jahre alt. Wie viele Nationalliberale betrachtete er die Reichsgründung als große politische Tat, verehrte Bismarck und die konstitutionelle Monarchie. Als gebürtiger Sachse, passionierter Leipziger, wechselte er - nach Zwischenstationen in Tübingen (1900) und Kiel (1909) - 1913 an die Berliner Universität. Er bejahte die preußische Hegemonie und bewunderte die wilhelminische Reichsverfassung. Triepel schrieb sachlich, nüchtern und ausgewogen und strebte zur monographischen Synthese. Er publizierte magistrale Hauptwerke wie Völkerrecht und Landesrecht (1899), Die Reichsaufsicht (1917) oder Die Hegemonie (1938); zur Weimarer Republik äußerte er sich aber nicht in derart bündiger, monographischer Form. Eine gewisse Zurückhaltung war ihm hier durch seine zentrale Stellung im Fach und seine Aufgabe und Rolle in der 1922 gegründeten Staatsrechtslehrervereinigung auferlegt. Es ist vermutlich kein Zufall, dass er seine Gründung eine „Vereinigung“ nannte: 
ein „politisch-sittliches Aktivum“ (Smend), das eine produktive Vergemeinschaftungs- und Vereinigungsform finden sollte. Triepel konnte den Fachdiskurs und die Zunft damals nur organisieren und „vereinigen“, wenn er sich nicht allzu stark exponierte und positionierte. Eine „neutrale“ Mediatoren- oder Vermittlungsrolle hat er aber auch nicht gesucht. Vielmehr äußerte er sich zu manchen Fragen doch sehr dezidiert, wobei er einen „nationalen“ Standpunkt selbstverständlich unterstellte. Wie die folgenden Texte zeigen, positionierte er sich im Richtungsstreit eindeutig gegen Hans Kelsen und nahe zu Rudolf Smend. ${ }^{1}$ Smend hat Triepels zentrale Rolle 1938 in einem Geburtstagsartikel auch eindrücklich erinnert ${ }^{2}$ und später noch eine rückblickende Würdigung publiziert. ${ }^{3}$

Sondiert man Triepels damalige Schriften anhand der Bibliographie, die Gassner ${ }^{4}$ in seiner einschlägigen Triepel-Monographie abdruckte, so hat Triepel in der Epoche der Weimarer Republik, zwischen 1919 und 1933,

1 Dazu auch Triepels scharfe Ablehnung von Kelsens Smend-Kritik in seiner Rezension von Hans Kelsen, Der Staat als Integration. Eine prinzipielle Auseinandersetzung, Wien 1930, in: Deutsche Juristen-Zeitung 35 (1930), Sp. 1041.

2 Rudolf Smend, Heinrich Triepel zum 70. Geburtstag, in: Forschungen und Fortschritte 14 (1938), S. 58-59; Wiederabdruck in: Reinhard Mehring (Hg.), „Auf der gefahrenvollen Straße des öffentlichen Rechts“. Briefwechsel Carl Schmitt - Rudolf Smend 1921-1961, 2010, 2. verb. Aufl. Berlin 2012, hier S. 194 f: „Triepel hat nie vorher ein Programm aufgestellt, sondern hat im Ringen mit dem Stoff und mit seinen eigenen, etwa durch seine Beziehung zu Binding bezeichneten wissenschaftlichen Voraussetzungen schrittweise den Weg von überwiegend konstruktiver Behandlung zu einer immer stärker in Geschichte und politischer Wirklichkeit begründeten Arbeitsweise gefunden - und hat damit den einzigen zwingenden Beweis für die methodische Richtigkeit des neuen Denkens geliefert. Er hat das Neue auch grundsätzlich vertreten, besonders reizvoll und eindrücklich in der berühmten Berliner Rektoratsrede von 1926 über ,Staatsrecht und Politik'. Aber er hat seine Lebensaufgabe nicht in der Beteiligung am Methodenstreit gesehen, sondern in strengster und gewissenhaftester Arbeit am Stoff und in dem so zu gewinnenden Höchstmaß an Einsicht in die Dinge und in das Gesetz, das in und über den Dingen ist. Diese wissenschaftliche Haltung hat seine Autorität begründet, die in den verworrenen Jahren nach Versailles und Weimar nach so vielen Seiten zum Guten gewirkt hat. Sie hielt die Fachgenossen in unruhiger Zeit in der von ihm gegründeten und anfangs geleiteten Vereinigung der Deutschen Staatsrechtslehrer zusammen und hat in diesen Kreisen manchen bedenklichen Abweg verhindert. Sie war ein politisch-sittliches Aktivum im äußeren wie im innerpolitischen deutschen Kampf - um so eindrücklicher, je entschiedener Triepel im Gegensatz zum Versailler wie zum Weimarer System stand.“

3 Rudolf Smend, Heinrich Triepel, 1966, in: ders., Staatsrechtliche Abhandlungen und andere Schriften, 3. erw. Aufl. Berlin 1994, S. 594-608.

4 Ulrich M. Gassner, Heinrich Triepel. Leben und Werk, Berlin 1999, S. 524-536; ders., Heinrich Triepel, in. Hans-Christof Kraus (Hg.), Geisteswissenschaftler II 
nicht wenige Abhandlungen, Aufsätze und Rechtsgutachten, Zeitungsartikel und Rezensionen publiziert. Beachtlich ist auch seine Quellensammlung zum Deutschen Reichsstaatsrecht, die, 1901 erstmals erschienen, 1922 für die dritte Auflage völlig neu bearbeitet wurde und 1926 und 1931 ergänzt erschien. Viele eingehend analysierte Texte sind parallel in der Quellensammlung dokumentiert, die für Triepels Sicht der Weimarer Verfassungsgeschichte mit zu berücksichtigen ist. Der umfangreiche Festschriftbeitrag Streit zwischen Reich und Ländern, 1923 auch als selbständige Publikation erschienen, ${ }^{5}$ wurde nicht in die vorliegende Sammlung aufgenommen, zumal ein zeitnaher Beitrag zur Föderalismus-Thematik enthalten ist. Nur einige Texte gehören heute noch zum Lektürekanon: insbesondere die Berliner Rektoratsreden und Broschüren Staatsrecht und Politik, Die Staatsverfassung und die politischen Parteien sowie der Vortrag Wesen und Entwicklung der Staatsgerichtsbarkeit, den Triepel auf der dritten Tagung der Staatsrechtslehrervereinigung 1928 in Wien gehalten hat. Einige der hier abgedruckten Texte, insbesondere die Zeitungsartikel, dürften dagegen nahezu unbekannt sein, sind aber für ein geschlossenes Bild seiner Sicht der Verfassungsgeschichte Weimars unverzichtbar.

Bei der Durchsicht der Bibliographie und Texte fällt auf, dass Triepel schon sehr früh zum Systemwechsel 1918/19 Stellung bezog und die Verfassungsfragen, wie Max Weber und andere, eingehend analysierte. Die lange Abhandlung Die Entwürfe zur neuen Reichsverfassung, im Februar 1919 abgeschlossen, scheint dabei von einer geringschätzenden Ablehnung von Hugo Preuß ${ }^{6}$ polemisch gefärbt zu sein. Vielleicht spielten hier Berliner Animositäten und Konkurrenzen mit hinein: Es ist bekannt, ${ }^{7}$ dass auch Max Weber gerne statt Preuß von Ebert zum Staatssekretär und verantwortlichen Redakteur des Verfassungsprozesses ernannt worden wäre. Triepels liberale Argumentation gegen den „demokratischen Absolutis-

(Berlinische Lebensbilder), Berlin 2012, S. 189-209; vgl. auch Christian Tomuschat, Heinrich Triepel (1868-1946), in: Festschrift 200 Jahre Juristische Fakultät der Humboldt-Universität zu Berlin. Geschichte, Gegenwart und Zukunft, hrsg. Stefan Grundmann u.a., Berlin 2010, S. 497-521.

5 Heinrich Triepel, Streitigkeiten zwischen Reich und Ländern. Beiträge zur Auslegung des Artikels 19 der Weimarer Reichsverfassung, Tübingen 1923.

6 Dazu aber Triepels respektvolle nekrologische Rezension von Hugo Preuß, Reich und Länder. Bruchstücke eines Kommentars zur Verfassung des Deutschen Reiches, Berlin 1928, in: Deutsche Juristen-Zeitung 34 (1929), Sp. 583; zu Preuß vgl. Michael Dreyer, Hugo Preuß. Biografie eines Demokraten, Stuttgart 2018.

7 Dazu wegweisend Wolfgang Mommsen, Max Weber und die deutsche Politik, 1959, Tübingen 2. erw. Aufl.1974, S. 396 ff.; vgl. Michael Dreyer, Hugo Preuß. Biografie eines Demokraten, Stuttgart 2018, S. $336 \mathrm{ff}$. 
mus“ und föderalen „Partikularismus“ mag heute irritieren und befremden; der ständige Vergleich mit den historischen Parallelen von 1848, mit Bismarck und der wilhelminischen Reichsverfassung scheint die außenpolitischen Determinanten, im nationalstaatlichen Drehbuch befangen, etwas zu vernachlässigen. Ein Abgleich von Triepels Bedenken und Befürchtungen vom Februar 1919 mit der späteren Geschichte der Weimarer Republik ist hier aber nicht Thema. Die detaillierte Analyse der frühen Verfassungsentwürfe wird hier im vollen Umfang als Lehrstück und Muster einer multiperspektivischen verfassungspolitischen Erwägung abgedruckt. Eine lange Abhandlung Der Weg der Gesetzgebung nach der neuen Reichsverfassung, $1920 \mathrm{im}$ - von Triepel mit herausgegebenen - Archiv des öffentlichen Rechts publiziert, ${ }^{8}$ kann als positivrechtliches Gegenstück zur Entwürfe-Abhandlung betrachtet werden, wurde aber in die vorliegende Sammlung nicht auch noch aufgenommen. Die Entwürfe-Abhandlung, Triepels AntiPreuß, fürchtet eine übermäßige Unitarisierung und wünscht eine angemessene Berücksichtigung der föderalen Eigenstaatlichkeit. Nicht zu übersehen ist auch die - über Weber und Preuß hinausgehende - Bejahung einer starken Stellung des Reichspräsidenten und ein Misstrauen gegenüber dem „System der parlamentarischen Regierung“, wobei Triepel vor allem das Instrument der Ministerverantwortlichkeit kritisiert. ${ }^{9}$ So schreibt er:

„In dem Streit über die Vorzüge und die Fehler des parlamentarischen Regierungssystems sind die Akten noch längst nicht geschlossen. [...] Der Verfasser dieses Aufsatzes hat sich niemals davon überzeugen können, daß das System innerlich begründet oder gar notwendig sei [...] $\mathrm{Da}$ das deutsche Parteiwesen mit seiner kaum sehr bald zu beseitigenden Zersplitterung dem parlamentarischen System die größten Schwierigkeiten bereiten wird, kann im Ernste nicht geleugnet werden.“ (hier S. 116)

Bei solchen Sätzen verwundert es nicht, dass Triepel 1923 einen - fast unbekannten - Artikel über die Krisis des Parlamentarismus in der Welt veröffentlichte. Beim Übergang zur Weimarer Republik erklärte er sich ansonsten gegen eine Instrumentalisierung des Völkerbundes durch die Siegermächte, namentlich die USA, und gegen die Auslieferung des Kaisers, ge-

8 Heinrich Triepel, Der Weg der Gesetzgebung nach der neuen Reichsverfassung, in: AÖR 39 (1920), S. 456-546.

9 Dazu noch die grundsätzlichen Einwände von Florian Meinel, Vertrauensfrage. Zur Krise des heutigen Parlamentarismus, München 2019, S. 53 ff. 
gen eine Konzeption des Staatsgerichtshofes als Strafgericht und für eine (Frankfurter) Nationalversammlung und einen großdeutschen Wiederanschluss „Deutsch-Österreichs“, wobei Triepel mit Traditionen von 1848 argumentierte. Insgesamt geht er 1918/19 selbstverständlich vom Fortbestand des Deutschen Reiches und nationalstaatlicher Souveränität aus. Das sind einige seiner Ausgangspositionen vor der Verabschiedung der Weimarer Verfassung und Unterzeichnung des Versailler Vertrages.

Die frühen Krisen der Weimarer Republik thematisiert Triepel 1923/24 in knappen Interventionen auch als „Krisis“ des Parlamentarismus; er betont die Spannung zwischen der liberalen Konzeption des freien Abgeordneten und der „Wirklichkeit“ des Parteienstaates und kritisiert die verfassungswidrige Antwort und Lösung, Regierbarkeit durch „Ermächtigungsgesetze“ zu erzwingen. Dabei unterscheidet er zwischen der parlamentarischen Regierungspraxis und den Ermächtigungsgesetzen des Reichspräsidenten auf Grund des Art. 48, die er nicht weiter problematisiert. Nicht den Reichspräsidenten, damals noch Ebert, sondern den „Parlamentsabsolutismus" und die Praxis labiler Koalitionsregierungen fürchtet er Ende 1923, auf dem Höhepunkt der Hyperinflation. So schreibt er in der Deutschen Juristen-Zeitung:

„Wenn es sich einbürgert, daß die sich ablösenden Regierungen durch Sondergesetze Ermächtigungen von dem Ausmaß erhalten, wie jetzt geschehen, so würden offenbar die organisatorischen Hauptstücke der RVerf. aus den Angeln gehoben. Nur eine formalistische Denkweise gestattet die Auffassung, daß das durch ein Gesetz, gleichviel welcher Form, so nebenher bewerkstelligt werden könnte. Es mag sein, daß sich zuzeiten eine Verfassung als unbrauchbar erweist, um das Staatsschiff durch die Brandung zu steuern, und daß es sich dann rechtfertigen läßt, die Verf. um der Not des Volkes und Staates willen beiseite zu setzen. Aber man muß sich klar darüber sein, daß die Abkehr von der Verf., obwohl sie sich in ein Gesetz kleidet, nicht Anwendung, sondern Verletzung der Verfassung ist. Auch die gesetzgebende Gewalt kann einen Staatsstreich unternehmen. Sie sollte sich aber dann offen zu ihm bekennen." (hier S. 132)

Intensiver noch erörtert Triepel die Spannung von Unitarismus und Föderalismus. Für die Zeitschrift für Politik erneuert er 1924 hier seine frühen Bedenken gegen den unitaristischen Ehrgeiz der Reichsverfassung, kritisiert aber auch den bayerischen Separatismus und „Partikularismus" und bejaht den Zug zur Unitarisierung in der deutschen Nationalgeschichte; er meint, dass eine "gewalttätige Beschleunigung der unitarischen Entwick- 
lung" durch die Weimarer Verfassung eine „föderalistische Reaktion“ und Opposition provoziert habe, die ihrerseits reichsfeindlich wurde. Triepel beruft sich dagegen auf den Freiherrn vom Stein und die kommunale „Selbstverwaltung“ und hofft auf Preußen als hegemonialen Anwalt einer maßvollen Balance von Unitarisierung und Föderalisierung. Er bejaht eine Stärkung des Föderalismus und engere Verknüpfung von Preußen und Deutschland. Ein Bismarck fehle dafür aber heute. So schließt Triepel 1924 mit den Sätzen:

„Vor zwei Menschenaltern ward uns ein Staatsmann geschenkt, dem der große Wurf gelang. Es ist bitter, zu wissen, daß die Gottheit eine solche Gunst einem Volke nicht zweimal in hundert Jahren gewährt.“

Solche Sätze zeigen deutlich, wie sehr Triepel Weimar an Bismarck und dem Wilhelminismus maß. Seine Ausführungen zur preußischen Hegemonie und "geschichtlichen Mission“ Preußens weisen dabei auf das spätere magistrale Werk Die Hegemonie voraus.

Seine grundlegenden Überlegungen und Überzeugungen expliziert Triepel 1926/27 in seinen beiden Berliner Rektoratsreden Staatsrecht und Politik und Die Staatsverfassung und die politischen Parteien. Staatsrecht und Politik positioniert sich dabei im Richtungsstreit deutlich gegen die „normlogische Schule" Hans Kelsens und bejaht die Einbeziehung politisch-teleologischer Gesichtspunkte ins Staatsrecht. Triepel argumentiert historisch wie systematisch; mit Verweis auf die politischen Professoren des 1848er-Parlaments betont er den politischen Gehalt des Staatsrechts und das Akteursengagement der Staatsrechtslehrer. Er zieht eine wissenschaftsgeschichtliche Linie konstruktivistischer Jurisprudenz von Gerber über Laband zu Kelsen, polemisiert aber vor allem gegen Kelsen, der die juristische Konstruktion dogmatisch verabsolutiert und vom Zweckgehalt isoliert habe. Sein imposantes Gesamtpanorama der Entwicklung der Staatsrechtslehre ist nicht ohne ironische Pointe: Triepel stellt Kelsen, den erbitterten Kritiker des Naturrechts, ${ }^{10}$ nämlich in das ältere vormoderne Naturrecht zurück, das die „lückenfüllende Konstruktion“, wie noch Kelsen, blind gesucht und betrieben habe, weil es sich über seine impliziten Wertungen täuschte. Triepel lehnt die juristische Konstruktion nicht grundsätzlich ab; sie gehöre selbstverständlich zum juristischen Handwerk und zur „Berufsanschauung“; nur solle man eben die „Maske des Logischen“ ablegen und sich „in voller Offenheit“ zur politisch-teleologischen Betrachtung und

10 Dazu nur Hans Kelsen, Die philosophischen Grundlagen der Naturrechtslehre und des Rechtspositivismus, Berlin 1928. 
Wertung bekennen. Triepel argumentiert also, ähnlich wie einst Max Weber oder Gustav Radbruch, für eine scharfe Trennung von Erkenntnis und Bekenntnis und eine offene Explikation politischer Motive und Interessen.

Diese Maxime beherzigte er selbst aber nicht konsequent. So finden sich schon im Vortrag Staatsrecht und Politik herzensmonarchistische Signale, wenn Triepel auf das „monarchische Prinzip“ und die Abdankungserklärung verweist, die ein Monarch „nicht namens des Staats, sondern gegenüber dem Staat abgibt"; eine solche Entscheidung solle nicht als Regierungsakt konstruiert werden. Offenbar kritisiert Triepel die Form der Abdankung des Kaisers bei Kriegsende; er betont, dass er es "gerade im Staatsinteresse für geboten halte, das Staatsoberhaupt ganz frei darüber entscheiden zu lassen, ob es sein Verbleiben im Amte oder sein Ausscheiden für notwendig halte." Diese Freiheit wurde Wilhelm II. am 9. November 1918 genommen. Der Reichskanzler erklärte der Öffentlichkeit den vollständigen Thronverzicht, noch bevor Wilhelm II. sich auch nur zur Abdankung als Kaiser (bei Erhalt der preußischen Königswürde) bereit erklärt hatte. ${ }^{11}$ Wenn Triepel in seiner Rektoratsrede 1926 daran erinnert, klingt sein Herzensmonarchismus, wie 1918/19 in den Interventionen gegen die Auslieferung des Kaisers, deutlich an; viele konservative Kollegen und Hörer der Rektoratsrede werden das in der Friedrich-Wilhelms-Universität zu Berlin jedenfalls so verstanden haben. ${ }^{12}$ Ganz offen explizierte also auch Triepel seine politischen Sympathien nicht.

Preußisch-monarchistische Töne finden sich auch in der Rektoratsrede Die Staatsverfassung und die politischen Parteien, die laut Vorwort „zur Erinnerung an den König Friedrich Wilhelm III., den Stifter der Universität“ gehalten wurde. Triepel kontrastiert hier die preußischen Reformen und den klassischen Liberalismus mit der Lage des „Parteienstaats“ in der „Massendemokratie“. Dabei unterscheidet er Liberalismus und Demokra-

11 Detaillierte Darstellung bei Ernst Rudolf Huber, Deutsche Verfassungsgeschichte seit 17.89. Bd. V: Weltkrieg, Revolution und Reichserneuerung 1914-1919, Stuttgart 1978, S. $678 \mathrm{ff}$.

12 Zur politischen Geschichte der Universität bis 1933 vgl. Michael Grüttner, Die Universität in der Weimarer Republik. Der Lehrkörper 1918-1932, in: Heinz-Elmar Tenorth (Hg.), Geschichte der Universität Unter den Linden Bd. II: Die Berliner Universität zwischen den Weltkriegen 1918-1945, Berlin 2012, S. 67 ff., 135 ff, hier etwa S. 76: Ministerpräsident Otto Braun „plädierte 1928 für ein Verbot der Reichsgründungsfeiern, weil er in ihnen, versteckte Versuche zur Pflege monarchistischer Überlieferungen' sah". 
tie, auch unter Berufung auf Carl Schmitts Parlamentarismuskritik, ${ }^{13}$ sowie vier „Stadien“ der Legalisierung des Parteienstaats; er konstatiert ein Ende des freien Abgeordnetenmandats im Parteienzwang und fragt, ob die Entwicklung schon bis zur vollen „Inkorporation“ der Parteien in den Staat gelangt, ob der „Parteienstaat“ also bereits konsequent institutionalisiert sei. Triepel betont einen Widerspruch zwischen der juristischen Theorie und der „Wirklichkeit des politischen Lebens": Als Negation des freien Mandats sei der Parteienstaat zwar „rechtlich undenkbar“; faktisch aber sei er in Weimar „zur Tatsache geworden“: „So stehen sich also hier nach liberalen Prinzipien geformtes Recht und massendemokratische Wirklichkeit unversöhnlich gegenüber.“ Triepel hofft in dieser Lage auf eine „Überwindung“ der parteienstaatlichen Massendemokratie durch eine neue „Führeroligarchie“14 und eine „neue Selbstverwaltung“. Nicht ohne Weiteres ist dieser Befund etwa mit Max Webers Sicht von Parlament und Regierung im neugeordneten Deutschland in Einklang zu bringen; Triepels bedeutungsschwer wiederholte Forderung nach "Selbstverwaltung" bleibt unausgeführt und hält sich in den damaligen Verfassungsdebatten bedeckt. Sein Schüler Gerhard Leibholz wertete den „Parteienstaat“ dann für die Bundesrepublik positiv um. ${ }^{15}$

So wilhelminisch und konservativ Triepel auch dachte, war er doch ein Anhänger des liberalen Rechtsstaats. So erklärte er sich 1924 auf dem 33. Deutschen Juristentag in Heidelberg, als zweiter Berichterstatter kurzfristig eingesprungen, gegen „stillschweigende“ Verfassungsänderungen für förmliche Positivierungen nach Maßgabe von Art.76 WRV und optierte auch für ein richterliches Prüfungsrecht des Staatsgerichtshofs. Er formulierte dazu sogar eine Ergänzung des Art. 76 und betrachtete solche Erweiterungen als „Triumph der Idee des Rechtsstaats“. ${ }^{16}$ Triepel antwortete auf den Verfassungswandel und die Ermächtigungsgesetze also mit der Forde-

13 Carl Schmitt, Die geistesgeschichtliche Lage des heutigen Parlamentarismus, München 1926.

$14 \mathrm{Zu}$ Triepels Führungsverständnis dann insgesamt ders., Die Hegemonie. Ein Buch von führenden Staaten, Stuttgart 1938; Delegation und Mandat im öffentlichen Recht. Eine kritische Studie, Stuttgart 1942.

15 Dazu etwa Gerhard Leibholz, Der moderne Parteienstaat (1960), in: ders., Verfassungsstaat-Verfassungsrecht, Stuttgart 1973, S. 68-94; dagegen etwa Wilhelm Hennis, Der „Parteienstaat“ des Grundgesetzes. Eine gelungene Erfindung (1992), in: ders., Auf dem Weg in den Parteienstaat. Aufsätze aus vier Jahrzehnten, Stuttgart 1998, S. 107-135.

16 Heinrich Triepel, Zulässigkeit und Form von Verfassungsänderungen ohne Änderung der Verfassungsurkunde, in: Verhandlungen des 33. Deutschen Juristentags, Berlin 1925, S. 1-22, hier: 21. 
rung nach einem Ausbau der Verfassungsgerichtsbarkeit. Sein Wiener Vortrag Wesen und Entwicklung der Staatsgerichtsbarkeit beruft sich 1928 dann gegen Kelsen ${ }^{17}$ und auch Schmitt mit Smend, dem Berliner Kollegen, auf ein „materiales“ Verständnis der Verfassung als „Rechtsordnung des staatlichen Integrationsprozesses" und deutet das Wesen und die Entwicklung liberal, in Traditionen der Gewaltenteilung, als Entkriminalisierung des politischen Prozesses: Mit der Trennung der Staatsgerichtsbarkeit vom Strafgericht wurden politische Streitfragen dem Strafrecht entzogen: „Es kommt nicht immer darauf an," schreibt Triepel, „daß ein Prozeßgegner als Leichnam auf dem Schlachtfelde liegen bleibt. Am wenigsten kann dies das Ziel in den Fällen sein, wo der Streit zwischen den verschiedenen politischen Gewalten geführt wird. Hier muß das Ziel häufiger der Ausgleich von Gegensätzen, die Harmonisierung gestörter Einheitlichkeit, auf der Grundlage einer vom Gerichte herbeigeführten Klärung der Rechtslage bilden.“ Triepel plädiert für ein „objektives Verfahren“, das „Disharmonie, soweit es möglich ist, harmonisch" auflöst.

Diese positive Sicht einer ausgleichenden Staatsgerichtsbarkeit unterscheidet sich deutlich etwa von Schmitts ${ }^{18}$ Kritik am Staatsgerichtshof als „Hüter der Verfassung“. Deshalb mag es verwundern, dass Triepel Ende 1932 in seinem Artikel Die Entscheidung des Staatsgerichtshofs im Verfassungsstreit zwischen Preußen und dem Reiche das Leipziger Urteil scharf kritisiert, „weil es eine unmögliche Teilung der Regierungsgewalt für möglich hielt“ und den sog. „Preußenschlag“ des Reichs voll berechtigte. Triepel kritisiert damals nicht die Zuständigkeit des Gerichts, sondern lediglich das vorliegende Urteil. Dass er in der Frage einer Teilung der preußischen Regierungsgewalt keinen salomonischen Kompromiss suchte, wie sein Wiener Vortrag erwarten ließe, könnte politische Motive gehabt haben, die der Artikel nicht erörtert. Offenbar ging er damals von einer preußischen Verletzung von Bundespflichten aus. Die Hegemonie schließt 1938 noch mit apologetischen Ausführungen zum „Schlußstrich“ Hitlers und dessen Verwirklichung des „vollen Einheitsstaats“. ${ }^{19}$

17 Dazu vgl. Thomas Olechowski, Hans Kelsen. Biographie eines Rechtswissenschaftlers, Tübingen 2020, S. $416 \mathrm{ff}$.

18 Carl Schmitt, Der Hüter der Verfassung, Tübingen 1931.

19 Dazu Heinrich Triepel, Die Hegemonie, Stuttgart 2. Aufl. 1943, S. 578: „Der klägliche Ausgang des Konflikts von 1932 durch die unbefriedigende Entscheidung des Staatsgerichtshofs ist bekannt. Er bildet das tragische Schlusskapitel der traurigen Geschichte der Weimarer Republik. Wenige Monate darauf hat die nationalsozialistische Revolution dieser Verfassung den Garaus gemacht. Sie hat damit auch den Schlussstrich unter die Geschichte von Wachstum und Untergang der 
Wie sehr Triepel die „Zerstörung des Parteienstaats“ und „legale Revolution" des Nationalsozialismus begrüßte, zeigt seine umgehende Verteidigung des Ermächtigungsgesetzes vom 23./24. März 1933, durch das Hitler, in Kategorien Schmitts gesagt, vom „kommissarischen“ zum „souveränen“ Diktator wurde, der nach der Exekutive auch noch die Legislative übernahm. Der Artikel erschien am 2. April 1933, einen Tag nach den antisemitischen Boykottaktionen vom 1. April und wenige Tage vor der Verabschiedung des "Gesetzes zur Wiederherstellung des Berufsbeamtentums“, das den öffentlichen Dienst arisierte. Nach nationalsozialistischen Kategorien galt Triepels Frau als „nicht arisch“, er selbst also als „jüdisch versippt“". Schon die ersten antisemitischen Exzesse dürften Triepels anfängliche Bejahung der nationalsozialistischen Machtübernahme als legale und legitime "nationale Revolution“ deshalb irritiert und erschüttert haben. Wenn er die „nationale Revolution“ im April 1933 auch auf die Legalität verpflichtet und die Legitimität an den Nationalismus bindet, steht sein Artikel dennoch als ein fatales Zeugnis innerer Distanz und Mentalreservation, die der Gründer der Staatsrechtslehrervereinigung und führende Repräsentant des „Vernunftrepublikanismus“ am Ende offenbar gegen Weimar hegte. Triepel erneuerte seine Bejahung der „nationalen Revolution" auch in einem redaktionellen Vorspruch des Archivs des öffentlichen Rechts zum neuen Jahrgang 1934. Seine Versicherung loyaler Mitarbeit am „Reich der Zukunft“ erschien aber bereits zu einem Zeitpunkt, an dem er, wie auch Smend, seine Herausgeberschaft mit dem Ende des Jahres 1933 niedergelegt hatte. ${ }^{20} \mathrm{Im}$ Archiv hat Triepel fortan nicht weiter publiziert. Dennoch ist es schwer zu bestreiten, dass er auch nach dem Ermächti-

preußischen Hegemonie gezogen. Eine kurze Zeit hat noch im jetzigen Reiche Preußen eine privilegierte Stellung behalten [...] Aber bald danach hat Adolf Hitler in Deutschland den vollen Einheitsstaat begründet und damit den bisher noch nie vollkommen erfüllten Traum der deutschen Einheit zur Wirklichkeit werden lassen. Die preußische Hegemonie gehört nunmehr der Vergangenheit an. Indes, wie der preußische Ministerpräsident Hermann Göring in seiner Rede im preußischen Staatsrat am 18. Juni 1934, einer Abschiedsrede an das alte Preußen festgestellt hat: ,die ewige Ethik des Preußentums' ist geblieben. Und so wird, so wollen wir zuversichtlich hoffen, die preußische Hegemonie auch über ihren Tod hinaus als Quelle deutscher Kraft und Einheit dem deutschen Volk in Zukunft ihren Segen spenden.“ Mit diesen Worten endet Triepels Hegemonie noch in der 2. Auflage von 1943.

20 So Stolleis, Geschichte des öffentlichen Rechts in Deutschland, 1999, Bd. III, S. 301 ff.; vgl. detailliert Lothar Becker, „Schritte auf einer abschüssigen Bahn“. Das Archiv des öffentlichen Rechts (AöR) und die deutsche Staatsrechtswissenschaft im Dritten Reich, Tübingen 1999. 
gungsgesetz noch den Nationalsozialismus ein Stück weit mit der „nationalen Revolution“ verwechselte und eine „Überwindung“ des Weimarer „Parteienstaats“ durch eine neue „Selbstverwaltung" erhoffte. Dass die nationalsozialistische Diktatur anderes brachte, versteht sich von selbst. Auch 1933 war es aber schon einigermaßen naiv, den Nationalsozialismus in der historischen Parallele zu den preußischen Reformen oder Bismarcks Reichsgründung zu sehen. Triepel blieb als Kind des Wilhelminismus in nationalstaatlichen Kategorien befangen.

Nach 1933 hat er sich ganz aus der Arbeit am Staatsrecht zurückgezogen und auf die völkerrechtliche Arbeit konzentriert. Zwei Monographien publizierte er noch: Die Hegemonie (1938) sowie Delegation und Mandat im offentlichen Recht (1942). Nur wenige kleinere Texte erschienen ansonsten, nichts, das die Entwicklung des öffentlichen Rechts im Nationalsozialismus direkt thematisierte. In der Hegemonie finden sich einige Bemerkungen, auch zum nationalsozialistischen Schrifttum, ${ }^{21}$ die als Positionierung zu diskutieren wären. Triepels Haltung nach 1933 wird hier aber nicht weiter dokumentiert. Für die Gesamteinschätzung sei aus der Literatur auf Gassners umfassende Darstellung verwiesen. Epilogisch werden nur noch drei kurze Texte abgedruckt: Ein Nachruf auf Viktor Bruns, den Gründer des Berliner Kaiser-Wilhelm-Instituts für ausländisches öffentliches Recht und Völkerrecht, steht dabei als einer der wenigen Texte, die Triepel im Weltkrieg publizierte; ein Auszug aus dem posthum erschienenen Spätwerk Vom Stil des Recht bekundet „Ekel“ und „Abscheu“ gegenüber der „Normwidrigkeit“ des Nationalsozialismus; ein nach 1945 geschriebener, posthum publizierter Text Zweierlei Föderalismus hofft für die offene „Frage nach einer künftigen Verfassung“, wie einst 1918/19, noch auf eine kommende Nationalversammlung und Volksabstimmung und argumentiert so erneut in den nationalliberalen Traditionen und nationalstaatlichen Kategorien, denen Triepel stets verbunden blieb und die nach 1945 in Deutschland eigentlich ausgespielt hatten.

21 Zur Stellung zu Schmitt vgl. Reinhard Mehring, ,Ich müsste mich mit Triepel auseinandersetzen'. Heinrich Triepel, Carl Schmitt und Die Hegemonie, in: Der Staat 59 (2020), S. 29-47. 
Teil I: Ausgangslage 1918/19 


\section{Text 1}

Der Völkerbund ${ }^{1}$

Der Vorschlag, die Staaten des Erdkreises zu einem dauernden Bunde zusammenzuschließen, der fest genug ist, um den Ausbruch eines Krieges zwischen den Bundesgliedern unmöglich zu machen, ist kein Gedanke von ehegestern. Seit vielen Jahrzehnten ist er von den Anhängern der politischen Richtung, die unter dem Namen „Pazifismus“ bekannt ist, beredt und energisch vertreten worden. Aber er ward schon zu einer Zeit erwogen, als von einer Friedensbewegung in modernem Sinne noch nicht die Rede war. Die Geschichtsschreiber des modernen Pazifismus haben darauf aufmerksam gemacht, daß bereits zu Beginn des 14. Jahrhunderts der französische Kronjurist Pater Dubois den Plan zu einem europäischen Staatenplan entworfen hat, mit einem ständigen Schiedshofe, dessen Einrichtung nicht viel von der Art und Weise dessen abweicht, nach der die Friedenskonferenz von 1899 das Haager Schiedsgericht zu bilden unternahm. Es mag dahingestellt bleiben, ob sich wirklich zwischen jenen mittelalterlichen Ideen und den föderalistischen Bestrebungen der Gegenwart ein $\mathrm{Zu}$ sammenhang herstellen läßt. Soviel ist jedenfalls gewiß, daß sich mindestens seit dem Beginn des 18. Jahrhunderts, seit dem berühmten Werke des Abbé de Saint Pierre „Projet pour perpétuer la paix“ (1713) Juristen und Philosophen, Dichter und Geschichtsschreiber, immer wieder mit Plänen einer bundesmäßigen Organisation der Staatenwelt zur Herbeiführung eines dauerhaften Friedens getragen und ihre Gedanken darüber häufig zu umfänglichen Entwürfen verdichtet haben.

Niemanden wird es Wunder nehmen, wenn solche Vorschläge in unseren Tagen von neuem auftauchen und mit gesteigerter Lebhaftigkeit erörtert werden. Das erschütternde Erlebnis eines Krieges von so ungeheurer Ausdehnung und mit so verheerenden Wirkungen wie die des Weltkrie-

1 In: Daheim. Ein deutsches Familienblatt mit Illustrationen 55 (1918/19), Nr. 2 vom 12. Oktober 1918, S. 8-9; am 12. Oktober 1918 erschienen, kurz vor Kriegsende in den Tagen der Waffenstillstands- und Friedensverhandlungen. Am 3. Oktober hatte der Reichskanzler den amerikanischen Präsidenten, Wilson, um Frieden ersucht. Dessen Antwort vom 8. Oktober formulierte Vorbedingungen, die Triepel in seinem Artikel abzulehnen scheint, ohne wörtlich darauf zu sprechen zu kommen. Deutschland nahm die Bedingungen aber am 12. Oktober an, am Tag des Erscheinens des Artikels.]. 
ges, in dem wir stehen, muß auch bei unempfindlicheren Naturen den Wunsch nach einem wirksamen Mittel rege machen, das die Wiederkehr solcher Schrecknisse ein für alle Male vereitelt. Auch der ältere Pazifismus hat in bitteren Kriegserfahrungen die besten Stützen seiner Bestregungen gefunden. Das Buch des Abbé de St. Pierre erschien in dem Jahr, in dem der spanische Erbfolgekrieg zu Ende ging, und es geschah während des ersten Koalitionskriegs der europäischen Mächte gegen Frankreich, daß Immanuel Kant seine berühmte Schrift "Zum ewigen Frieden“ veröffentlichte, worin er die Begründung eines „Völkerbundes“, eines „Friedensbundes" forderte, der nicht, wie ein gewöhnlicher Friedensvertrag, bloß einen einzelnen Krieg, sondern alle Kriege auf immer zu endigen trachten soll (1795).

Es ist also ein alter Wein, der in neue Schläuche gegossen wird, wenn sich heute die politische Welt mit Plänen zur Herstellung einer Friedensliga der Nationen beschäftigt. Auch läßt sich nicht sagen, daß in den modernen Entwürfen organisatorische Gedanken von verblüffender Ursprünglichkeit zutage treten. Jetzt wie früher stellt man sich unter der Völkerliga einen Staatenverband vor, nach dessen Verfassung den Mitgliedern verboten ist, sich zu bekriegen, innerhalb dessen jeder Streit zwischen den Bundesgliedern durch ein Vereinstribunal geschlichtet und Widersetzlichkeit gegen Verbandsbeschlüsse und Entscheidungen durch eine Bundesexekution zu Boden geschlagen wird. Daß „Bundesexekution“ nur ein anderer Name, aber keine andere Sache ist als ein Krieg und daß sich auf solche Weise der ewige Friede ganz gewiß nicht erreichen läßt, pflegen die Heutigen ebenso wenig zu begreifen wie ihre Vorläufer. In den neuesten Projekten versucht man freilich auch mit feineren Exekutionsmitteln zu arbeiten: mit Boykottierung des Friedensstörers, mit Absperrung seiner Grenzen, mit Blockade seiner Küste. Daß sich aber ein in seinen Lebensinteressen bedrohter Staat durch die Aussicht auf ein derartiges Bundesdisziplinarverfahren abhalten lassen würde, die Wege zu gehen, die er zu seinen Zielen für erforderlich erachtet, daß ferner ein von jeglichem Verkehr abgeschlossener Staat wahrscheinlich versuchen wird, das ihm über den Kopf geworfene Netz mit Gewalt zu zerreißen, daß also die ganze Maschinerie ein höchst fragwürdiges Mittel sein dürfte, den Weltfrieden zu erhalten, das sind Eindrücke, die von den Pazifisten der Gegenwart genau so leicht genommen werden wie das schon ihren Vorgängern entgegengehaltene grundsätzlich Bedenken, ob denn nicht überhaupt die Idee eines ewigen Friedens mit dem psychologischen Wesen des Staates als solchem in unversöhnlichem Widerspruch stehe. 
So wenig originell nun die heutigen Erörterungen über Weltfriede und Völkerbund erscheinen, so unterscheiden sich doch die äußeren Umstände, unter denen sie erfolgen, in einigen bedeutsamen Punkten sehr wesentlich von denen, unter denen die Angelegenheit in früherer Zeit verhandelt worden ist.

Die älteren Vorschläge zu Friedensbündnissen der Kulturstaaten sind in Schriften politischer oder philosophischer Schriftsteller enthalten, die mit keiner anderen Autorität als der ihres wissenschaftlichen Namens aufzutreten vermochten. Sie wurden folglich als literarische Schöpfungen hingenommen, zumeist als Erzeugnisse dichterischer Phantasie gewertet und, wofern sie überhaupt Beachtung fanden, nach einiger Zeit in dieselben Fächer der Bibliotheken eingereiht, in denen sich die „Insel Utopia“ des Thomas More oder Bacons „Neue Atlantis“ und andere Staatsromane befanden. Kaum jemals haben sich Regenten und leitende Staatsmänner mit aufrichtig gemeinten Vorschlägen zu einer „Organisation der Welt" hervorgewagt: der „große Plan“ Heinrichs IV. von Frankreich und seines Ministers Sully war nicht uneigennützig, die Anregung Napoleons III. nicht bestimmt genug, um auf die Zeitgenossen einen nachhaltigen Eindruck zu machen. Heute aber erleben wir es, daß das Oberhaupt einer mächtigen Republik, der Präsident der Vereinigten Staaten, mit vollem Ernste das Wort von der Friedensliga der Völker in die internationale Debatte wirft, und daß ihm in ebenso ernsthafter Weise von den Staatsmännern der anderen Mächte geantwortet wird. Ja, die Aufnahme, die seine Anregung in Europa gefunden hat, ist bei seinen Kriegsgegnern zunächst fast günstiger gewesen als bei seinen Verbündeten. Damit hat das Problem aufgehört, ein bloß wissenschaftliches zu sein. Es ist ganz augenscheinlich zu einer brennenden Frage der praktischen Politik geworden.

Nun würde man diese Frage in aller Ruhe und mit aller Gründlichkeit behandeln können, wenn sie gestellt worden wäre, nachdem die jetzt im Kriege befindlichen Staaten ihre großen Streitigkeiten durch einen endgültigen Friedensschluß bereinigt haben. Seltsamerweise ist dem aber nicht so, und das ist das Zweite, was der Angelegenheit ein besonderes und, um es gleich zu sagen, für uns Deutsche bedenkliches Gesicht verleiht. Man muß sich vor Augen halten, daß Präsident Wilson, heute der unbestrittene Führer der gegen die Mittelmächte gerichteten Koalition, die Stiftung des Völkerbundes für ein Kriegsziel erklärt hat, das nur in Verbindung mit einer ganzen Reihe anderer Forderungen erreicht werden könne. In seiner Botschaft vom 8. Januar 1918, an der seine späteren Verlautbarungen nichts Wesentliches geändert haben, bildet die „allgemeine Vereinigung der Staaten zur gegenseitigen Verbürgung der politischen Unabhängigkeit 
und Unverletzlichkeit der großen wie der kleinen Nationen" nur einen, und zwar den letzten von vierzehn Programmpunkten. Die Liga kann, so ist die Meinung, erst dann gebildet werden, wenn den anderen Ansprüchen Genüge geschehen ist. Diese enthalten nach Wilsons Ansicht das Mindestmaß dessen, was die allgemeine Gerechtigkeit verlangt. Den gerechten Zustand soll der Friede herbeiführen, ihn für ewig zu sichern, ist der Völkerbund bestimmt. Was fordert nun aber die Gerechtigkeit? Es ist nicht wenig! Nicht nur, daß das ganze ehemals russische Gebiet geräumt, Belgien, Rumänien, Serbien, Montenegro vorbehaltlos wiederhergestellt und Serbien mit einem Zugang zur Adria versehen wird. Sondern auch daß Elsaß-Lothringen an Frankreich herausgegeben und daß ein polnischer Staat errichtet werde, der alle von unzweifelhaft polnischer Bevölkerung bewohnte Länder umfaßt und eine freie Verbindung mit dem Meere besitzt. Weiter, daß den Nationalitäten der österreichisch-ungarischen Monarchie eine „autonome Entwicklung“ ermöglicht, daß die italienischen Grenzen nach dem „nationalen Besitzstande“ berichtigt, daß die unter der Herrschaft der Pforte stehenden nicht-türkischen Völker, also z.B. die Armenier, die Araber, die Ägypter, befreit werden. Die kolonialen Ansprüche sollen nach den „Interessen der betroffenen Bevölkerungen“ geschlichtet werden; das bedeutet natürlich: da Deutschland die Eingeborenen seiner Kolonien stets mißhandelt hatte, so dürfe es seine Schutzgebiete niemals zurückerhalten. Schließlich wird von Wilson eine Beschränkung der Rüstungen auf das niedrigste, „mit der inneren Sicherheit“ der Staaten verträgliche $\mathrm{Maß}$ vorgeschlagen; das heißt unter anderem: da für die innere Sicherheit des die Erde umspannenden britischen Reichs eine große Flotte notwendig, für das seiner Kolonien entledigte Deutschland selbst eine kleine überflüssig sei, so darf England seine Flotte behalten, während Deutschland seine Kriegsschiffe als altes Eisen zu verkaufen hat.

Man kann sich nicht vorstellen, daß ein Deutscher diese Friedensbedingungen gelesen habe, ohne daß ihm die helle Röte des Zorns auf die Wangen getreten wäre. Auch Wilson wird nicht im Zweifel darüber sein, daß seine Vorschläge nur von einem vollkommen niedergeworfenen Deutschland angenommen werden könnten. Und dasselbe gilt für dessen Verbündete. Was bedeutet dann aber die Einladung an uns, mit den Amerikanern und ihren Genossen zu einem ewigen Friedensverbande zusammenzutreten? Doch nichts anderes als die Zumutung, daß wir uns zunächst in den Staub treten lassen sollen, um uns dann einem Vereine anzuschließen, dessen Hauptzweck darin besteht, unsere Ohnmacht zu verewigen. Wilson gleicht einem Manne, der einer Frau erklärt: ich wünsche mit dir eine auf 
gegenseitiger Neigung beruhende, stets friedfertige Ehe einzugehen; nur bitte ich um die Erlaubnis, vorerst dir die Glieder zu zerbrechen.

Bei dieser Sachlage hat es heute schwerlich Sinn, sich den Kopf darüber zu zerbrechen, wie der künftige Weltenbund einzurichten sei, mit welchen Organen er ausgestattet werden und in welcher Weise er seine Beschlüsse fassen und vollstrecken solle. Wenn jetzt die deutsche Gesellschaft für Völkerrecht einen Ausschuß zum Studium dieser Frage einsetzt und wenn ein bekannter Parlamentarier bereits einen vollständigen Verfassungsentwurf für die Völkerliga ausarbeitet, ${ }^{2}$ so dürfte für solche Unternehmungen die Stunde recht unglücklich gewählt sein. Der große Drahtzieher der Ententepolitik in Washington wird die Kunde von diesen Vorgängen mit grimmigem Lächeln als einen Erfolg buchen und als ein Zeichen annehmen, daß wir bereit seien, uns auch in anderen Dingen unter seinen Willen zu beugen.

Präsident Wilson selbst hat es bisher sorgfältig vermieden, seine Gedanken über die Organisation des Völkerbundes in Worte zu kleiden. Aber es bedarf keiner Kunst, um seine Wünsche in dieser Hinsicht zu erraten. Selbstverständlich soll der Friedensverein so eingerichtet werden, daß in ihm die angelsächsischen Staaten die Führung besitzen, daß dagegen Deutschland und was ihm anhängt, verurteilt ist, für immer eine Minderheitspartei zu bilden. Es gibt ja zwei Wege, auf denen man, wenigstens theoretisch angesehen, die Kriege beseitigen kann. Entweder durch die Unterjochung aller Staaten durch eine übergewaltige Großmacht, die den Unterworfenen nur dem Namen nach eine Selbständigkeit beläßt; in einem Weltreiche, wie etwa in dem Alexanders des Großen oder in dem der Römer, gibt es keine Kriege, sondern höchstens Aufstände unbotmäßiger Vasallen. Der andere Weg ist der des freien Bündnisses zwischen sämtlichen, sich gegenseitig als gleichberechtigt ansehenden Genossen der Staatenwelt. Wilson predigt einen Kreuzzug zur Erreichung des zweiten Zieles, während er in Wirklichkeit das erste im Auge hat. Man sollte endlich einmal bei uns begreifen, daß hinter der von den Vereinigten Staaten ausgehenden Friedensbewegung nichts anderes steckt als die mit echt amerikanischer Heuchelei geschickt maskierte Herrschsucht des beutelüsternen Angelsachsentums!

2 [Dazu vgl. etwa Walther Schücking, Der Bund der Völker. Studien und Vorträge zum organisatorischen Pazifismus, Leipzig 1918]. 


\section{Text 2 \\ Der Zusammenschluß des Deutschen Reichs und des Staates Deutsch-Österreich ${ }^{1}$}

I.

Die folgende Skizze will sich ausschließlich mit den nächstliegenden rechtlichen Fragen beschäftigen, zu denen die in Aussicht stehende Vereinigung der deutsch-österreichischen Länder mit dem Deutschen Reiche Veranlassung gibt. Die polit is che Seite der Angelegenheit bleibt außer Spiel. Der Verfasser geht davon aus, daß der Zusammenschluß der bisher getrennten deutschen Gebiete für Deutsch-Österreich schlechthin eine Lebensfrage, für das Reich aus außer- wie innerpolitischen Gründen zum mindesten ein dringendes Bedürfnis ist. Er weiß, daß es Leute gibt, die anderer Meinung sind; aber er beabsichtigt nicht, sich an dieser Stelle mit ihnen auseinanderzusetzen. Auch möchte er es vermeiden, von den internationalen Schwierigkeiten zu sprechen, mit denen die Verwirklichung des großdeutschen Programms zu kämpfen hat. Sie sind ohne Zweifel sehr groß. Bei der Lage, in der wir sowohl wie Österreich uns befinden, muß die Wucht des in uns und in Österreich vorhandenen Lebenswillens ersetzen, was uns beiden zurzeit an militärischer Macht abgeht, und eine geschickte Diplomatie muß die Wege erschließen, die sich das Schwert nicht mehr zu öffnen vermag.

Noch in einer anderen Beziehung werden sich die nachfolgenden Ausführungen eine Beschränkung auferlegen. Das Problem, das in der nächs-

1 [In: Großdeutsch oder Kleindeutsch? Reden über den Anschluss Deutsch-Österreichs an die Deutsche Republik, Berlin 1919, S. 32-39; Triepel schrieb seinen Beitrag zur "großdeutschen“ Beteiligung Deutsch-Österreichs an der Weimarer Nationalversammlung offenbar nach dem 12. November und vor dem 29. November 1918. Die Entscheidung für eine Nationalversammlung war damals noch nicht getroffen. Am 29. November beschloss der Rat der Volksbeauftragten, Elsass-Lothringen und Deutsch-Österreich in die Nationalversammlung einzubeziehen. Am 30. November erfolgte eine Verordnung des Rates über die Wahlen zur Nationalversammlung, die am 19. Dezember dann auf den 19. Januar terminiert wurden. Triepel spricht in seinem Beitrag nicht von Elsass-Lothringen, rechnet aber noch mit einem möglichen Einbezug Österreichs, der schon durch ein Veto der Ententemächte dann verhindert wurde.]. 
ten Zeit gelöst werden muß, zerfällt in zwei gleichwichtige Fragen. Erstlich: in welcher Form hat sich der Zusammenschluß des Reichs und Deutsch-Österreichs zu vollziehen? Zweitens: Welche Form soll dem künftigen Zusammenleben gegeben, welche Stellung soll Deutsch-Österreich im großdeutschen Gesamtstaate eingeräumt werden? Eine Erörterung der zweiten dieser Fragen soll in diesem Augenblicke nicht erfolgen. Sie schließt in sich wieder eine Fülle der schwierigsten staatsrechtlichen, verwaltungsrechtlichen, wirtschaftlichen Einzelfragen ein, deren Lösung in befriedigender Weise nicht kurzer Hand, jedenfalls nicht von einem Einzelnen in Angriff genommen werden kann. Nur eines mag gesagt sein: Die Ereignisse der letzten Wochen haben sehr deutlich gezeigt, daß Deutschland, wie bisher, so auch in nächster Zukunft keine radikal unitarische Verfassung vertragen kann. Gewiß muß das kommende deutsche Staatsrecht mit allerlei überlebten Einrichtungen des bisherigen föderalistischen Systems gründlich aufräumen. Aber wer den unitarischen Bogen überspannen wollte, würde angesichts der in Süddeutschland in bedrohlicher Form zutage tretenden separatistischen Neigungen das Gegenteil von dem erzielen, was er erreichen will. Die deutschen Mittelstaaten sind offenbar nicht gesonnen, auf ein staatliches Eigenleben in bestimmten Grenzen zu verzichten, und dem muß eine besonnene Politik einfach Rechnung tragen. Das wird aber auch für die künftige Stellung Deutsch-Österreichs von Bedeutung und den Deutsch-Österreichern, wie man annehmen darf, willkommen sein. Sie werden nicht in einem deutschen Einheitsstaate aufgehen müssen, sondern als Mitglieder eines Bundesstaates gleichberechtigt neben anderen Mitgliedern stehen können. Daß ihnen der Eintritt durch Übergangsvorschriften, namentlich in Bezug auf die Einführung der im Reiche geltenden Gesetze, und durch gerecht abwägende Bestimmungen finanzieller Natur erleichtert werden muß, versteht sich von selbst.

Die andere Frage, in welcher Weise sich der Vorgang des Zusammenschlusses zu vollziehen habe, erheischt eine sofortige Antwort. Soll sie befriedigend ausfallen, so ist es erforderlich, von dem gegenwärtigen Rechtsverhältnisse zwischen den beiden in Betracht kommenden Faktoren auszugehen.

Deutsch-Österreich hat sich als selbständiger Staat konstituiert. Es hat sich durch den „Beschluß der provisorischen Nationalversammlung über die grundlegenden Einrichtungen der Staatsgewalt“ vom Oktober 1918 und durch das "Gesetz über die Staats- und Regierungsform" vom 12. November 1918 (Staatsgesetzbl. Nr. 1 u. 5) eine vorläufige Verfassung gegeben, und diese steht nach allem, was wir wissen, nicht bloß auf dem $\mathrm{Pa}$ pier, sondern ist lebendige Wirklichkeit. An der Entstehung des neuen 
Staates ist mithin nicht zu zweifeln. Daß über seine Grenzen noch einige Ungewißheit herrscht, tut dem keinen Eintrag. Die Ereignisse der letzten Jahre haben uns auch an anderen Stellen die Bildung neuer Staaten gezeigt, deren Grenzen sehr viel unsicherer waren, als es bei Deutsch-Österreich der Fall ist. Gewiß gibt es keinen Staat ohne ein Gebiet. Aber es genügt, wenn das Volk, das sich zum Staat entwickelt, überhaupt nur einen gesicherten Raum sein eigen nennt. Ob sich an das Sichere noch ein Gebiet des Unsicheren anschließt, ist gleichgültig.

Der neue Staat Deutsch-Österreich hat nun seinen Anschluß an das Deutsche Reich bereits in ganz formeller Weise erklärt. Artikel 2 des Gesetzes vom 12. November 1918 besagt: „Deutsch-Österreich ist ein Bestandteil der Deutschen Republik. Besondere Gesetze regeln die Teilnahme Deutsch-Österreichs an der Gesetzgebung und Verwaltung der Deutschen Republik, sowie die Ausdehnung des Geltungsbereiches von Gesetzen und Einrichtungen der Deutschen Republik auf Deutsch-Österreich“. Mit dieser Erklärung hat es aber seine eigene Bewandtnis. Sie ist ganz einseitig erfolgt. Das Deutsche Reich, d. h. dessen vorläufige Regierung, hat offiziell noch nicht einmal ausgesprochen, der Anschluß Deutsch-Österreichs sei Deutschland erwünscht, geschweige denn, daß ein reichsdeutsches Gesetz eine der österreichischen entsprechende Kundgebung erlassen und seinerseits erklärt hätte, daß Deutsch-Österreich ein Bestandteil des Deutschen Reiches sei. Bezeichnend für die Lage war es, daß bei der jüngst abgehaltenen Reichskonferenz der Vorsitzende den anwesenden Vertreter der österreichischen Regierung, Dr. Ludo Hartmann, als „Gast" begrüßte, was dieser mit der Bemerkung quittierte, er betrachte sich bereits als „zugehörig“. Der Beifall, mit dem die Versammlung diese Worte aufnahm, kann natürlich eine formelle Aufnahmeerklärung ebenso wenig ersetzten, wie die gewiß aufrichtig gemeinte, aber immerhin vorsichtige Äußerung des Staatsekretärs Solf, das Auswärtige Amt lasse es sich angelegen sein, die „Anschlußbestrebungen zu fördern, und an der Vereinigung und Verschmelzung der beiden Länder tätig mitzuwirken“ (28. November). Wir können die Gründe für die zögernde Behandlung der Angelegenheit durch die vorläufige Reichsregierung nur vermuten, nicht wissen, enthalten uns deshalb einer Kritik. Jedenfalls haben wir es mit der seltsamen Erscheinung zu tun, daß ein außerhalb des Reichs stehender Staat sich als Bestandteil des Reichs erklärt, ohne daß das Reich zu erkennen gibt, es betrachte seinerseits den anderen als einen Bestandteil seiner selbst.

Die österreichische Anschlußerklärung hat also zunächst nur den Charakter einer platonischen Liebeserklärung. So faßt man die Sache auch in Österreich selber auf. In der Sitzung der Nationalversammlung vom 
12. November sagte der Staatskanzler Dr. Renner, der Artikel 2 des Gesetzes sei „einstweilen eine sogenannte lex imperfecta“. Ob diese Bezeichnung juristisch ganz korrekt ist, mag dahingestellt bleiben. Der Sinn ist jedenfalls der: die Bestimmung hat fürs erste keine praktische Bedeutung. Und das ist unzweifelhaft richtig. Wäre Deutsch-Österreich bereits ein Bestandteil der deutschen Republik, so müßte es sich von dieser schon jetzt regieren und nach außen vertreten lassen. Ebenso wenig wie das Deutsche Reich das beansprucht, ebenso wenig würden es sich die Deutsch-Österreicher gefallen lassen. Im gegenwärtigen Augenblicke sind also das Reich und Deutsch-Österreich noch zwei getrennte, rechtlich von einander vollkommen unabhängige Staaten. Wie soll der Zusammenschluß der beiden Mächte vollzogen werden?

\section{II.}

Es ist vielleicht nützlich, daran zu erinnern, daß ähnliche Probleme wie das vorliegende der deutschen Politik in der Geschichte der letzten zwei Menschenalter schon mehrmals gestellt gewesen sind. Aber freilich, die Art, wie sie gelöst wurden, bietet für die Form des Vorgehens im heutigen Falle nur sehr unsichere Anhaltspunkte.

Die Frage, ob Österreich mit dem übrigen Deutschland in einem einheitlichen Staatswesen zusammengeschlossen sein könne, ist bekanntlich eine der wichtigsten Fragen gewesen, mit denen sich im Jahre 1848 das Frankfurter Parlament zu beschäftigen gehabt hat. Allein damals war die Rechtslage insofern wesentlich anders, als der österreichische Kaiserstaat mit seinen dem alten Reiche angehörig gewesenen Gebietsteilen Mitglied des Deutschen Bundes war und dieser Bund formell noch zu Recht bestand. Die Aufgabe der Paulskirche war es, den Bund in einen Bundesstaat umzuwandeln, und für diesen eine Form zu suchen, bei der es möglich war, daß Österreich im Gesamtstaate v e r b l e ib e n könne. Daraus ergab sich z. B., daß an den Beratungen des Frankfurter Parlaments selbstverständlich auch Mitglieder aus den österreichischen Ländern teilnehmen konnten und mußten - was für die bevorstehende Nationalversammlung nicht von vornherein selbstverständlich ist.

Eine in gewissem Sinne der heutigen Sachlage ähnliche Situation war im Jahre 1870 vorhanden, als sich der Norddeutsche Bund anschickte, die süddeutschen Staaten bei sich aufzunehmen. Aber diese Aufgabe war einfacher als die uns heute beschäftigende. Der Norddeutsche Bund hatte eine fertige Verfassung. Es handelte sich für ihn lediglich darum, mit den süd- 
deutschen Staaten die vergleichsweise geringfügigen Änderungen zu vereinbaren, die als Bedingung ihres Eintritts festgesetzt werden mußten. Heute soll sich das Reich mit dem außerhalb des bundesstaatlichen Verbandes stehenden Österreich über den Zusammenschluß einigen und soll sich gleichzeitig eine vollkommen neue Verfassung geben.

In einer bestimmten Beziehung erinnert endlich die heutige Lage an die der Jahre 1866 und 1867. Bekanntlich mußte sich damals die bundesstaatliche Einigung Deutschlands aus internationalen Gründen auf den Norden beschränken, die Ausdehnung des Bundesstaats auf den Süden hinausgeschoben werden. Gleichwohl erachtete jedermann den baldigen Eintritt der süddeutschen Staaten als eine ausgemachte Sache. Als daher der konstituierende Reichstag von 1867 die Bundesverfassung beriet, legte er sich auf Schritt und Tritt die Frage vor, ob die Fassung der einzelnen Artikel auch passen werde, wenn die Brücke über den Main geschlagen worden sei. Nun würde eine reichsdeutsche Nationalversammlung unserer Tage in ganz derselben Weise die auszuarbeitende Reichsverfassung auf den künftigen Eintritt Deutsch-Österreichs zuschneiden müssen. Aber der Unterschied zwischen heute und damals besteht darin, daß im Jahre 1867 Regierungen und Völker von zweiundzwanzig bis dahin souveränen Staaten einen völlig neuen Bundesstaat begründeten, während heute der Bundesstaat, der sich seine neue Verfassung geben will, seit vielen Jahrzehnten besteht und nicht beabsichtigt, sich aufzulösen.

Von dieser Tatsache muß nun aber unter allen Umständen ausgegangen werden. Für uns Reichsdeutsche handelt es sich nicht und darf es sich nicht handeln um die N e u e r r i c h t u n g eines Bundesstaates. Wenn wir nicht, für unsere internationale Verhandlungsfähigkeit, für unseren Kredit, für das Funktionieren des Verwaltungsapparats im Inneren, für unsere Kriegs- und Übergangswirtschaft die allerschwersten Gefahren heraufbeschwören wollen, so dürfen wir keinen Augenblick den Gedanken aufkommen lassen, daß unser Reich durch die Revolution untergegangen sei. Trotz der gewaltigen Krisis, die wir durchmachen, und obwohl an Stelle der legitimen Reichsorgane revolutionäre Elemente tatsächlich die Reichsgewalt ausüben, ist doch das Reich als solches nicht tot und steht die Reichsverfassung in Geltung, insbesondere soweit sie die Kompetenzen des Reichs und sein Verhältnis zu den Einzelstaaten regelt. Eine Sezession aus dem Reich wäre heute nicht weniger Hochverrat, wie sie es vor drei Monaten gewesen wäre! Dieser Standpunkt muß aber auch entscheidend sein für die Wahl der Formen, unter denen wir den Anschluss Deutsch-Österreichs vorzubereiten und zu vollziehen haben. Für uns kann es sich nur 
handeln um die Aufnahme eines bisher fremden Staates in das be s t e h e n d e und bestehen bleibende Reich.

Lebten wir in normalen Zeitläufen, so wäre die Form für diesen Vorgang einfach vorgezeichnet. Das Reich und Deutsch-Österreich hätten einen Vertrag miteinander zu schließen, der die Bedingungen der Aufnahme festsetzte. $\mathrm{Zu}$ diesen würde in erster Linie eine Änderung der Reichsverfassung gehören. Das Reich würde sie in der von der Verfassung selbst gebotenen Weise vornehmen. Mit dem Inkrafttreten der Verfassungsänderung wäre die Aufnahme vollzogen. Nun hat aber die Revolution den regulären Weg verbaut. Die für eine Änderung der Verfassung zuständigen Organe sind gewaltsam außer Funktion gesetzt. Was ihnen sonst zukommen würde, kann heute nur von der Nationalversammlung besorgt werden. Die Frage der Aufnahme Österreichs ins Reich ist nicht die erste, sondern die zweite der großen Fragen, die von der Reichsversammlung beim Neubau unseres Verfassungsrechts gelöst werden müssen.

Man könnte deshalb daran denken, die Behandlung der beiden Fragen sachlich und zeitlich zu trennen. Die Nationalversammlung würde sich zunächst darauf beschränken, eine für das Reich gültige Verfassung festzustellen, die Verständigung mit Deutsch-Österreich würde sich anschließen. Allein aller Wahrscheinlichkeit nach würde sich eine solche Verständigung doch nur um den Preis einer abermaligen, vielleicht sogar recht einschneidenden Verfassungsänderung erzielen lassen. Ganz abgesehen davon, daß dadurch der Zusammenschluß ernstlich gefährdet werden könnte, würde ein solches Verfahren eine solche Zeit- und Kraftverschwendung bedeuten, die wir uns heute unmöglich leisten können. Es bleibt also nichts übrig, als daß wir die Entscheidung über die neue Reichsverfassung und über die Aufnahme Deutsch-Österreichs in einen Akt zusammenziehen. Die reichsdeutsche Nationalversammlung muß sich gle ich ze it ig mit der Totalrevision der bisherigen Reichsverfassung und mit der Frage der Aufnahme Deutsch-Österreichs befassen. Ist sie von der Notwendigkeit des Zweiten überzeugt, so wird sie die neue Verfassung sofort für GroßDeutschland, d. h. für das um Deutsch-Österreich erweiterte Reich verfassen. Und ebenso muß die Einigung mit Deutsch-Österreich, da sie nicht bis zum Abschlusse unseres Verfassungswerkes aufgeschoben werden kann, mit diesem unmittelbar verbunden werden. Das läßt sich, wie ich meine, in folgender Weise bewerkstelligen.

Das Reich hat mit Deutsch-Österreich zunächst eine bindende Vereinbarung über den Zusammenschluß zu treffen. Die Offerte zum Vertrage ist von Deutsch-Österreich bereits gemacht worden. Sie liegt in dem Erlasse 
des Artikel 2 des Gesetzes vom 12. November. Von seiten des Reichs genügt ein einfaches Ja, um den Vertrag zustande kommen zu lassen.

Jenes Angebot haben aber die Deutsch-Österreicher selbstverständlich nicht in dem Sinne getan, daß sie sich blindlings unter jede gemeindeutsche Verfassung ohne alle Rücksicht auf ihren Inhalt stellen würden. Sie setzen mit Recht voraus, daß es ihnen möglich sein werde, einen Einfluß auf die Gesamtverfassung auszuüben. Und es ist weiterhin selbstverständlich, daß hierbei nicht ihre provisorische Regierung, sondern das deutschösterreichische Volk selbst das entscheidende Wort wird sprechen wollen. Da die Verfassung nicht gleichzeitig in einer reichsdeutschen und in einer österreichischen Nationalversammlung beraten und beschlossen werden kann, so muß auch hier eine Zusammenziehung erfolgen. Die re ichs deutsche Nationalversammlung ist durch Abgeordnete aus Deutsch-Österreich zu ergänzen. Diese sind in allen Gebieten zu wählen, in denen sich zurzeit die Herrschaft des deutsch-österreichischen Staates betätigen kann. Natürlich müßte die Wahl in einem Verfahren vollzogen werden, das mit dem für das Reich in Aussicht genommenen übereinstimmt.

III.

Die Maßregeln, die im vorstehenden vorgeschlagen wurden, sind gewiß ungewöhnlich. In außerordentlichen Zeiten kann man sich eben nicht in ausgetretenen Geleisen bewegen. Aber das Verfahren ist doch so, daß sich auch ein empfindliches juristisches Gewissen damit zufrieden geben kann.

Vom Standpunkte des deutschen Reichsrechts ist es durchaus richtig, wenn die Aufnahme Deutsch-Österreichs in den Reichsverband in der Form eines Reichsgesetzes, nämlich durch den Erlaß der neuen Reichsverfassung erfolgt. Die norddeutsche Bundesverfassung enthielt in Art.79, Abs. 2 folgende Vorschrift: „Der Eintritt (richtiger: die Aufnahme) der süddeutschen Staaten oder eines derselben in den Bund erfolgt auf den Vorschlag des Bundespräsidiums im Wege der Bundesge setzgebung“. Bei der Redaktion der Reichsverfassung ist die Bestimmung natürlich weggelassen worden. Aber man wird es auch heute als eine im geltenden Verfassungsrechte begründete Norm bezeichnen dürfen, daß ein außerdeutscher Staat „im Wege der Reichsgesetzgebung“ und nur auf diesem Wege ins Reich aufgenommen werden kann. Das Anormale besteht allein darin, daß nicht die verfassungsmäßigen Organe des Reichs, sondern die Nationalversammlung die Aufnahme verfügt. 
Vom Standpunkte des Reichsrechts betrachtet, trägt das Aufnahmegesetz den Grund seiner verbindlichen Kraft allein in sich selbst. Dem aufgenommenen Staate freilich und seinen Angehörigen gegenüber würde es als ein Akt reiner Gewalt erscheinen, wenn sich die Aufnahme nicht mit der Einwilligung des in den Kreis der Bundesglieder einbezogenen Staates vollzöge. Aber diese Einwilligung ist schon im voraus durch den Beschluß der provisorischen deutsch-österreichischen Nationalversammlung vom 12. November erklärt worden; der Erlaß der Wahlordnung, die Vornahme der Wahlen und die Beteiligung der österreichischen Abgeordneten an der reichsdeutschen Nationalversammlung würde das bereits Gesagte nur mit aller Deutlichkeit bestätigen.

Gehen wir davon aus, daß das Deutsche Reich als solches fortbesteht, daß folglich die künftige Nationalversammlung ein Organ dieses Reiches ist, so muß es an sich als eine Anomalie erscheinen, wenn sich an dieser Versammlung auch Abgeordnete aus einem bisher noch reichsfremden Staate beteiligen. Aber dieser durch die besonderen Umstände der Zeit bedingte Vorgang trägt formell eben doch seine Rechtfertigung in einem Rechtssatze des Reichs, nämlich in der Bestimmung des die Wahlen anordnenden Gesetzes. Wie der Vorgang juristisch zu „konstruieren“ sei, das kann füglich der Kunst künftiger Jurisprudenz überlassen bleiben. Hält man aber solche Konstruktion jetzt schon für geboten, so würde sich etwa folgendes darüber sagen lassen.

Es ist in der modernen Verfassungsgeschichte häufig vorgekommen, daß bei dem Erlasse einer neuen Staatsverfassung nicht die dem bisherigen Rechte gemäße, sondern diejenige Form gewählt wurde, die dem zukünftigen, in Aussicht genommenen Rechtszustande entsprach. Die Geltung der künftigen Verfassung wurde also gewissermaßen antezipiert. Absolute Staaten, die sich in konstitutionelle verwandeln wollten, bedienten sich bei der Überleitung aus dem alten in das neue Recht schon im voraus der Form konstitutioneller Gesetzgebung. Der Herrscher stellte die Verfassung im Verein mit einer ad hoc berufenen Volksvertretung fest; die Verfassung wurde nicht oktroyiert, sondern paktiert. Auch in unserem Fall handelt es sich um gar nichts anderes, als um eine aus besonderem Anlasse für notwendig erachtete Vorausnahme des dem künftigen Reichsrechte konformen Verfahrens. Denn eine Reichsversammlung, an der sich österreichische Abgeordnete beteiligen, wird das Urbild des späteren deutschen Reichstages, zum mindesten seines Volkshauses, darstellen.

Man mag sich die Sache auch so zurecht legen: das Reich von heute erweitert sich für die e i n e Aufgabe der Verfassungsänderung schon jetzt um das der deutsch-österreichischen Republik gehörige Gebiet. Wir hätten 
es mit einem Gebilde zu tun, das sich etwa mit dem Deutschen Zollverein in den Jahren 1867 bis 1870 vergleichen ließe. Bekanntlich war die Organisation des Zollvereins in engste Anlehnung an die des Norddeutschen Bundes gebracht, dergestalt, daß der Norddeutsche Bundesrat durch Bevollmächtigte, der norddeutsche Reichstag durch Abgeordnete aus den süddeutschen Staaten ergänzt wurden und in dieser Erweiterung als Zollvereinsorgane funktionierten. Man hat den Zollverein von 1867 gelegentlich als einen „Spezial-Bundesstaat" bezeichnet, d. h. als einen für den besonderen Zweck der Zoll- und Handelsgesetzgebung gebildeten, durch eine Erweiterung des Norddeutschen Bundes ad hoc geschaffenen Bundesstaat. Etwas Ähnliches würde man heute für den besonderen Zweck der Herstellung einer großdeutschen Verfassung ins Werk setzen. Als selbstverständlich ist dabei angenommen, daß die der Reichsversammlung beitretenden österreichischen Abgeordneten - wie es ja auch wohl nicht anders sein kann - auch nur bei jener einen Aufgabe der Nationalversammlung mitzuwirken haben.

IV.

Nach dem Vorstehenden dürfte, was die provisorische deutsche Regierung $\mathrm{zu}$ tun hat, einfach genug vorgezeichnet sein: Verständigung mit der deutsch-österreichischen Regierung, Aufnahme entsprechender Bestimmungen in das Wahlgesetz. Dringend erforderlich ist es, daß man den zahlreichen, bei uns wohnhaften Deutsch-Österreichern die Möglichkeit verschafft, sich an den Wahlen zu beteiligen. Da es aus äußeren Gründen schwierig sein möchte, sie in Deutsch-Österreich an der Wahl teilnehmen zu lassen, so sollte man ihnen das Recht verleihen, bei uns mit den Reichsbürgern zusammenzustimmen. Auch das ist natürlich wieder etwas sehr Außergewöhnliches. Aber im Grunde handelt es sich doch auch hier um nichts anderes als um eine Vorausnahme des künftigen Rechtszustandes von Gesamtdeutschland. Denn kommt das zustande, was wir hoffen und wünschen, so wird es fortan in Groß-Deutschland nur ein „Reichsindigenat" geben. Voraussetzung wäre natürlich, daß man in Deutsch-Österreich den dort wohnhaften Reichsdeutschen das entsprechende Recht gewährleistete. Die Frage, wer als „Deutsch-Österreicher“ zu betrachten sei, mag einige Schwierigkeiten bereiten. Man wird sich dadurch helfen können, daß man das Wahlrecht an den Besitz des Heimatrechts in einer Gemeinde anknüpft, die dem „Rechtsbereiche“ des jetzigen Deutsch-Österreich im Sinne der Staatserklärung vom 22. November 1918 (Staatsgesetzbl. Nr. 4) 
angehört. Wenn man so verfährt, wird man schwerlich sehr viele Elemente von der Wahlurne ausschließen, die es verdienen, zugelassen zu werden, und schwerlich viele zulassen, die aus nationalen Gründen ferngehalten werden sollten.

Was nun aber getan werden muß, das möge bald getan werden. Eile tut not! Es sollte auf jeden Fall vermieden werden, daß die gesamtdeutsche Nationalversammlung gleichzeitig mit oder gar erst nach den Landesversammlungen tagt. Darin läge eine große Gefahr. Die künftige Reichsverfassung wird den Raum abstecken, innerhalb dessen sich das Sonderleben der Einzelstaaten vollziehen darf; und sie wird Bestimmungen enthalten, die für den Inhalt der Landesverfassungen unbedingt maßgeblich sind. Die Aufgabe der Nationalversammlung würde unendlich erschwert sein, wenn ihr die konstituierenden Versammlungen der Gliedstaaten zuvorkämen. Erst das Reich, dann das Land - das muß auch hier die Losung sein!

\section{Nachschrift}

Nach Fertigstellung des Aufsatzes kommt mir die von der Reichsregierung erlassene Verordnung über die Wahlen zur Nationalversammlung vom 30. November 1918 zur Hand. Hier finden sich in $\$ 25$ Bestimmungen, die zum Teil die im Vorstehenden ausgesprochenen Wünsche erfüllen. ${ }^{2}$ Nur freilich läßt die Forderung, meines Erachtens unzweckmäßigerweise, den Eintritt der österreichischen Abgeordneten von einem förmlichen Beschlusse der Nationalversammlung selber abhängen. Will man den Österreichern zumuten, die entsprechenden Wahlen vorzunehmen, auf die Gefahr hin, daß die Nationalversammlung - was doch die Verordnung deutlich als möglich hinstellt - die Aufnahme Deutsch-Österreichs ablehnt? Oder sollen die Österreicher die Wahlen aufschieben, bis die Entscheidung der Nationalversammlung gefallen ist? Offenbar hielt sich die Reichsregierung nicht für befugt, der Entscheidung der Nationalversammlung vorzu-

2 „Beschließt die deutsche Nationalversammlung, daß Deutsch-Österreich seinem Wunsche entsprechend in das Deutsche Reich aufgenommen wird, so treten die deutsch-österreichischen Abgeordneten ihr als gleichberechtigte Mitglieder bei. Voraussetzung für den Beitritt ist, daß die Abgeordneten auf Grund allgemeiner, gleicher, unmittelbarer und geheimer Wahlen unter Beteiligung auch der Frauen nach den Grundsätzen der Verhältniswahl gewählt werden. Die Zahl der Abgeordneten wird auf der Grundlage bestimmt, daß durchschnittlich auf 150000 Seelen ein Abgeordneter entfällt. Der Wahltag braucht mit dem deutschen Wahltag nicht zusammenzufallen“. 
greifen. Aber sie hat bekanntlich auf anderen Gebieten, und zwar solchen, auf denen sie des Einverständnisses der Volksmehrheit längst nicht in gleichem Maße, wie hier, sicher sein konnte, eine sehr viel geringere Zurückhaltung geübt! 


\section{Text 3 \\ Das Frankfurter Parlament und die künftige Nationalversammlung 1}

In einer an die gegenwärtige Reichsleitung gerichteten Kundgebung haben die Bürger von Frankfurt den Wunsch ausgesprochen, es möge die kommende Nationalversammlung ihre Tagung in den Mauern der einstigen freien Reichsstadt am Main abhalten; die Pforten der Paulskirche würden ihr mit derselben Gastlichkeit wie dem Parlament von 1848 geöffnet werden. Es ist noch nicht an der Zeit, Erwägungen darüber anzustellen, ob es geraten ist, dieser Einladung Folge zu leisten. Denn in dem Augenblicke, da wir dieses niederschreiben, ist der Zusammentritt der verfassungsgebenden Reichsversammlung keineswegs eine bereits sichere Tatsache. Kein Zweifel, daß er von der großen Mehrheit des deutschen Volkes stürmisch verlangt wird. Aber eine Minderheit scheint entschlossen zu sein, sich der Einberufung energisch zu widersetzen, und niemand vermag zu sagen, wer in diesem Kampfe der Sieger bleiben wird. Immerhin haben die wackeren Männer von Frankfurt zur rechten Stunde die Erinnerung an die Tage wachgerufen, in denen zum ersten Male einer aus allgemeinen Wahlen des ganzen deutschen Volkes hervorgegangenen Nationalversammlung die Aufgabe gesetzt gewesen ist, einem geeinigten Deutschland durch eine Reichsverfassung eine vollkommen neue Form staatlichen Lebens zu verschaffen. Äußerlich betrachtet, hat das Frankfurter Parlament diese Aufgabe erfüllt. In langer, mühsamer Arbeit hat es eine umfangreiche, sorgfältig redigierte Verfassung hergestellt; am 28. März 1849 ist sie von Präsident und Schriftführern beurkundet, von fast vierhundert Mitgliedern der Versammlung mitunterzeichnet worden. Aber die Verfassung ist niemals gel-

1 [In: Daheim. Ein deutsches Familienblatt mit Illustrationen 55 (1918/19), Nr. 16 vom 18. Januar 1919, S. 9-10; Triepels Artikel erschien am 18. Januar 1919 einen Tag vor den Wahlen zur Nationalversammlung. Dass diese Nationalversammlung ab dem 6. Februar 1919 dann tatsächlich stattfinden konnte, hält Triepel damals noch nicht für gesichert. Berlin hatte die letzten Wochen bürgerkriegsähnliche Ausschreitungen erlebt, der "Januaraufstand" der radikalen Linken gegen die Formierung einer „bürgerlichen“ Demokratie war gerade erst niedergeschlagen worden. Liebknecht und Luxemburg wurden in diesen Tagen ermordet. Triepel scheint mit seinem Artikel unter Verweis auf die 1848er-Paulskirchenversammlung noch für Frankfurt als Ort der künftigen Nationalversammlung zu optieren.]. 
tendes Recht geworden! Wir fragen: Wird unter den jetzigen Verhältnissen einer deutschen Nationalversammlung ein besseres Schicksal beschieden sein? Es ist natürlich heute noch nicht möglich, sich von der Zusammensetzung dieses Volksrates eine genaue Vorstellung zu machen. Allein aller Wahrscheinlichkeit nach wird er ein wesentlich anderes Aussehen besitzen als das deutsche Parlament von 1848. Da man bei den Wahlen den Frauen das Stimmrecht gegeben hat, so konnte man nicht umhin, ihnen auch die Wählbarkeit zu verleihen, und so werden vermutlich, wenn nicht viele, so doch eine Anzahl von weiblichen Mitgliedern auf den Bänken der Abgeordneten sitzen. Die Frankfurter Nationalversammlung war in der Hauptsache eine Vertretung des deutschen Bürgertums. Die gewaltige Umänderung, die unsere Gesellschaft in den letzten zwei Menschenaltern erfahren hat, und der Charakter der Revolution, dem die künftige Nationalversammlung ihr Dasein verdanken wird, muß zur notwendigen Folge haben, daß sich in ihr die arbeitenden Klassen in starkem Maße durch Angehörige ihres Standes vertreten lassen werden. Im Frankfurter Parlament spielte das akademische Element eine sehr große Rolle. Ein ansehnlicher Teil der Abgeordneten entstammte dem höheren Beamtentum und dem Lehrkörper der Universitäten; man hat ja die Versammlung oft als das „Professorenparlament“ bezeichnet. Überhaupt hatten sich die Wähler bemüht, möglichst viele geistig hochstehende, allgemein angesehene Männer zu schicken. Es hat niemals wieder in Deutschland eine Volksvertretung gegeben, in der sich eine solche Menge von politischem und historischem Wissen, von soviel allgemeiner geistiger Bildung zusammengefunden hat. Das gab den Verhandlungen zuzeiten einen gewaltigen Schwung, aber freilich auch vielfach einen stark doktrinären Zug und eine umständliche Breite. Hieran und nicht bloß an der Schwierigkeit des Gegenstandes lag es, daß man mit der Verfassung so langsam vorankam, daß man bis Ende Dezember noch nicht weiter als bis zur Feststellung der „Grundrechte“ des deutschen Volkes gediehen war. Nun wird es sich hoffentlich auch dieses Mal das deutsche Bürgertum angelegen sein lassen, seine besten Köpfe in die verfassungsgebende Versammlung zu senden, und die geistigen Führer der Nation sollten sich dem Rufe nicht entziehen, im Gegenteil, sie sollten sich um die Erlangung eines Mandates bemühen. Wenn es nicht geschieht, stehen die höchsten Güter deutscher Kultur in größter Gefahr! Allein trotzdem werden aller Wahrscheinlichkeit nach in der Versammlung die Männer der Praxis aus allen Schichten des Volkes stärker vertreten sein als die Männer der Theorie, und es kann sein, daß dies dazu beitragen wird, die Verfassung schneller zuwege zu bringen, als es im Jahre 1848 der Fall war. Freilich ist nicht zu übersehen, daß heute gerade bei den radikalen 
Parteien der Doktrinarismus in üppiger Blüte steht, und die Redelust ist in Deutschland in den letzten Jahrzehnten gewiß nicht geringer geworden, als sie im Wiegenalter des Parlamentarismus gewesen ist.

Dafür mag ein anderer Umstand dazu beitragen, die Verhandlungen einer kommenden Nationalversammlung geschlossener und straffer $\mathrm{zu}$ machen: Als das Frankfurter Parlament zusammentrat, gab es noch keine über ganz Deutschland verbreiteten, einheitlich organisierten Parteien. In weiten Gebieten Deutschlands, vor allem in Preußen, fehlte es ja damals noch an dem konstitutionellen Leben, das die Vorbedingung für eine entwicklungskräftige Parteibildung darstellt. Natürlich waren überall bestimmte politische Richtungen vorhanden, und die Abgeordneten waren auf Grund von Programmen gewählt worden, die jenen Richtungen entsprachen. Aber das war doch ohne äußeren Zusammenhalt und ohne planmäßige Leitung geschehen. Erst im Parlamente selbst und nur allmählich fanden sich die Gleichgesinnten zusammen und vollzog sich eine Gliederung in einigermaßen fest abgegrenzte Parteien. Heute steht es anders. Kommt jetzt eine Nationalversammlung zustande, so werden sich ihre Mitglieder vom ersten Tage an in „Fraktionen“ einordnen, die den großen Parteien im Lande entsprechen. Der Wahlkampf wird ein gewaltiger Kampf organisierter Parteien sein. Diese Parteien werden allerdings mit den bisherigen nur zum Teil übereinstimmen. Wenigstens in den Kreisen des Bürgertums vollzieht sich in diesen Tagen eine große Verschiebung innerhalb der überlieferten Parteibildung, die alten Programme sind heute zum großen Teile unbrauchbar geworden. Ängstlich gehütete Scheidewände stürzen ein, Verschmelzungen bisher scharf getrennter Gruppen kündigen sich an. Wie weit dieser Prozeß gehen wird, steht noch dahin. Aber soviel ist sicher - die Reichsversammlung wird von Anfang an aus Parteien bestehen, und das wird ihre Arbeit erleichtern.

Als Heinrich von Gagern den Vorsitz der Frankfurter Nationalversammlung übernahm, tat er dies mit folgenden Worten: „Wir haben die größte Aufgabe zu erfüllen. Wir sollen schaffen eine Verfassung für Deutschland, für das gesamte Reich. Der Beruf und die Vollmacht zu dieser Schaffung, sie liegen in der Souveränität der Nation. "2 Das Parlament hat sich der Auffassung, die hierin ausgesprochen war, sofort angeschlossen: das souveräne deutsche Volk gibt sich seine Verfassung selbst. Das war ein stolzer und kühner Gedanke. Allein er stand in vollem Widerspruch nicht nur zu

2 [Franz Wigard, Stenographischer Bericht über die Verhandlungen der Deutschen Constituierenden Nationalversammlung zu Frankfurt am Main, Bd. I, Frankfurt 1848, S. 17; 2. Sitzung v. 19. Mai 1848]. 
dem geltenden Rechte, sondern auch zu den harten Tatsachen der Wirklichkeit. Gewiß war es eine große Volksbewegung gewesen, der das Parlament seine Entstehung verdankte. Aber diese Bewegung hatte die herrschenden Regierungsgewalten zwar mit sich gerissen, aber nicht fortgespült. Noch stand der Deutsche Bund, die Zusammenfassung der deutschen Einzelstaaten, in anerkannter Wirksamkeit. Die Revolution hatte zwar manche der deutschen Regierungen arg ins Wanken gebracht, aber keine von ihnen, vor allem keine der großen, war zusammengebrochen. Gewiß überließen sie für die Feststellung des Verfassungstextes dem Parlament die Führung. Aber sie hatten den Standpunkt nicht aufgegeben, daß der künftige Rechtszustand Deutschlands nicht einseitig von der Nationalversammlung bestimmt werden könne, vielmehr auf einer Vereinbarung zwischen ihr und den Regierungen beruhen müsse. Und an diesem Zwiespalt ist dann schließlich das Werk gescheitert. Als sich zeigte, daß die deutschen Landesherren nicht gesonnen waren, ihre Souveränität in dem Maße zu opfern, wie es die Frankfurter Verfassung ihnen zumutete, da war es entschieden, daß diese nicht zu geltendem Rechte werden konnte. Sie blieb toter Buchstabe, nicht weil sie an sich schlecht, unklug, lebensunfähig war, sondern weil die rechtmäßigen Regierungsgewalten den Willen und vor allem die Macht besaßen, sie nicht ins Leben treten zu lassen.

Heute liegen die Dinge wesentlich anders. Die Revolution von 1918 hat die legitimen Gewalten völlig außer Wirksamkeit gesetzt, im Reiche ebenso wie in den Einzelstaaten. Die deutschen Landesherren haben abgedankt oder doch auf die Ausübung ihrer Regierungsbefugnisse verzichtet, zum Teil sind sie abgesetzt worden. Die rechtmäßigen obersten Organe des Reichs - Kaiser, Bundesrat, Reichstag - sind außer Wirksamkeit gestellt oder fristen doch, wie der Bundesrat, nur von der Gnade der Revolutionsregierung ein bescheidenes Dasein. Im Reich und Einzelstaat wird die Herrschaft zurzeit ausschließlich von provisorischen Revolutionsregierungen geführt, die bisher unter sich noch nicht einmal in einen größeren $\mathrm{Zu}$ sammenhang gebracht worden sind. Wenn dieses rechtliche Chaos überhaupt in einen Zustand rechtlicher Ordnung hinübergeführt werden und wenn Deutschland nicht völlig auseinanderfallen soll, so gibt es in der Tat nur einen einzigen Weg: das ist die Schaffung einer neuen einheitlichen Verfassung durch das Volk selbst. Kommt die Nationalversammlung zustande, so wird sie mit besserem Rechte als das Frankfurter Parlament erklären dürfen, daß ihr Beruf und ihre Vollmacht in der Souveränität des Volkes gelegen seien. Wenn die zukünftige Nationalversammlung auf der einen Seite für ihre Arbeit freiere Bahn finden wird als ihre Vorgängerin 
von 1848, so ist doch ihre Aufgabe nach verschiedenen Richtungen hin unendlich viel schwieriger als die Aufgabe, die jener gestellt war.

Das Frankfurter Parlament tagte im tiefsten Frieden. Die Kriegsgefahr, die im Frühjahr 1848 von Frankreich herüberzudrohen schien, hatte sich bald verzogen. Die Nationalversammlung von 1919 wird als erstes, hartes und verantwortungsvolles Geschäft den Abschluß des Friedens mit den Mächten des Vierverbandes vorzuschlagen haben. Denn schon heute unterliegt es keinem Zweifel, daß unsere Gegner nur mit einer ordnungsmäßig gebildeten deutschen Regierung einen Friedensvertrag eingehen werden, und nur der Weg über die Nationalversammlung kann zu einer solchen Regierung führen.

Die Nationalversammlung wird ferner über die Grenzen zu bestimmen haben, innerhalb deren sich der deutsche Staat in Zukunft aufbauen soll. Das hängt nur zum Teil mit der Frage des Friedens zusammen. Denn es handelt sich dabei vor allem um die Entschließung darüber, ob und in welcher Form unsere deutschen Brüder in Österreich in den Verband des Deutschen Reiches aufzunehmen seien. Allerdings wird uns auch hierin ein Problem gestellt, mit dem sich bereits das Frankfurter Parlament zu beschäftigen hatte. Aber im Jahre 1848 wurde uns die Entscheidung durch die Donaumonarchie abgenommen. Der österreichische Gesamtstaat war es, der es uns unmöglich machte, seine deutschen Bestandteile uns einoder anzugliedern. Heute ist der alte Kaiserstaat aus den Fugen gegangen. Deutsch-Österreich will sich und muß sich aus inneren Gründen uns anschließen. In welcher Weise das geschehen soll, ist nicht einfach zu bestimmen. Indes bei gutem Willen hüben und drüben wird sich ein Weg finden lassen, der beiden Teilen zum Segen gereicht.

Aber es ist noch ein drittes und, wie ich meine, Entscheidendes, was der Tätigkeit einer künftigen Reichsversammlung ihr besonderes Gepräge geben wird. Die treibenden Kräfte der Revolution von 1848 waren rein politischer Natur. Es handelte sich um nationale Einheit und um politische Freiheit. Wirtschaftliche und soziale Probleme standen durchaus im Hintergrunde. Die Revolution von 1818 dagegen ist eine soziale Revolution. Sie ist von einer bestimmten Gesellschaftsschicht um gesellschaftlicher Interessen willen begonnen worden und soll ganz bestimmte soziale Forderungen gewaltsam durchsetzen. Sie richtet sich gegen die herrschenden Gewalten nicht in erster Linie, weil ihre Form den Führern der Revolution mißfällt, sondern weil nur durch ihren Sturz die Erfüllung wirtschaftlicher Ansprüche ermöglicht zu werden scheint. Daher wird in der Nationalversammlung nicht nur und vielleicht nicht einmal in erster Reihe um die Fragen Einheitsstaat oder Bundesstaat, Monarchie oder Republik gerungen 
werden, sondern darum, wie eine Verfassung aussehen muß, die das sozialistische Programm zu erfüllen geeignet ist. Das ist es, was das deutsche Bürgertum in den kommenden Wochen und Monaten recht wohl im Auge behalten möge. Der Kampf geht darum, ob der künftige deutsche Staat ein bürgerlicher oder ein sozialistischer sein wird. Das Bürgertum wird sich gesunden, sozialen Fortschritten nicht widersetzen. Allein es wird nicht die Torheit besitzen, sich dem Sozialismus mit Haut und Haaren zu verschreiben. Will es sich aber von der sozialistischen Flut nicht verschlingen lassen, so muß es sich zusammenschließen. Daß dies so rasch, so eng und so kräftig wie möglich geschehe, ist das dringende Gebot der Stunde. 


\section{Text 4 \\ Die Auslieferung des Kaisers ${ }^{1}$}

Schon in den ersten Monaten des Kriegs wurde in englischen und französischen Zeitungen wiederholt das Verlangen erhoben, man solle nach vollzogener Niederwerfung Deutschlands die für die europäische Katastrophe verantwortlichen Männer, als den Hauptschuldigen aber den Deutschen Kaiser persönlich zur Rechenschaft ziehen. Als der Krieg Jahr für Jahr neue gewaltige Menschenopfer forderte, als in den besetzten Ländern die Leiden der Bevölkerung und in den Kampfgebieten die durch die Heere angerichteten Schäden ins Ungeheure wuchsen, wurde der Ruf nach Bestrafung der „Missetäter“ leidenschaftlicher. In Frankreich, in England, in den Vereinigten Staaten schrie man Rache; man forderte allen Ernstes den Kopf des Kaisers. Wir haben anfänglich solche wilden Ausdrücke des Hasses auf die leichte Achsel genommen. Wir betrachteten sie als hysterische Anfälle, von denen überreizte Chauvinisten geschüttelt wurden, und stellten sie zu den ähnlich gehaltenen Äußerungen ohnmächtiger Wut, in denen die Zertrümmerung und Zerstückelung Deutschlands, die Versklavung des deutschen Volkes, die Zerstörung unserer gewerblichen Anlagen als oberstes Kriegsziel bezeichnet wurde.

Wider alles Erwarten hat nun aber die Angelegenheit mit einem Male ein sehr ernsthaftes Ansehen erhalten. Es sind nicht mehr nur Leute in unverantwortlicher Stellung, die von der Notwendigkeit der Bestrafung des Kaisers reden. Seit einigen Monaten wird in der aus behördlichen Quellen

1 [In: Deutsche Politik. Wochenschrift 4 (1919), S. 299-305; zu Text 4 und 5: Die im kurzen zeitlichen Abstand geschriebenen Texte vom Februar/März 1919, Monate vor dem Versailler Vertrag publiziert, argumentieren thematisch verwandt gegen eine strafrechtliche Kriminalisierung des einstigen Kaisers wie anderer politisch verantwortlicher Akteure. Da sie sowohl eine französische Denkschrift als auch den Entwurf zur Schaffung eines deutschen Staatsgerichtshofs als „Ausnahmegericht" und "Strafgericht" scharf ablehnen, scheint Triepel die strafrechtliche Verantwortung politischer Akteure insgesamt zurückzuweisen. Der Versailler Vertrag enthielt mit dem „Kriegschuldparagraphen“ auch einen Auslieferungsartikel, der bald zu umfangreichen Auslieferungslisten führte. Die deutsche Zusage eigener Strafverfolgung wurde von den Alliierten aber dann akzeptiert und es erfolgte in Deutschland keine scharfe Strafverfolgung von politisch Verantwortlichen oder auch Kriegsverbrechern. Die Niederlande gewährten Wilhelm II. lebenslanges Asyl.]. 
gespeisten Ententepresse mit Nachdruck gefordert, es solle an die niederländische Regierung der Antrag auf Auslieferung des Kaisers gerichtet und der Ausgelieferte von einem Strafgerichte abgeurteilt werden. Der französische Ministerpräsident Clémenceau hat die Sache in das Fahrwasser amtlicher Behandlung und Verhandlung geleitet. Er hat sich von zwei Pariser Gelehrten, dem Professor des öffentlichen Rechts Larnaude und dem Professor des Völkerrechts de Lapradelle - in den Zeitungen sind die Namen meist verstümmelt wiedergegeben worden - eine Denkschrift ausarbeiten lassen, die seinen Absichten eine juristische Unterlage verschaffen soll, und er hat diese Denkschrift der Konferenz der „alliierten und associierten" Regierungen vorgelegt. Die Konferenz hat einen Ausschuß mit der Feststellung der „Verantwortlichkeiten“ im Weltkriege beauftragt, zu dessen Vorsitzenden der amerikanische Staatssekretär Lansing, und zu dessen Generalsekretär Professor de Lapradelle bestellt worden sind. Man sieht also deutlich, wohin die Fahrt gehen soll.

Die deutsche Regierung und das deutsche Volk haben allen Anlaß, sich mit der Frage, die von den Staatsmännern und Juristen der Entente aufgeworfen ist, sehr gründlich zu beschäftigen. Die Frage ist keineswegs allein zwischen den Mächten des Vielverbandes und den Niederlanden auszutragen. Sie berührt auch uns in unmittelbarster Weise. Sie betrifft unsere nationale Würde und Ehre, nicht minder aber unser Recht. Wir müssen sie von diesem Standpunkte aus behandeln, ganz gleichgültig, wie wir uns zur Persönlichkeit und zur Politik Kaiser Wilhelms II. stellen mögen. Denn der Kaiser ist, obwohl er der Krone entsagt hat, ein Deutscher geblieben. Jeder Deutsche aber hat kraft ausdrücklicher Vorschrift unserer Reichsverfassung (Art.3) dem Auslande gegenüber Anspruch auf den Schutz des Reiches. Verfassungsmäßige Pflichten des Reichs hat jede Reichsregierung zu erfüllen, mag sie aus dieser oder jener Partei hervorgegangen sein. Auch ohne förmliches Anrufen des Berechtigten hat die Regierung von Amts wegen darauf zu achten, daß dem im Auslande weilenden Deutschen von einer fremden Regierung keine Unbill angetan wird.

Nun ist es an sich ohne Zweifel das souveräne Recht jeden Staates, über die Erfüllung eines von einem anderen Staate an ihn gerichteten Auslieferungsbegehrens selbständig zu entscheiden. Auch dann, wenn die Person, deren Auslieferung verlangt wird, einem dritten Staate angehört. Der ersuchte Staat braucht den dritten nicht um seine Zustimmung anzugehen. Im Gegenteil. Hat sich ein Staat durch einen allgemeinen Auslieferungsvertrag zur Auslieferung flüchtiger Verbrecher verpflichtet, so würde er seiner Vertragspflicht untreu werden, wenn er - falls es ihm nicht durch den Vertrag gestattet ist - im Einzelfalle die Auslieferung von der Einwilli- 
gung des dritten Staates abhängig machen wollte. Denn der Dritte könnte zumeist diese Einwilligung gar nicht geben. Zum Exempel wäre im vorliegenden Falle die deutsche Regierung schlechterdings außerstande, ohne Bruch des Reichsrechts ihre Zustimmung zur Auslieferung des Kaisers zu erteilen. Unser Strafgesetzbuch ( $\$ 9)$ erklärt, daß ein Deutscher niemals einer ausländischen Regierung zur Verfolgung oder Bestrafung überliefert werden dürfe. Offenbar kommt es aber auf eins hinaus, ob man einen Staatsangehörigen dem Auslande unmittelbar überliefert, oder ob man einem anderen Staate gestattet, ihn dem Auslande zu überantworten. Die niederländische Regierung ist viel zu korrekt, als daß sie, um sich aus einer unbequemen Lage zu befreien, versuchen sollte, die Entscheidung durch eine Anfrage in Berlin auf uns abzuwälzen. Würde sie dies aber tun, so könnte ihr, wenn bei uns nach Recht und Gesetz verfahren wird, nur ein unbedingtes Nein zur Antwort gegeben werden.

Das niederländische Kabinett muß also die Entscheidung allein treffen. Dabei befindet es sich indes in einer besonderen Lage. Während nämlich andere Regierungen einen Fremden ausliefern können, auch wenn sie vertragsmäßig nicht dazu verpflichtet sind, ist - nach belgischem Vorbilde von der niederländischen Verfassung und dem ihr entsprechenden Auslieferungsgesetze jede Auslieferung verboten, deren Vornahme nicht kraft eines gen erellen Auslieferungsvertrags gefordert werden kann. Dabei spielt es keine Rolle, ob die Auslieferung eines Niederländers oder die des Angehörigen eines fremden Staats in Frage steht. In beiden Fällen würde sich die Regierung, die eine nicht konventionsmäßige Auslieferung vollziehen wollte, einer schweren Verletzung des Landesgesetzes schuldig machen. Das hat nun auch für unser Verhältnis zu den Niederlanden Bedeutung. Denn vermöge des uns nach anerkanntem Völkerrechte zustehenden Schutzrechts können wir verlangen, daß jene Gesetzesbestimmung nicht zu ungunsten eines Deutschen durchbrochen werde. Gewiß können wir nicht beanspruchen, daß ein auswärtiger Staat seine Auslieferungsgesetzgebung in jeder Hinsicht auf Einheimische und Fremde gleichmäßig zuschneidet. Wir können z. B. nicht verlangen, daß der staatsrechtliche Grundsatz, der die Auslieferung eigener Untertanen unter allen Umständen verbietet, auf fremde Staatsangehörige ausgedehnt werde. Aber wenn das Auslieferungsgesetz eines auswärtigen Staats eine Norm enthält, die nach Wortlaut und Sinn allen Fremden zugute kommen soll, die in seinem Gebiete ein Asyl gesucht haben, so können wir uns in der Tat dagegen wehren, daß die Norm zum Schaden eines unserer Staatsangehörigen mißachtet wird. Erst recht freilich würden wir Einspruch erheben dürfen, wenn die Auslieferungsprozedur, ihrem innersten Zwecke zuwider, 
mißbraucht werden sollte, um unseren Kriegsgegnern lediglich die Befriedigung ihrer Rachegelüste zu ermöglichen. Die ausländische Regierung haftet uns dafür, daß das Verfahren gegen unsere Staatsgenossen „im Wege Rechtens vor sich gehe und nicht Deckmantel eines Gewaltstreiches sei“.2

Für das völkerrechtliche Verhältnis zwischen uns und den Niederlanden, für die Rechtsbeziehung zwischen den Niederlanden und der Entente und schließlich für die verfassungsmäßige Verantwortlichkeit der niederländischen Regierung ihrem eigenen Parlamente gegenüber kommt also alles darauf an, ob sich die Ententemächte bei einem Gesuche um Auslieferung des Kaisers mit Grund auf ihre mit den Niederlanden abgeschlossenen Auslieferungsverträge zu berufen vermögen. Daß davon nicht die Rede sein kann, haben objektiv denkende englische und amerikanische Juristen offen ausgesprochen, so der hervorragende Völkerrechtslehrer Sir Thomas Barclay und der amerikanische Generalstaatsanwalt George Wickersham. Es ist den Pariser Professoren vorbehalten geblieben, sich auf einen anderen Standpunkt zu stellen - wie wir glauben, nicht zum Nutzen ihres wissenschaftlichen Rufes. Die Denkschrift, die sie verfaßt haben, liegt uns allerdings nicht im Wortlaute vor. Aber französische und englische Zeitungen haben so ausführliche Auszüge daraus gebracht, daß wir uns von ihren Hauptargumenten ein genügendes Bild machen können.

Alle mit Holland abgeschlossenen Auslieferungsverträge, die hier in Betracht kommen könnten, zählen die strafbaren Handlungen, wegen deren eine Auslieferung beantragt werden kann, in Form von Katalogen genau und erschöpfend auf. Von allen den dort genannten Verbrechen: Mord, Münzfälschung, Bigamie, Einbruchsdiebstahl, Notzucht und anderem, kann natürlich dem Kaiser kein einziges zur Last gelegt werden. Aber die Franzosen sagen, man könne ihn für alle Verbrechen haftbar machen, die von Angehörigen der deutschen Wehrmacht in Feindesland oder auf der See begangen worden seien. Eine höchst seltsame Anschauung! Wenn deutsche Soldaten während des Kriegs echte Verbrechen gegen Angehörige der feindlichen Armee oder des feindlichen Landes begangen haben, so haben sie sich strafbar gemacht und sollten bestraft werden. Man möge uns die Fälle nennen, und wir werden sie untersuchen. Wir werden allerdings unsere Gegenrechnung aufmachen, und es steht zu erwarten, daß sie nicht kürzer ausfallen wird als die uns vorgelegte. Allein für Verbrechen einzelner Soldaten das Staatsoberhaupt strafrechtlich verantwortlich zu machen, ist eine rechtliche Ungeheuerlichkeit. Die Franzosen unterstellen mit einer Kühnheit ohnegleichen, daß solche Verbrechen vom Kaiser ge-

2 v. Martitz, Internationale Rechtshilfe in Strafsachen, Bd. I, 1888, S. 353. 
wollt oder gar befohlen und ihm daher zuzurechnen seien. Sie berufen sich auf einen an Kaiser Franz Josef gerichteten Brief, worin Kaiser Wilhelm in starken Ausdrücken eine grausame Kriegsführung gegen Frankreich als unerläßlich bezeichnet habe. Aber selbst wenn dieser Brief echt sein sollte, so würde kein vernünftiger Richter in der ganzen Welt auf den Gedanken kommen, daß damit die Mitschuld des Kaisers an irgendwelchen Verbrechen von Heeresangehörigen bewiesen werden könne. Ebenso merkwürdig ist es, daß sich die beiden Pariser Herren auf die Ausführungen des deutschen Staatsrechtslehrers Laband über das Wesen der kaiserlichen Kommandogewalt beziehen; diese sei eine aus der übrigen Reichsgewalt ausgeschiedene, dem Kaiser zu ganz selbständiger Ausübung zugewiesene, besondere Gewalt. Aber Labands Konstruktion ist von den Gutachtern infolge ihrer mangelhaften Kenntnis unseres Staatsrechts vollkommen mißverstanden worden. Sie bezieht sich lediglich auf die Frage, ob Akte der Kommandogewalt einer Gegenzeichnung bedürftig seien oder nicht, hat mit unserer Frage nicht das geringste zu schaffen, und ist im übrigen vom Verfasser in der neusten Auflage seines Werks gestrichen worden! Die deutsche Kommandogewalt als solche ist keine andere, als die französische oder englische, und mit demselben Rechte, mit dem man den Oberbefehlshaber des deutschen Heeres für Verbrechen seiner Soldaten haftbar machen will, könnte man den französischen Generalissimus für jede Untat eines uniformierten Senegalnegers und den König von England für den Baralongmord zur Rechenschaft ziehen.

Am erstaunlichsten aber ist, daß die französischen Juristen die Behauptung aufstellen, der Kaiser könne und müsse auch für den Krieg als solchen und für die von Deutschland befolgten Methoden der Kriegsführung, also für die Kriegserklärungen, für den Einmarsch der deutschen Truppen in Belgien, für den Tauchbootkrieg usw. vom Strafrichter verantwortlich gemacht werden. Man greift sich an den Kopf. Gibt es eine Bestimmung des französischen, belgischen, englischen, amerikanischen Strafrechts, wonach eine von einem fremden Staatsoberhaupte ausgegangene Kriegserklärung oder die Verletzung garantierter Neutralität oder die durch fremde Souveräne verübte Verletzung völkerrechtlicher Kriegsregeln oder Kriegsbräuche mit Strafe bedroht ist? Gibt es einen Auslieferungsvertrag, der solche Handlungen in den Katalog der Auslieferungsdelikte aufgenommen hat? Ein ganz unmöglicher Gedanke. Gesetzt den Fall, der deutsche Einmarsch in Belgien oder die von uns angewendete Form des Unterseekriegs seien rechtswidrig gewesen - wir bestreiten es, wollen uns aber darüber 
nicht noch einmal ${ }^{3}$ auslassen -, so würde es sich dabei in aller Regel ${ }^{4}$ nicht um die Verletzung einer staatlichen Norm und um eine nach irgendeinem Landesrechte strafbare Handlung, sondern um ein Delikt gegen das Völkerrecht gehandelt haben. Völkerrechtliche Delikte werden aber vom Staate begangen, nicht von einem Einzelnen, und nur der Staat als solcher haftet für sie. Natürlich handelt jeder Staat durch Organe; anders kann er ja gar nicht handeln. Aber eben deshalb sind die Handlungen seiner Organe seine Handlungen, ihre Delikte seine Delikte. Der Staat haftet völkerrechtlich für seine Organe, nicht die Organe für den Staat.

Die französischen Gutachter haben sich eine eigene Theorie zurecht gemacht. Nach strafrechtlichen Grundsätzen, sagen sie, sei eine Strafe gegen eine Aktiengesellschaft ausgeschlossen; ihren Direktor aber könne man vor den Strafrichter ziehen. Ebenso sei es beim Staate. Den Staat als Ganzes könne man nicht bestrafen, darum müsse man den Souverän, jedenfalls den abgedankten, zur Rechenschaft ziehen dürfen. Aber das ist eine handgreifliche Verdrehung. Man straft den Direktor einer Aktiengesellschaft für seine eigenen Verbrechen, nicht für die der Korporation. Und es hängt ganz von den Anschauungen des Strafgesetzgebers über die Delikts- und Straffähigkeit juristischer Personen ab, ob er sie staatlichen Strafen, z. B. Geldstrafen, unterstellen will oder nicht. Über souveräne Staaten gibt es aber überhaupt keine Strafgerichtsbarkeit. Es ist ein eigenartiges juristisches Kunststück, das Völkerrecht, das die Bestrafung eines Staates nicht kennt und nicht kennen kann, dadurch zu korrigieren, daß man die staatlichen Repräsentanten für Delikte der Staaten strafrechtlich haftbar macht. $\mathrm{Da}$ übrigens die Kriegserklärung als solche, gleichviel, ob sie mit oder ohne zureichenden Grund erfolgt ist, auch nicht einmal als völkerrechtliches Delikt betrachtet werden kann, sei nur nebenher angemerkt.

Die beiden französischen Gelehrten haben sich, nach Angabe der Zeitungen, Mühe gegeben, in der völkerrechtlichen Literatur einen Gewährsmann für ihre Ansicht zu finden. Das war offenbar nicht leicht. Sie haben bis ins 18. Jahrhundert zurückgehen müssen, also bis in die Zeit, in der Kriege Kabinettskriege waren und in der man zwischen Staat und Fürst noch nicht so scharf unterschied wie heute. In dem Schweizer Emmerich von Vattel haben sie einen Kronzeugen aufgetrieben. Dabei scheint ihnen

3 [Dazu etwa Heinrich Triepel, Der Luisitania-Fall im Urteile von deutschen Gelehrten, in: Zeitschrift für Völkerrecht 9 (1916), S. 231-236; ders., Die Freiheit der Meere und der künftige Friedensschluss, Berlin 1917; Konterbande, Blockade und Seesperre, Berlin 1918].

4 [im Originaldruck: „in alle Wege“]. 
aber ein arges Mißgeschick begegnet zu sein. Allerdings sagt Vattel, es sei in der Ordnung, einen Fürsten, der einen „ungerechten“ Krieg begonnen habe, zum Schadensersatze anzuhalten und ihn sogar, wenn es zur Sicherheit des Angegriffenen und der menschlichen Gesellschaft erforderlich sei, zu bestrafen (III, $\mathbb{1} 185$ ). Aber wenige Seiten später fügt er hinzu, das sei nur eine Forderung des Naturrechts; im positiven Völkerrechte (droit volontaire) sei sie nicht anerkannt und könne sie nicht anerkannt werden, da es an einem Richter über den Staaten fehle, der über Gerechtigkeit und Ungerechtigkeit von Kriegen unparteiisch zu urteilen vermöge. Daher müsse ein in gehöriger Form eröffneter Krieg hüben und drüben immer als ein gerechter Krieg betrachtet werden. Beginne ein Fürst einen ungerechten Krieg, so handele er vom Standpunkte des Naturrechts aus unrechtmäßig; aber das positive Völkerrecht gewähre ihm jedenfalls „l'impunité parmi les hommes“ (III, $\mathbb{S} \mathbb{S} 188-192)$ ! Wir müssen mit unserem Urteil zurückhalten, bis wir in die Lage kommen, den Wortlaut des Gutachtens vor Augen zu haben. Würde aber richtig sein, was die Zeitungen mitteilen, so wäre nur zweierlei möglich: Entweder haben die Pariser Herrn im Vattel nur die erste, nicht die zweite Stelle gelesen. Dann haben sie unerhört leichtfertig gehandelt. Oder sie glaubten darauf rechnen zu könne, daß ihre Auftraggeber ihr Zitat nicht nachprüfen würden. Das wäre dann allerdings bei Männern der Wissenschaft ein Verfahren, das zu brandmarken kein Wort einer lebenden Sprache stark genug sein könnte.

Nach alledem muß jedes Gesuch um Auslieferung, das die Ententemächte an die Niederlande stellen, schon an der einen Tatsache scheitern, daß dem Kaiser kein nach irgendeinem Strafgesetze der verbündeten Staaten strafbares Vergehen zur Last gelegt werden kann. Wir brauchen deshalb gar nicht erst auf die anderen Hindernisse hinzuweisen, die der Erfüllung eines Auslieferungsantrages entgegenstehen würden. Nach geltenden Grundsätzen muß z. B. die Handlung, wegen deren die Auslieferung begehrt wird, nach dem Rechte ebensowohl des ersuchten wie des ersuchenden Staates strafbar sein. Im vorliegenden Falle möchte sich das schwerlich beweisen lassen. Eine Auslieferung kann ferner niemals wegen politischer Delikte verlangt werden. Sollte es überhaupt möglich sein, dem Kaiser aus Akten der deutschen Kriegsführung strafrechtlich einen Strick zu drehen, so wäre es ganz selbstverständlich, daß jede der in Betracht kommenden Handlungen als ein Delikt von politischem Charakter betrachtet werden müßte. Der Auslieferungsantrag setzt endlich voraus, daß von einem Strafgerichte des ersuchenden Staats eine Untersuchung eröffnet oder ein Straferkenntnis gefällt worden ist. Davon ist hier wiederum nicht die Rede und kann es nicht sein. Die französischen Gelehrten haben das auch einge- 
sehen. Sie wollen daher den Kaiser vor einen erst zu diesem Zwecke zu schaffenden, außerordentlichen, internationalen Gerichtshof gestellt sehen, der ein Organ der künftigen „société des nations“ darstellen, aber natürlich nur mit Richtern aus den alliierten Staaten besetzt sein solle - eine in der Geschichte des modernen Rechts ganz unerhörte Prozedur!

Die strafrechtlichen und völkerrechtlichen Fragen liegen in bezug auf die Möglichkeit der Auslieferung Kaiser Wilhelms so ungemein einfach, daß es nur leidenschaftlicher $\mathrm{Ha}$ und ungezügelte Rachegier fertigbringen konnten, sie zu verwickeln. Ob die auf der Friedenskonferenz gegen uns verbündeten Staaten geneigt sein werden, sie nach den Grundsätzen des Rechts zu entscheiden, steht noch dahin. Die nächsten Wochen werden darüber Klarheit bringen. Zu anderen Zeiten bemühten sich kriegführende Staaten, in ihren Friedensschlüssen durch weitgegriffene Amnestieklauseln die im Kriege begangenen wirklichen Verbrechen straflos zu machen. Jetzt soll die Welt das empörende Schauspiel erleben, daß eine „Friedenskonferenz" etwas strafbar macht, was kein Verbrechen war. Dagegen müssen wir uns auflehnen mit allen Mitteln, die uns zu Gebote stehen. Es ist Sache unserer Regierung, sich rechtzeitig gegen den Anschlag zu wappnen. Sie wird erfolgreich sein, wenn sie entschlossen ist. Von der niederländischen Regierung, deren völkerrechtliche Loyalität sich in diesem Kriege mehr als einmal erprobt hat, dürfen wir erwarten, daß sie nicht die Hand dazu bietet, daß unter dem Scheine eines rechtlichen Verfahrens rechtlose Grausamkeit gegenüber einem Unglücklichen verübt wird. Auch die holländische Regierung wird unbezwinglich sein, wenn sie ihr gutes Recht mit Festigkeit verteidigt. 


\section{Text 5 \\ Der Entwurf des Reichsgesetzes über die Errichtung eines Staatsgerichtshofs ${ }^{1}$}

Das Deutsche Reich hat vor kurzem den feindlichen Mächten den Vorschlag unterbreitet, die Vorgänge, die zum Ausbruche des Weltkriegs geführt haben, durch eine internationale Untersuchungskommission unparteiisch prüfen und feststellen zu lassen. Am Widerspruche Englands ist der Vorschlag sofort gescheitert. Die deutsche Regierung hätte sich nun damit begnügen können, vor aller Welt diese Ablehnung als das festzunageln, was sie ist: als die offene Bekundung eines schlechten Gewissens. Aber bei einer solchen Erklärung glaubte sie es nicht bewenden lassen zu dürfen. Das Volk, meinte sie, habe ein Recht, „Aufklärung“ zu verlangen. Die Regierung müsse also von sich aus alles tun, was an ihr liege, um „die Wahrheit ans Licht zu bringen“. Der Weg, den sie hierzu als geeignet ansah, ist in dem Gesetzentwurfe über die Errichtung eines Staatsgerichtshofs angegeben, der nach der Mitteilung einer offiziösen Zeitung soeben der Nationalversammlung vorgelegt worden ist.

Die Ziele freilich, die sich dieser Entw. gesteckt hat, sind nicht mehr dieselben wie die, denen man bei dem mißglückten Antrage an die Ententeregierungen zustrebte. Denn was man durch die vorgeschlagene internationale Untersuchungskommission beantwortet wissen wollte, war die Frage, ob wir oder ob die anderen Schuld an der Katastrophe tragen, von der die Welt durch einen vierjährigen Krieg von riesenhafter Ausdehnung heimgesucht worden ist. Der Entw. aber will eine Feststellung darüber herbeiführen, wer das deutsche Volk, indem er den Krieg herbeiführte oder indem er ihn verlorengehen ließ, ins Unglück gestürzt hat. Die Untersuchung, die der Entw. verlangt, soll sich darauf beziehen, welche Vorgänge $(\$ 1)$ und Personen $(\$ 2)$,zum Ausbruch, zur Verlängerung oder zum Verlust des Krieges beigetragen haben“. Und die „Schuldigen“ werden von den Urhebern des Entw. ausschließlich im eigenen Lande gesucht. Denn das in Aussicht genommene Verfahren vor dem Staatsgerichtshofe richtet sich gegen „Deutsche“, gegen Personen, die „vermöge ihrer Stellung im öffentlichen Leben in der Lage waren, Einfluß auf die Politik des Reiches zu nehmen“

1 [In: Deutsche Juristen-Zeitung 24 (1919), Sp. 366-374]. 
$(\$ 2)$. Es wird also nicht mehr danach gefragt, welches Maß von Verantwortung an dem allgemeinen Unheil die einzelnen am Kriege beteiligten Staaten tragen, sondern es wird nach den Männern gefahndet, die in Deutschland für das dem Vaterlande widerfahrene Unglück verantwortlich sind.

Man braucht sich nur über diese Verschiebung des thema probandum ins klare gekommen zu sein, um sofort zu erkennen, welch ungeheurer politischer Fehler schon mit der Einbringung des Entw. begangen worden ist. Bis zu einem gewissen Grade läßt sich ja verstehen, daß ein Volk nach einem unglücklichen Kriege, der ihm gewaltige Opfer zugemutet hat, die Männer haftbar gemacht haben will, denen es die Schuld an seiner Niederlage zuschreibt. Das ist in der Welt immer so gewesen. Man hat Monarchen vom Throne gestürzt, wenn sie Kriege verloren hatten, und hat Feldherren, denen der erhoffte Sieg versagt geblieben, den Kopf vor die Füße gelegt. Die Athener belegten Miltiades nach dem unglücklichen Unternehmen gegen Paros mit unerschwinglicher Geldbuße, die Italiener bestraften den Admiral Persano für die Niederlage bei Lissa mit Verlust von Amt und Rang, und Bazaine büßte die Kapitulation von Metz mit kriegsgerichtlicher Verurteilung zu Tod und Degradation. Es wäre freilich ein Zeichen der Reife gewesen, wenn sich unser Volk zu der Erkenntnis durchgerungen hätte, daß die Schuld für die Heimsuchung, die uns betroffen, nicht allein bei einzelnen Staatsmännern und Heerführern, sondern zum Teil in Umständen, die außerhalb unserer Einwirkung lagen, zum anderen Teile in unser aller, in des ganzen Volkes eigenen Sünden zu finden sei. Immerhin, die Suche nach Einzelpersönlichkeiten, die für unsere Niederlage verantwortlich sind, läßt sich wenigstens menschlich begreifen. Allein der Entw. geht weit darüber hinaus. Er brandmarkt nicht nur jeden Deutschen, der zu dem unglücklichen Ausgange, sondern auch den, der zum „Ausbruche“ des Kriegs schuldhaft beigetragen hat, von vornherein mit dem Stempel des Verbrechertums. Da nun der Krieg, wie unzweifelhaft feststeht, durch die von Deutschland an Rußland erfolgte Kriegserklärung „ausgebrochen" ist, so stellt der Entwurf - anders ist er beim besten Willen nicht zu verstehen - die Eröffnung des Krieges selber vor aller Welt als ein Verbrechen hin, ohne Rücksicht auf die Umstände, die uns im Jahre 1914 das Schwert in die Hand gezwungen haben. Gewiß, nur als ein Verbrechen am deutschen Volke! Aber das Ausland wird die Sache auf seine Weise ansehen. Es wird sagen: da die Deutschen unmöglich die Narretei begehen können, einen Verteidigungskrieg als ein Verbrechen am Vaterlande zu bezeichnen, so gestehen sie nun offen zu, daß sie und nur sie die Schuld am Weltkriege tragen. So sind wir Deutschen wieder einmal im Begriffe, in selbstmörderischer Weise unsern Feinden eine Waffe in die Hand zu 
drücken, deren sie sich ohne Zweifel mit bekanntem Geschick in dem literarischen Verleumdungsfeldzuge bedienen werden, der dem Kampfe der Heere und Flotten vorausgegangen ist, der ihn fortdauernd begleitet hat und der ihn jahrelang überdauern wird. Und wir werden diesen Streit für unsere Gegner noch dadurch erleichtern, daß wir, ohne irgendwelche Hoffnung auf Gegenseitigkeit hegen zu können, das gesamte Material unserer Archive in aller Ruhe vor ihren Augen ausschütten. Nach dem Entwurfe soll der Staatsgerichtshof auf Grund öffentlicher und mündlicher Verhandlung entscheiden $(\$ 10)$. Die Reichsregierung hat ihm alle Akten und Urkunden, die er verlangt, vorzulegen $(\$ 5)$. Der ganze Vorgang ist in der Geschichte der Staatenwelt ohne jedes Beispiel. Selbst der Prozeß gegen den russischen Kriegsminister Suchomlinow, ${ }^{2}$ der die meisten Analogien zu zeigen scheint, war in anderer Weise aufgezäumt; die „Schuld am Kriege" spielte in ihm nur die Rolle eines Inzidentspunktes.

Viel härter aber noch als das politische, muß das juristische Urteil über den Gesetzentwurf ausfallen. Er stellt sich zu den grundlegendsten Gedanken unserer bisherigen Rechtsordnung in Widerspruch, und er leidet an formellen Gebrechen so stark, wie nur je ein hastig und ab irato ausgearbeitetes Werk der Gesetzgebung gelitten hat.

Der Entw. verlangt zunächst, daß die Nationalversammlung aus ihrer Mitte einen Ausschuß von fünfzehn Mitgliedern bilde zur Untersuchung der Vorgänge in der politischen und militärpolitischen Leitung des Reichs, die zum Ausbruche, zur Verlängerung oder zum Verlust des Krieges beigetragen haben $(\mathbb{1} 1)$. Die Verhandlungen des Ausschusses sind nicht öffentlich. Sieht man von der Frage ab, ob ein parlamentarischer, also nach parteipolitischen Rücksichten zusammengesetzer Ausschuß das richtige Organ für eine solche Aufgabe sei, so könnte man sich zur Not mit einem Verfahren, wie es der $\mathbb{1} 1$ in Aussicht nimmt, befreunden. Man könnte es verstehen, wenn das Gesetz eine Kommission zur Fes ts tellung vo n $\mathrm{T}$ a t s a c h e n einsetzte, um, soweit es die Unvollständigkeit des Materials und die Unvollkommenheit der menschlichen Einsicht gestatten, dem lebenden Geschlechte ein Urteil zu ermöglichen über die Ereignisse beim Ausbruche, bei der Führung und bei der Beendigung des Krieges, auch über den Anteil an den Kriegsbegebenheiten, der den von vielen Seiten als „schuldig“ bezeichneten Personen zuzuschreiben ist. Ja, man kann sagen,

2 [Wladimir A. Suchomlinow (1848-1926) war seit 1909 russischer Kriegsminister. 1916 bereits inhaftiert, wurde er im September $1917 \mathrm{zu}$ lebenslanger Haft verurteilt, am 1. Mai 1918 dann von den Bolschewiki amnestiert. Er emigrierte nach Deutschland und verstarb in Berlin.]. 
daß manche der in Parlament und Presse so viel geschmähten Männer ein wohlbegründetes Interesse an solcher Feststellung besitzen. Die Einrichtung einer Untersuchungskommission würde eine staatsrechtliche Analogie zu dem Institute der internationalen Untersuchungskommissionen bilden, die, im Art. 9 ff des Haager Abkommens zur friedlichen Erledigung zwischenstaatlicher Streitigkeiten vom 18. Oktober 1907 vorgesehen, zu unparteiischer und gewissenhafter Prüfung von Tatfragen, zur „Feststellung von Tatsachen" bestimmt sind, wobei den Parteien volle Freiheit in Ansehung der Folge gelassen wird, die dieser Feststellung zu geben ist. Aber leider bricht der Entw. gerade an der Stelle ab, an der er etwas Nützliches hätte schaffen können. Denn der von ihm vorgesehene Prüfungsausschuß soll zwar untersuchen, aber er soll gerade nichts feststellen. Er hat ein eigenes Urteil überhaupt nicht abzugeben. Das würde ihm auch gar nicht möglich sein. Denn seiner Prüfung unterliegen nur Urkunden und Akten, die ihm die Reichsregierung auf seinen Wunsch zur Verfügung zu stellen hat; Zeugen, Sachverständige oder „Beschuldigte“ darf er nicht vernehmen.

Der Ausschuß hat nur das Recht, allerdings auch die Pflicht, gegen Personen, die er für „verdächtig“ hält, zu dem Ausbruche, der Verlängerung oder zum Verluste des Krieges schuldhaft beigetragen zu haben, das Verfahren vor dem Staatsgerichtshofe zu eröffnen. Auch kann jeder Deutsche bei ihm die Eröffnung des Verfahrens gegen sich selbst beantragen $(\mathbb{2}$ ); dem Antrage muß aber offenbar nur dann stattgegeben werden, wenn der Ausschuß selber genügende Verdachtsmomente als vorliegend ansieht. Der Ausschuß erhält also, wie es die Begr. ausdrückt, die Rolle eines politischen (?) A nklägers zugewiesen. Das tritt dann noch besonders dadurch in Erscheinung, daß der Ausschuß ,zur Wahrung seines Standpunktes" einen Beauftragten bestimmt - ob aus seiner Mitte oder nicht, wird nicht gesagt -, der allen Beweisaufnahmen und Verhandlungen des Staatsgerichtshofs beiwohnen kann $(\mathbb{8} 8)$.

Der Staatsgerichtshof verhandelt nun ganz in der Weise eines $S \mathrm{tr}$ a fgerichts. Sein Verfahren erfolgt nach Vorschriften, die denen der StrPO. nachgebildet oder an sie angelehnt sind ( $\$ \$ 5-14)$. Der „Verdächtigte" oder „Beschuldigte“ wird durchaus als Angeklagter behandelt. Wenn er auf geschehene Ladung zur mündlichen Verhandlung ausbleibt, kann seine Vorführung verfügt werden. Wird er für schuldig erklärt, so darf man ihm die baren Auslagen des Verfahrens ganz oder teilweise auferlegen. Der Spruch des Staatsgerichtshofs hat festzustellen, ob die zur Verantwortung gezogene Person ein Verschulden trifft, ob ein solches Verschulden nicht erwiesen oder ob die Nichtschuld erwiesen ist. Und wenn der Gerichtshof 
ein Verschulden feststellt, so „kann“ er den Schuldigen für dauernd unfähig erklären, öffentliche Ämter zu bekleiden und in öffentliche Körperschaften gewählt zu werden. Das bedeutet die Verurteilung zu einer Kriminalstrafe, und zwar zu einer Strafe von außerordentlicher Schwere. Sie stellt den Verurteilten auf die Stufe eines Zuchthäuslers (StGB $\$ 31$ ). ${ }^{3}$ An dem Strafcharakter der Maßregel wird auch dadurch nichts geändert, daß der Gerichtshof zu ihrer Verfügung nur berechtigt, nicht verpflichtet ist. Freilich zeigt sich darin deutlich die klägliche innere Unsicherheit, an der die Verfasser des Entw. leiden. Wären sie überzeugt gewesen, daß es sich um eine Sühne für wirkliche Verbrechen handele, so hätten sie die Zuerkennung der Strafe nicht bloß in das Ermessen des Richters stellen dürfen. Zumal dem geltenden deutschen Strafrechte dergleichen völlig fremd ist; unser Strafgesetzbuch überläßt wohl die Verurteilung zu gewissen Nebenstrafen der richterlichen Freiheit, aber die Auferlegung der Hauptstrafe ist grundsätzlich richterliche Pflicht. Der Entwurf bürdet hiernach dem Gerichtshofe eine kaum erträgliche Last auf, die um so schwerer wiegt, als zu erwarten steht, daß der Richter seinen Spruch unter dem „Kreuzige!“ einer schreienden Menge zu fällen haben wird.

Daß die Verfasser des Entwurfs dem Gesetze die Form eines Strafgesetzes gegeben haben, gehört zu den vielen Ungeheuerlichkeiten, die uns die gesetzgeberische Arbeit der Revolutionsmonate beschert hat. Der Satz des geltenden Strafgesetzbuchs: „Eine Handlung kann nur dann mit einer Strafe belegt werden, wenn diese Strafe gesetzlich bestimmt war, b e v o r die Handlung begangen wurde“ ( $\mathbb{2}$ StrGB.), ist einer der Grund- und Ecksteine unseres ganzen Strafrechts. Nulla poena sine lege praevia. Die Kritik mag an der Starrheit dieses Satzes manches mit Recht getadelt haben. Aber sein Inhalt ist doch nun einmal seit unendlich langer Zeit in unser Rechtsbewußtsein eingedrungen. Zum mindesten enthält er eine Forderung, die kein gerecht Denkender auch nur im entferntesten bestreiten wird: daß es unzulässig sei, jemanden wegen Zuwiderhandlung gegen eine Rechtsnorm zu bestrafen, die noch nicht bestand, als er seine Tat beging. Eben das aber will der Entwurf geschehen wissen. Wer in Deutschland überhaupt noch einen Sinn für die Würde des Rechts besitzt, muß das als einen Schlag ins Gesicht empfinden. Die amerikanische Demokratie hat vor mehr als hundertdreißig Jahren den Grundrechten der Unionsverfassung das Verbot der ex post factolaws, d. h. der Strafgesetze mit rückwirkender Kraft, einver-

3 In den Augen radikaler Politiker ist allerdings die in Aussicht genommene Strafe noch viel zu gering. E. Kettner, Vorwärts Nr. 188 vom 12. April 1919, fordert Verbannung! 
leibt. Die französische Revolution schrieb in die Erklärung der Menschenund Bürgerrechte den Satz: Niemand kann auf Grund eines Gesetzes bestraft werden, das erst nach seiner Tat aufgestellt und verkündet worden ist. Und die Jakobinerverfassung von 1793 gebraucht die starken Worte: Ein Gesetz, das ein vor Erlaß des Gesetzes begangenes Delikt mit Strafe bedroht, ist ein Akt der Tyrannei. Es scheint der deutschen Revolution von 1918 vorbehalten zu sein, eine Einrichtung zu schaffen, die von ihren Vorgängerinnen mit Ausdrücken des lebhaftesten Abscheus bezeichnet worden ist.

Nun sehe man sich aber weiterhin die Formulierung an, die der Verf. des Entw. den Tatbeständen gegeben hat, die er unter Strafe gestellt sehen will.

Als Täter kommt in Betracht, wer vermöge seiner Stellung im öffentlichen Leben in der Lage war, Einfluß auf die Politik des Reichs zu nehmen. So viel Worte, so viel Unklarheiten. Welche Personen hat der Entwurf im Auge? Natürlich in erster Linie Staatsmänner des Reichs, die Reichskanzler, Staatssekretäre, Reichsgesandten, andere Beamte in hohen Stellungen, Generalstäbler, Heerführer. Aber der Wortlaut greift sehr viel weiter. Er deckt selbstverständlich auch Mitglieder des Bundesrats und Minister der Einzelstaaten, er deckt auch sämtliche Mitglieder des Reichstags. Nehmen wir einmal vorläufig an, daß in der Bewilligung von Kriegskrediten im dritten oder vierten Kriegsjahre ein vorsätzliches, also schuldhaftes Beitragen zu einer „Verlängerung“ des Kriegs zu finden sei - ich wüßte in der Tat nicht, was sich dagegen sagen ließe -, so hätten sich sämtliche Reichstagsabgeordneten, die dabei mitgewirkt, der strafbaren Handlung schuldig gemacht. Ihre Immunität nach RV. Art. 30 würde sie zwar für ihre Abstimmung, nicht aber für das, was sie „außerhalb des Hauses“ zu jenem Anschlusse beigetragen, dem Verdikte des Staatsgerichtshofs entziehen! Allein außer Beamten, Offizieren und Parlamentariern gibt es noch Scharen von anderen Leuten, die nach $\mathbb{2}$ des Entwurfs als Täter in Betracht kommen können: die Männer der Presse in erster Linie, ${ }^{4}$ ferner politische Schriftsteller von Ansehen, dazu Hunderte von Führern und Mitgliedern einflußreicher politischer und wirtschaftlicher Vereinigungen. Es steht zu fürchten, daß es keinen Saal in Deutschland gibt, der imstande wäre, die zahllosen Angeklagten zu fassen, die nach der Ansicht des Entw. vor der Barre des Gerichtshofs zu erscheinen haben. Auf der anderen Seite aber -

4 Der erwähnte Vorwärtsartikel hat schon darauf hingewiesen und hat sich beeilt, den „kriegshetzerischen“ Journalisten zu nennen, auf den er es in erster Reihe abgesehen hat. 
warum beschränkt sich der Entw. auf Personen, die bei Kriegsausbruch oder während des Krieges „im öffentlichen Leben“ gestanden haben? Ist es denn ausgeschlossen, daß Freunde oder Vertraute der Staatsoberhäupter, Adjutanten, Geistliche, wissenschaftliche Gutachter - alles Leute, für die das Prädikat des Entw. nicht zutrifft - auf folgenschwere Entschließungen einen ebenso großen Einfluß ausgeübt haben wie Männer in verantwortlichen Stellungen?

Die Tat besteht nach dem Entw. in dem schuldhaften, also offenbar sowohl fahrlässigen wie vorsätzlichen Beitragen zum Ausbruche, zur Verlängerung und zum Verluste des Kriegs. Nach $₫ 12$ hat allerdings der verurteilende Spruch des Staatsgerichtshofs nur das "Verschulden“, nicht das schuldhafte Beitragen festzustellen; aber das ist wohl nur eine der mancherlei Liederlichkeiten, an denen der Entwurf leidet. Schlimmer ist die Formulierung des Tatbestandes selbst. Zunächst: der Ausbruch des „Krieges" Welches Krieges? Der Weltkrieg ist eröffnet worden durch die deutsche Kriegserklärung an Rußland. Die Kriegserklärung an Frankreich ist gefolgt. Aber England hat den Krieg an uns erklärt. Gehört das mit zum „Ausbruch des Krieges“? Und wie steht es mit dem Ausbruche der Feindseligkeiten zwischen uns und den vielen anderen Staaten, die sich auf die Seite unserer Hauptgegner geschlagen haben? Nach der Ansicht des Entw. sollen doch gewiß auch die getroffen werden, die den Krieg mit Italien, Rumänien, vor allem mit den Ver. Staaten verschuldet haben. Oder gehört das zur „Verlängerung“ des Krieges? Das mag in Bezug auf den Krieg mit den Ver. Staaten zutreffen. Aber auch für den mit Italien und Rumänien? Das dürfte doch sehr zweifelhaft sein! Was wichtiger als das ist - wer und was alles zum Ausbruch des Kriegs „beigetragen“ hat, das läßt sich überhaupt durch keinen richterlichen Spruch, mag er so gewissenhaft und so eingehend sein, wie nur denkbar, sicher und vollständig feststellen. Zum Ausbruche des Kriegs hat nicht nur beigetragen, wer auf unsere Kriegserklärungen oder auf eine der politischen oder militärischen Maßregeln hingewirkt hat, die unsern Gegnern den formalen Kriegsgrund geboten haben. Beigetragen zum Kriege hat alles, mag es gut oder schlecht begründet, wohl erwogen oder leichtherzig beschlossen gewesen sein, was uns im Auslande Feindschaft oder Neid erweckt, was uns Freunde oder gar Verbündete gekostet hat. Hätten wir keine Kolonial- und keine Flottenpolitik getrieben, so wäre uns der Krieg mit England und mit Japan ganz sicher erspart geblieben. Will man die Forderung des Entwurfs erfüllen, so muß man bis auf das Krügertelegramm, auf die Beteiligung an der europäischen Demarche gegenüber Japan am Schlusse des japanisch-chinesischen Krieges, auf die Kündigung des deutsch-russischen Rückversicherungsvertrags, 
ja im Grunde bis auf den Frankfurter Frieden und die Gründung des Deutschen Reichs zurückgehen. Aber selbst wenn man sich auf das beschränkt, was dem Ausbruche des Kriegs unmittelbar vorausgegangen ist, und was sich seither ereignet hat, so mutet man dem Richter eine schlechthin unlösbare Aufgabe zu, wenn man von ihm verlangt, er solle sich über den Kausalzusammenhang zwischen den Handlungen oder Unterlassungen deutscher Staatsmänner und dem Ausbruche und der Fortsetzung des Krieges aussprechen. Welcher gewissenhafte Richter wird z. B. den Mut haben, als erwiesen anzusehen, daß uns ohne den Einmarsch in Belgien England den Krieg nicht erklärt hätte, oder daß ohne den verschärften Unterseebootskrieg die Vereinigten Staaten dem Kriege ferngeblieben wären? Mit Recht sagt die Begr., es sei letzten Endes die Aufgabe der Ge schichtsschreibung, die Frage, durch wessen Schuld der Krieg verursacht worden, erschöpfend zu beantworten. Da ist es doch ein vollendeter Widerspruch, wenn man dieselbe Aufgabe jetzt einem Strafrichter zuweist. Oder soll dieser die Frage etwa nicht „erschöpfend“ erledigen? Aber es wäre eine schreiende Ungerechtigkeit, einzelne Männer, die irgendein Stück in die unendlich lange und unendlich verwickelte Kausalkette gefügt haben, um die es sich hier handelt, für den Krieg als solchen verantwortlich zu machen.

Was für den Ausbruch des Krieges gilt, das trifft auch auf seinen für uns so unglücklichen Ausgang zu. Es hat einen guten Sinn, wenn man nach dem Verluste eines Krieges militärische Führer, die ihre Pflichten gröblich verletzt haben, vor ein Kriegsgericht stellt und hart bestraft. Mit Recht sind im Jahre 1806 die Kommandanten der preußischen Festungen, die nach der Schlacht von Jena in schimpflicher Weise kapituliert hatten, strenger Strafe zugeführt worden. Dabei handelt es sich um ganz bestimmte, in Verlauf und Folgen genau nachweisbare Einzelvorgänge, und die militärischen Strafgesetze pflegen hierfür im voraus die erforderlichen Vorschriften zu erlassen (MilStrGB. \$63). Aber wer will sich vermessen, aus der ungeheuer großen Zahl aller derer, denen im Jahre 1918 eine Schuld an dem völligen Zusammenbruche von Heer und Heimat zuzuschreiben ist - die Schuldigen sind vielleicht die Tausende von Namenlosen, deren man niemals habhaft werden kann! - einige wenige herauszugreifen? Über den Begriff der „Verlängerung“ des Krieges schließlich könnte man, wenn die Sache nicht so verzweifelt ernst wäre, nur eine Schale bittersten Spottes ausgießen. Der Staatsgerichtshof mag die Herren, die den Entwurf ausgearbeitet haben, um eine authentische Erklärung ersuchen, wie lange der Krieg nach ihrer Ansicht im höchsten Falle hätte dauern dürfen. 
Der $S \mathrm{ta}$ atsge richts hof soll beim Reichsgerichte gebildet werden und sich aus 15 Mitgliedern zusammensetzen. Fünf davon sollen beamtete Richter sein: die Präsidenten des Reichsgerichts, des Reichsmilitärgerichts, des Preuß. Oberverwaltungsgerichts, des Bayerischen Obersten Landesgerichts und des Oberlandesgerichts Hamburg. Daß nach geltendem Rechte der Präsident des Reichsmilitärgerichts ein General oder Admiral ist, der an der Rechtsprechung niemals teilnehmen darf ( $\$ 73$ MilStrGO.), scheinen die Verf. des Entwurfs nicht gewußt zu haben. Die anderen Richter sollen je zur Hälfte von der Nationalversammlung und vom Staatenausschusse gewählt werden. Jeder Deutsche ist wählbar; nur darf er keiner der beiden wählenden Körperschaften angehören. Man mag billig bezweifeln, ob diese Art der Richterernennung eine Gewähr für die volle Unbefangenheit der Mitglieder des Staatsgerichtshofs bietet. Die Nat.-Vers. kann bei einer derartigen Wahl der Natur der Sache nach von Parteirücksichten nicht absehen; es ist ihr daraus nicht einmal ein Vorwurf zu machen. Der Staatenausschuß repräsentiert Regierungen, die auch aus politischen Parteien hervorgegangen sind, und seine Wahl hängt von Instruktionen ab, die seine Mitglieder von jenen Regierungen empfangen. Wie heikel die Angelegenheit ist, kann man aus dem Artikel des „Vorwärts“ erkennen, der allen Ernstes verlangt, daß im Staatsgerichtshof keine „Gesinnungsgenossen der Angeklagten“ sitzen dürfen, und dem „angesichts der bekannten reaktionären Gesinnung der hohen Beamten des alten Systems" schon die fünf Gerichtspräsidenten als viel zu viel erscheinen. Man sieht daraus, auf welche abschüssige Bahn man sich begibt, wenn man ein Ausnahmegericht schafft, folglich wiederum - wie mit der Mißachtung des Grundsatzes: nulla poena sine lege - einen der festesten Steine aus dem Gebäude der überlieferten Rechts- und Staatsordnung (GVG. \$16) herausbricht.

Wenn das englische Parlament in der Zeit des Kampfes gegen die Stuarts seine Rache an einem politischen Feinde auslassen wollte, dem mit den Mitteln des gemeinen Rechts nichts anzuhaben war, so drückte es eine Bill of attainder durch, ein Gesetz, das für einen bestimmten Einzelfall, „pro re nata“, die Strafe des Hochverrats verhängt. Auf solche Weise machte sich das Parlament durch einen einzigen Akt zum Strafgesetzgeber, Ankläger und Richter. Den Grafen von Strafford und manche andere hat es durch dieses Verfahren dem Beile des Henkers überliefert. Das Gesetz, dessen Erlaß man in unsern Tagen der Nat.-Vers. von Weimar vorschlägt, unterscheidet sich von einer Bill of attainder allein dadurch, daß es die Erhebung der Anklage auf einen parlamentarischen Ausschuß, den Urteilsspruch auf einen nur teilweise vom Parlamente besetzten Gerichtshof abschiebt. Bei Lichte besehen sind das indes nur kümmerliche Verkleidun- 
gen. Trotz seiner generalisierenden Fassung richtet sich das Gesetz im Grunde doch gegen eine Anzahl ganz bestimmter Personen; ihre Namen sind in aller Munde. Dafür, daß der Gerichtshof sie verurteilen wird, läßt sich durch die Auswahl der Richter und durch den Druck der „öffentlichen Meinung" sorgen. Als sich die amerikanischen Kolonien ihre Unabhängigkeit von England erkämpft hatten, machten sie das Verbot der Bill of attainder zu einem Fundamentalsatze ihrer jungen Verfassung. Auch in diesem Punkte scheint die deutsche Demokratie im Begriffe zu stehen, die guten Lehren in den Wind zu schlagen, die ihr die amerikanische gegeben hat.

Wir hoffen, daß sich in der Nat.-Vers. eine Mehrheit finden wird, die Festigkeit genug besitzt, um sich gegen die ungesunden Gedanken des ihr vorgelegten Entw. zu wehren. Möchte es uns erspart bleiben, daß man dereinst dem Strafverfahren gegen unsere Staatsmänner und Heerführer etwas Ähnliches nachsagt wie dem verfassungswidrigen Verfahren, das die Athener nach der Seeschlacht bei den Arginusen gegen ihre Feldherrn anstellten: daß es durchgesetzt worden sei von „oligarchischer Bosheit im Bunde mit ochlokratischer Meisterlosigkeit“. Sollte der Entw. zum Gesetze werden, so wird der Tag, an dem dies geschieht, für alle Zeiten als ein schwarzer Tag in der Geschichte des deutschen Rechts zu verzeichnen sein. 


\section{Text 6}

\section{Die Entwürfe zur neuen Reichsverfassung ${ }^{1}$}

Inhaltsverzeichnis: I. Der Preußsche Entwurf und der Entwurf des Staatenausschusses. Private Entwürfe. - II. Die Aufgabe des Verfassungsgesetzgebers. Der Staatenbestand des Rechts. Die Maßstäbe der Kritik. Die Grundrechte. - III. Das Verhältnis zwischen Reich und Einzelstaaten. Unitarismus und Föderalismus. Die Vorschläge des Preußschen Entwurfs über die Zuständigkeitsverteilung. Die Reichsräte. Das Staatenhaus - IV. Die föderalistische Umbiegung des Entwurfs durch den Staatenausschuß. Die Reservatrechte. Die Kompetenzregulierung. Der Reichsrat. - V. Reichstag und Reichspräsident.

\section{I.}

In der schönen Vorrede, die Friedrich Christoph Dahlmann dem Verfassungsentwurfe der siebenzehn Vertrauensmänner vom April 1848 voranstellte, findet sich der Satz: „Dieses Deutschland, welches die vielhundertjährigen Strafen seiner Entzweiung getragen hat, muß seine Volks- und Staatseinheit jetzt erreichen, unverzüglich, bevor noch das zweite Jahrhundert seit jenem Frieden abläuft, welcher seine Schwäche heilig spricht. Niemand in der Welt ist so mächtig, ein Volk von 40 Millionen, welches den Vorsatz gefaßt hat, sich selbst fortan anzugehören, daran zu verhindern,

1 [In: Schmollers Jahrbuch 43 (1919), S. 459-510; Abschluss des Textes auf Ende Februar 1919 datiert. Abdruck der Verfassungsentwürfe bei Triepel, Quellensammlung zum Deutschen Reichsstaatsrecht, 4. Aufl. Tübingen 1926, S. 6 ff.; die ersten beiden Entwürfe zur Reichsverfassung wurden im Januar 1919 ausgearbeitet. Michael Dreyer (Hugo Preuß. Biografie eines Demokraten, Stuttgart 2018, S. 355) schreibt zum ersten Entwurf: „Alles in allem trägt er eindeutig die klare Handschrift von Preuß. [...] Nur dieser Entwurf I entspricht wirklich den Vorstellungen von Hugo Preuß.“ Triepel beruft sich gegen Preuß im Text immer wieder auf den konkurrierenden Entwurf eines „Vereins Recht und Wirtschaft", an dem Triepel selbst beteiligt war: Dazu Heinrich Triepel / Erich Kaufmann / Franz Lusensky, Entwurf einer Verfassung des Deutschen Reiches, hrsg. vom Verfassungsausschauss des Vereins Recht und Wirtschaft, Berlin 1919]. 
niemand auch dürfte nur wünschen, es zu sein. " ${ }^{2}$ Wer vermöchte diese Worte in unseren Tagen anders als in tiefer Bewegung und mit Gefühlen heißer Scham zu lesen! Die Volks- und Staatseinheit, um die unsere Väter noch „mit treulich fortgesetztem Bemühen“ zu kämpfen hatten, ist uns ein halbes Jahrhundert lang ein kostbarer Besitz und die Grundlage unvergleichlichen Aufstiegs gewesen. Heute aber liegt die Verfassung, durch die sie verbürgt wurde, zerbrochen vor unseren Füßen. Wenn wir jetzt in aller Eile daran gehen, ein neues Reichsgrundgesetz herzustellen, so ist diesmal die Forderung des „unverzüglich“ aus weit härterer Not geboren als im Jahre 1848. Wir wissen, daß jede Woche der Saumseligkeit landesverräterische Bestrebungen ermuntert, die unsere Staatseinheit von innen auszuhöhlen trachten. Und wir wissen, daß es energischer Bekundung nationalen Eigenwillens und entschlossener staatsbildender Taten bedarf, wenn wir äußere Mächte daran hindern wollen, uns, einem Volk von nunmehr bald 70 Millionen, einen zweiten Westfälischen Frieden aufzuzwingen, der zum anderen Male unsere Schwäche auf Jahrhunderte heilig sprechen würde.

Die Erkenntnis der Dringlichkeit unserer Aufgabe hat seit dem November vorigen Jahres viele Federn in Bewegung gesetzt. In zahlreichen Aufsätzen der Tageszeitungen und Wochenschriften sind Pläne für den Neubau des Reichsverfassungsrechts entwickelt worden, auch an formulierten Verfassungsentwürfen fehlte es nicht. Was uns geboten wurde, war freilich sehr ungleich an Wert. Neben viel Unreifem fand sich manches Wohlerwogene und Gutdurchdachte. Sehr verschieden waren auch die Beweggründe, von denen sich die Verfasser leiten ließen. Bei manchen trat recht unverhüllt die Neigung zutage, das, was sie die „Errungenschaften“ der Revolution zu nennen belieben, zum Nutzen bestimmter Parteigruppen rasch und sicher in die Scheuern zu bringen. Bei anderen zeigt sich das edlere Bestreben, starke Gedenken einer bewegten neuen Zeit für die organisatorische Ausgestaltung des Staates fruchtbar zu machen. Wieder andere versuchen, von dem Erbgute des alten Staatswesens zu retten, was des Erhaltens wert und bedürftig erscheint, und mit ihm in vorsichtiger Auswahl Neues zu verknüpfen, was von einer drängenden Gegenwart gefordert wird. Über alle diese von unbeamteter Seite stammenden Vorschläge soll

2 [Entwurf zum deutschen Reichsgrundgesetze. Der Hohen deutschen Bundesversammlung als Gutachten der siebzehn Männer des öffentlichen Vertrauens überreicht am 26. April 1848, Frankfurt 1848, Vorwort, S. 3-8, hier: 4]. 
aber im folgenden nicht gesprochen werden ${ }^{3}$. Nur einer von ihnen, der Entwurf, den der vom Vereine „Recht und Wirtschaft" gebildete Verfassungsausschuß ausgearbeitet hat, wird gelegentlich Erwähnung finden ${ }^{4}$. Da der Verfasser dieser Abhandlung an ihm mitgewirkt hat, wird man es ihm nicht verargen, wenn er sich dann und wann zur Verdeutlichung seiner Ansichten auf ihn beruft. Im allgemeinen soll sich jedoch die folgende Untersuchung nur mit den amtlichen Entwürfen beschäftigen, die von der vorläufigen Reichsregierung ausgegangen sind. Es sind nicht weniger als drei. Der erste ist im vormaligen Reichsamte des Inneren entstanden und veröffentlicht worden ${ }^{5}$. Der zweite ist aus Verhandlungen mit den Landesregierungen hervorgegangen, formell aber gleichfalls als ein Entwurf der Reichsregierung dem Staatenausschusse in Weimar vorgelegt worden 6 . In die Öffentlichkeit ist er nicht in seinem vollen Wortlaute gelangt, doch sind die Zeitungen in der Lage gewesen, über seinen Inhalt Mitteilungen zu bringen. Der dritte Entwurf ist die der Nationalversammlung gemachte Vorlage ${ }^{7}$.

Der im Reichsamte des Inneren ausgearbeitete Verfassungsentwurf ist das Werk des Staatssekretärs, jetzigen Reichsministers des Inneren Dr. Hugo Preuß. Die Denkschrift, die dem Texte vorangeht, ist von ihm unter-

3 Von formulierten Verfassungsentwürfen sind mir folgende bekannt geworden: Die neue Reichsverfassung. Ein Vorschlag von Hermann Weck. Berlin 1919. - Entwurf einer deutschen Verfassung. Von Dr. Kurt Löwenstein und Dr. Fritz Stern. Königsberg i. Pr. (o. J.). - Entwurf für die Verfassung des neuen Deutschen Reiches. Sonderheft der Zeitschrift „Die deutsche Nation“. Dezember 1918. - Heinrich Horst, Über Staatsformen, nebst einem Verfassungsentwurf für eine demokratisch-parlamentarische deutsche Republik. Berlin-Schöneberg 1918. - Die Verfassungsurkunde der Vereinigten Staaten von Deutschland (Demokratische Reichsrepublik). Ein Entwurf mit Begründung von Dr. Fritz Stier-Somlo. Tübingen 1919. - Entwurf einer Reichsverfassung. Herausg. von Dr. J. V. Bredt. Berlin 1919. - Entwurf einer Verfassung des Deutschen Reiches. Von Dr. A. Roth. Mannheim 1919.

4 Entwurf einer Verfassung des Deutschen Reiches. Herausg. vom Verfassungsausschuß des Vereins Recht und Wirtschaft, e.V. in Berlin. Berlin 1919. Das Vorwort nennt die Namen der Mitwirkenden [Erich Kaufmann, Franz Lusensky, Heinrich Triepel]. Es fügt hinzu, daß nicht jeder von ihnen in der Lage ist, für alle Einzelheiten des Entwurfs einzustehen. Das trifft auch auf den Verfasser dieses Aufsatzes zu. - Eine kurze Begründung des Entwurfs hat E. Kaufmann [Der Verfassungsentwurf des Vereins ,Recht und Wirtschaft'] in der Zeitschrift „Recht und Wirtschaft“ [8 (1919)], S. 46 [-51], eine kritische Würdigung Binding, das. S. 61 ff. gegeben.

5 Deutscher Reichsanzeiger Nr. 15 vom 20. Januar 1919. - Der Entwurf ist auch im Buchhandel, bei Reimar Hobbig in Berlin, erschienen.

6 Drucksachen des Staatenausschusses, Tagung 1919, Nr. 4.

7 Drucksachen der verfassunggebenden deutschen Nationalversammlung, Nr. 59. 
zeichnet worden. Aber auch ohne dies würde jeder, der die staats- und verwaltungsrechtlichen Arbeiten des Berliner Gelehrten gelesen hat, den Verfasser sofort erkannt haben. An der Eigenart der Schreibweise, die von dem herkömmlichen Stile amtlicher Gesetzesbegründungen - nicht durchweg in erfreulicher Weise - sehr kräftig abweicht, vor allem an den vorgetragenen Gedanken, an den Urteilen, die über den „Obrigkeitsstaat“ und über die Bismarcksche Reichsverfassung, ihren Charakter, ihre Leistungen, ihren geschichtlichen Untergrund ausgesprochen werden. Obwohl sich Denkschrift und Verfassungstext auffälligerweise nicht an jeder Stelle decken - es finden sich sogar sehr seltsame Widersprüche, die vermuten lassen, daß die letzte Redaktion des Textes erst nach Ausarbeitung der Denkschrift stattgefunden hat -, so ist doch der Inhalt der Verfassung offenbar in allem Wesentlichen auf die Initiative des Staatssekretärs zurückzuführen. Der staatsrechtliche Theoretiker sowohl wie der Kommunalpolitiker Preuß haben die Gelegenheit wahrgenommen, Lieblingsdoktrinen und Lieblingsforderungen in die Tat umzusetzen. An einigen Stellen des Entwurfs ist allerdings auch der Einfluß Max Webers zu bemerken, und der seltsame Absatz 3 des Artikel 2: „Das Reich erkennt das geltende Völkerrecht als bindenden Bestandteil seines eigenen Rechtes an“, scheint aus der Feder eines Völkerrechtslehrers geflossen zu sein, der es für angebracht hielt, bei dieser Gelegenheit ausländische Vorurteile hinsichtlich der Völkerrechtsfreundlichkeit des Deutschen Reichs zu zerstreuen. Über die Klausel, die einen Lehrsatz der englischen und anglo-amerikanischen Jurisprudenz in mißverständlicher Form dem deutschen Rechte einverleiben will, lohnte es sich, ein besonderes Kapitel zu schreiben; an dieser Stelle mag die Angelegenheit einstweilen auf sich beruhen ${ }^{8}$. Auch sonst wird der Staatsekretär für die Formulierung des Verfassungstextes nicht überall persönlich die Verantwortung übernehmen wollen. Manche Sätze sind vortrefflich redigiert. Aber neben ihnen finden sich andere, die durchaus unklar oder in ihrer Tragweite ungenügend erwogen sind.

Der Preußsche Entwurf hat keine gute „Presse“ gehabt ${ }^{9}$. Sein Verfasser hat sich, wie er bei mehreren Gelegenheiten erklärte, damit getröstet, daß

8 Bei der Umarbeitung des Entwurfs hat der Absatz die Fassung erhalten: „Die allgemein anerkannten Regeln des Völkerrechts gelten als bindende Bestandteile des deutschen Reichsrechts“ (Art. 8). Das ist eine Verbesserung, aber es ist immer noch nicht verständlich genug.

9 Von ausführlichen Besprechungen sind zu nennen: Gmelin, Warum ist der Reichsverfassungs-Entwurf für uns Süddeutsche unannehmbar? Gießen (o. J.). - Rothenbücher, Der Entwurf der deutschen Reichsverfassung (S.-A. aus der Zeitschrift für Rechtspflege in Bayern). München u. Berlin 1919. - Thoma, Annalen für soziale 
die Verfassungsentwürfe seiner bedeutenden Vorgänger, des Freiherrn vom Stein, Dahlmanns und Bismarcks, noch viel heftiger angegriffen worden seien als der seinige. Es war nicht sehr vorsichtig von ihm, die drei großen Schatten zu beschwören; denn das forderte zu Vergleichen heraus, die schwerlich zu seinen Gunsten ausgefallen wären. Aber wir widerstehen der Versuchung, Parallelen zu ziehen. Tatsache ist jedenfalls, daß keiner von den früheren Entwürfen zu einer deutschen Reichsverfassung so rasch und so gründlich in der Versenkung verschwunden ist wie der Preußsche. Sofort nach seinem Erscheinen zeigte sich, daß er bei allen Parteien, in wesentlichen Punkten auch bei der Partei, der sein Verfasser angehörte, starken Widerspruch fand. Von der regierenden Sozialdemokratie wurde der Versuch gemacht, ihn als „Privatarbeit" hinzustellen, was offensichtlich der Wahrheit widersprach. Vor allem erregte der Entwurf das starke Mißfallen der einzelstaatlichen Regierungen, die zu den Vorarbeiten nicht zugezogen worden waren. Am 25. Januar begann im Rechtsamte des Inneren eine Besprechung, an der zahlreiche Kommissare der obersten Reichsbehörden, der preußischen Ministerien und Delegierte der anderen Landesregierungen teilnahmen. Nach sehr lebhaften Debatten, über deren Gang die Öffentlichkeit nur mangelhaft unterrichtet worden ist, wurde die Einsetzung einer Kommission beschlossen, die zunächst über den Entwurf eines provisorischen Grundgesetzes beraten, in zweiter Linie sich mit dem Preußschen Entwurfe beschäftigen sollte. Die Verhandlungen der Kommission haben in Berlin begonnen und sind in Weimar fortgesetzt worden.

Der weitere Gang des Verfahrens wurde durch das am 10. Februar 1919 von der Nationalversammlung beschlossene Gesetz über die vorläufige Reichsverfassung (RGBl. S. 169) bestimmt. Die Notverfassung setzte nämlich einen aus Vertretern der Einzelstaaten bestehenden Staatenausschuß ein, eine Körperschaft, die für den von der Revolution beseitigten Bundesrat, ohne ihm in jeder Beziehung zu gleichen, Ersatz schaffen sollte. Die Notverfassung verordnete weiter, daß die Reichsregierung alle Vorlagen, die sie an die Nationalversammlung bringen wolle, dem Staatenausschusse zur Zustimmung vorzulegen habe. Komme eine Übereinstimmung zwischen Regierung und Staatenausschuß nicht zustande, so dürfe jeder Teil

Politik und Gesetzgebung 6 (1919), S. 409 ff., - Anschütz, Deutsche Juristenzeitung 24 (1919), Sp. 199 ff. - Binding, Die staatsrechtliche Verwandlung des Deutschen Reiches. Leipzig (o. J.), S. 35 ff. - E. Kaufmann, Grundfragen der künftigen Reichsverfassung. Berlin 1919. - Bredt, Hoetzsch, Flügge, Rang. Das Werk des Herrn Preuß oder wie eine Reichsverfassung nicht aussehen soll. Berlin 1919. 
seinen Entwurf der Nationalversammlung unterbreiten. Am 17. Februar brachte das inzwischen geschaffene „Reichsministerium“ des Inneren den von der Kommission umgearbeiteten Entwurf beim Staatenausschusse ein. Da die Kommission im Grunde von Anfang an eine Kommission des Staatenausschusses gewesen war, dauerte die Beratung nur kurze Zeit. Der Staatenausschuß nahm den Entwurf im großen und ganzen unverändert an. Immerhin wurden an einigen Stellen nicht unwichtige Zusätze gemacht oder Abstriche vorgenommen und manches in der Fassung verbessert; ein Artikel über den Amtseid des Reichspräsidenten wurde eingeschoben, die Vorschriften über das Eisenbahnwesen wurden erweitert und modifiziert, ein neuer Abschnitt mit Schlußbestimmungen wurde hinzugefügt. Aus den 73 Paragraphen des Preußschen Entwurfs, der sich auf den „allgemeinen Teil“ beschränkt und die besonderen Abschnitte über Verkehrs-, Zoll- und Handelswesen, Reichsfinanzen und Rechtspflege noch vorbehalten hatte, sind im zweiten Entwurfe 109, in der Schlußredaktion 118 Artikel geworden ${ }^{10}$. Nur mit drei von diesen Artikeln hat sich der Staatenausschuß nicht einverstanden erklärt ${ }^{11}$. Unter dem 21. Februar 1919 legte der Reichsminister des Innern der Nationalversammlung den Entwurf zur Beschlußfassung vor. Soweit Regierung und Staatenausschuß sich nicht geeinigt hatten, wurde der Regierungsvorschlag im Texte, der Vorschlag des Staatenausschusses in Anmerkungen mitgeteilt ${ }^{12}$.

10 Der Entwurf gliedert sich jetzt in acht Abschnitte: 1. Das Reich und seine Gliedstaaten. - 2. Die Grundrechte des deutschen Volkes. - 3. Der Reichstag. - 4. Der Reichspräsident und die Reichsregierung. - 5. Das Finanz- und Handelswesen. 6. Das Verkehrswesen. - 7. Die Rechtspflege. - 8. Schlußbestimmungen. - Die systematische Anordnung ist nicht überall gut. So gehört zum Beispiel der größere Teil der Artikel über die Rechtspflege in die Grundrechte hinein, die Bestimmungen über den Reichsrat würden besser in einem besonderen Abschnitte zusammengefaßt, während sie jetzt mit den Kompetenzbestimmungen in dem Abschnitte „Reich und Gliedstaaten“ untergebracht sind u.f.f.

11 Es handelt sich um Art. 15 (Zusammenschluß der Einzelstaaten), Art. 19 (Stimmenverteilung im Reichsrate), Art. 40 (fremdsprachliche Volksteile des Reichs).

12 Da sich der dem Staatenausschusse und der der Nationalversammlung vorgelegte Entwurf nur in einigen Punkten unterscheiden, so können sie im allgemeinen zusammen besprochen werden. Ist daher im folgenden vom „zweiten“ Entwurf die Rede, so wird darunter, wenn nichts anderes gesagt ist, die Vorlage an die Nationalversammlung mitverstanden. 
II.

Die Aufgabe, die eine Staatsverfassung zu erfüllen hat, besteht in zweierlei. Die Verfassung hat sich erstlich über die Organisation der staatlichen Gewalt, zum mindesten in ihrer obersten Spitze, auszusprechen, d. h. sie hat die Bildung der obersten Staatsorgane, ihre Zuständigkeit und ihre gegenseitigen Beziehungen zu regeln. Sie hat zweitens das Verhältnis zwischen Staat und Untertan, oder, wenn man diesen Ausdruck nicht mehr liebt, zwischen Staat und Staatsgenossen, zum wenigsten in den grundsätzlichen Beziehungen zu bestimmen. Im System der modernen Verfassungsurkunden pflegt diese Zwiefältigkeit der Aufgabe dadurch zum Ausdrucke zu kommen, daß ein „Plan of Government“ und eine „Bill of rights“, d. h. organisatorische Rechtssätze auf der einen, Erklärungen der Bürger- oder Grundrechte auf der anderen Seite nebeneinandergestellt werden. Für eine bundesstaatliche Verfassung ergibt sich eine dritte Aufgabe aus der Notwendigkeit, das Verhältnis zwischen der Zentralgewalt und den Einzelstaaten zu normieren. Dem deutschen Verfassungsgesetzgeber ist die Lösung dieser dritten Aufgabe schwieriger gemacht als anderen, weil die große Ungleichheit der Gliedstaaten an territorialem Umfang, an Bevölkerungszahl, an politischer und wirtschaftlicher Bedeutung die Angelegenheit ungemein verwickelt. Vor allem ist die Tatsache, daß sich bei uns innerhalb eines bundesstaatlichen Rahmens der Großstaat Preußen mit einer Mehrzahl von Mittel- und einer großen Menge von Kleinstaaten zusammenfindet, seit Jahrzehnten die Quelle staatsrechtlicher und politischer Schwierigkeiten gewesen. Die Ereignisse der jüngsten Gegenwart haben die hierin gelegenen Probleme von neuem akut werden lassen. Über die zweckmäßige Regelung des Staatenbestandes innerhalb des Reichs, insbesondere über die Frage, ob die Erhaltung des preußischen Staates mit den Interessen der Reichsgesamtheit verträglich sei, ist erbitterter Streit entstanden.

So groß und weittragend die Bedeutung dieser letzten Angelegenheit für die Zukunft des deutschen Verfassungslebens ist, so soll sie doch, um den Umfang der Darstellung nicht allzusehr anschwellen zu lassen, hier nicht ausführlicher erörtert werden. Dazu bedürfte es einer Abhandlung für sich. Der bisherige Verlauf der Berliner und Weimarer Verhandlungen hat den Kreis der strittigen Fragen auch bereits einigermaßen eingeengt. Bei der Konferenz der Regierungen vom 25. Januar zeigte sich schon am ersten Tage, daß der für den Bestand des preußischen Staates so ungemein bedrohliche $\$ 11$ des Preußschen Entwurfs - wie einer der Delegierten es ausdrückte - eine „Leiche“ geworden war. Der $\$ 11$ gab nämlich der Bevölkerung jedes „Landesteiles“ das Recht, ihre Loslösung aus dem bisherigen 
Staatsverbande, sei es zum Zwecke der Vereinigung mit anderen Staaten, sei es in der Absicht völliger Emanzipation, anzuregen. Über die Anregung sollte eine von der Reichsregierung anzuordnende Volksabstimmung entscheiden. Der neue Entwurf hat dies schonungslos gestrichen. Von der Möglichkeit der „Zerschlagung“ großer Einzelstaaten ist in ihm überhaupt nicht die Rede. Er beschränkt sich darauf, den Gliedstaaten das Recht zu geben, sich zum Zwecke der Bildung größerer leistungsfähiger Staatsgebilde im ganzen oder in Teilen zusammenzuschließen, und stellt hierfür einige „grundsätzliche“ Richtlinien auf, mit denen man sich im Wesentlichen einverstanden erklären kann (Art.15). Kommt die Vereinigung bei den Verhandlungen der Nächstbeteiligten nicht zustande, so darf die „Vermittlung" der Reichsregierung angerufen werden. Allerdings klafft an dieser Stelle noch jetzt zwischen der Auffassung der jetzigen Reichsregierung und der des Staatenausschusses ein tiefer Riß. Die Reichsregierung wünscht, daß wenn die Vermittlung erfolglos bleibt, die Angelegenheit auf Antrag eines der Beteiligten durch verfassungsänderndes Reichsgesetz geregelt werden könne ${ }^{13}$. Diesen Vorschlag des Entwurfs hat der Staatenausschuß nicht angenommen. Die Nationalversammlung wird also zu wählen haben. Allein sie hat für die Lösung der Frage in gewissem Sinne schon ein Präjudiz geschaffen, indem sie in den $\$ 4$ der Notverfassung die ihre Souveränität einschränkende Bestimmung einfügte: „Die künftige Reichsverfassung wird von der Nationalversammlung verabschiedet. Es kann jedoch der Gebietsbestand der Freistaaten nur mit ihrer Zustimmung geändert werden." Damit sind allerdings noch nicht alle Gefahren beschworen. Der Souverän kann seinen Willen ändern. Aber es steht doch zu hoffen, daß die Konstituante den Lockungen eines ungeschichtlichen Radikalismus nicht völlig nachgeben wird. Gewiß ist es ein vernünftiger Gedanke, leistungsunfähige Zwergstaaten zu beseitigen und wirtschaftlich oder politisch unleidlich gewordene Grenzzüge zu verschieben. Aber ein Mißgedanke ist es, ein leistungsfähiges Staatsgebilde, wie Preußen, in fünf oder mehr leistungsunfähige Mittelstaaten zu zerschneiden. Warum will man das alte Unglück unserer Geschichte, die Kleinstaaterei, von neuem heraufbeschwören, warum will man das einzige deutsche Land, das die Nation zu großstaatlichem Empfinden erzogen hat, gewaltsam vernichten, warum will man einen Samen ausstreuen, aus dem mit Naturnotwendigkeit ein öder Kantönligeist emporsprießen muß? Würde man Preußen heute zerstückeln, so würden sich wahrscheinlich morgen die Teilstücke wie-

13 Das ist im Grunde eine ganz überflüssige Bestimmung. Denn schließlich kann in Zukunft durch eine Reichsverfassungsänderung alles beschlossen werden! 
der zu Zweckverbänden zusammenschließen müssen, weil sie die Zerreißung ihres durch gemeinsame Verwaltung und Wirtschaft gegebenen $\mathrm{Zu}$ sammenhangs einfach nicht ertragen könnten. Die Gründe, die man gegen den Fortbestand Preußens bisher allenfalls ins Feld führen konnte, werden mit der Zerstörung der Hauptstützen der preußischen Hegemonie, des Kaisertums und des Bundesrats, und mit dem bevorstehenden Übergange der preußischen Eisenbahnen auf das Reich, aber auch mit der zu erwartenden Einengung der einzelstaatlichen Kompetenzen überhaupt, sehr bald weggefallen sein. Und die kulturelle Hegemonie, die ein großes PreuBen auch unter den veränderten Verhältnissen in Deutschland zu üben vermag, wird der Nation gewiß nicht zum Nachteile, sondern zum Segen gereichen.

Aber, wie gesagt, diese Fragen sollen im folgenden nicht näher erörtert werden. Unsere Besprechung wird sich auf die grundrechtlichen, die organisatorischen und auf die Abschnitte der Verfassungsentwürfe beschränken, die es mit der Verteilung der Kompetenzen zwischen Reich und Einzelstaaten zu tun haben. Die Darstellung kann und will übrigens auch hierin nicht erschöpfend sein. Auf Einzelheiten wird sie nur insoweit eingehen, als es erforderlich ist, um das Urteil über den Grundcharakter der Entwürfe zu begründen. Sie begnügt sich damit, diese nach ihrem wichtigsten Inhalte zu analysieren und kritisch zu würdigen.

Über den $\mathrm{Ma}$ a s a b, an den sich die Kritik zu halten hat, wird man sich ohne Schwierigkeiten verständigen. Es ist selbstverständlich, daß wir heute an den Entwurf einer neuen Reichsverfassung nicht mit denselben Voraussetzungen herantreten können, wie wir es vor einem oder gar vor vier Jahren getan hätten. Damals würden es wohl die meisten von uns für schlechterdings unmöglich erklärt haben, daß uns in naher Zukunft Verfassungsvorschläge nach Art der jetzigen gemacht würden. Nun wäre es gewiß verächtlich, wenn wir festbegründete politische Überzeugungen unter dem Eindrucke der jüngsten Ereignisse wegwerfen wollten wie ein abgetragenes Kleid. Aber wir können doch auch nicht die Augen vor der Tatsache schließen, daß zwischen einst und heute die Revolution des 9. November liegt. Die Versicherung, man wolle sich „auf den Boden der gegebenen Tatsachen stellen", ist bereits so abgegriffen und ist so oft zum Deckmantel der Feigheit und Gedankenlosigkeit benutzt worden, daß man sich scheut, sie nachzusprechen. Indes eine Erklärung ähnlichen Inhalts muß schließlich jeder abgeben, der bei politischer Rede und Gegenrede ernst genommen sein will. Unter den Bedingungen nun, die von der allgemeinen politischen Lage geschaffen worden sind, unterliegt es nicht dem geringsten Zweifel, daß die künftige Verfassung Deutschlands nur auf einer de- 
mokratischen Grundlage ruhen, und daß sie - was nicht dasselbe ist - vorerst keine andere als die republikanische Staatsform schaffen kann. Ebenso unzweifelhaft ist nach den Erfahrungen der jüngsten Monate, daß das Deutsche Reich nach wie vor als Bundesstaat eingerichtet werden muß. Setzt man dies alles als feststehend voraus, so kann die Frage nur lauten: Ist die Verfassung, die man uns jetzt vorschlägt, geeignet, einem großen, gebildeten, arbeitsfrohen Volke Bürgschaften für seine Selbstbehauptung neben anderen Völkern und für die Stetigkeit seiner inneren Entwicklung zu geben? Schafft sie den rechten Ausgleich für die vielen gegensätzlichen Kräfte, die landsmannschaftlich und politisch, sozial und wirtschaftlich unser nationales Leben durchziehen? Gibt sie Gewähr für äußere und innere Sicherheit, für Ordnung und Stetigkeit, für eine starke Regierung, für eine dem Stande unserer Kultur entsprechende Rechtsbildung? Und ist sie in der Lage, die Freiheit des Bürgers gegenüber der Obrigkeit - auch im demokratischen Staate gibt es eine Obrigkeit! - genügend zu wahren?

Die letzte dieser Fragen wird heute von vielen für müßig erklärt. Man meint, daß mit dem demokratischen Staate die bürgerliche Freiheit von selbst gegeben sei. Allein das ist ein gefährlicher Irrglaube. Demokratie bedeutet an sich nichts anderes als umfassende Beteiligung des Volks an der staatlichen Herrschaft. Sie gewährt die Freiheit zur Mitbestimmung im Staate, aber sie sichert nicht die Freiheit des Einzelnen gegenüber dem Staate. Das demokratische Naturrecht, in der schärfsten Zuspitzung Rousseaus Contrat social, hat die Lehre gepredigt, in der Demokratie gehorche jeder sich selbst, sei also frei, weil in dem von allen gebildeten Gemeinwillen der Wille des Einzelnen enthalten sei. Indes das ist nur zur Hälfte wahr. Denn niemals kann der Gemeinwille des demokratischen Staates anders als durch Mehrheitsbeschlüsse zustande kommen. So ist in jedem Falle die Minderheit an einen Willen gebunden, der nicht ihr eigener Wille ist. Je folgerichtiger also der Staat das demokratische Prinzip durchführt, um so näher liegt die Möglichkeit, daß die Minderheit durch die ihre Macht rücksichtslos ausübende Mehrheit vergewaltigt wird. Die konstitutionelle Monarchie mit ihrer gesunden Mischung monarchischer und demokratischer Elemente, mit der Teilung der Gewalten und dem verfassungsmäßigen Gleichgewicht zwischen Legislative und Exekutive, bietet der Freiheit einen Schutz, wie ihn die reine Demokratie niemals gewähren kann. Wie die Geschichte lehrt, vermag demokratischer Absolutismus entsetzlicher zu sein als monarchischer Despotismus. Nachdem nun die Revolution die konstitutionelle Monarchie zerschlagen und dadurch wertvolle Schutzmittel für die Freiheit vernichtet hat, ist es eine besondere Aufgabe, 
in der künftigen Verfassung Gegengewichte gegen den drohenden demokratischen Absolutismus anzubringen. Das wird um so notwendiger sein, als die sozialistische Gedankenwelt, die im künftigen Staate in großem Umfange zur Verwirklichung kommen wird, einer starken Ausdehnung der staatlichen Gewalt geneigt ist. Mehr als früher wird deshalb das Bedürfnis bestehen, die Freiheit des Bürgers vom Staate zu betonen.

Von diesem Standpunkte aus betrachtet, gewinnen manche Dinge, auf die wir im bisherigen Staate weniger zu achten pflegten, ein ganz neues Gesicht.

Das gilt in besonderer Weise für die Frage, ob und in welchem Umfange die Rechtsverfassung Grundrechte des deutschen Volkes aufzustellen habe. Unser bisheriges Reichsgrundgesetz hat das bekanntlich unterlassen. Und obwohl seine Urheber darob von inländischen wie von ausländischen Beurteilern häufig hart getadelt worden sind, so waren sie doch nicht im Unrechte. Denn als die Reichsverfassung entstand, befanden sich die Einzelstaaten fast ausnahmslos im Besitze von Verfassungsurkunden, die über die Grund- und Freiheitsrechte der Bürger umfängliche Bestimmungen enthielten. Die Verfassung des Reiches änderte nichts an ihnen; sie hätte dazu auch keine Veranlassung gehabt, da sich viele der Grundrechte auf Sachgebiete bezogen, die nach dem Willen der Reichsverfassung außerhalb der Zuständigkeit des Reiches bleiben sollten. Zudem hatte die Erfahrung gezeigt, daß sich die Kataloge der Grundrechte in den modernen Verfassungsurkunden vielfach in nichtssagenden Deklamationen ergingen, daß sie sich auf Verheißungen beschränkten, die erst durch Sondergesetze ihre Erfüllung und ihre notwendige Umgrenzung erhalten konnten. Bis zu gewissem Grade ist ja ein solches Bedenken auch heute nicht von der Hand zu weisen. Und doch liegt es jetzt anders als 1867 und 1870. Die Zuständigkeit des Reichs wird ohne jeden Zweifel auf viele Gebiete ausgedehnt werden, die ihr bisher entzogen waren. Die alten Landesverfassungen sind zerbrochen. Nach welchen Grundsätzen die neuen gestaltet werden, ist nicht mit Bestimmtheit vorauszusehen. Aber mit einer an Gewißheit grenzenden Wahrscheinlichkeit ist schon heute vorauszusehen, daß das Reich wie die Gliedstaaten rein demokratische Gemeinwesen sein werden. Ihre gesetzgebenden Körperschaften werden nach dem Einkammersystem eingerichtet sein, sie werden auf einem radikalen Wahlrechte ruhen, von den Stimmungen der Massen abhängen. Wenn, wie zu erwarten steht, in Reich und Einzelstaaten die sogenannte parlamentarische Regierungsweise rechtens wird, so ist die Trennung der Gewalten im wesentlichen beseitigt, die Exekutive von der Legislativen aufgesogen, eine wirkliche Ministerverantwortlichkeit illusorisch gemacht. Trifft dies aber 
$\mathrm{zu}$, so ist es dringend geboten, daß die Freiheitsrechte der Bürger in der Reichsverfassung genau und umfassend festgestellt werden und hierdurch einen Schutz nicht nur gegenüber der Exekutive, sondern vor allem gegenüber der Ge se t z g e b u n g des Reichs und der Einzelstaaten empfangen. Seine Ergänzung muß dies dann dadurch erhalten, daß den Ge rich ten ein freies Prüfungsrecht hinsichtlich der Verfassungsmäßigkeit der Gesetze eingeräumt wird.

In der Reihe der von den Entwürfen aufgezählten Grundrechte finden sich manche alte Bekannte, die selbstverständlich nicht fehlen durften: Freiheit der Wissenschaft und ihrer Lehre, Freiheit der Presse, Petitionsund Beschwerderecht, Unverletzlichkeit des Postgeheimnisses und anderes. Aber allerlei ist doch neu, und unter dem Neuen findet sich manches, was um seiner weitgreifenden Fassung willen Bedenken erregt. Wenn zum Beispiel der $\$ 22$ (Art. 33) allen Deutschen das unbeschränkte Recht verleiht, sich ohne besondere Erlaubnis friedlich und ohne Waffen zu versammeln und Vereine zu bilden, so geht das beträchtlich über das geltende Recht hinaus. Das Vereinsgesetz gibt bekanntlich Vereins- und Versammlungsfreiheit nur zu Zwecken, die den Strafgesetzen nicht zuwiderlaufen, und es macht öffentliche Versammlungen unter freiem Himmel von polizeilicher Genehmigung abhängig. In einer Zeit, in der die Politik zu großem Teile auf der Straße gemacht wird, glaubt man offenbar von solcher Beschränkung absehen zu müssen! Wenn nach $\$ 24$ und $\$ 25$ des ersten Entwurfs das Eindringen in die Wohnung und Haussuchungen nur nach Maßgabe eines Reichsgesetzes gestattet waren, und eine Verhaftung nur auf Grund eines richterlichen Haftbefehls für zulässig erklärt wurde, so waren dadurch zahlreiche, ganz unentbehrliche Bestimmungen des Landespolizeirechts, zum Beispiel des preußischen Gesetzes zum Schutze der persönlichen Freiheit vom 12. Februar 1850, ohne weiteres außer Kraft gesetzt. Der Entwurf letzter Fassung hat das eingesehen; nach ihm können behördliche Eingriffe in Freiheit und Hausfrieden durch "Gesetz“, also auch durch Landesgesetz erlaubt werden. Besonders unglücklich war im Preußschen Entwurfe die von der Gleichberechtigung der Deutschen handelnde Vorschrift gefaßt $(\mathbb{1 8})$. Sie wollte nicht nur die Vorrechte des "Standes" in dem bisher gebräuchlichen Sinne des Wortes, sondern auch alle „Vorrechte und rechtlichen Nachteile der Geburt, des Berufs oder Glaubens" abschaffen. Damit würde zum Beispiel nicht nur das Kommunalsteuerprivileg der Beamten und das Militärdienstprivileg der katholischen Studierenden der Theologie, sondern auch jede Abweichung in der Rechtsstellung der unehelichen Kinder gegenüber der der ehelichen mit einem Schlage beseitigt gewesen sein. So berechtigt die Bestrebungen sind, 
die Stellung der unehelichen Kinder zu verbessern, so würde doch eine derartige Aufhebung jedes Unterschieds zwischen ehelich und unehelich Geborenen eine schwere Gefahr für die Sittlichkeit bedeutet haben. Ja, die Bestimmung hätte sogar jeden rechtlichen Unterschied zwischen Mann und Frau aus der Welt geschafft, eine Folge, deren sich die Verfasser schwerlich bewußt gewesen sind. Der zweite Entwurf hat hier eine wesentliche Verbesserung gebracht. Er verwirft nur die Vorrechte und Nachteile der Geburt und des Standes, und auch nur solche von öffentlich-rechtlichem Charakter. Auch beseitigt er sie nicht, wie der Entwurf Preuß, mit einem Schlage, sondern verlangt nur, daß sie aufgehoben werden (Art. 28). Wäre es bei der ersten Fassung geblieben, so würde namentlich in den Rechtsverhältnissen des Hochadels eine heillose Verwirrung eingetreten sein. Weniger glücklich formuliert ist eine Vorschrift, die der zweite Entwurf in die Grundrechte eingefügt hat: „Die Arbeitskraft als höchstes nationales Gut steht unter dem besonderen Schutze des Reichs" (Art. 34). Das klingt sehr schön; aber man kann sich schlechterdings nichts Bestimmtes, jedenfalls nichts von rechtlicher Bedeutung dabei denken. Auch die Anordnungen über die Rechte der fremdsprachlichen Volksteile des Reichs geben zu starken Bedenken Anlaß. Wir wollen indes diese besondere Frage, die einer sehr ausführlichen Behandlung bedürftig ist, im Augenblicke nicht weiter verfolgen.

Wenn die Entwürfe die Sphäre der individuellen Freiheit auf der einen Seite weiter abstecken, als erforderlich und gut ist, so haben sie dafür an anderer Stelle entschieden zu wenig getan. Daß die Freizügigkeit, die Gewerbefreiheit, das Verbot einer Strafverhängung ohne vorhergehende Strafandrohung und einer Strafandrohung ohne gesetzliche Grundlage nicht verfassungsmäßig gesichert werden, mag allenfalls angehen. Man wird geglaubt haben, daß das geltende Recht hierin überall ausreichenden Schutz gewähre, und daß kein Gesetzgeber der Zukunft auf den Gedanken kommen werde, Verschlechterungen einzuführen, - eine Erwägung, die freilich in bezug auf die Preßfreiheit und anderes ebenfalls hätte angestellt werden können. Eine andere Unterlassungssünde des Preußschen Entwurfs ist inzwischen gut gemacht worden. Dieser erklärte zwar das Eigentum für unverletzlich und verlangte für Enteignungen eine gesetzliche Grundlage ( $(26)$. Aber er erwähnte bezeichnenderweise nichts von einer Entschädigung! Der zweite Entwurf hat das zum Glücke eingefügt (Art. 37). Völlig ungenügend ist aber die Art, in der beide Entwürfe die religiösen Grundrechte geregelt haben. Sie legen den Nachdruck auf die individuelle Gewissens- und Bekenntnisfreiheit, also auf die Freiheit, die der Einzelne in religiöser Beziehung gegenüber staatlichen oder 
kirchlichen Gewalten genießen soll. Aber sie unterlassen es, die Rechte der Religionsgesellschaften, insbesondere die der historischen Kirchen, dem Staate gegenüber sicherzustellen und dem religiösen Leben als solchem den Schutz zu verheißen, auf den es Anspruch erheben darf. Im Gegenteil, der Preußsche Entwurf versuchte es, für die Lösung des Problems: Trennung von Staat und Kirche, ein der Sache und der Form nach höchst bedenkliches Präjudiz zu schaffen. Keine Religionsgesellschaft, so bestimmte er, solle vor anderen Vorrechte durch den Staat genießen, und über die „Auseinandersetzung“ zwischen Staat und Kirche solle ein Reichsgesetz Grundsätze aufstellen, deren Durchführung Sache der deutschen Freistaaten sei $(\Omega 19)$. Damit wäre mit einem Federzuge die Stellung der Kirchen als öffentlich-rechtlicher Korporationen beseitigt, ihre finanzielle Dotierung durch den Staat unmöglich gemacht, jede staatliche Unterstützung bei der Einziehung kirchlicher Umlagen verboten worden. Und die „Auseinandersetzung“, d. h. also doch wohl die Trennung von Staat und Kirche, wäre reichsverfassungsmäßig zum Programm erhoben gewesen, ohne daß die Verfassung dem Reichsgesetzgeber, dem sie die Aufstellung der „Grundsätze“ zuschob, in irgendeiner Form eine Schranke gezogen hätte. Hier hat nun freilich der zweite Entwurf eine andere Haltung eingenommen. Er geht davon aus, daß die Regelung des Verhältnisses von Staat und Kirche in der Hauptsache Landessache bleiben müsse. Er beschränkt sich deshalb darauf, die freie Ausübung gottesdienstlicher Handlungen und die Freiheit der Vereinigung zu Religionsgesellschafen zu gewährleisten (Art. 30). Aber sagte der Preußsche Entwurf zu viel, so sagt der zweite Entwurf zu wenig. Denn indem er in der Frage des Verhältnisses der bestehenden Kirchen zum Staate die Souveränität der Einzelstaaten völlig unangetastet läßt, liefert er Kirche und religiöses Leben vollkommen der Willkür der Landesparlamente aus. Man braucht nicht erst auseinanderzusetzen, welche Gefahr darin für die Kirche gelegen ist.

Auch in bezug auf das Unterrichtswesen lassen die Grundrechte der beiden Entwürfe zu wünschen übrig. Der Preußsche Entwurf beschränkte sich auf eine kurze, dafür vieldeutige Bestimmung: „Der Unterricht soll allen Deutschen gleichmäßig nach Maßgabe der Befähigung zugänglich sein“ (\$20). Der zweite Entwurf ist weniger wortkarg. Er legt jedoch das ganze Gewicht auf gewisse Forderungen, die hinsichtlich der Einrichtung des öffentlichen Unterrichts an die Einzelstaaten zu stellen sind: vor allem Unentgeltlichkeit des Volksschulunterrichts, Aufbau des Unterrichts in mittleren und höheren Bildungsanstalten auf die Volksschulbildung, staatliche Aufsicht über das öffentliche Unterrichtswesen (Art.31). Aber in einer Verfassung, die dem deutschen Volke seine Grundrechte schaffen 
will, sollte doch auch ein Wort über die Unterrichtsfreiheit zu finden sein. Dafür liegt unter den jetzigen politischen Verhältnissen ein dringendes Bedürfnis vor. Es ist bezeichnend, daß eine kürzlich erlassene sächsische Verordnung bereits verfügt hat, die Genehmigung der Errichtung von Privatschulen solle in Zukunft nur noch ausnahmsweise erteilt werden ${ }^{14}$. In einem parlamentarisch, d. h. nach Parteirücksichten regierten Staate muß aber den Eltern die Möglichkeit gegeben sein, ihre Kinder in Schulen unterrichten zu lassen, deren Erziehungsgrundsätze in nationaler und religiöser Hinsicht sich mit ihren, der Eltern, Anschauungen decken, auch wenn sich diese von den Anschauungen der jeweilig regierenden Parteigruppen entfernen. Der Staat hat kein Recht, dies unmöglich zu machen. Es genügt, wenn er die Befugnis, Erziehungs- und Unterrichtsanstalten zu gründen und zu leiten, von der Erfüllung gesetzlicher Anforderungen in sittlicher Hinsicht abhängig macht und solche Anstalten in bezug auf die wissenschaftliche Eignung, das Gehalt und die Disziplin der Lehrer sowie in bezug auf die Gesundheitspflege seiner Gesetzgebung und Aufsicht unterwirft ${ }^{15}$.

Nach alledem wird die Nationalversammlung allen Anlaß haben, den Abschnitt über die Grundrechte recht sorgsam zu prüfen. Sie möge aber auch darauf bestehen, daß die Grundrechte die durchaus erforderliche Sicherung erhalten, indem den Gerichten ausdrücklich das Recht zugestanden wird, die Verfassungsmäßigkeit der Gesetze zu pr üfen. Der Preußsche Entwurf sprach hiervon mit keiner Silbe. Der zweite Entwurf bestimmt: „Streitigkeiten darüber, ob eine landesrechtliche Vorschrift mit dem Reichsrechte vereinbar ist, entscheidet auf Grund eines Reichsgesetzes ein oberster Gerichtshof des Reiches" (Art. 11). Dadurch wird allerdings die Möglichkeit geschaffen, daß Landesgesetze, die sich mit den grundrechtlichen Vorschriften der Reichsverfassung in Widerspruch befinden, durch eine reichsrichterliche Entscheidung außer Geltung gesetzt werden. Aber da die Regelung des hierbei zu beobachtenden Verfahrens in vollem Umfange einem künftigen Reichsgesetze überlassen wird, so ist noch ganz ungewiß, ob dieses Reichsgesetz dem Bürger selbst oder etwa nur der Reichsgewalt das Recht geben wird, die Verfassungswidrigkeit eines Landesgesetze zur gerichtlichen Feststellung zu bringen. Vor allem aber zeigt der Entwurf keinen Weg, auf dem die deutsche Freiheit vor verfassungswidrigen Attentaten des Reichsgesetzge bers geschützt werden kann. Wir müssen darauf dringen, um der Freiheit willen darauf

14 Verordnung v. 12. Dez. 1918 (Gesetz- und Verordnungsblatt S. 392), $\ 2$ Abs. 4.

15 Vgl. die Vorschläge im Entwurfe des Vereins Recht und Wirtschaft, Art. 69 ff. 
dringen, daß die Verfassung die Gerichte schlechthin berechtigt und verpflichtet, zu prüfen, ob sich die von ihnen anzuwendenden Reichs- und Landesgesetze inhaltlich mit der Reichsverfassung im Einklage befinden ${ }^{16}$. Die Bürger der Vereinigten Staaten betrachten das richterliche Prüfungsrecht als ein Palladium ihrer Freiheit. Die Deutschen werden gut daran tun, nach einem gleichen Schutzmittel zu rufen.

\section{III.}

Das Verhältnis zwischen Re i ch und Einzels ta a te n zu regeln, bietet dem Verfassungsgesetzgeber der Gegenwart Schwierigkeiten, die größer sind als die, mit denen die Schöpfer der bisher geltenden Verfassung zu kämpfen hatten. Als Bismarck bei der Gründung des Norddeutschen Bundes die „deutsche Frage“ in der von ihm für richtig erachteten Form zu lösen unternahm, konnte er sich den Regierungen gegenüber auf die Kräfte des siegreichen preußischen Staates stützen; im verfassungvereinbarenden Reichstage stand ihm eine mittelparteiliche Mehrheit zu Diensten, die zwar in bezug auf die konstitutionelle Frage Schwierigkeiten machte, die ihm aber in bezug auf das bundesstaatliche Problem unbedingte Gefolgschaft leistete. Im Jahre 1870 mußte freilich der Eintritt der süddeutschen Staaten mit föderalistischen Konzessionen erkauft werden. Allein sie waren doch keineswegs bedeutend genug, um an den bereits feststehenden Grundlagen der deutschen bundesstaatlichen Verfassung etwas Wesentliches zu ändern. Auf welche Schultern sollen sich nun aber heute die Staatsmänner stützen, die genötigt sind, die Verteilung der staatlichen Kräfte zwischen dem Gesamtstaate und seinen Gliedern von neuem vorzunehmen? Die Revolution hat den preußischen Staat seiner führenden Stellung beraubt. Überall im Reiche kämpfen unfertige, unter sich uneinige Regierungen um ihr Dasein. Und im Parlamente gibt es keine Partei, auf die in der Grundfrage unbedingt gerechnet werden könnte. Denn der Gegensatz zwischen Unitarismus und Föderalismus hat sich weder in der bisherigen Entwicklung der deutschen Parteien, noch bei ihrer Umwandlung aus Anlaß der Revolution als ein selbständiges parteienbildendes, richtiger parteienscheidendes Prinzip erwiesen. In der bundesstaatlichen Frage geht der Riß mitten durch die Parteien hindurch.

Dabei sind die Gegensätze, die miteinander kämpfen, stärker als je zuvor. Noch in den ersten Jahren des Kriegs konnte man erwarten, daß das

16 Vgl. Art. 147 des Entwurfs des Vereins Recht und Wirtschaft. 
Bewußtsein der Reichseinheit nach beendigtem Kampfe so tief wie nie vordem empfunden, der Reichsgedanke so stark wie nie zuvor gedacht werden würde. Zum ersten Male seit Jahrhunderten hatte wieder ein deutscher Kaiser ein deutsches Heer ins Feld gerufen; das Reich führte den Krieg, und Deutschland kämpfte für sein Reich und für seine Einheit. Es schien den meisten von uns selbstverständlich zu sein, daß das verfassungsrechtliche Ergebnis des Kriegs in einer bedeutenden Erweiterung der unitarischen Elemente bestehen werde. Aber die Hoffnung, daß sich diese Entwicklung kampflos vollziehen werde, hat uns getrogen. Eine unglaublich ungeschickte Politik hat während der zweiten Hälfte des Kriegs eine starke Reichsverdrossenheit entstehen lassen. Zahllose Mißgriffe in der Verwaltung, namentlich in Ernährungsangelegenheiten, haben eine üble Verstimmung zwischen Ost und West, vor allem zwischen Nord und Süd hervorgerufen. Das hätte sich vermutlich ausgleichen lassen, wenn der Krieg mit einem Siege geendet hätte. Nun ist leider Gottes das Gegenteil eingetreten, und die Revolution mit ihren bekannten Folgeerscheinungen hat das Ihrige dazu getan, um die schon klaffenden Risse zu erweitern. So erleben wir jetzt ein unheimliches Erstarken nicht nur des Föderalismus, sondern eines ganz rohen Partikularismus, der da und dort sogar zu bedrohlichen separatistischen Neigungen geführt hat. Es gibt süddeutsche Politiker, die geradezu auf dem Standpunkte stehen, das Reich sei durch die Revolution schlechthin aufgelöst worden; eine vollkommene Neugründung sei erforderlich, wenn es wieder zusammengefügt werden solle. Ob sich wohl diese Leute überlegt haben, was ihre Behauptung, falls sie wahr wäre, für den finanziellen Kredit, für die internationale Verhandlungsfähigkeit des Reichs, für die Liquidierung des Kriegs und für den Gang der Verwaltung in Reich und Einzelstaaten bedeuten würde? Und ob sie sich eine Vorstellung darüber gemacht haben, in welcher Weise unter den heutigen Umständen fünfundzwanzig wieder vollkommen souverän gewordene deutsche Staaten die „Neugründung“ eines Reichs bewerkstelligen sollen?

Die Verfassungsentwürfe stellen sich verständigerweise nicht auf diesen Boden. Für sie handelt es sich nicht um die Herstellung eines neuen, sondern um die Fortsetzung des bestehenden Reichs. Daher keine Präambel in der Form, wie sie die bisherige Verfassung besaß, kein Abschluß eines „ewigen Bundes“ zwischen den Staaten. Vielmehr sagt der Eingang des zweiten Entwurfs - der Preußsche hatte überhaupt keine Einleitung vorgesehen -, das deutsche V o 1 k wolle „sein Reich" auf der Grundlage der Freiheit und Gerechtigkeit „erneuern und festigen“. Aber freilich, nicht die Organe, die von der bisher geltenden Verfassung dazu bestimmt gewe- 
sen wären, sondern das durch die Revolution zur Souveränität gelangte deutsche Volk selber ist es, das die neue Verfassung ausrichtet.

Bei diesem Volke liegt die gesamte Staatsgewalt. Und zwar beim d e u t $\mathrm{schen} \mathrm{Volke} \mathrm{in} \mathrm{seiner} \mathrm{ungeschiedenen} \mathrm{Einheit.} \mathrm{Nur} \mathrm{daß} \mathrm{dieses} \mathrm{Volk}$ zur Ausübung seiner Gewalt eine zweifache Organisation herstellt, getrennt nach Reichs- und Landesangelege nheiten. In den ersteren wird die Staatsgewalt von den auf Grund der Reichsverfassung bestehenden Organen ausgeübt, in den letzteren durch die Organe der deutschen Gliedstaaten (Art.2). Allerdings handeln die Organe der Einzelstaaten „nach Maßgabe der Landesverfassungen“. Aber da die Quelle aller Staatsgewalt beim deutschen Volke ruht, so ist es im letzten Grunde eben doch dieses, von dem die einzelstaatlichen Organe ihre Gewalt ableiten ${ }^{17}$. So erscheinen auch die Gliedstaaten als Delegatare der gemeindeutschen Nationalsouveränität. Es ist eine eigene Bundesstaatstheorie, die im Artikel 2 ausgesprochen wird, und auf sie läßt sich wohl in erster Linie die Einseitigkeit und Schroffheit zurückführen, mit der der Preußsche Entwurf das föderative Problem behandelte.

Denn dieser Entwurf trug den partikularistischen Strömungen, die sich seit der Revolution so kräftig bemerkbar gemacht hatten, ebensowenig Rechnung wie der Tatsache, daß der Eintritt Deutsch-Österreichs in den Reichsverband ohne föderalistische Konzessionen kaum möglich sein wird. Der Entwurf war unitarisch angelegt bis ins Extrem. Er führte zwar der Form nach noch nicht bis zum Einheitsstaate. Aber in der Sache ließ er von der Staatlichkeit der deutschen Territorien nur geringe Reste übrig.

Das zeigte sich zunächst in der Art, in der die Kompetenze n zwischen Reich und Gliedstaaten verteilt wurden.

Im Vergleich mit dem bisher geltenden Rechte war die a usschli e ß li che Zuständigkeit des Reichs in Gesetzgebung und Verwaltung gewaltig erweitert. Sie umfaßte die Beziehungen zum Auslande ohne jede Ausnahme; den Einzelstaaten sollte also nicht nur jedes aktive und passive Gesandtschafts- und Konsularrecht, sondern auch jede Möglichkeit zum Abschlusse selbst unbedeutender Verträge mit fremden Staaten genommen werden. Nicht nur Zollwesen, Post und Telegraphie, sondern auch das Eisenbahnwesen, soweit es sich um Staatsbahnen handelt, die Binnenschifffahrt auf den mehreren deutschen Staaten gemeinsamen Was-

17 Der zweite Entwurf hat den Satz: „Alle Staatsgewalt liegt beim deutschen Volke“ abgekürzt. Es sagt: „Die Staatsgewalt liegt beim Volke.“ Eine Änderung der Auffassung liegt dem wohl nicht zugrunde. Denn kurz vorher wird vom „deutschen Volke" gesprochen. 
serstraßen und das ganze Militärwesen wurde ausschließlich zur Reichssache erklärt. Sogar der „Handel“, einschließlich des Bank- und Börsenwesens, das Münz-, Maß- und Gewichtswesen, der gesamte Verkehr mit Kraftfahrzeugen zu Lande und in der Luft wurde nicht allein der Gesetzgebung, sondern der eigenen und unmittelbaren Verwaltung des Reichs unterstellt ( 3 3). Danach würde zum Beispiel die Aufsicht über die Börsen nicht mehr von Landesbehörden, sondern allein von Reichsbehörden zu führen gewesen sein. Ja, der Marktverkehr und der Verkehr mit Automobildroschken hätte fortan durch Reichspolizeiorgane geregelt und überwacht werden müssen! Man darf vermuten, daß sich der Verfasser des Entwurfs kaum darüber klar geworden ist, welche Aufgaben er hiermit dem Reiche nicht geschenkt, sondern aufgeladen hätte. Dagegen war es wohl nicht bloß auf ein Versehen zurückzuführen, daß das Kolonialwesen in diesem Entwurfe mit keiner Silbe erwähnt worden war.

Auch soweit der Preußsche Entwurf dem Reiche eine sogenannte fakultative, richtiger: eine mit der entsprechenden Landeskompetenz k o nk u r ri e r e n d e Zuständigkeit zur Gesetzgebung verlieh ( $\$ 4)$, gaben seine Bestimmungen zu manchen Bedenken Anlaß. Auf der einen Seite zeigte der Entwurf seltsame Lücken. Zum Beispiel war vom Wohnwesen nicht die Rede. Das Privateisenbahnwesen war nicht erwähnt. Nur die für das Reich zu erhebenden Steuern und Abgaben sollten der Gesetzgebung des Reichs unterliegen, während doch niemand im Zweifel sein kann, daß das Reich in Zukunft um der Planmäßigkeit und Einheitlichkeit des deutschen Finanzsystems willen die Möglichkeit erhalten muß, auch für das Landessteuerwesen mindestens Normativbestimmungen aufzustellen. Auf der anderen Seite zog der Entwurf die Grenzen der Reichskompetenz außerordentlich weit. Außer den Gegenständen, die bereits nach Art. 4 der bis jetzt geltenden Verfassung der Reichsgesetzgebung unterliegen, wollte er ihr auch das gesamte Armenwesen und in großem Maßstabe die Bodengesetzgebung zuweisen. Vor allem - Kirche und Schule. Freilich „im Rahmen der $\$ \mathbb{S} 19$ und 20“, d. h. im Rahmen der für Kirche und Schule erlassenen Bestimmungen der Grundrechte. Aber damit war doch im Grunde die ganze Materie dem Zugriffe der Reichsgesetzgebung ausgeliefert; denn die in Bezug genommenen grundrechtlichen Klauseln waren so weich und dehnbar, daß sich mit ihnen alles hätte anfangen lassen. Die Methode, die der Entwurf an dieser Stelle verfolgte, zeugte von einer völligen Verkennung der Aufgaben, die eine bundesstaatliche Verfassung in Ansehung der Grundrechte zu erfüllen hat. Denn soweit die Grundrechte das Verhältnis der Bürger zur Einzelstaatsgewalt betreffen, sollen sie nichts anderes sein als Richtschnur und Schranke für die Betätigung der Staatsgewalt der Ein- 
zelstaaten selber. Wenn der Gesamtstaat in den Sätzen über die Grundrechte Direktiven für die Gesetzgebung der Einzelstaaten gibt, nimmt er nicht für sich selbst das Recht in Anspruch, auf den fraglichen Gebieten Gesetze zu erteilen, sondern er wahrt sich nur die Befugnis, seine Beaufsichtigung darauf zu richten, daß die Einzelstaaten in Gemäßheit jener Direktiven verfahren. So ist die Sache von den Verfassungen der Vereinigten Staaten und der Schweizer Eidgenossenschaft, aber auch von der deutschen Reichsverfassung von 1849 aufgefaßt worden. Es war ein Mißgriff, daß man sich jetzt der Grundrechte als Sprungbrett bedienen wollte, um eine starke Ausdehnung der Reichskompetenz in das Vorbehaltsgebiet der Einzelstaaten hinein zu ermöglichen.

Dieses Vorbehalts gebiet der Gliedstaaten war ohnehin nach der Tendenz des Preußschen Entwurfs in ganz enge Grenzen gebannt. Außer dem Landessteuerwesen verblieb der ausschließlichen Gesetzgebung und Verwaltung der Einzelstaaten im Grunde nur einiges aus dem Bereiche der Sicherheitspolizei, die Bau- und Sittenpolizei, das Wasserrecht, das Wegewesen, die Urproduktionen, auch das alles mit Abzügen. Gerade das aber, was die Gliedstaaten bisher am ängstlichen gehütet hatten, die Selbständigkeit in der Regelung ihrer Verfassungsverhältnisse und ihres Kommunalwesens, sollte ihnen genommen werden. Wiederum waren es die Grundrechte, die zu diesem Einbruch in die Landeskompetenz benutzt wurden $(\$ 12)$. Hier wurden nämlich den Einzelstaaten über den Inhalt ihrer Verfassungen so genaue Vorschriften gegeben, daß ihnen für eine eigene Regelung in den wichtigsten Dingen kaum noch ein Spielraum übrig blieb: Einkammersystem, allgemeines, gleiches, direktes, geheimes Wahlrecht, Frauenstimmrecht, Verhältniswahl, parlamentarisches Regierungssystem wurden ihnen vorgeschrieben; sogar das Enqueterecht der Parlamente war nicht vergessen worden. Dazu traten dann genaue Anordnungen über die Gemeindeverfassung, insbesondere über das kommunale Wahlrecht und die Bestellung der Gemeindevorstände, über die - natürlich eng begrenzte - Staatsaufsicht, über die Beseitigung der Gutsbezirke; es wurde verlangt, daß die Ortspolizei in den Händen der Gemeinden oder der Gemeindeverbände liegen müsse. Auch die Bestimmung, daß die Angehörigen jedes deutschen Staats in dem anderen deutschen Staate die gleichen Rechte und Pflichten wie die eigenen Staatsangehörigen haben sollten, gehört in diesen Zusammenhang $(\mathbb{1 7})$. Denn sie würde die Einzelstaaten genötigt haben, das Wahlrecht und die Wählbarkeit zu Landes- und Gemeindevertretungen allen landesfremden Deutschen, die in ihrem Gebiete wohnen, zuteil werden zu lassen. 
Die ohnehin sehr stark unitarisierenden Vorschriften über die Reichsgesetzgebung wurden nun noch ergänzt und verschärft durch weittragende Sätze über die Reichsaufsicht. Schon früher hatte sich Preuß des öfteren darüber beschwert, daß nach dem geltenden Rechte die Reichsaufsicht gegenüber der Landesverwaltung auch innerhalb der Reichskompetenz fast ohnmächtig sei ${ }^{18}$. In der Denkschrift wiederholte er dieses harte Urteil. Er glaubte die Zeit gekommen für eine „klare und schärfere Gestaltung" des Aufsichtsrechts der Reichszentralbehörden über die einzelstaatlichen Verwaltungsämter. Zu diesem Zwecke wollte er der Reichsregierung das Recht geben, die Überwachung der Ausführung von Reichsgesetzen durch Beauftragte vornehmen zu lassen, die „in die deutschen Freistaaten“ entsendet und denen jede gewünschte Auskunft erteilt und die Akteneinsicht verstattet werden sollten. Dadurch wurden also die sämtlichen Landesbehörden, bis in die untersten Stellen hinein, der unmittelbaren Kontrolle der Reichszentrale unterstellt. Und nicht genug damit, es wurde der Reichsregierung die Befugnis eingeräumt, zur Berichtigung einzelstaatlicher Verwaltungsakte alle mit der Ausführung von Reichsgesetzen betrauten Landesbehörden über den Kopf der Landesregierungen hinweg mit „Anweisungen“ zu versehen. Ja, es wurde den „schuldigen Landesbeamten“ ein Vorgehen „auf Grund der für die Reichsbeamten geltenden Disziplinarvorschriften“, also eine Disziplinierung durch die Reichsbehörden selbst, in Aussicht gestellt $(\mathbb{8} 8$ ). Mit alledem war das für das Verhältnis zwischen Zentral- und Landesgewalt kritische Problem des Bundesstaatsrechts im Sinne einer vollkommenen Unitarisierung gelöst worden. Denn überall, wo die Aufsicht des Gesamtstaats über den Einzelstaat die Linie der „Oberaufsicht“ überschreitet, d. h. wo sie nicht nur die Regierung, sondern auch die Mittel- und Unterorgane des Gliedstaats unmittelbar der Einwirkung des Kontrollierenden unterwirft, wird die Grenze zwischen Aufsicht und Eigenverwaltung verwischt. Jede „unmittelbare“ Aufsicht wird, praktisch gesehen, zur eigenen und unmittelbaren Verwaltung. Nun war ja schon dem bisherigen Reichsrechte solche unmittelbare Reichsaufsicht keineswegs fremd. Sie war im Militärwesen, im Eisenbahnwesen, zum Teil im Zollwesen von der Verfassung anerkannt; viele Einzelgesetze hatten sie auch auf anderen Gebieten eingeführt. Aber doch immer nur für besondere Fälle, niemals generell. Der Preußsche Entwurf wollte zur Regel machen, was bis jetzt die Ausnahme gewesen war. Die „Selbstverwaltung“,

18 Wieweit die Klage berechtigt war, wieweit nicht, habe ich in meinem Buche über die Reichsaufsicht[. Studien zum Staatsrecht des Deutschen Reiches, Berlin] (1917), S. 685 ff. geprüft. 
die er den Einzelstaaten auf den reichsgesetzlich geregelten Gebieten beließ, war eitel Schein. Die Gliedstaaten behielten hier in Wahrheit überhaupt keine Verwaltung mehr, das Reich nahm sie in eigene Hand.

Die Haltung, die der Entwurf dem Problem der Reichsaufsicht gegenüber einnahm, stand in augenfälligem Widerspruche zu den Grundsätzen, zu denen sich Preuß in seinen bekannten kommunalpolitischen Schriften immer bekannt hatte. Auch mit den organisatorischen Grundgedanken, nach denen er nach Angabe der Denkschrift das Reich aufgebaut wissen wollte, ließ sich seine Stellungnahme nicht in Einklang bringen. Niemand hat so energisch wie Preuß die Forderung verfochten, daß die Aufsicht des Staats über die Ge meinden in den engsten Grenzen gehalten werden müsse. Der Entwurf zur Reichsverfassung versuchte ja, dieser Forderung endgültig zum Siege zu verhelfen ( $\mathbb{1 2}$ Abs. 3). Nun soll sich nach der von Preuß schon früher, mit besonderer Wärme aber auch in der Denkschrift vertretenen „organischen“ Auffassung das Reich „von unten nach oben“ aufbauen, es soll „mit seiner ganzen inneren Lebenstätigkeit auf dem organischen Unterbau seiner kommunalen und einzelstaatlichen Glieder" ruhen. Nach dieser Anschauung sind die Einzelstaaten in der Tat nichts anderes als große Selbstverwaltungskörper des Reichs, die ganze Kompetenzregulierung ist darauf angelegt, sie auf das Niveau von Großkommunen herabzudrücken. Von diesem Standpunkte aus ist es aber schwer begreiflich, daß in bezug auf das Beaufsichtigungsrecht den großen Selbstverwaltungskörpern versagt bleiben soll, was den Gemeinden zugesprochen wird. Erklärlich wird es allein, wenn man das Problem, wie Preuß es tut (Denkschrift S. 10f.), ganz einseitig vom Standpunkte des parlamentarischen Regierungssystems aus betrachtet. Die Verantwortlichkeit der Regierung für die sinngemäße Ausführung der Reichsgesetze, soweit diese der Landesverwaltung obliegt, bleibt, wie er meint, eine inhaltlose Form, wenn die Reichsregierung nicht in der Lage ist, die Landesverwaltung aufs stärkste zu beeinflussen. Dafür ist eine bloße Oberaufsicht ungenügend. Es bedarf der unmittelbaren Berührung der Reichszentrale mit den Mittelund Unterorgangen der Einzelstaaten. Allein das ist eine sehr anfechtbare Deduktion. Nicht die Ministerverantwortlichkeit entscheidet über das $\mathrm{Ma} ß$ des den Einzelstaaten aufzulegenden aufsichtsrechtlichen Druckes, sondern es hängt umgekehrt von dem Umfange der Aufsichtsgewalt ab, ob, wann und wofür die Minister verantwortlich gemacht werden können. Im Grunde soll die im Entwurfe vorgeschlagene Lösung der Aufsichtsfrage nur dazu dienen, den parlamentarischen Machthunger zu befriedigen. Dem Reichsparlamente soll die Möglichkeit gegeben werden, durch das Medium der Ministerverantwortlichkeit die einzelstaatliche Verwaltung 
unter scharfe eigene Kontrolle zu stellen. Die Gefahr, die darin für das Eigenleben der Einzelstaaten liegt, könnte allein dadurch gemildert werden, daß die Betätigung der Reichsaufsicht noch mehr, als es im bisherigen Rechte schon geschehen ist, in die Form einer Verwaltungsgerichtsbarkeit gekleidet wird ${ }^{19}$. Daß das in der Absicht des Preußschen Entwurfs gelegen war, konnte vielleicht, aber keinesfalls mit Sicherheit, aus einer Andeutung ( $(9)$ entnommen werden.

Wenn eine bundesstaatliche Verfassung die Selbständigkeit der Einzelstaaten durch eine zentralisierende Regelung der Zuständigkeiten stark beschneidet, so kann sie das ausgleichen, indem sie den Gliedstaaten in dem Rechte, an der Bildung des gesamtstaatlichen Willens in entscheidender Weise teilzunehmen, einen Ersatz verschafft. Bekanntlich ist Bismarck in dieser Weise vorgegangen. Als Gegengabe für die Landesregierungen zugemutete Aufopferung wichtigster Souveränitätsrechte bot er ihnen den Bundesrat, in dem sie durch instruierte Vertreter an der Herstellung des Reichswillens mitzuwirken in der Lage waren. Da der Bundesrat das uneingeschränkte Recht zur Sanktion der Reichsgesetze erhielt, und da er außerdem mit umfassenden Kompetenzen der Regierung und der Verwaltung (insbesondere auch auf dem Gebiete der Reichsaufsicht) ausgestattet wurde, war die Gegenleistung nicht gering zu bewerten. Dieses föderalistische Reichsorgan aber hatte der Preußsche Entwurf gestrichen, und er hatte damit eines der stärksten Gegengewichte gegen die unitarischen Elemente der Reichsverfassung beseitigt.

Als Entgelt bot er den Einzelstaaten zweierlei an.

Er gewährte den Regierungen der deutschen Freistaaten das Recht, zur Reichsregierung „Vertreter“ zu entsenden. Diese sollten befugt sein - ähnlich wie die Bundesratsbevollmächtigten nach Artikel 9 der jetzigen Reichsverfassung -, im Reichstage den Standpunkt ihrer Regierungen gegenüber jedem Gegenstande der Verhandlung zur Geltung zu bringen; auf Verlangen sollte ihnen während der Beratung jederzeit das Wort erteilt werden. Vor allem sollten aus diesen Vertretern bei den einzelnen Reichsministerien nach Bedarf R e i c h s r ä te gebildet werden, Kollegien, die offenbar als Analoga der vormaligen Bundesratsausschüsse gedacht waren. Das war an sich gewiß ein glücklicher Gedanke ${ }^{20}$. Nur freilich war den Reichsräten ein sehr magerer Anteil an den Geschäften der Reichsregie-

19 Vgl. darüber meine Reichsaufsicht S. 310 f., 326 f., 698 ff.

20 Der Entwurf des Vereins Recht und Wirtschaft ist unabhängig von Preuß zu demselben Vorschlage gekommen (Art. 106), nur daß er seinen „Reichsausschüssen" weiter greifende Befugnisse zugestanden sehen will. 
rung zugedacht. Sie sollten lediglich mit ihren „Gutachten“ vor der Einbringung von Gesetzesvorlagen beim Reichstage und vor dem Erlasse der zur Ausführung der Reichsgesetze erforderlichen allgemeinen Verwaltungsvorschriften gehört werden ( $\mathbb{S} 14-16)$.

Als zweiter Ersatz für den Verlust des Bundesrats war den Einzelstaaten der Einfluß auf die Besetzung des $S$ ta a te $n$ ha us es zugestanden, das mit dem Volkshause zusammen den Reichstag zu bilden bestimmt war ( $\$ 30 \mathrm{ff}$.). Während das Volkshaus aus den vom „einheitlichen deutschen Volke" unmittelbar in allgemeiner Abstimmung zu wählenden Abgeordneten besteht, soll sich das Staatenhaus aus „Abgeordneten der deutschen Freistaaten" zusammensetzen; die Landtage wählen die Abgeordneten aus der Mitte der Staatsangehörigen nach Maßgabe des Landesrechts. Da bei der Bildung des Staatenhauses grundsätzlich auf eine Million Landeseinwohner ein Abgeordneter entfallen sollte, so würde das Haus ein Kollegium von annähernd 70 Mitgliedern geworden sein. Indessen war, um Preußen nicht allzu stark hervortreten zu lassen, die Bestimmung hinzugefügt, daß kein Einzelstaat durch mehr als ein Drittel aller Abgeordneten vertreten sein dürfe. Dieses Staatenhaus wurde also in der Tat durch die Einzelstaaten als solche, nämlich durch ihre Hauptorgane, die Landtage, besetzt. Aber es war natürlich etwas ganz anderes als der einstige Bundesrat. Es war, wie der Senat in den Vereinigten Staaten und der Ständerat in der Schweizerischen Eidgenossenschaft, als das Oberhaus eines Parlaments gedacht. Die Abgeordneten sollten, ungeachtet ihres partikularen Ursprungs, Vertreter des ganzen deutschen Volks, sie sollten, anders als die Bundesratsbevollmächtigten, an Aufträge und Instruktionen nicht gebunden sein, sie sollten ihre Stimmen nach ihrer eigenen freien Überzeugung abgeben. Es versteht sich von selbst, daß in einem solchen Staatenhause zwar die Interessen der Einzelstaaten zu Worte kommen können, daß aber die Einzelstaaten selber als staatliche Individualitäten in ihm nicht vertreten sind. Vor allem wenn, wie der Entwurf festsetzte, für das Staatenhaus ebenso wie für das Volkshaus die Legislaturperiode drei Jahre dauern soll ( $\$ 37)$. Auch wenn sich also während der Dauer der Legislaturperiode die Zusammensetzung eines Landtags, der die Wahlen zum Staatenhause vollzogen hat, durchaus veränderte, so würde dies auf den Bestand seiner „Abgeordneten" zum Staatenhause nicht den geringsten Einfluß haben. Endlich sah der Entwurf eine Auflösung des Staatenhauses durch den Reichspräsidenten vor, und zwar sollte die Möglichkeit bestehen, das Staatenhaus ohne gleichzeitige Auflösung des Volkshauses aufzulösen $(\mathbb{S} 40$, 44). Vermöge des parlamentarischen Systems würde also das Volkshaus in der Lage ge- 
wesen sein, die Auflösung eines ihm unbequemen Staatenhauses zu erzwingen!

IV.

Man braucht dem Preußschen Entwurfe die unitarische Richtung, die er mit unerbittlicher Konsequenz einhielt, nicht unbedingt zum Vorwurfe zu machen. Die Entwicklung, die unser bundesstaatliche Leben schon vor dem Kriege genommen hatte, zeigte dem aufmerksamen Beobachter schon längst eine starke Neigung nach der Seite des Einheitsstaates ${ }^{21}$. Und es ist durchaus unbegründet, wenn man diese Entwicklung an sich selbst für eine unglückliche erklärt. Mag man im Übrigen darüber denken, wie man will, so viel ist doch gewiß, daß die gewaltigen Aufgaben, die das Reich in Zukunft auf wirtschafts- und finanzpolitischem Gebiete zu erfüllen haben wird, mit innerer Notwendigkeit zu einer starken Zentralisation drängen werden. Aber es wäre richtiger gewesen, die Verfassung so elastisch zu gestalten, daß sie der Entwicklung freie Bahn ließ, statt diese Entwicklung mit rauher Faust von vornherein in bestimmte Richtung zu drängen.

Vor allem war der Fehler, den der Verfasser des Entwurfs beging, ein taktischer. Er schätzte die partikularen Widerstände, auf die er nach den Erfahrungen der letzten Monate rechnen mußte, allzu niedrig ein. Er übersah, daß in den deutschen Einzelstaaten noch immer ein zäher Wille zu staatlichem Eigenleben vorhanden ist. Er befand sich in einem schweren Irrtum, wenn er glaubte, daß das Staatsbewußtsein der Territorien durch die Beseitigung ihrer Dynastien geschwächt worden sei. Unsere Staaten sind freilich vor Zeiten durch die Arbeit ihrer Fürsten geschaffen worden. Aber der innere Zusammenhalt, den ihnen eine jahrhundertelange Verwaltung, nicht zuletzt aber die konstitutionelle Verfassung und das parlamentarische Leben gegeben, ist viel zu groß, als daß er durch den Sturz der Dynastien hätte aus den Fugen gehen können. Das Gefühl dieses Zusammenhalts lebt nicht etwa nur bei der einzelstaatlichen Bureaukratie, die die Revolution überdauert hat, sondern mindestens ebenso stark bei den Bevölkerungen. Daß der Krieg und die Revolution das Ihrige getan hatten, um in Mittel- und Süddeutschland eine entschiedene Feindschaft gegen

21 Vgl. meine Schrift „Unitarismus und Föderalismus im Deutschen Reiche[.Eine staatsrechtliche und politische Studie, Berlin] (1907), dazu den Aufsatz: Bismarck und die Reichsverfassung, in der Zeitschrift "Das Neue Deutschland“ 3 [1914/15], S. 185[-191]. 
zentralistische Bestrebungen zu erzeugen, haben wir schon gesehen. Diesen Stimmungen muß aber zurzeit einfach Rechnung getragen werden. Weder die Reichsregierung noch die Nationalversammlung darf mit einer nachlässigen Gebärde an ihnen vorübergehen. Man mag die Lage, in die wir geraten sind, beklagen. Aber es würde ein Schlag ins Wasser sein, wenn die Nationalversammlung eine unitarische Verfassung nach dem Rezepte des Preußschen Entwurfs verabschieden wollte.

Die Nationalversammlung von Weimar kann gewiß mit besserem Rechte als einst das Frankfurter Parlament erklären, daß ihr Beruf und ihre Vollmacht, eine deutsche Verfassung zu schaffen, auf der Souveränität des ganzen deutschen Volkes beruhe. Aber ihre Souveränität ist doch im Grunde nur eine solche der Form, nicht der Sache. Bei der Beratung am 25. Januar hat ein mittelstaatlicher Delegierter geäußert: „Was würde geschehen, wenn die Nationalversammlung sich für souverän erklären würde? Damit wäre die Sache nicht zu Ende gebracht, da die Nationalversammlung eine Exekutive nicht besitzt. Ohne Zustimmung der Einzelstaaten kann die Reichsverfassung nicht zustande kommen." Damit wird die heutige Situation blitzartig scharf erleuchtet. Mag die Verfassung, die in Weimar zustande kommt, ein Gesicht tragen, wie sie will, noch immer sind die Einzelstaaten mächtig genug, um ihr den Lebensfaden abzuschneiden, wenn sie mit ihr innerlich nicht zufrieden sind. Die Nationalversammlung in Weimar befindet sich in einer ganz ähnlichen Lage wie zur Zeit der ersten deutschen Revolution das Parlament von Frankfurt. Sie ist wie dieses zur Ohnmacht verurteilt, wenn sie sich nicht mit den Einzelstaaten zu verständigen weiß. Damals waren es die Kronen, an deren Widerstand das Verfassungswerk gescheitert ist. Heute sind es die revolutionären Regierungen der Gliedstaaten, die gewillt und gerüstet sind, jedem Unternehmen entgegenzutreten, das die Reichsverfassung über ihre Köpfe hinweg zustande bringen will. Nur daß im Jahre 1849 die preußische Krone, wenn sie die nötige Energie besessen hätte, in der Lage gewesen wäre, Deutschland in die Bahn bundesstaatlicher Einigung zu reißen. Jetzt hat man das preußische Königtum, den preußischen Staat, die preußische Armee zerbrochen und damit die stärksten Kräfte zerstört, die Auseinanderstrebendes zum Zusammenhalten, das Reich selbst in neuen Bahnen hätten zwingen können.

Die Verhältnisse haben nun auch schon die vorläufige Reichsregierung genötigt, der föderalistischen Strömung der Gegenwart bedeutende Zugeständnisse zu machen. Der neue Entwurf der Reichsverfassung, den sie mit dem Staatenausschusse vereinbart hat, trägt ein ganz anderes Gesicht als der Preußsche Entwurf. In den unitarischen Wein ist viel föderalistisches 
Wasser gegossen worden. So viel, daß man sogar ernstlich fragen muß, ob dabei nicht des Guten zu viel geschehen sei. Bei unbefangener Prüfung scheint es, daß der zweite Entwurf die „Bedürfnisgrenze“ in föderalistischer Richtung ebenso stark überschreitet, wie es sein Vorläufer in der unitarischen Richtung getan hatte. Sowohl die neue Art der Kompetenzregulierung wie die jetzt vorgeschlagene Organisation der Reichsgewalt gibt zu lebhaften Bedenken Anlaß.

Als ein arger Schönheitsfehler im Bilde der Verfassung erscheinen zunächst die Reservatrechte der süddeutschen Staaten; ein großer Teil von ihnen soll aus der alten in die neue Verfassung hinübergenommen werden. So zunächst im Militärwesen. Allerdings erklärt der Entwurf, es solle auf diesem Gebiete sowohl die Gesetzgebung ausschließlich dem Reiche zustehen, als auch die Verwaltung durch den Reichswehrminister geführt werden (Art. 5). Beschränkte er sich auf diese Vorschrift, so würde er alles Lob verdienen. Die Erfahrungen der Friedens-, namentlich aber der Kriegszeit lassen es dringend geboten erscheinen, daß beim Landheere mit dem hergebrachten Kontingentssystem aufgeräumt wird. Und wie sehr die Verhältnisse der Gegenwart dazu drängen, dem Reiche ein zentralistisches eigenes Heer zur Verfügung zu stellen, wurde schon vorhin angedeutet. Aber der Entwurf durchbricht den Grundsatz schon dadurch, daß er dem künftigen Wehrgesetze die Aufgabe stellt, den obersten Kommandostellen in den einzelnen „Landesteilen“" selbständige Verwaltungsbefugnisse einzuräumen, die sich auf die Pflege „der besonderen Stammestüchtigkeit (!) und landsmannschaftlichen Eigenart" richten sollen - eine Bestimmung, die einer für die Einheitlichkeit des Heeres außerordentlich gefährlichen Dezentralisation Tür und Tor öffnet. Darüber hinaus sollen aber die Staaten, in denen nach den bisherigen Verfassungsgrundlagen selbständige Militärverwaltungen bestanden haben - also Preußen, Bayern, Sachsen, Württemberg -, in ihren sich „hieraus ergebenden“ Sonderrechten ohne ihre Zustimmung nicht beschränkt werden dürfen ${ }^{22}$. Soweit Bayern nach dem Novembervertrage von 1870 noch weitergehende Sonderrechte genießt,

22 Der Satz ist überaus unklar. Aus dem Besitze selbständiger Militärverwaltung folgt an sich kein „Sonderrecht“. Die Sonderechte ergeben sich aus der Verfassung und den von ihr in Bezug genommenen Verträgen, und der Besitz eigener Militärverwaltung war nach der Verfassung gerade kein Vorrecht einzelner, sondern stand grundsätzlich allen Bundesstaaten zu. Ob Sachsen auf Grund der in ihrer Gültigkeit stark angefochtenen Militärkonvention "Sonderrechte“ besaß, war zweifelhaft. Preußen hatte überhaupt keine militärischen "Sonderrechte“. Seine Stellung war durch die Bestimmungen der Verfassung über Verfassungsänderungen tatsächlich geschützt. 
sollen sie ihm gleichfalls nur mit seiner Zustimmung verkürzt werden $\left(\right.$ Art. 5) ${ }^{23}$. Ferner wird das Postreservatrecht Bayerns und Württembergs aufrechterhalten. Allerdings „kann“ das Reich das Post- und Telegraphenwesen dieser Staaten gegen Entschädigung in eigene Verwaltung übernehmen, aber nur im Wege des „Vertrages“. Bis das geschehen ist, bleiben die bisherigen Vorrechte in Kraft. Nur wird der Post- und Telegraphenverkehr mit den an Bayern und Württemberg angrenzenden nichtdeutschen Staaten fortan ausschließlich vom Reiche geregelt, und die Postwertzeichen sollen für das ganze Reich gemeinsam sein (Art. 87, 88). Auch in bezug auf die Bierbesteuerung bleibt es bei der Reservatstellung der drei süddeutschen Staaten, und das ihnen im Reichsgesetze über das Branntweinmonopol vom 26. Juli 1918 zuerkannte Sonderrecht wird ungeschmälert erhalten. Sogar das bayerische Reservatrecht in Sachen des Immobilienversicherungswesens ist nicht vergessen worden (Art. 116-118). In dem Eisenbahnwesen ist der Entwurf mit der Austeilung von Reservatrechten so freigebig, daß er noch beträchtlich über das hinausgeht, was die bisherige Reichsverfassung zugestand. Bis jetzt genoß auf diesem Gebiete nur Bayern eine Ausnahmestellung, und zwar im wesentlichen nur gegenüber der Verordnungs- und Aufsichtsgewalt des Reiches. Jetzt erklärt der Entwurf: es sei zwar die „Aufgabe“ des Reichs, alle dem allgemeinen Verkehre dienenden Eisenbahnen gegen Entschädigung in eigene Verwaltung zu übernehmen; aber die Übernahme solle nur im Wege des Vertrags erfolgen dürfen. Das Entsprechende wird für die dem allgemeinen Verkehre dienenden Binnenwasserstraßen und die nach den großen Häfen der Ost- und Nordsee führenden Seewasserstraßen angeordnet (Art. 102, 103). Diese Vorschriften sind insofern besser als die des Preußschen Entwurfs, als dem Reiche nicht mit einem Schlage die uneingeschränkte eigene Verwaltung im ganzen Umkreise des Verkehrswesens überwiesen wird. Aber sie sind höchst bedenklich, insofern sie allen Einzelstaaten, die sich im Besitze von Staatsbahnen und Wasserstraßen befinden, ein Reservatrecht schenken, das ihnen bisher nicht zustand. Nun mag es gewiß nicht leicht sein, die süddeutschen Staaten zur Aufgabe ihrer Vorzugsstellung zu bewegen. Aber welcher Rückschritt liegt darin, daß man den Umfang der Reservatrechte noch erweitert! Es ist zu wünschen, daß die Nationalversammlung noch einmal den Versuch unternimmt, hier zu bremsen, oder daß sie we-

23 Nur wird Bayern die Verpflichtung auferlegt, in Zukunft die Verwendung der Mittel, die für sein Kontingent bekanntlich im Reichsetat in einer Summe ausgeworfen werden, dem Reiche gegenüber nachzuweisen. 
nigstens die ärgsten jener föderalistischen Anachronismen aus dem deutschen Verfassungsrechte entfernt.

Größeren Beifall als die Schonung partikularer Sonderrechte verdient die Haltung, die der neue Entwurf in bezug auf die der ausschließlichen Gesetzgebung und der eigenen Verwaltung des Reichs anheimfallenden Angelegenheiten einnimmt. Von den Eisenbahnen und Wasserstraßen war eben schon die Rede. Mit Recht hat ferner der Entwurf die Regelung des Handelsverkehrs, des Bank- und Börsenwesens, des Verkehrs mit Kraftfahrzeugen der fakultativen Gesetzgebungskompetenz des Reiches zugewiesen, und er hat vor allem auf diesen Gebieten die Verwaltung, die Preuß dem Reiche zugedacht, den Gliedstaaten überlassen (Art. 9, 103). Die Erhebung der Zölle und Verbrauchssteuern wird - mit Recht - grundsätzlich dem Reiche übertragen (Art. 7 Abs. 3); daß für Sachsen, die vier süddeutschen Staaten, Bremen und Hamburg eine Ausnahme gemacht wird (Art. 115), ist wieder weniger zu billigen. Die Erhebung und Verwaltung der übrigen Reichsabgaben wird von vornherein den Einzelstaaten belassen. Doch kann die Reichsgesetzgebung bezüglich indirekter Reichsabgaben, die nicht Verbrauchssteuern sind, den Übergang der Erhebung und Verwaltung auf das Reich vornehmen; dasselbe kann bezüglich der anderen Reichs- aber auch der Landesabgaben auf Antrag eines Gliedstaates geschehen (Art. 7, Abs. 3-5). Im Bereiche der auswärtigen Angelegenheiten gesteht der Entwurf den Einzelstaaten das Recht zu, mit auswärtigen Staaten Verträge zu schließen, soweit sich diese auf Gegenstände beziehen, die ihrer Gesetzgebung unterstehen; nur bedürfen solche Verträge der Zustimmung des Reichs (Art. 4). Das ist zu billigen. Dringend erforderlich möchte es aber sein, dem Reiche die ihm heute leider fehlende Befugnis einzuräumen, Fremden den Aufenthalt im Reichsgebiete oder in einzelnen Teilen des Reichsgebiets zu untersagen. Es ist ein unwürdiger Zustand, wenn die Reichsregierung die Ausweisung reichsschädlicher Ausländer von den Einzelstaaten als eine Gefälligkeit erbitten muß. Daß der Staatenausschuß das Kolonialwesen wieder ausdrücklich erwähnt hat (Art. 6), entspricht einem Gebote der nationalen Würde.

Besser als der erste Entwurf hat der jetzige den Kreis der Angelegenheiten umgrenzt, die der - konkurrierenden - Gesetzgebung des Reichs, der Verwaltung der Einzelstaaten unterliegen sollen (Art 9). Hier ist manche Lücke geschlossen worden, die der Preußsche Entwurf offen gelassen hatte. Die zwischenstaatliche Rechts- und Verwaltungshilfe, das Wohnungswesen sind eingefügt, der Bergbau wird ausdrücklich erwähnt, die Zuständigkeit des Reichs zur Regelung des Enteignungswesens in vollem Umfange anerkannt. Die Kompetenz des Reichs in 
Sachen der Landessteuern ist erweitert. Nicht nur in bezug auf Zulässigkeit und Erhebungsart solcher Landesabgaben, die sich im Rahmen des Zollvereinsvertrags vom 8. Juli 1867 bewegen, und zur Verhütung von Doppelbesteuerungen, sondern auch insofern, als dem Reiche das Recht der Gesetzgebung über alle Abgaben und Einnahmen verliehen wird, die ganz oder te i l w e is e für seine Zwecke in Anspruch genommen werden (Art. 7, Abs. 2). Die von Preuß unvollständig geregelte Kompetenz zur Gesetzgebung im Eisenbahnwesen ist in einer der bisherigen Verfassung entsprechenden Weise normiert worden (Art. 89). Eingefügt ist eine Bestimmung, die "den Schutz der öffentlichen Sicherheit und Ordnung und die öffentliche Wohlfahrtspflege, soweit ein Bedürfnis für den Erlaß gleichmäBiger Vorschriften vorhanden ist“, der Reichsgesetzgebung zuweist (Art.9, Z. 11), - eine sehr elastische Klausel, die vermutlich in der Zukunft eine recht große Rolle spielen wird. Dasselbe gilt für die Vorschrift, daß dem Reiche die „Regelung der Herstellung und Verteilung der wirtschaftlichen Güter für die deutsche Gemeinwirtschaft" zustehen solle (Art. 9, Z. 15). Auffällig ist, daß, wie bei Preuß, das gesamte Armenwesen unter die Reichszuständigkeit gestellt worden ist (Art. 9, Z. 1), obwohl doch diese Materie mit dem Kommunalwesen in engstem Zusammenhange steht. Dagegen hat man die Kompetenz des Reichs zur Bodengesetzgebung durch eine schärfere Formulierung eingeengt (Art. 9, Z. 14). Auf der anderen Seite ist der Schutz und Pflege der schulentlassenen Jugend der Reichsgesetzgebung zugewiesen worden (Art. 4, Z. 16). Es wäre richtiger gewesen, diese Angelegenheit den Einzelstaaten zu überlassen. Um so mehr, als man im übrigen verständigerweise das Schulwesen - von den grundrechtlichen Bestimmungen abgesehen - der Landesgesetzgebung ebenso vorbehalten hat wie die Beziehungen zwischen Staat und Kirche.

Es ergibt sich aus alledem, daß das Vorbe halts ge biet der Einzelstaaten in dem neuen Entwurfe nicht wesentlich weiter abgesteckt worden ist als im Entwurfe des Staatssekretärs Preuß. Aber doch mit einer sehr wichtigen Ausnahme: die von Preuß vorgeschlagenen tiefen Eingriffe in das Kommunalrecht hat man kategorisch zurückgewiesen, und ebenso hat man von den Normativbestimmungen über den Inhalt der Landesverfassungen das meiste mit einem energischen Federstriche beseitigt. Nur die Vorschrift, daß die Landesverfassung republikanisch, die Volksvertretung nach einem dem Reichstagswahlrechte entsprechenden Verfahren zusammengesetzt und das Regierungssystem parlamentarisch sein müsse, ist stehen geblieben (Art. 16). Beachtlich ist auch, daß der neue Indigenatsartikel (Art. 29) verständigerweise den Einzelstaaten die Entscheidung überläßt, 
ob sie Angehörige anderer deutscher Staaten an der Ausübung politischer Rechte teilnehmen lassen wollen oder nicht.

Weniger befriedigend als die Regelung der Gesetzgebungs- und Verwaltungskompetenz des Reichs ist dem neuen Entwurfe die Gestaltung der Reichsaufsicht gelungen (Art. 14). Allerdings bedeutet es eine Verbesserung, daß die extremen Preußschen Vorschläge - die generelle Ersetzung der Oberaufsicht durch eine unmittelbare Aufsicht - nicht angenommen worden sind. Aber in der Verwerfung der unmittelbaren Aufsicht scheint doch der neue Entwurf über das erforderliche Maß hinausgegangen zu sein. Er ermächtigt die Reichsregierung grundsätzlich nur, an die Landeszentralbehörden Beauftragte zur Überwachung der Ausführung der Reichsgesetze zu entsenden, und er verpflichtet lediglich die Landesregierungen, auf Ersuchen der Reichsregierung Mängel, die bei der Ausführung der Reichsgesetze hervorgetreten sind, zu beseitigen. Eine Ausnahme gilt allein im Bereiche des Eisenbahnwesens (Art.96). Nun ist aber schon das bisherige Reichsrecht an vielen Stellen über die Linie der bloßen Oberaufsicht hinausgegangen. Sollen etwa die zahlreichen reichsgesetzlichen Bestimmungen im Zoll- und Steuerwesen, in den Seuchengesetzen, im Auswanderungs-, Münz-, Eichwesen und anderem, die der Aufsichtsgewalt des Reichs eine unmittelbare Berührung mit Mittel- und Unterbehörden der Einzelstaaten gestatten, durch die neue Verfassung aufgehoben sein? Das wäre ein unleugbarer Rückschritt. Der Entwurf gibt bloß in dem Abschnitte über das Finanz- und Handelswesen eine Handhabe, die „Befugnisse der Reichsaufsichtsbehörden“ durch Reichsgesetz über die vom Art. 14 gesteckte enge Grenze auszudehnen (Art. 81). Es wäre erwünscht, dies in deutlicherer Form durch eine für alle Gebiete der Reichskompetenz geltende Klausel zu tun ${ }^{24}$. Und noch in einer anderen Beziehung geht der Entwurf - wie übrigens auch schon der Preußsche - in der bedenklichsten Weise hinter das heute geltende Recht zurück. Er beschränkt die Reichsaufsicht auf diejenigen Angelegenheiten, die durch Reichsgesetzgebung geregelt sind. Er versagt also dem Reiche die sogenannte „selbständige Aufsicht“, d. h. die Befugnis, zum Schutze von Reichs- und anderen allgemeinen Interessen die Einzelstaaten auch dann schon zu beaufsichtigen, wenn das Reich von seiner Zuständigkeit zum Erlasse eines Reichsgesetzes noch

24 Vgl. den Entwurf des Vereins Recht und Wirtschaft Art. 9, Abs. 2: „Auf den Gebieten, auf denen das Reich das Recht zur Gesetzgebung besitzt, können ihm durch Reichsgesetz Befugnisse eigener Verwaltung und Gerichtsbarkeit sowie das Recht übertragen werden, Landesverwaltungsbehörden unmittelbar mit Anweisungen zu versehen." 
keinen Gebrauch gemacht hat. Der Besitz dieses selbständigen Aufsichtsrechts ist nach Wortlaut und Entstehungsgeschichte der heutigen Reichsverfassung (Art. 4) dem Reiche schlechterdings nicht abzustreiten. Die Praxis hat sich seiner ständig bedient, zum Beispiel im Auswanderungs-, Gesundheits-, Wasserstraßenwesen oder in Bezug auf die Kontrolle der Seeschiffahrtszeichen. Wenn sich die Reichsregierung gelegentlich auf einen anderen Standpunkt stellte, wie etwa hinsichtlich der Aufsicht über die einzelstaatliche Fremdenpolizei, hat sich der Reichstag immer energisch für die Anerkennung der selbständigen Reichsaufsicht eingesetzt ${ }^{25}$. Diese ist in der Tat für das Reich ganz unentbehrlich, aus internationalen, militärischen, wirtschaftlichen und anderen Gründen, und der Entwurf muß hier entschieden ergänzt werden ${ }^{26}$.

Auf der anderen Seite ist der Entwurf berechtigten Wünschen entgegengekommen, indem er die föderative Organisation der Reichsaufsicht, die der bisherigen Verfassung eigentümlich war, so gut wie ganz in unitarischer Weise ausgestaltet hat. Anders als der frühere Bundesrat soll der künftige Reichsrat das Recht der „Mängelabhilfe“ nicht besitzen. Nur im Eisenbahnwesen ist eine Ausnahme gemacht worden (Art.96), über deren Berechtigung man wird streiten können ${ }^{27}$. Im übrigen liegt die Ausübung der Reichsaufsicht ausschließlich in der Hand der Reichsregierung, und der Austrag von Streitigkeiten zwischen Reich und Einzelstaaten auf diesem Gebiete soll nunmehr auf gerichtlichem Wege, in erster Linie durch den in Aussicht genommenen Staatsgerichtshof, erfolgen (Art.11, 14 Abs. 3, 17). Es wird sich von selbst verstehen, daß auch die dem Reichspräsidenten übertragene Reichsexekution (Art. 67) nur auf Grund eines Erkenntnisses des Staatsgerichtshofs erfolgen kann. Daß die Mängelabhilfe im Verfahren der Reichsaufsicht in letzter Instanz der Entscheidung eines unparteiischen Richters anvertraut wird, ist zu begrüßen. Aber freilich nur

25 Vgl. meine Reichsaufsicht S. $411 \mathrm{ff}$.

26 Vgl. den Entwurf des Vereins Recht und Wirtschaft Art. 12, Abs. 2: „Solange das Reich auf den seiner Gesetzgebung zugänglichen Gebieten gesetzliche Anordnungen nicht getroffen hat, wacht es darüber, daß die Bundesstaaten die dem Schutze des Reichs anvertrauten Interessen wahren."

27 Die Aufsicht über die Eisenbahnen soll durch den Ausschuß des Reichsrates für das Eisenbahnwesen geführt werden. Das Reichseisenbahnamt hat lediglich die Geschäfte des Ausschusses vorzubereiten. Allerdings kann der Ausschuß dem Reichseisenbahnamte seine Kompetenz teilweise delegieren. Diese Regelung geht wiederum, wie ich glaube, noch hinter das jetzige Recht zurück; denn dieses hat den Bundesrat bereits wesentlich zugunsten des Reichseisenbahnamtes depossediert. Vgl. meine Reichsaufsicht S. 576 ff. 
für solche „Aufsichtskonflikte“, bei denen sich die Reichskontrolle auf die formelle Legalität des einzelstaatlichen Verfahrens bezieht. Es gibt sehr viele Fälle, in denen die Reichsaufsicht nicht in reicher "Rechtskontrolle“ besteht, in denen sie vielmehr mit Erwägungen des Nützlichen und Notwendigen zu arbeiten hat. Und zur Entscheidung von Aufsichtskonflikten, bei denen politische, finanzielle, technische Gesichtspunkte in Frage kommen, ist ein Staatsgerichtshof nicht das geeignete $\operatorname{Organ}^{28}$. Will man unter allen Umständen auch in solchen Fällen die Kompetenz des Staatsgerichtshofs festlegen, so sollte zum mindesten in dem künftigen Ausführungsgesetze dafür gesorgt werden, daß das Gericht in Fragen des politischen Ermessens an die Entscheidung der Reichsregierung gebunden ist.

Überblickt man die Reihe der vom neuen Entwurfe getroffenen Kompetenzbestimmungen, so zeigt sich, genau wie beim Preußschen Entwurfe, ein starker Mangel an Elastizität. Nur daß Preuß die Reichskompetenz zu einseitig nach der unitarischen Seite festgelegt hatte, während der jetzige Entwurf das föderalistische Prinzip allzu schroff betont. Das hat seine großen Bedenken, weil in Zukunft die Verfassungsänderungen im Vergleiche mit dem bisherigen Rechtszustande sehr erschwert sein sollen. Sie können vom Reichstage nur beschlossen werden, wenn wenigstens zwei Drittel der gesetzlichen Mitgliederzahl des Reichstags anwesend sind und mindestens zwei Drittel der Anwesenden zustimmen (Art. 54); auch im Reichsrate ist die Zustimmung einer Zweidrittelmehrheit erforderlich (Art. 23 Abs. 4). Nun sagt der Entwurf zum Beispiel in Art. 9 Abs. 2, daß die Ausführung der Reichsgesetze „grundsätzlich“ durch die Landesbehörden zu erfolgen habe. Das ist sehr vernünftig; bisher galt derselbe „Grundsatz". Aber die Reichsgesetzgebung hat ihn bereits an zahlreichen Stellen durchbrochen, indem sie dem Reiche mannigfache Rechte eigener Gerichtsbarkeit und eigener Verwaltung einräumte - man denke nur an das Versicherungswesen, an das Patentwesen, an die Reichsgerichtsbarkeit. Eine solche Ausdehnung der Reichszuständigkeit ließ sich in den meisten Fällen ohne jede Schwierigkeit bewirken. Es genügte, daß sich im Bundesrate weniger als vierzehn Stimmen gegen die Neuerung aussprachen; im Reichstage bedurfte es für Verfassungsänderungen überhaupt keiner höheren Majorität als bei einfachen Gesetzen. Erhob sich also gegen eine Erweiterung der Verwaltungskompetenzen des Reichs im Reichstage Widerspruch, so war er leicht zum Schweigen zu bringen, wenn man sich darauf berufen konnte, daß sich der Bundesrat mit der für Verfassungsänderun-

$28 \mathrm{Vgl} \mathrm{meine} \mathrm{Reichsaufsicht} \mathrm{S.} \mathrm{702,} 704 \mathrm{ff}$. 
gen nötigen Mehrheit der Stimmen einverstanden erklärt habe. In $\mathrm{Zu}$ kunft wird jedesmal der dornenvolle Weg der formellen Verfassungsänderung eingeschlagen werden müssen, wenn von dem "Grundsatze“ des Art. 9 selbst bei verhältnismäßig geringfügigem Anlasse abgewichen werden soll. Ja, es erhebt sich der Zweifel, ob nicht durch diesen „Grundsatz“ alle bestehenden Einrichtungen, die ihm zuwiderlaufen, wie Patentamt, Reichsversicherungsamt oder gar das Reichsgericht, aus den Angeln gehoben sind! Es möchte sich empfehlen, dem allen dadurch vorzubeugen, daß in der Verfassung eine Ermächtigung für die einfache Reichsgesetzgebung ausgesprochen und eine salvatorische Klausel in die Schlußbestimmungen eingefügt wird ${ }^{29}$.

Es handelt sich aber nicht allein darum, dem Reiche eine Erweiterung seiner Zuständigkeit zu erleichtern. Es muß ihm auch durch möglichst weitgreifende Bestimmungen die Möglichkeit geboten werden, von den ihm verfassungsmäßig zustehenden Kompetenzen einen allseitigen und wirksamen Gebrauch zu machen. Das gilt in erster Linie für das Recht zur Gesetzgebung selbst. Das Reich könnte häufig eine seiner Regelung unterstellte Angelegenheit nicht sachgemäß, nicht erschöpfend, nicht einheitlich regeln, es könnte oft die Wirksamkeit seiner Anordnungen nicht genügend gegen Beeinträchtigung schützen, wenn es nicht dabei auch in das an sich den Einzelstaaten vorbehaltene Gebiet hinübergriffe. Es kann, um nur ein Beispiel zu geben, die Vorschriften über die Entschädigung der Reichstagsabgeordneten nicht vor Durchkreuzung bewahren, wenn es nicht auch Bestimmungen über die Landtagsdiäten der Doppelmandatare erläßt - wozu es an und für sich natürlich nicht befugt sein würde. Man wird sagen, das sei selbstverständlich, es habe auch bisher schon gegolten und sei stets so gehandhabt worden. Das ist richtig ${ }^{30}$. Aber so selbstverständlich war es doch nicht, daß es nicht zuzeiten innerhalb des Reichstags bestritten worden wäre; bei der Beratung des Diätengesetzes hat bekanntlich ein recht harter Kampf darüber stattgefunden. Bisher konnte man in solchen Fällen die Opponenten leicht zur Ruhe bringen, indem man ihnen erklärte, daß sich im Bundesrate keine oder doch nur weniger als vierzehn Stimmen gegen den Vorschlag ausgesprochen hätten, daß also die

29 Vgl. oben S. 86, Anm. 1 - Man könnte ja vielleicht das Wort „grundsätzlich“ im Art. 9, Abs. 2 so verstehen wollen, daß Ausnahmen im Wege der einfachen Gesetzgebung beschlossen werden können. Wenn das gemeint sein sollte, müßte es aber viel deutlicher ausgedrückt werden.

30 Vgl. meine Abhandlung: Die Kompetenzen des Bundesstaats und die geschriebene Verfassung[, in: Staatsrechtliche Abhandlungen.] Festgabe für [Paul] Laband [zum 50. Jahrestag der Doktor-Promotion, Bd. II, Tübingen] 1908, S. 249[-335]. 
Form gewahrt sei, selbst w e $\mathrm{n} n$ es sich um eine Erweiterung der Reichskompetenz handeln sollte. Das wird nun, wie wir sahen, in Zukunft anders sein. Es muß deshalb in der Verfassung ausdrücklich bestimmt werden, daß sich die Gesetzgebung des Reichs, soweit es zur wirksamen Regelung einer ihr durch die Verfassung zugewiesenen Angelegenheit erforderlich ist, auf andere Gebiete erstrecken dürfe ${ }^{31}$. Auch im übrigen wäre es gut, wenn man Zuständigkeitsregeln, die man sonst nur durch Schlußfolgerung aus den geschriebenen Verfassungsklauseln ableiten könnte, mit Worten in die Verfassungsurkunde einfügte. Man muß zum Beispiel jeden Zweifel darüber ausschließen, daß das Reich über die Ausübung der ihm zugewiesenen Regierungs- und Verwaltungskompetenzen, etwa über Reichsaufsicht, Reichsexekution oder Beamtenanstellung, Gesetze erlassen kann; und so empfiehlt sich die Einstellung eines der amerikanischen „sweeping clause“ entsprechenden Artikels: „Das Reich kann alle Gesetze erlassen, die zur Durchführung seiner verfassungsmäßigen Obliegenheiten erforderlich sind ${ }^{32}$."

Weit deutlicher noch als bei der Regelung der Kompetenzfragen ist der neue Entwurf von den Preußschen Vorschlägen bei der Ausgestaltung der obersten Re i ch sorga n e abgerückt. Er hat mit einer energischen Geste das Staatenhaus beseitigt, an seine Stelle einen außerhalb des Reichstags stehenden Reichsrat geschaffen und damit das vielbehandelte Problem: Bundesrat oder Staatenhaus, von neuem zur Diskussion gestellt.

In seinem äußeren Aufbau ist der Reichsrat das Abbild des bisherigen Bundesrates. Er ist ein Kollegium, das den deutschen Einzelstaaten eine Mitwirkung bei der Gesetzgebung und Verwaltung des Reichs ermöglichen soll (Art. 18), und er besteht deshalb aus Mitgliedern der einzelstaatlichen „Regierungen“ (Art. 21). Über die Art der Stimmenverteilung sind sich die vorläufige Reichsregierung und der Staatenausschuß nicht ganz einig geworden. Der von beiden angenommene Grundsatz (Art. 19) besteht darin, daß das Stimmgewicht der Einzelstaaten von der Zahl ihrer Einwohner nach der jeweilig letzten Volkszählung abhängen soll. Die Stimmenzahlen werden also mit der Zunahme und der Abnahme der Bevölkerung automatisch steigen und fallen. Im allgemeinen soll auf eine Million Ein-

31 Vgl. Art. 6, Abs. 2 des Entwurfs des Vereins Recht und Wirtschaft.

32 Vgl. Art. 50 des Entwurfs des Vereins Recht und Wirtschaft. Ähnlich schon die Frankfurter Reichsverfassung $\mathbb{} \$ 62$ - Angebracht wäre auch eine ausdrückliche Ermächtigung für das Reich, Akte der v o 11 z i e h e n d e n G e w a 1 t vorzunehmen, insbesondere Einrichtungen zu treffen und Anstalten zu errichten, die der Durchführung seiner verfassungsmäßigen Aufgaben zu dienen bestimmt sind. So Art. 10 des Entwurfs des Vereins Recht und Wirtschaft. 
wohner eine Stimme entfallen; ein Überschuß von mehr als einer halben wird einer vollen Million gleichgerechnet. Um auf die Kleinstaaten einen Druck zum Zusammenschlusse auszuüben, wird vorgeschrieben, daß Gliedstaaten von weniger als einer Million Einwohner nur dann eine Stimme führen dürfen, wenn durch Reichsgesetz anerkannt wird, daß überwiegende wirtschaftliche Gründe eine besondere Vertretung erfordern. (Hier weicht der Staatenausschuß ab; er will, daß das Minimum auf eine halbe Million herabgesetzt werde, und er verlangt außerdem, daß Staaten mit mehr als einer Million Einwohner ebenfalls nicht weniger Stimmen erhalten, als ihnen nach der früheren Reichsverfassung zustehen würden.) Um zu verhüten, daß Preußen, seiner überragenden Größe entsprechend, die absolute Mehrheit im Reichsrate gewinne, ist vorgesehen, daß kein Einzelstaat mehr als ein Drittel der sämtlichen Stimmen bekommen dürfe; nimmt man also zum Beispiel die Gesamtstimmenzahl mit 60 an, so würden auf Preußen nur 20 Stimmen entfallen. Umgekehrt mußte dafür gesorgt werden, daß Preußen nicht zu kurz kommt, wenn sich durch Wegfall von Stimmen das Verhältnis verschiebt. Es könnte sich ja ereignen, daß sich norddeutsche Kleinstaaten mit Preußen vereinigen; dadurch würde die Gesamtstimmenzahl und mit ihr das für Preußen festgesetzte Maximum heruntergehen, Preußen würde also Stimmen einbüßen, obwohl sich seine Bevölkerung um Millionen vermehrte. Daher wird bestimmt, $\mathrm{da}$, falls die Stimmenzahl Preußens unter achtzehn sinkt (d. h. unter die von ihm jetzt geführten siebzehn zuzüglich der mitverwalteten Waldeckschen Stimme), das Stimmenverhältnis im Wege der Verfassungsänderung neu geregelt werden solle. Alles das soll freilich erst nach drei Jahren vom Inkrafttreten der Verfassung an in Wirksamkeit treten. Bis dahin ist eine vorläufige Ordnung vorgesehen, auf deren Einzelheiten wir nicht eingehen wollen.

Ist hiernach der in Aussicht genommene Reichsrat zunächst im großen und ganzen nach dem Muster des ehemaligen Bundesrats gebildet, so hat er im übrigen in Beziehung auf Organisation und Kompetenzen eine Gestalt empfangen, die von der seines Vorläufers ganz wesentlich abweicht. Der Entwurf macht den eigenartigen Versuch, dem Reichsrate eine Mittelstellung zwischen Regierungskollegium und parlamentarischem Oberhause anzuweisen, sucht also zwischen den beiden gegensätzlichen Konstruktionen, Bundesrat und Staatenhaus, einen Kompromiß zu schließen. Der Versuch scheint mir nicht geglückt zu sein.

Der Entwurf bestimmt zunächst überraschender Weise, daß die Mitglieder des Reichsrats, also die Delegierten der einzelstaatlichen Regierungen, anders als die Bevollmächtigten zum einstigen Bundesrate, an Weisungen 
nicht gebunden sein, daß sie also ihre Stimmen nach eigener freier Überzeugung abgeben sollen (Art. 21). Allein das ist doch offenbar nur eine Maske, die der neuen Einrichtung gewissen populären Anschauungen zuliebe vorgebunden wird. Denn die Regierungen haben es in der Hand, die ihnen nicht willfährigen Vertreter nach Gefallen abzurufen; es kann also mit der Abstimmungsfreiheit der Delegierten von vornherein nicht weit her sein. Außerdem werden im Reichsrate zum einen Teile leitende Regierungsmänner der Einzelstaaten, also Führer der herrschenden parlamentarischen Parteien, zum anderen Teile, wie bisher, hohe Regierungsbeamte sitzen, und es versteht sich von selbst, daß jene auf die Wünsche ihrer Parteien, diese auf die Wünsche der Ressorts, denen sie entstammen, eingeschworen sind. Vor allem aber sagt der Entwurf, daß, genau wie im Bundesrate der alten Verfassung, die Stimmen des Gliedstaats nur einheitlich abgegeben werden dürfen; in den Ausschüssen führt ohnehin ,jeder stimmberechtigte Gliedstaat" nur eine Stimme. Damit ist aber das Verbot des imperativen Mandats zu völliger Wirkungslosigkeit verurteilt. Man fragt sich vergebens, wie es achtzehn preußische Delegierte - denn jeder Staat darf so viele Vertreter entsenden, wie er Stimmen besitzt - fertig bringen sollen, nach eigener Überzeugung zu stimmen, wenn die Stimmen nur einheitlich abgegeben werden können! Auch ein anderes Zugeständnis an populäre Forderungen wird sich als eine papierene Dekoration erweisen: die Vorschrift, daß die Vollsitzungen des Reichsrats, von Ausnahmefällen abgesehen, ö f e e $\mathrm{t}$ l i c h sein sollen (Art. 23). Da die Hauptarbeit des Reichsrats, wie die des Bundesrats, in den Ausschüssen geleistet werden wird, da sich die Plenarversammlungen auf Abstimmungen und auf kurze Begründungen der Stimmenabgabe beschränken werden, so wird die Öffentlichkeit der Verhandlungen dem Publikum nicht eben viel nützen. Dieses wird von der Tätigkeit der Körperschaft und ihrer Mitglieder schließlich nicht mehr erfahren, als ihm auch ohnedies durch Zeitungsberichte und durch Regierungserklärungen in den Landtagen zu Ohren kommen würde.

Das Unternehmen, den Reichsrat auf der einen Seite zu einer Repräsentation der Landesregierungen zu machen, ihm auf der anderen Seite das Aussehen einer frei beschließenden und öffentlich verhandelnden parlamentarischen Körperschaft zu geben, mußte also von Anfang an zu einer Halbheit führen. Das Geschöpf ist nicht recht Fisch und nicht recht Fleisch geworden. Dies ungünstige Urteil wird aber noch verstärkt, wenn man die Zuständigkeiten betrachtet, die für den Reichsrat in Aussicht genommen sind. 
In erster Linie ist dem Reichsrate ein gemessener Anteil an der Reichsverwaltung zugedacht. Das ist zu begrüßen. Wie bisher, so soll auch in Zukunft die Geschäftskunde und die Geschicklichkeit des Landesbeamtentums in den Dienst des Reichs gestellt und damit der Mangel ausgeglichen werden, der einer Reichsbureaukratie immer anhaften muß, daß sie nämlich außer Fühlung steht mit der Verwaltung der Einzelstaaten, namentlich mit der der mittleren und unteren Instanzen. Aber freilich, die zentrale Stellung, die der ehemalige Bundesrat in der Reichsverwaltung einnahm, wird dem Reichsrate vom Entwurfe nicht eingeräumt. Aus dem Verfahren der Reichsaufsicht ist er, vom Eisenbahnwesen abgesehen (s. oben), entfernt worden. Mit Recht: denn die Erfahrungen, die man hierin mit dem Bundesrate gemacht hat, locken nicht zur Nachahmung. Die richterlichen Befugnisse des Bundesrats sollen nicht auf den Reichsrat übergehen. Wiederum mit Recht; denn für die richterliche Tätigkeit ist ein Kollegium von Regierungsdelegierten, die in der Hauptsache nach Instruktionen stimmen und außerdem bei der Entscheidung mit verschiedenem Stimmgewichte mitwirken, so ungeeignet wie möglich. Selbständige Verwaltungsbefugnisse sind dem Reichsrate nur im Bereiche des Eisenbahnwesens zugewiesen; er soll zum Beispiel über die Errichtung von Eisenbahnbeiräten „Anordnungen“ treffen (Art. 93) und durch seinen Eisenbahnausschuß die Notstandstarife festsetzen lassen (Art. 99). Im übrigen aber ist er auf Rechte der Zustimmung, der Beratung, der Auskunftseinholung beschränkt. Die Ausführungsverordnungen zu Reichsgesetzen, also auch die Verwaltungsvorschriften, erläßt nicht der Reichsrat, sondern mit seiner Zustimmung die Reichsregierung (Art. 27, Abs. 1). Das gleiche gilt für sämtliche Verordnungen im Gebiete des Post- und Telegraphenwesens (Art. 86) und für die Verordnungen, die den Bau, Betrieb und Verkehr der Eisenbahnen regeln (Art. 89). Über die Führung der Reichsgeschäfte ist der Reichsrat von den Reichsministerien „auf dem Laufenden zu halten“; seine Ausschüsse sollen zu „Beratungen“ über „wichtige“ Gegenstände zugezogen werden (Art. 27, Abs. 2). Nur im Gebiete des Etatwesens ist seine Stellung gehobener. Beschließt der Reichstag Ausgaben, die im Entwurfe des Haushaltsplans nicht vorgesehen sind, oder Erhöhungen dort vorgesehener Ausgaben, so können diese vom Reichsrate „endgültig“ wieder abgesetzt werden. Auch ist nicht nur dem Reichstage, sondern auch dem Reichsrate vom Reichsfinanzminister über die Verwendung der Einnahmen des Reiches Rechnung zu legen (Art. 82, Abs. 4; 84).

Auch im Verfahren der Reichsgesetzgebung ist der Reichsrat beträchtlich unter die Stellung gedrückt worden, die der einstige Bundesrat eingenommen hatte. Die Gesetzesinitiative (Art. 24) ist grundsätzlich in 
die Hand der Reichsregierung gelegt. Allerdings bedarf diese, sagt der Entwurf, der Zustimmung des Reichsrats, ehe sie dem Reichstage eine Gesetzesvorlage macht. Aber wenn sie diese Zustimmung nicht erlangt, so darf sie ihre Vorlage gleichwohl an den Reichstag bringen, nur muß sie dabei die abweichende Auffassung des Reichsrats darlegen. Das heißt auf deutsch: sie bedarf der Zustimmung des Reichsrates nicht. Auch der Reichsrat kann eine Gesetzesvorlage beschließen, und die Regierung muß sie, auch wenn sie ihr nicht zuzustimmen vermag, beim Reichstage einbringen, kann dabei indes ihren abweichenden Standpunkt darlegen. Allein da die Regierung dem Reichsrate nicht verantwortlich ist, so ist die Vorschrift eine lex imperfecta; auch werden der Natur der Dinge nach Originalentwürfe nur ganz selten aus dem Schoße des Reichsrats entspringen.

Die Hauptsache ist, daß der Reichsrat das wichtigste Recht des Bundesrats, die $S$ a n ktio on der Reichsgesetze, nicht besitzen soll. Er ist darauf beschränkt, gegen die vom Reichstage beschlossenen Gesetze unter Angabe der Gründe Einspruch zu erheben (Art. 26). Dazu steht ihm die reichlich knapp bemessene Frist von zwei Wochen zur Verfügung. Die Folge des Einspruchs ist, daß das Gesetz dem Reichstage zur nochmaligen Beratung vorgelegt wird. Bequemt sich der Reichstag dem Standpunkte des Reichsrats an, so ist die Sache in Ordnung. Im entgegengesetzten Falle stellt die Verfassung ausdrücklich zwei Wege zur Verfügung: Entweder kann der Reichspräsident über den Gegenstand der Meinungsverschiedenheit eine Volksabstimmung herbeiführen. Oder aber er kann das Gesetz in der vom Reichstage beschlossenen Fassung verkünden; das hat aber zur Voraussetzung, daß das Gesetz im Reichstage die für Verfassungsänderungen vorgesehene Mehrheit gefunden hat ${ }^{33}$. Der dritte Weg, daß nämlich der Reichspräsident, weil er den Einspruch für beachtenswert hält, die

33 Aus dem Entwurfe geht nicht mit voller Klarheit hervor, daß das alles auch für Verfassungsänderungen gelten soll. Von Haus aus ist dies natürlich anzunehmen. Denn Verfassungsänderungen sind „vom Reichstag beschlossene Gesetze“. Aber in Art. 23, Abs. 4 heißt es, bei Verfassungsänderungen sei im Reichsrate die „Zustimmung“ von zwei Dritteln der abgegebenen Stimmen erforderlich. Das könnte so ausgelegt werden, daß der Reichsrat bei Verfassungsänderungen nicht bloß das Recht des Einspruchs, sondern das Recht der Zustimmung besitze. Indes scheint dies nicht die Meinung zu sein. Dann besagt also Art. 23, Abs. 4: wenn der Reichsrat über eine vom Reichstage beschlossene Verfassungsänderung berät, so ist eine Mehrheit von zwei Dritteln für den Beschluß erforderlich, keinen Einspruch zu erheben. Anders ausgedrückt: es genügt zu einem Einspruchsbeschlusse die Erklärung von mehr als einem Drittel der Stimmen. - Da der Reichstag in solchem Falle bei seinem ersten Beschlusse ohnehin nur mit der für Verfassungsänderungen vorgesehenen Majorität stehen bleiben kann, so ist der Reichspräsi- 
Vorlage unter den Tisch fallen läßt, ist im Entwurfe nicht erwähnt, muß jedoch nach der Fassung als zulässig angesehen werden. Tatsächlich wird dieser Weg wahrscheinlich nur bei Gesetzen von geringerer Tragweite betreten werden, bei denen man sich scheut, den großen Apparat der Volksabstimmung in Bewegung zu setzen. Im übrigen aber wird der vermöge des parlamentarischen Systems vom Reichstage abhängige Reichspräsident kein Ministerium finden, das die Verantwortung dafür übernimmt, daß der in entschiedener Form vom Reichstage ausgesprochene Wille unbeachtet bleibt.

Nach alledem ist die dem Reichsrate zugedachte Rolle gewiß nicht glänzend. Von der großen autoritativen, entscheidenden Stellung, die der Bundesrat im Verfassungsleben des Reiches einnahm, ist nur ein schwacher Schatten übriggeblieben. Der Reichsrat wird wesentlich „negative“ Funktionen erfüllen; er wird nur der Hemmschuh am Reichswagen sein, um deswillen vermutlich noch geringere Popularität genießen als der vormalige Bundesrat. Auf dem Theater der großen Reichspolitik wird er nur als Nebenfigur erscheinen. Daß seine Mitglieder im Reichstage den Standpunkt ihrer Regierungen zu dem Gegenstande der Verhandlung vertreten dürfen und deshalb auf Verlangen jederzeit gehört werden müssen (Art. 25), und daß er selber die Berufung des Reichstags verlangen kann (Art. 45, Abs. 2), ändert daran nicht viel. Es kann kein Zweifel sein, daß die Einzelstaaten mit dem „Staatenhause“ weit besser fahren würden als mit dem Reichsrate in der vom Entwurfe gewählten Form. Und dies, obwohl, ja gerade weil ein solches Staatenhaus die erste Kammer eines Parlamentes bilden müßte. Gewiß können in dieser die „Vertreter“ der Einzelstaaten niemals mit Anweisungen versehen werden. Aber sie sind doch berufen und in der Lage, die Interessen des Partikularstaats, aus dem sie kommen, mit nicht geringerer Wucht zur Geltung zu bringen als instruierte Bevollmächtigte, zumal wenn das in den Einzelstaaten herrschende parlamentarische System dazu führt, daß die Landtage Führer und Mitglieder der großen Landesparteien in das Staatenhaus entsenden. Das Gewicht der partikularen Interessen kommt im Staatenhause viel besser als in einem Reichsrate zur Anerkennung, weil das Staatenhaus als ein mit dem Volkshause gleichberechtigtes Glied des Gesamtparlaments in vollem Maße an dessen Souveränität Anteil nimmt. Nur müßte freilich das Staatenhaus besser, als es der Preußsche Entwurf getan hatte, in Zusammenhang mit

dent nach Art. 26, Abs. 3 berechtigt, die Verfassungsänderung ohne Volksabstimmung zu verkünden. Man sollte jedoch meinen, daß hier eine Volksabstimmung unter allen Umständen vorgenommen werden müßte. 
der politischen Struktur der Einzelstaaten gebracht und unabhängiger von der Exekutive gestellt werden als das Volkshaus. Man müßte es von den Landtagen nach den Grundsätzen der Verhältniswahl wählen und die Wahlen bei jeder Erneuerung der Landtage wiederholen lassen; die Legislaturperiode des Volkshauses dürfte also nicht auch für das Staatenhaus Geltung erhalten. Auch sollte das Staatenhaus der Auflösungsbefugnis des Reichspräsidenten nicht unterworfen $\operatorname{sein}^{34}$. Den partikularen Interessen könnte daneben noch dadurch Rechnung getragen werden, daß man die Zustimmung des Staatenhauses zu solchen Verwaltungsverordnungen der Reichsregierung forderte, die sich an die Landesbehörden richten, und daß man ihm das Recht der Zustimmung oder gar des Vorschlags bei der Ernennung solcher Reichsbeamten einräumte, die im Gebiete der Einzelstaaten Funktionen ausüben ${ }^{35}$. Auch würde nichts im Wege stehen, den Einzelstaaten unmittelbar ein Initiativrecht bei der Gesetzgebung und wenigstens bei Verfassungsänderungen die Möglichkeit zu gewähren, Einspruch $\mathrm{zu}$ erheben und dadurch eine Volksabstimmung zu provozieren ${ }^{36}$; des Umwegs über einen Reichsrat bedarf es hierfür nicht. Als Ersatz für diesen würden die von den Landesregierungen gebildeten „Reichsausschüsse“ bei den Reichsministerien vollauf genügen (siehe oben).

Die Einrichtung des Reichsrats, wie ihn der Entwurf in Auge gefaßt hat, kommt also in mancher Hinsicht den unitarischen Tendenzen weiter entgegen als den föderalistischen. Und dennoch wird sie, wie wir glauben, auf der anderen Seite wieder die partikularistischen Strömungen im Reiche in sehr unerwünschter Weise verstärken. Weit mehr, als es der frühere Bundesrat getan hat. Denn dieser Bundesrat war doch keineswegs bloß ein Instrument des deutschen Föderalismus. Er war vor allem eines der Mittel, mit dem die preußische Hegemonie zu arbeiten in der Lage war, und diese Hegemonie war im Grunde eines der unitarischen Elemente im Reiche ${ }^{37}$. Im künftigen Reiche ist es damit vorbei; im Reichsrate wird es an einem Staate fehlen, der vermöge seines politischen Schwergewichts den Mittel-

34 Vgl. den Entwurf des Vereins Recht und Wirtschaft, Art. 115, 102. - Um die Landtage der großen Einzelstaaten nicht zu sehr zu bevorzugen, wird hier vorgeschlagen, daß kein Landtag mehr als ein Viertel der Mitglieder des Staatenhauses sollte wählen dürfen. Die übrigen, die nach dem Schlüssel (ein Abgeordneter für je 500000 Einwohner, mindestens aber zwei Abgeordnete) auf den Staat entfallen, sollen von den Vertretungen der Provinzen oder Länder (Österreich) gewählt werden. Das hätte mannigfache Vorteile.

35 Vgl. ebenda Art. 105, 107.

36 Vgl. ebenda Art. 103, 148.

37 Siehe meinen Unitarismus und Föderalismus, S. $111 \mathrm{ff}$. 
punkt für eine feste und dauernde Mehrheitsbildung abgeben kann. Dazu kommt, daß in den Einzelstaaten bisher keine parlamentarische Regierungsweise herrschte. Die Regierungen waren von ihren Landtagen verhältnismäßig unabhängig; sie konnten daher mit Leichtigkeit im Bundesrate Kompromisse eingehen, ohne sich groß fürchten zu müssen, daß ihre Landtage sie dafür zur Rechenschaft ziehen würden. In Zukunft werden die Mitglieder des Reichsrats die Knechte ihrer heimatlichen Landtage sein. Die Neigung zu Vergleichen innerhalb des Reichsrats wird dadurch auf ein höchst geringes Maß herabgedrückt werden, um so mehr als mit dem Sturze der Dynastien und dem Aufbau des Reichs auf der Volkssouveränität das ausgleichende Moment der fürstlichen „Vertragstreue“ geschwunden ist. Während im Bundesrate Majoritätsbeschlüsse zu den Seltenheiten gehörten, werden im Reichsrate fast immer Majorisierungen stattfinden. Und das wird aller Wahrscheinlichkeit nach zu Koalitionen zwischen Einzelstaaten führen, in denen man einen Ersatz für den mit der preußischen Hegemonie verschwundenen „Kristallisationspunkt“ der Mehrheitsbildung wird suchen wollen ${ }^{38}$. Es eröffnen sich damit sehr unerfreuliche Aussichten auf die Wiederkehr von Erscheinungen, an denen Deutschland zu den Zeiten des alten Deutschen Reichs und des Deutschen Bundes aufs schwerste gekrankt hat. So wirkt das Reichsratssystem doch schließlich nur dem Scheine nach unitarischer als das Staatenhaussystem. In Wirklichkeit öffnet es dem übelsten Partikularismus Tür und Tor. Die Aussicht, daß der Partikularismus durch einen sich entwickelnden „eidgenössischen Rechtssinn ", ${ }^{39}$ wie Treitschke das nannte, überwunden werden wird, ist in Deutschland zurzeit betrüblicherweise sehr gering.

Was die Einrichtung des Reichsrats noch weiter bedenklich erscheinen läßt, ist der Umstand, daß er die politische Stellung des Reichspräsidenten zu erschweren geeignet ist. Das führt uns aber bereits in ein anderes Kapitel hinüber.

38 Diese Dinge sind sehr einleuchtend auseinandergesetzt von E. Kaufmann im „Roten Tag“, Nr. 49 und 50 vom 9. und 11. März 1919.

39 [Heinrich v. Treitschke, Das constitutionelle Königthum in Deutschland, in: Historische und politische Aufsätze. Dritter Band: Freiheit und Königthum, 4. Aufl. Leipzig 1871, S. 604: „Seitdem hatte jener Unsinn der Kleinstaaterei sich bis zum höchsten Grade des Aberwitzes gesteigert, und weil die kleinen Höfe dies im Stillen selber fühlten, darum konnte die sittliche Grundlage des bündischen Lebens, der eidgenössische Rechtssinn, im Norddeutschen Bund nicht gedeihen. Solcher Rechtssinn lebte allerdings in der Krone Preußens."]. 
In das Zentrum der Reichsorganisation stellen die Entwürfe, der demokratischen Anlage der Verfassung entsprechend, den Reichstag als die Vertretung des souveränen Volkes. Über seine Zusammensetzung, die Gestaltung seiner inneren Ordnung, die Stellung seiner Mitglieder soll, um den Umfang dieses Aufsatzes nicht allzusehr anschwellen zu lassen, nicht ausführlich gesprochen werden. Der Erwähnung wert ist vielleicht, daß die Entwürfe die Prüfung der Wahlen und die Entscheidung über den Verlust der Reichstagsmitgliedschaft einem Wahlprüfungsgerichte anvertrauen, das sich aus Mitgliedern des Reichstags und des Reichsverwaltungsgerichts, bis zu dessen Errichtung aus Mitgliedern des Reichsgerichts, zusammensetzt. Das Gericht soll in der Besetzung von drei Abgeordneten und zwei richterlichen Mitgliedern entscheiden (Art. 51). So sehr es aus bekannten Gründen zu begrüßen ist, daß dem Reichstage als solchem die Entscheidung über die Legitimation seiner Mitglieder aus der Hand genommen wird, so bedauerlich ist es, daß man nicht ganze Arbeit getan und das Wahlprüfungsgericht ausschließlich aus Richtern gebildet hat, die dem Reichstag nicht angehören.

Von entscheidender Bedeutung für das künftige Verfassungsleben des Reichs wird es sein, in welcher Weise die Exekut ive ausgestaltet und wie ihre Beziehungen zum Träger der gesetzgebenden Gewalt, zum Reichstage, geordnet werden.

Eine ganz folgerichtig vorgehende Demokratie wird an sich immer dazu gelangen, die Leitung der vollziehenden Gewalt einem kollegialen Direktorium zu übertragen, das periodisch auf möglichst kurze Zeit von der Volksvertretung gewählt wird. Die Direktorialverfassung zur Zeit der ersten französischen Republik, die Verfassung der Schweizer Eidgenossenschaft liefern die bekanntesten Vorbilder. Die Preußsche Denkschrift erklärt mit Recht, daß dieses System für einen Großstaat und namentlich für Deutschland unbrauchbar sei. Es biete gewiß außer anderem den Vorteil, daß es eine einseitige Parteiherrschaft vermeiden lasse; denn die größeren Parteien seien in der Lage, sich über eine Verteilung der Sitze im Regierungskollegium nach dem Verhältnisse ihrer Stärke zu einigen. Aber dieser Vorzug werde leicht zum Nachteile, wenn es sich um einen Großstaat handle, da dieser „eine durch politische Homogenität in sich geschlossene und also tatkräftigere Regierung brauche." Ebenso richtig ist es, daß gerade bei uns die Vielheit der Parteien, aber auch landsmannschaftliche und konfessionelle Rücksichten die Bildung eines regierenden Direktoriums durch Wahl des Reichstags außerordentlich erschweren würden. Preuß hat 
daher vorgeschlagen, nach amerikanischem und französischem Muster an die Spitze der Republik einen R e i ch s p räside n t e n zu stellen, der seinerseits die „Regierung“ ernenne, und die anderen Entwürfe sind ihm darin gefolgt. Da sich diese in bezug auf die Stellung des Präsidenten dem Reichstage gegenüber nur in vergleichsweise geringfügigen Einzelheiten von dem Preußschen Entwurfe unterscheiden, so soll im folgenden nur auf den Entwurf letzter Fassung Rücksicht genommen werden.

Nach dem Vorbilde der Verfassung der Vereinigten Staaten soll der Präsident aus einer Volkswahl hervorgehen, und zwar soll er - hierin nach französischem Muster - auf sieben Jahre gewählt werden (Art. 61, 72). Für die Wählbarkeit wird die Vollendung des 35. Lebensjahres und deutsche Staatsangehörigkeit seit mindestens zehn Jahren verlangt. Gewählt ist, wer die absolute Mehrheit aller im Reiche abgegebenen Stimmen erlangt hat; kommt eine solche im ersten Wahlgange nicht zustande, so findet Stichwahl statt. Wiederwahl ist unbeschränkt zulässig; es ist zu erwarten, daß in dieser Beziehung politisches Taktgefühl und Praxis eine Grenze ziehen werden. Einen Vizepräsidenten im eigentlichen Sinne kennt der Entwurf nicht. Im Falle vorübergehender Verhinderung soll der Präsident durch den Reichskanzler vertreten, bei längerer Verhinderung die Vertretung durch Reichsgesetz geregelt werden; das Entsprechende soll, wenn der Präsidentenposten vorzeitig erledigt wird, bis zur Durchführung der Neuwahl gelten (Art. 71). Der Preußsche Entwurf hatte vorgeschlagen, daß der Präsident bei einer Verhinderung, die nicht länger als drei Monate dauere, durch den Präsidenten des Staatenhauses vertreten werden solle $(\mathbb{S} 66)$. Das war kein glücklicher Gedanke. Denn der Mann, den das Staatenhaus zu seinem Vorsitzenden bestimmt, wird nach ganz anderen Rücksichten ausgesucht als nach seiner Eignung für die Stellung eines Reichspräsidenten. Offenbar schwebte Preuß das amerikanische Recht vor. Aber in den Vereinigten Staaten wird der Vizepräsident vom Volke gewählt und ist kraft seiner Vizepräsidentenstellung der Vorsitzende des Senats; er ist nicht Senator, hat im Senate keine Stimme. Die Dinge liegen dort also ganz anders, und so ist die Lösung, die der neue Entwurf vorschlägt, entschieden die bessere.

Es ist zu begrüßen, daß der Entwurf die Wahl des Präsidenten in die Hand des Volks, nicht in die des Reichtags gelegt hat. Gewiß hat die Volkswahl ihre Nachteile. Bei der unseren Verhältnissen eigentümlichen Zersplitterung der Parteien wird man vermutlich sehr häufig, wenn nicht immer, zu Stichwahlen kommen, und das ist von Übel. Die Präsidentenwahlen werden ungeheuere Kosten verursachen, und das birgt Gefahren in sich. Man braucht deshalb nicht gerade zu fürchten, daß das amerikani- 
sche „Beutesystem“ bei uns Eingang finden werde; schon die Tatsache, daß die Verwaltungsämter in der Mehrzahl auch in Zukunft Landesämter sein werden, aber auch die parlamentarische Kontrolle der Stellenbesetzung würde das hindern. Allein es steht doch nun einmal so, daß für politische Zwecke große Summen in der Regel nur von Leuten gestiftet werden, die darauf zählen, bei Gelegenheit ihre Rechnung präsentieren zu können; die Folgen kann man sich leicht ausmalen. Trotz alledem sprechen ganz überwiegende Gründe dafür, den Reichspräsidenten aus einer Wahl des Volkes hervorgehen zu lassen. Will man den Präsidenten nicht zu einem Schattendasein verurteilen, will man ihm neben dem Parlamente die Möglichkeit einer wirklichen Regierung verschaffen, so muß man ihn zum Vertrauensmanne des Volkes machen. Das wird er aber selbst dann noch sein, wenn er seine Stellung nur einer Stichwahl zu verdanken hat.

Wenn nun der Entwurf durch die Einführung der „plebiszitären Reichsspitze“ den Zweck verfolgt, dem Präsidenten „die ebenbürtige Stellung neben der vom Volke unmittelbar gewählten Volksvertretung" zu verschaffen, so hat er die Erreichung dieses Zieles durch andere Mittel unmöglich gemacht, zum mindesten aufs höchste erschwert.

Das geschieht zunächst durch die im Art. 72 enthaltene Vorschrift, daß der Präsident auf Antrag des Reichstags durch eine Volksabstimmung a b gesetzt werden kann, - durch ein „Abberufungsreferendum“, wie es Max Weber ${ }^{40}$ genannt hat. Die Notwendigkeit, während seiner Amtsführung dauernd mit dieser Möglichkeit zu rechnen, bringt den Präsidenten von vornherein in fühlbare Abhängigkeit von der Körperschaft, von der der Absetzungsantrag auszugehen hat; daß der Antrag mit der für Verfassungsänderungen erforderlichen Mehrheit beschlossen werden muß, ändert daran etwas, aber nicht viel. Der Präsident steht also ständig unter parlamentarischem Drucke, und wird außerdem, um auf alle Eventualitäten gefaßt zu sein, von Anfang an zu einer unwürdigen Popularitätshascherei neigen. Nötig ist das Absetzungsreferendum schwerlich. Sollte sich der Reichspräsident einer Verfassungsverletzung schuldig machen, so kann ihn der Reichstag vor dem Staatsgerichtshofe anklagen, - selbstverständlich zu dem Zwecke, seine Amtsenthebung herbeizuführen (Art. 79) ${ }^{41}$. An Stelle der Entscheidung durch den unparteiischen Gerichtshof einen Os-

40 [Max Weber, Deutschlands künftige Staatsform, 1918, in: ders., Gesammelte Politische Schriften, hrsg. Johannes Winckelmann, 4. Aufl. Tübingen 1980, S. 470].

41 Der Entwurf sieht sogar die Möglichkeit einer Anklage wegen Verletzung einfacher Gesetze vor. Das ist bedenklich. Wie leicht läßt sich behaupten, daß von der Regierung ein Gesetz „verletzt“ worden sei! 
trazismus zu setzen, wäre in höchstem Grade anstößig. Macht sich etwa einmal die Entfernung des Präsidenten wegen unwürdiger Lebensführung notwendig, so gibt es Mittel genug, um ihn zur Abdankung zu veranlassen. Aber für alle diese Fälle ist das Abberufungsreferendum auch gar nicht in Aussicht genommen. Es ist gedacht als ein Mittel, um für politische Differenzen zwischen dem Präsidenten und dem Parlamente oder dessen Vertrauensmännern, den Ministern, einen Ausgleich zu schaffen. In Fällen eines schweren Konflikts soll die Volksabstimmung zeigen, ob der Reichspräsident oder ob der Reichstag der Stärkere ist. Entscheidet sich das Volk für den Präsidenten, so gilt das als Neuwahl ${ }^{42}$ und zieht, wie der Entwurf des Staatenausschusses folgerichtig hinzugesetzt hat, die Auflösung des Reichstags von Rechts wegen nach sich. Es steht indes zu vermuten, daß es der Präsident in den meisten Fällen auf die Volksabstimmung nicht wird ankommen lassen, sondern daß ihn schon die Drohung mit einer solchen veranlassen wird, sich dem Reichstage gefügig zu zeigen. Die ganze Einrichtung ist also nicht geeignet, die „Ebenbürtigkeit“ zwischen Präsident und Parlament zu sichern. Man wird einwenden, das Recht des Reichstags, das Absetzungsreferendum zu beantragen, entspreche dem Rechte des Präsidenten, durch die Auflösung des Reichstags an das Volk zu appellieren. Allein der wesentliche Unterschied besteht darin, daß der Präsident die Auflösung des Reichstags nur unter Gegenzeichnung des Ministeriums, also überhaupt nicht vornehmen kann, solange das Ministerium der Mehrheit des Reichstags entnommen ist, während das Parlament bei seinem Antrage auf Absetzung an keine anderen als an formale Erfordernisse gebunden ist.

Das hängt ja nun alles damit zusammen, daß der Entwurf das System der parlamentarischen Regierung in voller Schärfe durchgeführt hat. Alle „zivilen und militärischen“ Anordnungen und Verfügungen des Reichspräsidenten bedürfen zu ihrer Gültigkeit der Gegenzeichnung durch den Reichskanzler oder einen Reichsminister, der dadurch die Verantwortlichkeit übernimmt (Art. 70). Allerdings ist es nicht notwendig, daß das Ministerium durchweg aus Mitgliedern des Reichstags besteht. Aber der Reichskanzler und sämtliche Reichsminister bedürfen zu ihrer

42 Also wieder auf sieben Jahre. Das verwickelt die Angelegenheit ganz merkwürdig. Das Referendum verhilft vielleicht einem Präsidenten, der sonst nicht wiedergewählt worden wäre, zu einem second oder third term. Es nötigt ihn unter Umständen zur Agitation für eine Wiederwahl, die er sonst gar nicht angestrebt hätte. In jedem Falle verquickt es bei dem der Volksabstimmung vorangehenden Kampfe zwei Gesichtspunkte, die gar nichts miteinander zu tun haben sollten. 
Amtsführung des Vertrauens des Reichstags und müssen zurücktreten, wenn ihnen dieser sein Vertrauen durch einen ausdrücklichen Beschluß entzieht (Art.76). Und zwar trägt der Reichskanzler die Verantwortung nur für die Richtlinien der Reichspolitik, jeder Ressortminister „selbständig“ die Verantwortung für die Leitung seines Geschäftszweigs (Art. 77). Es gibt folglich keine solidarische Verantwortlichkeit des Kabinetts; weder der Reichskanzler noch der ganze Ministerrat sind zum Rücktritte genötigt, wenn das Parlament seine Unzufriedenheit mit einem einzelnen Minister bekundet. Aber gerade indem die besondere Verantwortlichkeit jedes Einzelministers in dieser Weise betont wird, erhält der Einfluß des Reichstags auf den Gang der Verwaltung eine besondere Stärke.

Die Stellung des Reichspräsidenten ist bei diesem System eine durchaus magere. Er ist auf Schritt und Tritt an die jeweilige Reichstagsmehrheit gefesselt. Alle Kompetenzen der Exekutive, die ihm die Verfassung zuweist völkerrechtliche Vertretung, militärischer Oberbefehl, Reichsexekution, Beamtenernennung, Begnadigung - können nur unter schärfster Parlamentskontrolle ausgeübt werden. Auf großen und wichtigen Gebieten wird der Einfluß des Reichstags ohnehin dadurch gesichert, daß Akte der vollziehenden Gewalt entweder an seine Genehmigung gebunden sind (Abschluß von Staatsverträgen, die sich auf Gegenstände der Gesetzgebung beziehen, Maßregeln zur Herstellung der gefährdeten Sicherheit und Ordnung, insbesondere Erklärung des Ausnahmezustandes), oder daß sie sogar in der Form des Gesetzes erfolgen müssen, wie Kriegserklärung und Friedensschluß oder der Erlaß von Amnestien (Art. 63, 65-69). Bei der Gesetzgebung hat der Präsident nicht einmal der Form nach das Recht der Initiative; denn die Gesetze werden beim Reichstage von der „Reichsregierung“ eingebracht (Art. 24), und diese besteht aus dem Reichskanzler und den Reichsministern (Art. 74). Gegenüber den vom Reichstage beschlossenen Gesetzen hat der Präsident kein Veto, auch kein suspensives, nicht einmal das Recht der Beanstandung ${ }^{43}$. Vielmehr ist er verpflichtet, die verfassungsmäßig zustande gekommenen Gesetze auszufertigen und binnen Monatsfrist zu verkündigen (Art. 64). Die Prärogative der Einberufung des Reichstags wird durch das diesem zugestandene Selbstversammlungsrecht (Art. 45) auf außergewöhnliche Fälle beschränkt. Die Befugnis, den Reichstag aufzulösen, ist dem Reichspräsidenten eingeräumt, aber er kann davon nur einmal aus dem gleichen Anlasse Gebrauch machen (Art. 47), und da

43 Ursprünglich scheint die Absicht bestanden zu haben, ihm ein solches Recht einzuräumen. Die Preußsche Denkschrift behauptete, es stehe im Entwurfe drin (S. 14). Dort findet sich aber kein Wort davon. 
die Auflösungsorder die Gegenzeichnung des Reichskanzlers tragen muß, so wird das Recht nur ausnahmsweise und jedenfalls nur in dem Falle praktisch werden, in dem ein in die Minderheit gedrängtes Parteiministerium den Versuch wagen will, die Karte der Volksabstimmung gegen die Parlamentsmehrheit auszuspielen ${ }^{44}$. Die Dinge werden sich also bei uns genau so entwickeln wie in Frankreich; dort hat es der Präsident seit dem Jahre 1877 noch niemals gewagt, die Deputiertenkammer aufzulösen.

In dem Streit über die Vorzüge und Fehler des parlamentarischen Regierungssystems sind die Akten noch längst nicht geschlossen. In ausführlicher Weise zu der Frage Stellung zu nehmen, ist hier nicht möglich; das würde eine Abhandlung für sich erfordern. Der Verfasser dieses Aufsatzes hat sich niemals davon überzeugen können, daß das System innerlich begründet oder gar notwendig sei, und er kann auch die Darlegungen der Preußschen Denkschrift über die Nachteile der amerikanischen Einrichtungen, die bekanntlich nichts von Parlaments- und Kabinettsregierung kennen, keineswegs überzeugend finden. Daß das deutsche Parteiwesen mit seiner kaum sehr bald zu beseitigenden Zersplitterung dem parlamentarischen System die größten Schwierigkeiten bereiten wird, kann im Ernste nicht geleugnet werden. Mit einem sozialistischem Staatswesen und mit großen Monopolverwaltungen, die einen von parlamentarischen Machtverschiebungen abhängigen Wechsel der Verwaltungsgrundsätze schlechterdings nicht vertragen, ist die Einrichtung besonders schwer in Einklang zu setzen. Es ist bezeichnend, daß sich kürzlich die Sozialistische Korrespondenz sehr deutlich dagegen ausgesprochen und die Einführung des amerikanischen Systems empfohlen hat. Die Demokratie als solche braucht sich jedenfalls, wie das transatlantische Beispiel zeigt, nicht notwendig auf die parlamentarische Regierung einzuschwören. Der Freiheit des Bürgers kommt es zugute, wenn zwischen Legislative und Exekutive deutliche Trennstriche gezogen sind; Konflikte zwischen beiden können teils durch das über beiden stehende souveräne Volk, teils durch die richterliche Gewalt geschlichtet werden. Wie sich freilich die Verhältnisse bei uns schon vor der Revolution entwickelt haben, ist zu vermuten, daß die Gegner der parlamentarischen Regierung tauben Ohren predigen. Über

44 Nach dem Preußschen Entwurfe war ein Appell an das Volk außerdem noch möglich, wenn zwischen Staatenhaus und Volkshaus über eine Gesetzesvorlage keine Übereinstimmung zu erzielen war (vgl. $\$ 60$, Abs. 2. - Die weitergehende Behauptung der Denkschrift war wiederum falsch). Aber auch das wäre natürlich nur praktisch, wenn der Widerstand beim Staatenhause liegt; einem obstruierenden Volkshause gegenüber würde der Präsident das Ministerium im Regelfalle nicht dazu bringen, den Aufruf ans Volk gegenzuzeichnen. 
eins aber muß sich jeder klar sein: daß mit der Einführung der Parlamentsregierung für den „starken Präsidenten“, den sich heute auch demokratische Kreise des Volkes wünschen, der Weg verschlossen ist. Will man den Präsidenten zu mehr machen als zu einem repräsentativen Dekorationsstück, so muß man ihm zum mindesten das Recht geben, Gesetzesbeschlüsse des Parlaments zu beanstanden, und muß diese Beanstandung von dem Erfordernisse der ministeriellen Gegenzeichnung befreien. Unter allen Umständen muß aber dem Reichspräsidenten die Auflösung des Reichstags ohne ministerielle Kontrasignatur ermöglicht werden ${ }^{45}$. Der Präsident soll nicht nur der Vertrauensmann des Volkes sein, er soll auch die Möglichkeit haben, sich auf das Volk, das ihn gewählt hat, zu stützen. Diese Möglichkeit hat er aber nur dann, wenn ihm bei einem Konflikt mit dem Parlamente der Weg zur Befragung des Volkes unversperrt bleibt.

Denn auf welche Elemente wird sich der Präsident im übrigen stützen können? Auf den Reichsrat doch gewiß nicht. Die Reichsregierung hat zwar im Reichsrate den Vorsitz, sie hat das Recht, an seinen Beratungen teilzunehmen, kann Anträge in ihm stellen (Artikel 22, 23). Aber ein wirksamer Einfluß auf ihn steht ihr nicht zu Gebote. Sie wird Kompromisse mit ihm zu schließen suchen, aber sie besitzt keine Möglichkeit, einen Druck auf ihn auszuüben. Umgekehrt ist der Reichsrat in der Lage, der Regierung durch Versagung der Zustimmung zu Verordnungen, zur Einbringung von Gesetzesentwürfen und durch Einspruch gegen Reichstagsbeschlüsse fort und fort Steine in den Weg zu werfen. Wird dem Präsidenten nicht die weiteste Möglichkeit geboten, in großen Fragen des politischen Lebens die letzte Entscheidung in die Hand des Volkes zu legen, so wird er bei jener Sachlage ohne weiteres dazu gedrängt, seine ganze Stütze im Reichstage zu suchen. Und damit ist seine Abhängigkeit von diesem besiegelt.

Der Nationalversammlung ist mit der Aufgabe, dem Reiche eine neue Verfassung zu geben, eine Last von Riesenschwere aufgebürdet. Möchte es ihr beschieden sein, die schwierigen Fragen, die sich ihr dabei auf Schritt und Tritt entgegenstellen, so zu lösen, daß dem deutschen Volke Segen daraus erwächst. Möchte sie sich bewußt bleiben, daß sie nicht nur für die Freiheit der Deutschen, sondern auch für die Macht des Reichs zu sorgen verpflichtet ist. In der Stunde, da wir diesen Aufsatz abschließen, ist die

45 Beides schlägt der Entwurf des Vereins Recht und Wirtschaft vor (Art. 99, Abs. 3). Dort wird auch die Anordnung einer Volksabstimmung bei Differenzen zwischen Staaten- und Volkshaus über Gesetzesvorlagen als nicht kontrasignaturbedürftig bezeichnet. 
Nationalversammlung von Gefahren bedroht, die uns die angstvolle Frage aufdrängen, ob es ihr wirklich gelingen wird, das Werk, das sie begonnen, zum Abschlusse zu bringen. Wir geben die Hoffnung nicht auf. Aber freilich, die Wirrnisse, in denen sich Reich und Volk in dieser wilden Zeit befinden, bestätigen den alten Erfahrungssatz, daß mit geschriebenen Artikeln einer Verfassungsurkunde noch nicht viel getan ist. Eine Verfassung wird erst dann lebendig, wenn sie sich stützt auf die Kräfte einer staatstreuen, pflichtbewußten und energischen Verwaltung und auf den Rechtssinn des Volkes. Was wir von beidem in der jüngsten Vergangenheit zu unserm Unglück verloren haben, - möchte es uns eine nicht zu ferne Zukunft wiederbringen!

B e r 1 i n, Ende Februar 1919. 
Teil II: Krisenbefund 1923/24 


\section{Text 7 \\ Die Krisis des Parlamentarismus in der Welt ${ }^{1}$}

In einem belehrenden Aufsatze über den Fascismus, den Konsul M. Immelen im letzten Heft der „Zeitschrift für Politik“2 veröffentlicht hat, heißt es am Schlusse, es sei verfehlt, zwischen dem italienischen Fascismus und den ihm äußerlich ähnlichen Bewegungen bei anderen Völkern Vergleiche zu ziehen. Der Fascismus sei ein rein italienisches Gewächs, für dessen Gedeihen anderswo alle psychologischen und materiellen Voraussetzungen fehlen würden. Das genaue Gegenteil behauptet M. W. Fodor ${ }^{3}$ in einem Artikel der „The Nation“, dem er den bezeichnenden Titel „Der Tod der Parlamente" gegeben hat. Der italienische Fascismus, sagt er, sei keine Einzelerscheinung. Vielmehr lasse sich in ganz Mittel- und Südosteuropa eine allgemeine „Revolte“ gegen den Parlamentarismus beobachten, die zwar von verschiedenen gesellschaftlichen Schichten geleitet werde, aber doch überall in dem einen sich gleich sei, dass sie die Bildung einer aus freien Wahlen des Volks hervorgehenden Repräsentation durch Mittel der Gewalt verhindere oder zu verhindern drohe, oder die doch das Parlament zum Diener einer brutalen Diktatur erniedrige. Das gegenwärtige Regime in Ungarn, in Jugoslawien, in Bulgarien, die Sowjetregierung in Russland wird mit der Herrschaft Mussolinis, die Nationalsozialisten in Bayern, die tschechischen Legionäre und die „Erwachenden Ungarn“ werden mit den Fascisten auf die gleiche Linie gestellt.

Es ist klar, daß der Verfasser hier vielerlei zusammengeworfen hat, was innerlich nicht zusammengehört. Die antiparlamentarische Diktatur der

1 [Deutsche Allgemeine Zeitung. Reichsausgabe 62 (1923), Nr. 184/185, S. 1-2; am 22. April 1923, als Triepels Artikel erschien, regierte Wilhelm Cuno als parteiloser Kanzler ein Minderheitskabinett bürgerlicher Mitte (DDP, DVP, Zentrum, BVP). Die politische Lage war stark vom „Ruhrkampf“ und der Beschleunigung der Inflation bestimmt. Im August 1923 folgte eine „Große Koalition“ unter Stresemann. Triepel argumentiert aber nicht innenpolitisch, sondern konstatiert einen allgemeinen Legitimitätsverlust des liberalen Parlamentarismus durch die Entwicklung zum Parteienstaat.].

2 [M. Immelen, Der Faszismus, in: Zeitschrift für Politik 12 (1923), S. 435-455].

3 [Marcel William Fodor, The Death of the Parliaments, in: The Nation, v. 14. März 1923, S. 298 f]. 
Lenin, Pasitsch ${ }^{4}$ und Mussolini stimmt weder in den Mitteln, noch in den Zielen überein, geschweige denn, daß sie auf dem gleichen politischen und sozialen Boden erwachsen wäre. Aber freilich lässt sich nicht leugnen, dass der Parlamentarismus in der Form und mit dem Inhalte, wie ihn der europäische Kontinent nach westlichen Vorbildern geschaffen hat, in einem großen Teile Europas zerstört oder zur Bedeutungslosigkeit verurteilt worden ist. Und ebenso sicher ist es, daß sich in anderen Ländern das parlamentarische System einer offenen Feindschaft ausgesetzt sieht, der es da oder dort vielleicht schon erlegen wäre, wenn nicht seine Gegner auch untereinander in erbitterter Fehde lägen. Der Parlamentarismus hält sich manchmal nur deshalb, weil der Angriff von der einen Seite nicht nur als Angriff auf das Parlament, sondern zugleich als Angriff auf die andere Partei, folglich als Signal zum Bürgerkriege betrachtet werden würde.

Die Frage liegt nahe, ob es sich in allen diesen Fällen um krankhafte Erscheinungen handelt, die in einzelnen Ländern durch den Krieg und seine für Besiegte und Sieger gleich unheilvollen Folgen hervorgerufen worden sind, oder ob wir es mit einer Bewegung zu tun haben, die zwar an bestimmten Stellen durch die Katastrophe der letzten Jahre befördert worden ist, die aber auf tiefer liegenden allgemeinen Ursachen beruht. Man wird nicht fehl gehen, wenn man sich im Sinne der zweiten Alternative entscheidet. Schon längst vor dem Kriege zeigte der Parlamentarismus greisenhafte Züge, und zwar nicht nur in den Ländern Süd- und Südosteuropas, in denen er jetzt einer gewalttätigen Auflehnung zum Opfer zu fallen scheint. Es ist eine unbestreitbare Tatsache, daß sich die Achtung vor dem parlamentarischen Wesen seit Jahrzehnten im Niedergange befindet. Und es sind nicht nur Äußerlichkeiten, die das bewirkt haben.

Natürlich ist die Heftigkeit, mit der der Parlamentarismus kritisiert oder bekämpft wird, nicht überall gleich. Aber die Abneigung ist doch, von wenigen Ausnahmen abgesehen, in fast allen Ländern mit parlamentarischen Einrichtungen zu beobachten. Schon dies beweist, daß es sich hier um eine Frage handelt, die mit der Staatsform an sich nichts zu tun hat. In der Republik wie in der Monarchie, in der konstitutionellen Monarchie des klassischen Stils wie in der Monarchie mit parlamentarischem Regime, in der parlamentarischen Demokratie Frankreichs wie in der die parlamentarische Regierung verabscheuenden Demokratie der Vereinigten Staaten zeigte und zeigt sich dieselbe Gegnerschaft. Auch ist diese keineswegs geringer geworden, seitdem sich die demokratische Unterlage der Parlamente verbreitert hat. Im Gegenteil. Nicht nur hat sich hierdurch erklärlicher-

\footnotetext{
4 [Nikola Pašić (1845-1926), langjähriger serbischer Regierungschef].
} 
weise die Mißstimmung der Kreise verstärkt, die von Hause aus antidemokratisch eingestellt sind, sondern sie hat sich auch auf diejenigen Schichten ausgedehnt, die sich erst mühsam den Zugang zum Parlamente erkämpft haben. Da ihnen die Erweiterung ihrer politischen Rechte bei weitem nicht gebracht hat, was sie hierdurch zu erringen hofften, so haben sie vielfach enttäuscht der ganzen Institution den Rücken gewendet.

Die Gründe für das Sinken der Achtung vor den Parlamenten liegen nicht auf der Oberfläche. Die Kritik an ihren Leistungen spielt nicht die erste Rolle. Kein Zweifel, daß manches Parlament schlechte Gesetze gibt, und daß mancher guter Gesetzentwurf durch die Volksvertretung verdorben wird. Aber es sind nicht nur Parlamentarier, die schlechte Gesetze machen, und im allgemeinen entstehen die Gesetze außerhalb, nicht innerhalb der Volksvertretung. Es ist auch nicht bloß die augenfällige Vergröberung der parlamentarischen Sitte, die den Parlamentarismus unbeliebt gemacht hat, die unsachliche Behandlung der Beratungsgegenstände in den Vollversammlungen, die Vergeudung kostbarer Zeit durch Parteigezänk und demagogische Hetze. So abstoßend das ist, so weiß doch im allgemeinen auch wer nicht zu den Eingeweihten gehört, daß solche Redegefechte in der Hauptsache nur Theaterdonner sind, und daß wenigstens in den Sitzungen parlamentarischer Ausschüsse vielfach ernsthafte und ruhige Arbeit, auch in friedlichem Zusammenwirken politischer Gegner, geleistet wird. Und soweit es sich bei jenen Dingen um wirkliche Mißstände handelt, so sind sie doch nur sekundäre Erscheinungen, die auf viel wichtigeren und schlimmeren Gebrechen beruhen.

Gräbt man etwas tiefer, so findet man, daß sich die öffentliche Meinung mehr und mehr der inneren Widersprüche und Unwahrhaftigkeiten bewußt geworden ist, an denen das System des Parlamentarismus krankt, oder die sie doch ihm zuschreiben zu müssen glaubt.

Nach dem ursprünglichen Gedanken der konstitutionellen Verfassungen, der im Wortlaut noch der neuesten Verfassungsurkunden festgehalten wird, ist jedes Mitglied des Parlaments ein Vertreter des Volkes, in dem doppelten Sinne, daß es vom Volke in freier Entschließung zum Vertreter der Volksinteressen gewählt wird, und daß es die Interessen des „gesamten" Volkes zu vertreten hat. In Wirklichkeit wird der Abgeordnete schon längst nicht mehr vom Volke „gewählt“, d. h. ausgesucht, sondern er wird von einer Parteiorganisation der Wählerschaft vorgeschlagen, ja, nach dem modernen System des Verhältniswahlrechts wird er einer Wählerschaft, der er vielfach nicht einmal dem Namen nach bekannt ist, geradezu aufgenötigt. Und der Abgeordnete ist nur ganz selten in der Lage, die Interessen der Volksgesamtheit ohne Sonderrücksichten zu vertreten. In Wahrheit ist 
er Vertreter seiner Partei, fühlt er sich als solcher, handelt er als solcher. Vielleicht ließe sich das ertragen, weil es bis zu gewissem Grade unvermeidlich ist. Aber zu diesen Widersprüchen gesellt sich sofort ein weiterer. Die Partei, unter deren Firma der Abgeordnete arbeitet, ist häufig nicht das, für was sie sich ausgibt. Sie behauptet, für eine bestimmte politische Anschauung, womöglich für eine Weltanschauung zu kämpfen, während sie die Vertreterin ganz nackter materieller Interessen ist, von deren außerparlamentarischen Trägern sie finanziell ausgehalten, aber auch gegängelt oder tyrannisiert wird. Selbst dies möchte erträglich sein, wenn es zugegeben würde. Aber gerade hier wird krampfhaft geleugnet, was jedermann weiß. Deshalb glaubt man dem Parlamentsredner auch dann nicht, wenn er ehrlich für allgemeine Interessen eintritt, und die parlamentarischen Parteien glauben einander nichts von dem, was sie in solchen Fällen predigen.

Die zweite Lüge: der Volksvertreter ist nach der Verfassung ein unabhängiger Mann, nur seinem Gewissen untertan. Kein Auftrag bindet ihn, niemand kann ihn zur Rechenschaft ziehen. In Wahrheit ist der Abgeordnete völlig unfrei. Er ist nicht nur abhängig von der Stimmung seiner Wähler und der außerparlamentarischen Parteiorganisation, die ihm zu seinem Mandate verholfen hat, sondern er ist abhängig von einer Fraktion, die ihn einer harten Disziplin unterwirft, ohne deren Erlaubnis er in den öffentlichen Sitzungen den Mund nicht öffnen darf, die den Inhalt seiner Reden diktiert, die seine Abstimmung leitet.

Der dritte Widerspruch: der Parlamentarismus gibt vor, daß er eine Auslese der Tüchtigsten, Kundigsten, Ehrlichsten veranstalte, um die Interessen des Volks durch die Besten des Volks vertreten zu lassen. Das war jedenfalls die Vorstellung, die man sich von ihm bei seiner Einführung auf dem europäischen Kontinente machte, und es ist die Begründung, mit der man das parlamentarische Regierungssystem im technischen Sinne zu rechtfertigen sucht. Das Parlament soll ja die großen politischen Führer heranbilden; es muß also doch wohl schon eine Elite umfassen, an der es seine Erziehungsarbeit leistet. In Wirklichkeit ist nach allgemeinem Zugeständnisse die Geistigkeit der Parlamente von Jahrzehnt zu Jahrzehnt gesunken. Die parlamentarische Welt ist eine Welt der Mittelmäßigkeit geworden. In ihr herrscht, wie es in Frankreich heißt, „la médiocrité masquée par une certaine habilité oratoire“. Die lange Dauer der Tagungen verhindert wertvolle Personen am Eintritt in die Volksvertretungen. Dadurch ist ein in seiner Geschäftigkeit gefährliches Berufspolitikertum gezüchtet worden, und die Verhältniswahl hat ein übriges getan. Denn die Organisationen, auf deren Tätigkeit dieses System alles abstellt, müssen 
ihre Wahlvorschläge mit den Namen der Parteifunktionäre und anderer Dutzendmenschen füllen, die kein anderes Verdienst haben, als daß sie irgendeiner Berufsschicht angehören, auf die man Rücksicht nehmen zu müssen glaubt.

Es gibt manche, die sich über alle solche Widersprüche zwischen Verfassungsidealen und politischer Wirklichkeit mit der Begründung hinwegsetzen, daß sich hier eine geschichtliche Entwicklung vollzogen habe, die man hinnehmen müsse. Allein wenn nicht alles trügt, ist die Stimmung der denkenden Kreise des Volks eine andere. Hier hat sich in den letzten Jahrzehnten, und seit dem Kriege in steigendem Maße, eine Änderung in der Einstellung zum staatlichen Leben überhaupt vollzogen. Die Einrichtung der kontinentalen Parlamente ist ein Geschöpf des individualistischen Nationalismus. Nationalistische Elemente haben auch an seinem Ausbau gewirkt; die Einführung der Verhältniswahl war ihr letztes charakteristisches Werk. Aber in der Generation, die sich heute denkend mit dem Staate beschäftigt, vor allem in der Jugend, hat sich allmählich eine Abkehr vom Nationalismus und vom Individualismus vollzogen. Und das ist, wie mir scheint, der tiefste Grund, weshalb sich die heutige Welt mehr und mehr dem Parlamentarismus ablehnend und feindlich gegenüberstellt. Sie fühlt und sie sieht, daß weder die Ideen, mit denen sich die Gegenwart abmüht, noch daß die Lebenskräfte, die heute die gesellschaftliche Gestalt des Volks und sein Schicksal bestimmen, in der Zusammensetzung und in der Arbeit der Parlamente ihren Ausdruck finden können. Deshalb ist gerade in Deutschland, wo man diese Dinge immer am tiefsten und am ernstesten behandelt, zwar nicht die äußere, aber die innere Krisis des Parlamentarismus am stärksten. Gewiß herrscht hier vielfach noch Unklarheit über die neuen Ziele und die Mittel, mit denen sie zu erreichen sind, und die neuen Ideale ringen noch um die zutreffende Form ihres Ausdrucks. Aber in den Umrissen zeigt sich doch mit zunehmender Deutlichkeit, was man ersehnt. Irre ich nicht, so liegt allen Bestrebungen, die heute mit Schlagworten wie „berufsständische Vertretung“, „Wirtschaftsparlament“, „Räteverfassung“ und anderem arbeiten, der gesunde, ja der große Gedanke zugrunde: das Parlament soll Krönung und Zusammenfassung alles dessen werden, was das Volk in den teils fertigen, teils im Aufbau befindlichen Einrichtungen der Selbstverwaltung besitzt, gleichviel, ob diese Selbstverwaltung auf territorialer oder auf personeller Grundlage beruht, ob sie wirtschaftliche oder ob sie geistige Interessen zur Einheit zusammenfügt. Heute steht das auf rein individualistischer Basis errichtete Parlament in persönlicher und sachlicher Hinsicht außer jedem Zusammenhange mit der andern Selbstverwaltung. Die Aufgabe ist, diesen Zu- 
sammenhang herzustellen, - was freilich nicht dadurch geschehen kann, daß man in dem Streben nach Einerleiheit den demokratischen Parlamentarismus in die Gemeinden und andere Selbstverwaltungskörper verpflanzt! Das englische Parlament, das organisch gewachsen, nicht rationalistisch konstruiert worden ist, hat seine Blüte in der Zeit erlebt, in der es die Spitze des englischen Selfgovernment gebildet hat. Es ist notwendig, daß man sich der erdgeborenen Weisheit, die aus dieser Verbindung spricht, bei uns mehr und mehr bewußt wird. 


\section{Text 8 \\ Die Ermächtigungsgesetze ${ }^{1}$}

Von den beiden „Ermächtigungsgesetzen“, die der Reichstag während des verflossenen Vierteljahrs erlassen hat, ist das erste, das RGes. v. 13. Okt. 1923 (RGBL I, S.943), nach wenigen Wochen in der Versenkung verschwunden. Eine bald darauf neugebildete Regierung hat dem Reichstage ein neues Gesetz mit gleichem Titel vorgelegt und seine Annahme nach allerhand parlamentarischen Schwierigkeiten durchgesetzt (ErmG. v. 8. Dez. 1923, RGBl I, S. 1179). Obwohl demnach das erste der beiden Gesetze bereits der Geschichte angehört, muß es doch mit dem zweiten zusammen besprochen werden. Nicht allein, weil es in dieser Zeitschrift bisher nur gestreift worden ist (1923, S. 664), sondern weil beide Gesetze in ihrer Gesamtheit, so verschieden sie in einigen Einzelheiten sind, eine für die gegenwärtige Krisis unseres Verfassungslebens bezeichnende Erscheinung bilden, oder vielleicht, besser gesagt, weil es gerade die Wiederholung im Erlasse solcher Gesetze ist, was den Charakter jener Krisis ausmacht.

$\mathrm{Da}$ das erste ErmG. bei seinem Erscheinen von den verschiedenen Parteien verschieden beurteilt, von der einen Seite als politische Sünde, von der anderen als vaterländisches Verdienst gepriesen wurde, ist nichts Verwunderliches. Eigentümlich aber war es, wie die Freunde und wie die Gegner die Bedeutung des Gesetzes im Verhältnis zum System des Parlamentarismus auffassen zu müssen glaubten. Von der einen Seite wurde behauptet, das Gesetz, das der „derzeitigen Reichsregierung" als dem Exponenten der „derzeitigen“ Parlamentsmehrheit die fast unbegrenzte Ermächtigung zur Vornahme entscheidendster Maßregeln auf großen Gebieten des öffentlichen Lebens gewährte, stelle sich geradezu als die Krönung des parlamentarischen Gedankens dar. Zum ersten Male habe bei uns die Parlamentsmajorität die den Parteien der westeuropäischen Parlamente eigentümliche Selbstzucht bewiesen, indem sie ihren Führern die wirkliche Führung in die Hand gegeben und die Regierung von den leidigen Fesseln fortdauernder Fraktionsgebundenheit befreit habe. Von der anderen Seite

1 [In: Deutsche Juristen-Zeitung 29 (1924), Sp. 2-7; Abdruck der Ermächtigungsgesetze bei Heinrich Triepel, Quellensammlung zum Deutschen Reichsstaatsrecht, 4. Aufl. Tübingen 1926, S. 237 ff.]. 
wurde erklärt, der Parlamentarismus habe sich mit der Erteilung diktatorischer Vollmachten an die Regierung sozusagen selbst überschlagen, und indem das Gesetz solche Vollmachten an eine Regierung von einer bestimmten „parteipolitischen Zusammensetzung“ erteilte, habe es den Gedanken des Parlamentarismus ins Lächerliche gekehrt. Für eine nüchterne Betrachtung enthält der eine wie der andere Gedanke eine Übertreibung. Aber der zweite kommt der Wahrheit doch wohl näher als der erste.

Es ist gewiß richtig, daß die bei uns seit 1919 herrschende Methode, die eine von einer Koalitionsmehrheit in den Sattel gehobene Regierung auf Schritt und Tritt von Fraktionsbeschlüssen und interfraktionellen Handelsgeschäften abhängig sein läßt, der Regierung ein wirkliches „Regieren“ beinahe unmöglich macht. Aber es ist weder richtig, daß das ErmG. v. 13. Okt. der Anwendung dieser Methode einen Riegel vorgeschoben, noch zutreffend, daß es durch seine diktatorischen Ermächtigungen die Form unseres Parlamentarismus dem westeuropäischen, will sagen: dem englischen Ideale genähert habe. Denn indem der $\$ 2$ des ErmG. die Fortdauer der damaligen „parteipolitischen Zusammensetzung“ der RRegierung zur Voraussetzung für die Fortdauer der Ermächtigung erhob, zwang es geradezu die Mitglieder des Kabinetts, unter sich eine Kompromißpolitik nach parteipolitischen Gesichtspunkten zu treiben, und ermöglichte es gleichzeitig den Fraktionen, das Kabinett unter ständigem parteipolitischen Drucke zu halten. In der Tat hat es sich ja gezeigt, daß schon das Stirnrunzeln einer der Koalitionsparteien das Kabinett ins Wanken, ihre Ungnade die „parteipolitische Zusammensetzung" aus dem Gleichgewichte und das ErmG. sehr bald zu Falle zu bringen vermochte. Und es geht schon hieraus hervor, daß die auf ein solches Gesetz gestützte „Diktatur" der Regierung schlechterdings nicht verglichen werden kann mit der starken Stellung, die das englische Kabinett gegenüber seinem Parlamente besitzt, einer Stellung, die übrigens von den Grundsätzen der „klassischen“ Parlamentsregierung weit entfernt ist; denn sie beruht bekanntlich auf der Tatsache, daß das englische Kabinett kraft der Bureaukratisierung der Verwaltung und Demokratisierung der Verfassung, die das 19. Jahrhundert geschaffen hat, seine Stütze gegenüber der Volksvertretung, anders als bei uns, in dem unpolitischen Beamtentum und in der Wählerschaft selbst zu finden vermag.

Auch die Kritik, die von der Rechten an dem ErmG. geübt worden ist, schoß ein wenig über das Ziel hinaus. Man kann nicht behaupten, daß eine vorübergebende „legale“ Diktatur der Regierung unter allen Umständen mit dem parlamentarischen System unvereinbar sei. Wie die Geschichte der Kriegskabinette in England und Frankreich beweist, läßt sich der- 
gleichen sogar bei einer Koalitionsregierung denken. Aber freilich nur unter der doppelten Voraussetzung, daß die koalierten Parteien Selbstbescheidung aufzubringen vermögen, und daß sie sich über die zu erreichenden Ziele im ganzen einig sind! In Deutschland sind diese beiden Voraussetzungen nicht gegeben, und so ist hier in der Tat eine durch eine Koalition ausgeübte Diktatur, eine „Diktatur der Verständigung“, ein in sich widerspruchsvolles und daher aussichtsloses Unternehmen.

Bei dieser Sachlage war es nicht einmal von sehr großem Belange, daß das erste ErmG. seine Geltung ausdrücklich auf die Dauer der „parteipolitischen Zusammensetzung“ der Regierung abstellte. Allerdings war diese die Struktur unserer Verfassung mit ungewöhnlicher Brutalität bloßlegende Ausdrucksweise überaus unklar. Das hätte zu praktischen Schwierigkeiten führen können, wenn die Gerichte über die Gültigkeit einer Verordnung zu entscheiden gehabt hätten, die etwa erlassen worden wäre, nachdem sich eine Verschiebung in der Zusammensetzung des Kabinetts Stresemann vollzogen hätte, die weniger eindeutig als der Austritt der sämtlichen sozialdemokratischen Minister ${ }^{2}$ gewesen wäre. Übrigens ließ schon der Eintritt des Grafen Kanitz in die Regierung die Frage entstehen, ob damit ein Wechsel in der parteipolitischen Zusammensetzung des Kabinetts vor sich gegangen sei, - wofür es offenbar gleichgültig war, ob dieser Parlamentarier als Minister aus der Fraktion, der er angehörte, ausschied oder nicht. Und wenn man auch sagen konnte, daß das Gesetz bei jenem Ausdrucke an die politische „Homogenität“ des Kabinetts im ganzen gedacht habe, so ließen sich doch Fälle genug denken, in denen es durchaus zweifelhaft sein mußte, ob ein Wechsel in einem oder mehreren Portefeuille seine Änderung in der bisherigen Homogenität herbeiführte. Allein da eine Koalitionsdiktatur bei unseren parlamentarischen Verhältnissen notwendig um so kurzlebiger sein muß, je umfassender die ihr gewährten Befugnisse sind, so war jene Frage von vornherein dazu verurteilt, eine bloße Doktorfrage zu bleiben.

Das neue ErmG. ist dieser Schwierigkeit aus dem Wege gegangen. Es ist lediglich als befristetes erlassen; es soll am 15. Febr. 1924 außer Kraft treten (das erste Gesetz hatte als „spätesten“ Endtermin seiner Geltung den 31. März 1924 vorgesehen). Das neue Gesetz sieht von der „derzeitigen“ Reichsregierung und ihrer parteipolitischen Zusammensetzung völlig ab. Es gewährt also scheinbar die Ermächtigung jeder Regierung, die innerhalb der angesetzten Frist ans Ruder kommen wird. In Wirklichkeit ist

2 [dazu vgl. Ernst Rudolf Huber, Deutsche Verfassungsgeschichte seit 1789. Bd. VII, Stuttgart 1984, S. 387 ff., Kabinettsliste ebd. S. 361]. 
aber damit kein Gegensatz zu dem vorangegangenen ErmG. gegeben. Denn selbstverständlich ist es die jetzige Regierung und die jetzige Regierungskoalition, die die neue Ermächtigung für sich erkämpft hat, und ob das neue Gesetz den Rücktritt der gegenwärtigen Regierung oder eine Änderung ihrer Zusammensetzung überleben wird, hängt ja schließlich nur von der Gnade des Reichstags ab. Ein praktischer Unterschied ist nur insofern gegeben, als bei einer Auflösung des Reichstags, falls diese im Zusammenhang mit einem Kabinettswechsel erfolgen sollte, das neue Kabinett auf Grund des ErmG. regieren könnte, während nach dem früheren Gesetz in solchem Falle die Geltung der Ermächtigung automatisch fortgefallen wäre.

Im übrigen ist die Stellung der RReg. nach dem neuen ErmG. teils stärker, teils schwächer als nach dem vorangegangenen. Das erste Gesetz begrenzte die Ermächtigung auf Maßnahmen, die sich auf „finanziellem, wirtschaftlichem und sozialem Gebiete" bewegten, und machte auch dann noch Ausnahmen in bezug auf die Regelung der Arbeitszeit und Einschränkung bestimmter Leistungen aus sozialpolitischen Einrichtungen. Das neue Gesetz ermächtigt schlechthin zu allen Maßnahmen, die von der Regierung für erforderlich und dringend erachtet werden; der Zusatz: „im Hinblick auf die Not von Volk und Reich" ist wohl eher als Angabe des Motivs des Gesetzgebers, denn als eine sachliche Begrenzung der Vollmacht zu verstehen. Auf der anderen Seite erlaubte das erste Gesetz, daß sich die Regierung bei ihren Forderungen über alle Grundrechte der RV. hinwegsetzte - wovon sie reichlich Gebrauch gemacht hat! -, während das zweite Gesetz eine Abweichung von den Vorschriften der Verf. schlechthin als unzulässig bezeichnet. In formeller Beziehung enthält das jetzt geltende ErmG. die Bestimmung, daß die erlassenen VO.en auf Verlangen nicht nur - wie nach dem ersten Gesetz - des Reichstags, sondern auch des Reichsrats aufzuheben sind. Diese Rücksichtnahme auf das föderalistische Element im Reiche tritt auch in einer anderen, wiederum neuen Klausel zutage: vor Erlaß der VO.en ist nicht nur ein fünfzehnköpfiger Ausschuß des Reichstags, sondern auch ein Ausschuß des Reichsrats zu hören. Freilich haben beide Ausschüsse nur ein Recht auf „vertrauliche Beratung“. Damit ist nicht nur der Einfluß der beiden Vertretungskörper auf den Inhalt der VO.en auf ein Mindestmaß beschränkt und die Minderheit des Reichstags so gut wie mundtot gemacht, sondern es ist auch dafür gesorgt, daß eine eilfertig und rücksichtslos arbeitende Ministerialbureaukratie der Kontrolle der öffentlichen Meinung sowie den nicht immer unberechtigten Einflüssen der Interessenten und der wirtschaftlichen und juristischen Sachverständigen entzogen bleibt. Überdies werden den Ausschüssen so 
zahlreiche und umfängliche VO.gen vorgelegt, daß von gründlicher Beratung keine Rede sein kann. Schon sagt man, daß der Reichstagsausschuß angesichts dieses Verfahrens erklärt habe, der Regierung die „volle Verantwortung" für die VO.en zuschreiben zu müssen, womit er freilich seine endgültige Abdankung vollzogen haben würde. Um es auch dem Reichstage selbst nicht zu leicht zu machen, gegen eine Verordnung vorzugeben, ist der Beschluß, durch den deren Aufhebung verlangt wird, an die Vornahme zweier, durch einen Zeitraum von mindestens drei Tagen getrennter Lesungen gebunden worden.

In beiden ErmG. hat die RReg. die Befugnis erhalten, „Maßnahmen“ zu treffen, die sie für erforderlich und dringend erachtet. Dieser Ausdruck hat nicht die weite Bedeutung wie der gleiche Ausdruck in Art. 48 Abs. 2 der RV.; die „Maßnahmen“, die der Reichspräsident auf Grund dieses Artikels treffen darf, können vielgestaltiger sein. Denn es ergibt sich aus den weiteren Bestimmungen des ErmG., daß die Maßnahmen der RReg. nur in „Verordnungen“ bestehen dürfen. Auf der anderen Seite aber kann die RReg. alle Verordnungen erlassen, die sie für erforderlich und dringend „erachtet"; der RP. ist auf die zur Wiederherstellung der öffentlichen Ordnung „nötigen“ Maßnahmen beschränkt, also immerhin einer gewissen Kontrolle seines Ermessens unterworfen. Jedenfalls aber sind die Maßnahmen der Regierung auf Grund des ErmG. und die Maßnahmen des RP. auf Grund des Art. 48 voneinander an sich völlig unabhängig. Die einen schließen die andern nicht aus. Die beiden „Diktaturen“ können also nebeneinander herlaufen. Über ihr gegenseitiges Verhältnis ließe sich manches sagen, ebenso über die der Verf. widerstreitende Anwendung des Art. 48, mit der man eine Zeitlang den Wegfall des ersten ErmG. wettzumachen versucht hat.

Über die politischen Bedenken, die sich gegen beide ErmG. erheben lassen, soll an dieser Stelle nicht gesprochen werden. Aber einige Worte über das Verhältnis dieser Gesetze zur Verfas s ung dürften am Platze sein. Es kann nicht zweifelhaft sein und war niemandem zweifelhaft, daß die umfassende Verordnungsdelegation, die von den Gesetzen vorgenommen wurde, nicht auf dem Wege der einfachen Gesetzgebung erfolgen konnte. Der Gesetzgeber hat kein unbeschränktes Recht, Verordnungsrechte zu schaffen, und der Umfang der in den ErmG. erfolgten Delegation geht über das verfassungsmäßig erlaubte Maß hinaus ${ }^{3}$. Nun sind die beiden Gesetze in den Formen erlassen worden, die von der RV. für Verfassungsän-

3 Vgl. die Verhandl. und Beschl. des Bamberger Juristentages von 1921, insbes. die Berichte von Triepel [Empfiehlt es sich, in die Reichsverfassung neue Vorschriften 
derungen vorgesehen sind, und das juristische Gewissen der heutigen Generation ist geneigt, sich bei der Feststellung dieser Tatsache zu beruhigen und alles in schönster Ordnung zu finden. Allein die Sache hat doch auch eine andere Seite. Man kann sich ja, obwohl die Frage recht umstritten ist, auf den Standpunkt stellen, daß Änderungen der Verfassung ohne Änderungen ihres Textes, wenn sie nur in den Formen des Art. 76 geschehen, zulässig sind, - wenigstens in solchen Fällen, in denen man nur eine Abweichung von der Verf. beschließt, ohne die Fortgeltung des entsprechenden Verfassungsgrundsatzes als solchen in Zweifel zu stellen. Nun widerspricht die Erteilung umfänglicher gesetzgeberischer Vollmachten an die RReg., wodurch auf lange Zeit die Einspruchsrechte des Reichsrates und des Reichspräsidenten sowie der Volksentscheid über Gesetzesbeschlüsse des Reichstags ausgeschaltet werden, sicherlich dem Geiste der RVerf.; diese hat ja mit voller Absicht sogar das Institut des Notverordnungsrechts verworfen. Immerhin könnte man sich mit dem gelegentlichen, in Form der Verfassungsänderung erfolgenden Erlasse eines entsprechenden Ausnahmegesetzes zur Not einverstanden erklären. Allein das Bild ändert sich in dem Augenblicke, in dem die Tendenz erkennbar wird, das, was eine vorübergebende Ausnahme sein sollte, für eine ungewisse Zeit zur Regel zu machen. Wenn es sich einbürgert, daß die sich ablösenden Regierungen durch Sondergesetze Ermächtigungen von dem Ausmaße erhalten, wie jetzt geschehen, so würden offenbar die organisatorischen Hauptstücke der RVerf. aus den Angeln gehoben. Nur eine formalistische Denkweise gestattet die Auffassung, daß das durch ein Gesetz, gleichviel welcher Form, so nebenher bewerkstelligt werden könnte. Es mag sein, daß sich zuzeiten eine Verfassung als unbrauchbar erweist, um das Staatsschiff durch die Brandung zu steuern, und daß es sich dann rechtfertigen läßt, die Verf. um der Not des Volkes und Staates willen beiseite zu setzen. Aber man muß sich klar darüber sein, daß die Abkehr von der Verf., obwohl sie sich in ein Gesetz kleidet, nicht Anwendung, sondern Verletzung der Verfassung ist. Auch die gesetzgebende Gewalt kann einen Staatsstreich unternehmen. Sie sollte sich aber dann offen zu ihm bekennen!

über die Grenzen zwischen Gesetz und Rechtsverordnung aufzunehmen?, in: Verhandlungen des 32. Deutschen Juristentags (Bamberg), Berlin 1922, Bd. II, S. 1135 u. S. 54-56] und Poetzsch, S. 11 ff. 


\section{Text 9 \\ Der Föderalismus und die Revision der Weimarer Reichsverfassung 1}

Die Frage, ob die jetzt seit fast fünf Jahren in Kraft stehende Reichsverfassung im Sinne eines stärker betonten Föderalismus umzugestalten sei, ist während der letzten Monate in ein akutes Stadium getreten. Schon dem vorigen Reichstage waren von mehreren Fraktionen Initiativanträge vorgelegt worden, die sich in jener Richtung bewegten: ein Antrag der Deutschnationalen Volkspartei, ein Antrag der bayerischen Volkspartei; der zweite

1 [In: Zeitschrift für Politik 14 (1924), S. 193-230] Nach einem im Main 1924 in der Juristischen Gesellschaft zu Berlin gehaltenen Vortrage, dessen Ausführungen ich an einigen Stellen erweitert habe. Mit Angabe von Literatur bin ich sparsam umgegangen, auch habe ich mich mit ihr nur gelegentlich auseinandergesetzt. Dem Kundigen wird nicht verborgen bleiben, wo ich mich an die schon von Anderen geäußerten Meinungen anschließe, und wo ich mich von ihnen entferne. Für das Thema im ganzen darf ich auf die Veröffentlichungen der Vereinigung der deutschen Staatsrechtslehrer, Heft 1 (Berlin und Leipzig 1924) hinweisen, wo sich über „den deutschen Föderalismus in Vergangenheit, Gegenwart und Zukunft" Referate von Anschütz (S. $11 \mathrm{ff}$.) und Bilfinger (S. 35 ff.) sowie ein Verhandlungsbericht (S. 60 ff.) finden [Triepel antwortet hier im Mai 1924 auf den „Zusammenstoß zwischen dem Reiche und Bayern“während der letzten Monate, auf dessen Beilegung durch die sog. „Homburger Vereinbarung“ und die im Januar 1924 von der bayerischen Regierung dem Reich übermittelte Denkschrift „Zur Revision der Weimarer Reichsverfassung“. Hintergrund war die bayerische Ernennung von Gustav v. Kahr zum Generalstaatskommissar und die Inanspruchnahme einer eigenen bayerischen Diktatur- und Militärgewalt. Einerseits wurde dadurch u.a. der Münchner Putsch vom November 1923 (Hitler-Putsch) niedergeschlagen, andererseits zielte dieser bayerische Sonderweg auf eine Beseitigung der parlamentarischen Demokratie. Nach dem Sturz Stresemanns und dem Eintritt der Bayerischen Volkspartei in die Regierung Wilhelm Marx erfolgte Mitte Februar 1924 mit der „Homburger Vereinbarung“ eine Beilegung des Konflikts. Triepel greift den föderalistischen Aspekt heraus und argumentiert gegen den bayerischen Separatismus für eine Hegemonie Preußens im bundesstaatlichen Gefüge. Zum Hintergrund vgl. Ernst Rudolf Huber, Deutsche Verfassungsgeschichte seit 1789 Bd. VII, S. 469 ff.; ders., Militärgewalt, Notstandsgewalt, Verfassungsschutzgewalt in den Konflikten zwischen Bayern und dem Reich, in: ders., Bewahrung und Wandlung. Studien zur deutschen Staatstheorie und Verfassungsgeschichte, Berlin 1975, S. 171-192]. 
war sogar mit ausführlichen Richtlinien für einen entsprechenden Gesetzesentwurf versehen. Es unterliegt keinem Zweifel, daß solche Anträge, vielleicht noch in bestimmterer Form gefaßt, dem jetzt (im Mai) neugewählten Reichstage von neuem zugehen werden. Aber auch die Regierungsstellen haben sich bereits in sehr ernsthafter Weise mit der Frage beschäftigt. Vor allem hat der scharfe Zusammenstoß zwischen dem Reiche und Bayern, der im vergangenen Jahre die politische Welt in Aufregung versetzte, den Anlaß zu einer amtlichen Erörterung des Problems geboten. Bei einer Konferenz der Reichsregierung mit den Ministerpräsidenten der Länder, die am 24. Oktober 1923 stattfand, wurde von den Länderregierungen der Wunsch geäußert, es möchten Verhandlungen über die fernere Gestaltung des Verhältnisses zwischen Reich und Ländern im Sinne einer größeren Selbstständigkeit der Länder eingeleitet werden, und der Reichskanzler S t r e s e m a n n erklärte sich zu solchen Verhandlungen bereit. Er teilte auch bald darauf, am 23. November, in einer Reichstagsrede mit, daß innerhalb der Reichsregierung Besprechungen nach dieser Richtung stattgefunden hätten; sein Nachfolger, der Reichskanzler Marx, nahm am 4. Dezember Gelegenheit, dies zu bestätigen. Die eigentlichen Verhandlungen über den Gegenstand sind dann durch die bekannte bayerische Denkschrift vom 8. Januar d. J. ${ }^{2}$ eröffnet worden. Ihr war schon im November des vorigen Jahres eine badische Denkschrift vorangegangen. Diese stellt freilich nicht eine Meinungsäußerung der badischen Regierung, sondern ein Memorandum dar, das der Präsident des Badischen Landtags, Dr. B a u m gartner, ${ }^{3}$ im Auftrage des Geschäftsordnungsausschusses verfaßt und dem Landtage überreicht hat; wie man hört, sollen sich die dort vorgetragenen Ansichten nur zum Teil mit den Auffassungen der gegenwärtigen Regierungsmehrheit in Baden decken. Zurzeit finden innerhalb der Reichsregierung und der beteiligten Fachministerien Beratungen über den Fortgang der Angelegenheit statt; sie werden vielleicht zur Ausarbeitung einer umfangreichen Denkschrift der Reichsregierung führen. So ist also die Angelegenheit in Fluß gekommen und wird nicht so bald wieder von der Tagesordnung verschwinden.

2 [Zur Revision der Weimarer Reichsverfassung. Denkschrift der Bayrischen Staatsregierung vom Januar 1924. Sonderbeilage zur Bayerischen Staatszeitung vom 5. Januar 1924; Wiederabdruck in: Verfassungsausschuss der Länderkonferenz. Beratungsunterlagen 1928, hrsg. v. Reichsinnenministerium, Berlin 1929, S.343361].

3 [Das Reich und die Länder. Denkschrift über den Ausgleich der Zuständigkeiten zwischen dem Reich und seinen Ländern in Gesetzgebung und Verwaltung. Dem Badischen Landtag vorgelegt von Eugen Baumgartner, Karlsruhe 1924]. 
Wenn sich ein Mann des Staatsrechts über das Problem des Föderalismus äußert, so hat er sich vor Augen zu halten, daß es sich dabei nicht nur um ein rechtliches, sondern auch um ein politisches Problem handelt. Das stellt ihn vor eine besondere Aufgabe. Nicht als ob er sich auf einem seiner Wissenschaft fremden Boden bewegte, wenn er es mit politischen Fragen zu tun hat! Wir Juristen haben allmählich gelernt, daß sich auch echte Rechtsfragen, selbst bloße Auslegungsfragen, fast niemals allein durch logische Denkoperationen und durch begriffliche Konstruktionen erledigen lassen, sondern daß sie letzten Endes nur durch Heranziehung von Urteilen wertenden Charakters gelöst werden können. Bei staatsrechtlichen Fragen sind es folglich politische Werturteile, die zu Hilfe genommen werden müssen, - vielleicht nicht immer, jedenfalls aber dann, wenn es sich um Grundprobleme der Staatsverfassung überhaupt handelt. Und das gilt natürlich erst recht, wenn nicht die Darstellung oder Interpretation des geltenden Rechts, sondern die Kritik des bestehenden Rechtszustandes oder die Beurteilung von Änderungsvorschlägen zur Aufgabe gesetzt ist. Hierbei wird die Stellung des Juristen noch schwieriger als sonst. Hat er es nämlich mit der Auslegung eines gegebenen Rechtsmaterials, insbesondere mit der Ergänzung von Lücken des Rechtsstoffs zu tun, so ist er befugt, und, sofern er korrekt verfährt, auch verpflichtet, sich bei der Abgabe von Werturteilen an die Wertmaßstäbe zu halten, die er im geltenden Rechts selber irgendwo und irgendwie ausgedrückt findet; erst wenn ihn darin das geschriebene oder ungeschriebene Recht im Stiche läßt, kann er und soll er sein eigenes Werturteil zur Entscheidungsmaxime machen, soll er, wie es das Schweizerische Zivilgesetzbuch vorbildlich ausgedrückt hat, "nach der Regel entscheiden, die er als Gesetzgeber aufstellen würde“.4 Setzt er sich jedoch eine kritische Prüfung des geltenden Rechts und eine Behandlung von Rechtsfragen de lege ferenda zum Ziele, so wird er sofort oder jedenfalls viel früher als sonst in die Sphäre des Subjektiven geraten. Je mehr nun innerhalb des Kreises, zu dem er spricht, die Ansichten über die in Betracht kommenden Werte auseinandergehen, um so mehr verlieren seine Argumente an wissenschaftlicher Überzeugungskraft. Sind aber jene Ansichten gar zu Dogmen politischer Parteien erhoben worden, so kann der Rechtslehrer von Anfang an darauf gefaßt sein, daß er von einem Teile seiner Hörer oder Leser zum Parteimanne gestempelt, und daß seine wissenschaftliche Glaubwürdigkeit in Zweifel gezogen wird.

Das muß nun freilich in Kauf genommen werden, und wir haben uns bereits daran gewöhnt. Immerhin wird der Staatsrechtslehrer den An-

4 [Schweizerisches Zivilgesetzbuch vom 10. Dezember 1907, $\mathbb{1} 1$. 
spruch, als objektiver Beurteiler angesehen zu werden, mit Fug erheben können, wenn er sich, soweit es angeht, darauf beschränkt, seine Beweisgründe in Erfahrungstatsachen oder Verhaltensregeln zu suchen, die er mit den Mitteln seiner Wissenschaft festzustellen vermag, wenn er, anders ausgedrückt, mit Waffen kämpft, die er dem Arsenale seiner Wissenschaft entnommen hat. Von den Betrachtungsweisen, die ihm hier zur Verfügung stehen, sind es vor allem zwei, die in Frage kommen: die verfassungsgeschichtliche und die verfassungstech$\mathrm{n}$ i s c he. Von ihnen setzt freilich die erste, wenn anders ihre Anwendung auf fruchtbaren Boden fallen soll, schon wieder eine Verständigung über eine Wertfrage voraus. Wer sich nicht zu einer „geschichtlichen Anschauung" bekennt, nach der die Staatsverfassung mit den historisch bedingten Wirklichkeiten im politischen Leben einer Nation in Einklang stehen, und wenn sie es nicht tut, in Einklang gesetzt werden muß, dem ist mit einer geschichtlich begründeten Kritik nicht beizukommen. Wenn daher im folgenden zunächst gefragt wird, ob und inwieweit sich die bundesstaatliche Struktur der Weimarer Verfassung in den Gesamtverlauf der deutschen Statsentwicklung einfügt, so wird die Antwort hierauf eher auf Zustimmung rechnen können, als die Antwort auf die weitere Frage: ob es ratsam sei, sich bei dem Ergebnisse einer gesetzmäßigen Entwicklung zu beruhigen, oder ob diese Entwicklung in eine andere Bahn zu lenken sei, und umgekehrt, ob man den aus dem Geleise der Geschichte gefahrenen Wagen in seine ursprüngliche Richtung schieben, oder ob man ihn in der neu eingeschlagenen weiter fahren lassen solle. Vielleicht gelingt es dann aber wieder besser, sich auf einer gemeinsamen Basis zu treffen, wenn der Versuch gemacht wird, das Organ is at i o n s te ch n is ch e des föderalistischen Problems herauszuarbeiten, wenigstens in dem Umfange, daß auf organisatorische Möglichkeiten und Konsequenzen hingewiesen wird, die sich aus den Einrichtungen der geltenden Verfassung und den zu ihrer Abänderung gemachten Vorschlägen ergeben.

Das eine wie das andere kann freilich im folgenden nur in großen Zügen, und ohne daß auf alle Einzelheiten eingegangen wird, unternommen werden. Insbesondere soll sowohl die Frage des Finanzausgleichs zwischen Reich und Ländern, als die Frage der Revision des Art. 48 der Verfassung beiseite bleiben oder doch nur gestreift werden, weil beides nur in sehr spezialisierenden Darstellungen erörtert werden könnte. ${ }^{5}$

5 Über den Finanzausgleich siehe die gut orientierende Abhandlung von Hensel, Grundsätzliches zur Reform des Finanzausgleichsrechts, in der Zeitschrift „Steuer 
Der Sinn des Ausdrucks „F ö de ral is mus“ bedarf einer Klarstellung. Das Wort hat leider bereits den Charakter eines Schlagworts angenommen, unter dem sich der eine dies, der andere das, mancher gar nichts denkt. Es hat nicht an Deutlichkeit gewonnen, seitdem man es mit adjektivischen Zusätzen geschmückt hat. Wir hören heute von einem „echten“, einem „veredelten“, einem „aufgeklärten“, einem „wohlüberlegten“ Föderalismus; einem „Krakeelföderalismus“ hat man einen „Föderalismus der Tat" gegenübergestellt. Die bayerische Denkschrift behauptet, die Bismarcksche Reichsverfassung sei „im vollen Sinne des Wortes föderalistisch" gewesen, da sie dem Reiche, was ihm notwendig war, gegeben und dabei doch Eigenständigkeit und Sonderleben der Einzelstaaten bis an die Grenzen des Möglichen geschont habe. Darnach würde also föderalistisch eine Verfassung sein, die einen richtigen Ausgleich zwischen den Interessen der Gesamtheit und denen der Partikulargewalten geschaffen hat, wobei nur fraglich bliebe, was als „richtiger“ Ausgleich zu betrachten sei. Damit stimmt es nur nicht überein, wenn dieselbe Denkschrift zwei Seiten weiter sagt: „Staaten können nach allen geschichtlichen Erfahrungen nur durch die Kräfte erhalten werden, die sie geschaffen haben. Das waren für das Deutsche Reich die im Föderalismus liegenden und von ihm ausgehenden Kräfte, nicht der Unitarismus. " Hier erscheint der Föderalismus als eine sich in den Einrichtungen einer Verfassung auswirkende Ideen- oder Geistesrichtung oder Tendenz, und zwar als etwas, was in einen bestimmten Gegensatz zum Unitarismus gebracht werden muß. Diese Auffassung ist entschieden richtiger als die erste. In der Tat gewinnt der Begriff des Föderalismus, sofern man ihn in Beziehung zu „bundesstaatlichen“ Bildungen bringt, nur dadurch die nötige Bestimmtheit, daß man ihn als das Widerspiel des Unitarismus betrachtet. Der Bundesstaat ist ein Mittelding zwischen Einheitsstaat und Staatenbund, ein Kompromiß zwischen zwei Strebungen, von denen die erste eine aus Stämmen oder anderen Bildungen bestehende Nation in die Form des Einheitsstaates zwingen, während

und Wirtschaft“ 1924 Sp. 577 ff. - Über den Artikel 48 handeln sehr ausführlich und tiefdringend die Referate von Carl Schmitt und Jacobi in den schon oben [S.133 Fn, 1] angeführten Veröffentlichungen der Vereinigung der deutschen Staatsrechtslehrer Heft 1 S. 63 ff., $105 \mathrm{ff} . ;$ vgl. dazu den Verhandlungsbericht S. $137 \mathrm{ff}$. Beziehen sich diese Abhandlungen auf das geltende Recht, so beschäftigen sich die auf dem Heidelberger Juristentage von 1924 gehaltenen ausgezeichneten Vorträge von Piloty und R. Grau mit dem Inhalte des noch ausstehenden Ausführungsgesetzes zu Art. 48, wollen aber auch diesen Artikel selbst ergänzen. 
die andere sie als Bund selbständiger Staaten organisieren will. Das Kompromiß bewirkt, daß sich in jedem Bundesstaate unitarische und föderalistische Elemente nebeneinander finden, nur daß der eine Bundesstaat mehr das eine, der andere mehr das andere Element betont. Daher ist unitarisch eine Einrichtung des Bundesstaats, die sich, allein betrachtet, wie die Einrichtung eines Einheitsstaates ausnimmt, weil sie von der Existenz der Einzelstaaten als besonderer Körper absieht: föderalistisch ist eine Institution, die das Staatliche des Bundesstaates beiseite setzt, die, allein angesehen, der Einrichtung eines Staatenbundes entspricht. Der Reichstag z. B. ist unitarisch konstruiert, weil er in einem deutschen Einheitsstaat nicht anders gebildet sein würde, als er es heute ist. Der Reichsrat ist föderalistisch, weil seine Organisation ohne wesentliche Veränderung in einen reinen Staatenbund übernommen werden könnte. Das Entsprechende gilt für Unitarismus und Föderalismus als politische Tendenzen. Eine Richtung, die die bündischen Elemente der Verfassung im Gegensatze zu den einheitsstaatlichen zu vertiefen oder zu entwickeln sucht, ist Föderalismus; die entgegengesetzte ist Unitarismus. Ein „echter“ Föderalismus würde sich also von einem andern höchstens durch die Stärke seiner Neigung und den Umfang seiner Forderungen, nicht aber im Wesen unterscheiden.

Es bedarf nun keines Beweises, weil es allgemein anerkannt ist, daß die Weimarer Verfassung die unitarischen Elemente weit stärker betont, als dies die Bismarcksche Verfassung getan hatte. Die Zuständigkeiten des Reichs in Gesetzgebung und Verwaltung sind gegen früher gewaltig erweitert, ihre Verfassungsautonomie ist in den wichtigsten Beziehungen vernichtet worden. Der Gebiets- und Länderbestand innerhalb des Reiches ist weithin der Verfügung der Reichsgewalt preisgegeben. Vorrechte und Reservatrechte sind beseitigt. Zollwesen, Militärwesen, Eisenbahnwesen sind durchaus einheitsstaatlich gestaltet, das föderalistische Institut der Matrikularbeiträge ist verschwunden, die Reichssteuerverwaltung sofort in eine unitarische Richtung gelenkt worden. Von den unitarischen Organisationen der ehemaligen Reichsverfassung ist zwar das Kaisertum zerstört, der Kaiser ist aber durch den unitarischen Reichspräsidenten ersetzt, dem unitarischen Reichstage ist eine schier erdrückende Machtfülle in die Hand gegeben worden. Die neuen, freilich vorerst papierenen Einrichtungen des Volksentscheids und des Volksbegehrens sind rein unitarischen Charakters, nicht minder die Einrichtung des Staatsgerichtshofs. Der einstige föderalistische "Gegenspieler" des Reichtags, der Bundesrat, ist allerdings im Reichsrate wieder auferstanden. Aber nur als Schattenbild ehemaliger Größe. Weder in bezug auf den Umfang seiner Zuständigkeit, noch in bezug auf das Gewicht seines Einflusses bei der Willensbildung 
des Reichs ist der Reichsrat dem Bundesrate ebenbürtig. Stand diesem bei der Reichsgesetzgebung ein volles „Sanktionsrecht“, d. h. entscheidende und letzte Stimme zu, und konnte ein Gesetzentwurf niemals ohne vorgängige Zustimmung des Bundesrats an den Reichstag kommen, so ist der Reichsrat gegen den vom Reichstage beschlossenen Gesetzen auf einen durch parlamentarische Zweidrittelmehrheit oder Volksentscheid überwindbaren Einspruch beschränkt, und kann die Reichsregierung ihre Gesetzesentwürfe auch gegen das Votum des Reichsrats an den Reichstag bringen. Dem Reichstage gegenüber ist der Reichsrat durch den Mangel des Selbstversammlungsrechts benachteiligt. Auch tagt er nicht unter einem Präsidium, das aus ihm selbst hervorgeht, sondern unter dem Vorsitze eines Mitglieds der Reichsregierung. Nur nach harten Kämpfen hat er durchgesetzt, daß in den Vollsitzungen bei Behinderung der Reichsminister wenigstens ein Staatssekretär den Vorsitz führt; in den Ausschußsitzungen kann noch jetzt ein Ministerialdirektor, gegebenenfalls ein Abteilungsdirigent, präsidieren. Mögen das Äußerlichkeiten sein, so dienen sie doch dazu, dem Reichsrate, der ohnehin nicht eine einheitliche Körperschaft ist, das äußere Ansehen, das „Prestige“ zu rauben. Er ist ja nach außen überhaupt nicht vertretbar. Eine repräsentative Stellung ist ihm also unmöglich gemacht. Hat sich auch in neuester Zeit der Reichsrat, z. B. im Gebiete des Verordnungswesens, eine etwas günstigere Position erobert, so findet doch eine weitere Erhöhung seiner Macht in der Verfassung unübersteigliche Schranken. Nimmt man das alles zusammen und erwägt man, daß von den „vertragsmäßigen Grundlagen“ der Bismarckschen Verfassung, an die diese in Wortlaut und Geist so viel erinnerte, keine Spur übriggeblieben, daß alles jetzt auf das vereinheitlichende Prinzip der gesamtdeutschen Volkssouveränität gestellt ist, so ist klar: die einheitsstaatlichen Elemente der Verfassung haben die föderalistischen so sehr in den Hintergrund gedrängt, daß der Schritt zum vollen Einheitsstaate nur mehr ein kleiner sein würde, daß er nach der Ansicht mancher Theoretiker sogar in Wirklichkeit schon vollzogen ist.

Man kann nun nicht sagen, daß eine Verbreiterung der unitarischen Basis der deutschen Reichsverfassung an sich etwas Widernatürliches gewesen sei. Im Gegenteil, es vollzog sich hier, jedenfalls bis zu gewissem Grade, ein Prozeß, der durchaus in der Linie geschichtlicher Entwicklung gelegen war. Der Drang, die Zersplitterung des deutschen Volks in eine Fülle gesonderter Staatsgebilde durch eine einheitliche Organisation der Gesamtnation aufzuheben, hat ja schon in demselben Augenblicke eingesetzt, in welchem der Untergang des heiligen römischen Reichs deutscher Nation die Zerklüftung endgültig besiegelt zu haben schien. Die lose Fö- 
deration des Deutschen Bundes erscheint uns Heutigen bei aller ihrer jammervollen Zaghaftigkeit doch schon als Fortschritt, wenn man sie mit den tatsächlichen Verhältnissen im alten Reiche vergleicht. Die ganze Geschichte des Deutschen Bundes von 1815 bis 1866 ist eine Geschichte des Vordringens des Einheitsgedankens, der sich trotz des Scheiterns der Versuche von Frankfurt und Erfurt schließlich siegreich behauptet hat. Bismarcks Werk war das mit Meisterschaft durchgeführte Unternehmen, die unitarischen mit den föderalistischen Strebungen ins Gleichgewicht zu setzen. Aber eine schärfere Beobachtung hat uns doch später gelehrt, daß bereits in der Reichsverfassung von 1871 die unitarischen Elemente den föderalistischen politisch wie rechtlich überlegen waren. Mit Recht sprach schon im konstituierenden Reichstage von 1867 der hessische Bundeskommissar Hofmann von einem „Reste“ föderativer Elemente, der noch im Verfassungsentwurf vorhanden sei. Es ist deshalb eine offenbare Verkehrung des historischen Tatbestandes, wenn heute die bayerische Denkschrift behauptet, die im Föderalismus liegenden Kräfte seien es gewesen, die das Deutsche Reich geschaffen hätten!

Dazu kommt nun aber, daß die ganze Geschichte der Reichsverfassung in den beinahe fünf Jahrzehnten ihres Bestandes eine nur gelegentlich von föderalistischen Rückschlägen unterbrochene Geschichte fortschreitender Unitarisierung gewesen ist. Das tritt in der dauernden Erweiterung der Reichskompetenzen, in der Fruchtbarkeit der Reichsgesetzgebung und der damit zusammenhängenden Verdunkelung der Landesangehörigkeit durch das Reichsbürgerrecht, in der gleichfalls damit zusammenhängenden Verstärkung der vollziehenden Reichsgewalt und der Einsetzung zahlreicher Reichsbehörden, in der fortschreitenden Abbröckelung der Reservatrechte, in der deutlichen Verschiebung der organisatorischen Machtverteilung, die sich zugunsten der kaiserlichen Regierung und auf Kosten des Bundesrats vollzogen hat, mit voller Klarheit zutage. Der Krieg und die durch ihn geforderte Konzentration der staatlichen Kräfte hat diese Entwicklung begünstigt und beschleunigt ${ }^{6}$. Und es ist schwerlich zu bezweifeln, daß der Unitarismus dem Föderalismus nach dem Kriege noch weitere schwere Wunden beigebracht haben würde, auch wenn der Krieg mit einem deutschen Siege nach außen und ohne Revolution im Inneren sei-

6 Die Einzelheiten müssen hier als bekannt vorausgesetzt werden. Der Verfasser darf wegen der näheren Belege auf seine Schrift „Unitarismus und Föderalismus im Deutschen Reiche (1907), auf seinen Aufsatz „Bismarck und die Reichsverfassung“ in der Zeitschrift „Das neue Deutschland“ 3 [1914/15], S. 185[-191] und auf die einschlagenden Kapitel in seinem Buche „Die Reichsaufsicht“ (1917) verweisen. 
nen Abschluß gefunden hätte. Noch vor dem Zusammenbruche haben die verfassungsändernden Gesetze vom 28. Oktober 1918 entscheidende Schritte nach unitarischer Richtung getan.

Ist das alles aber richtig, so wird sich gegenüber dem neuerlichen Vorstoße föderalistischer Strebungen zweierlei sagen lassen.

Es wäre ein Ding der Unmöglichkeit, weil eine vollkommene Umkehrung des geschichtlichen Gesamtverlaufs, wollte man in der Gestaltung des Verhältnisses zwischen Reich und Ländern noch hinter die Linie zurückgehen, die durch die Bismarcksche Verfassung gezogen worden ist. Daß für Deutschland eine Rückkehr zum „echten“ oder „reinen“ Föderalismus, d. h. zum Föderalismus des Frankfurter Bundestags ausgeschlossen ist, wird wohl von keinem ernsthaften Politiker bezweifelt werden. Aber es wäre ebenso widernatürlich, wenn man das Reich um Kompetenzen berauben wollte, deren Besitz ihm schon durch die Bismarcksche Reichsverfassung gewährleistet worden war, oder wenn man den Einzelstaaten Einflußrechte über das Maß der ihnen dort zugestandenen einräumen würde. Die bayerische Denkschrift setzt sich in einen auffälligen Widerspruch, wenn sie die Verfassung von 1871 als die den Lebensbedürfnissen des Reichs „vollständig auf den Leib geschnittene“ Verfassung preist, und wenn sie gleichwohl dem Reiche Zuständigkeiten nehmen will, die ihm eben in dieser Verfassung zugewiesen waren. Das gilt z. B. für die Gesetzgebung über die Fremdenpolizei. Die Denkschrift behauptet von dieser, ihre einheitliche Regelung sei heute gar nicht mehr möglich. Die Gründe, die dafür angegeben werden, beweisen aber höchstens, daß eine vom Reiche vorgenommene Regelung auf mancherlei besondere Landesinteressen wird Rücksicht nehmen müssen, aber nicht, daß sich das Reich überhaupt nicht gesetzgeberisch auf diesem Felde zu betätigen vermag. Man wird im Gegenteil nicht nur die Möglichkeit, sondern sogar die Notwendigkeit einer reichsgesetzlichen Regelung der Fremdenpolizei behaupten, ja darüber hinaus die Einführung einer gewissen Reichsexekutive auf diesem Gebiete fordern müssen; es ist ein unwürdiger und auf die Dauer unerträglicher Zustand, daß die Reichsregierung die Ausweisung reichsschädlicher Individuen von den Einzelstaaten erbitten muß. Ferner: die bayerische Denkschrift fordert nicht nur - wie ich glaube, mit Recht - eine durchgreifende Änderung in der bisherigen Regelung der Finanzwi r s c h a f t in Reich und Ländern. Aber wenn sie sich darüber beklagt, daß der Artikel 8 der Weimarer Verfassung die „alleinige Steuersouveränität“ des Reiches „herbeigeführt" habe, so übersieht sie, daß dieser Artikel in seinem entscheidenden Teile schon in der Bismarkschen Verfassung (Art. 4, Ziff. 2) enthalten war; es ist eine zwar verbreitete, aber darum nicht 
weniger irrige Ansicht, daß das Reich nach der ehemaligen Verfassung auf die Gesetzgebung über die indirekten Steuern beschränkt gewesen sei. Selbst der den Einzelstaaten unter Umständen bedrohliche Art. 11 der jetzigen Verfassung - er gestattet dem Reiche, Grundsätze über Zulässigkeit und Erhebungsart von Landesabgaben aufzustellen, soweit dies erforderlich ist, um Schädigungen der Reichseinnahmen, Doppelbesteuerungen usw. zu verhindern - enthält in allem wesentlichen nichts anderes, als was bereits im ehemaligen Verfassungsrechte zwar nicht ausdrücklich, aber „stillschweigend“ gesetztes Recht war ${ }^{7}$. Weiter: Die bayerische Denkschrift wendet sich gegen die Ausdehnung, welche die Reichsaufsicht durch Art. 15 der Verfassung erfahren habe. Vor allem sei das sogenannte selbständige Aufsichtsrecht des Reiches, d. h. das Recht, die Länder auf den Gebieten der Reichsgesetzgebung auch dann zu beaufsichtigen, wenn das Reich von seinem Rechte zur Gesetzgebung noch keinen Gebrauch gemacht hat, nicht nur überflüssig, sondern mit der „Selbständigkeit“ der Einzelstaaten unvereinbar. Aber dieses Recht ist nicht nur unentbehrlich man denke gerade etwa an die Fremdenpolizei und andere, die außenpolitischen Interesse des Reichs berührende Angelegenheiten -, sondern es ist auch nach richtiger Ansicht in der alten Verfassung vollauf anerkannt gewesen und dutzendfach angewendet worden. Hier überall würde uns also eine „Revision“ der Weimarer Verfassung im föderalistischen Sinne nicht nur hinter das Jahr 1919, sondern hinter das Jahr 1867 zurückführen. Das ist schlechterdings unmöglich. Am unmöglichsten aber dürfte es sein, die durch mannigfache Zuständigkeitsregeln verbürgte Einheitlichkeit der deutschen Wirtschaftsgesetzgebung aufzugeben: Mit Recht klagt die Denkschrift über die hypertrophische politische Machtstellung, die sich die Wirtschaft in ihrer Kartellierung und Vertrustung erobert habe. Wenn es aber die Aufgabe ist, die Macht der wirtschaftlichen Organisationen zu brechen, die heute dem Reiche ihren Willen aufzwingen, so dürfte der Vorschlag, „an die Stelle des einen politischen Zentrums, nach dem sich die Wirtschaft jetzt orientiert und das von ihr beherrscht wird, wieder eine Mehrheit von Zentren treten zu lassen“, ein Rezept von fragwürdiger Heilwirkung enthalten.

Aber ebenso unmöglich, weil ebenso unnatürlich, wie solche Rückwärtsrevidierungen, würde jedes Unternehmen sein, die von der Weimarischen Verfassung erzielte Vereinheitlichung auf solchen Gebieten zu besei-

7 Näheres über diese und andere Ausdehnungen der Reichszuständigkeit vermöge des Grundsatzes der „Konnexität“ in meiner Schrift: Die Kompetenzen des Bundesstaats und die geschriebene Verfassung [Tübingen] (1908) S. $294 \mathrm{ff}$. 
tigen, auf denen sie sich als Endpunkt einer schon längst im Laufe befindlichen, in ihrem Ausgange vorhersehbaren Entwicklung darstellt. So war z. B. das Recht der Einzelstaaten, mit außerdeutschen Staaten Ge$\mathrm{s}$ and ts chafts verkehr zu unterhalten und fremde Konsuln mit dem Exequatur zu versehen, ein seit langem dem Untergange geweihtes Überbleibsel aus einer überholten Periode deutschen Lebens. Es wäre ein Rückschritt, jenes Recht wieder einzuführen, und es wäre ebenso ein Rückschritt, wenn man das nach RV. Art. 78 eng begrenzte und unter präventive Reichsaufsicht gestellte Recht der Länder, $S$ t a a t s ve r t rä ge mit dem Auslande zu schließen, erweitern wollte. Ein Fortschritt war die noch von Bismarck vergeblich versuchte, aber doch allmählich sich vollziehende, auf allerlei föderalistischen Umwegen schrittweise vor sich gehende, in Weimar durchgeführte Vereinheitlichung des deutschen E isenbahnwesens. Daß wir hier nichts mehr werden rückgängig machen können, versteht sich von selbst; es hat aber keinen Wert, hierüber zu streiten, da wir uns auf fremdes Diktat hin soeben anschicken müssen, unsere Staatsbahnen überhaupt aus der Hand zu geben. Die Unitarisierung des Militärwe se n s hatte sich seit langem angebahnt; das System der Militärkonventionen, die Einheitlichkeit des Militäretats und der finanziellen Militärverwaltung, die in Vertretung des Reichsfiskus geführt wurde, die mehr und mehr zutage tretende Abhängigkeit der einzelstaatlichen Kriegsministerien von den Zentralinstanzen des Reichs, das alles hatte den Prozeß fast schon zur Reife gedeihen lassen. Noch kurz vor der Revolution hatte das Gesetz vom 28. Oktober 1918 die Verantwortlichkeit aller einzelstaatlichen Kriegsminister vor Bundesrat und Reichstag begründen wollen! Das schlechterdings einheitliche Reichsheer der Weimarer Verfassung ist also schließlich nichts anderes als die, freilich republikanisierte, Erfüllung eines alten Bismarckschen Traumes. Hatte doch der erste Reichskanzler schon 1869 von dem künftigen „Königlich deutschen Heere“ gesprochen, dem anzugehören sich die Söhne zur Ehre rechnen würden. Daß eine Wiedereinführung des Kontingentsystems für das Hunderttausendmannheer, das uns vom Versailler Friedensdiktat zugestanden worden ist, eine Absurdität bedeuten müßte, wird niemand leugnen. Auch die bayerische Denkschrift gibt zu, es sei eine Teilung der Militärhoheit nach dem früheren Muster aus militärisch-technischen Gründen unmöglich. Aber ebenso unmöglich wäre - und zwar nicht nur aus technischen, sondern aus inneren Gründen - die Wiederherstellung von einzelstaatlichen R e s e rvatrechten, z. B. auf dem Gebiet des Heerwesens, der Bierbesteuerung, des Postwesens oder im Rahmen des Art. 48 der Verfassung. Die Wegräumung der Reservatrechte durch die Weimarer Verfassung ist fast 
allgemein als Beseitigung einer hässlichen Anomalie empfunden worden. Wenn man, wie z. B. Kahl, um des lieben Friedens willen empfiehlt, in dieser Hinsicht den bayerischen Wünschen Zugeständnisse zu machen, so übersieht man, daß hier ein den Bayern hingeworfener Brocken sofort andere Hungrige an den Tisch locken, daß man, um mit Bilfinge $r$ zu sprechen, „den Partikularismus aller entfachen “8 würde. Was aber von der Verteilung der Zuständigkeiten zwischen Reich und Ländern gilt, das gilt auch von der Organisation der Reichsgewalt. So war nach der Bismarckschen Verfassung der Bundesrat grundsätzlich der Inhaber der Verordnu ngs ge walt im Reiche. Aber der steigende Einfluß der kaiserlichen Regierung auf die Arbeit des Bundesrats hatte allmählich dazu geführt, daß jene, wie auch andere „ministerielle“ Funktionen, zwar nicht formell, aber der Sache nach auf die Reichsregierung - die man nur aus Vorsicht als „Reichsleitung“ bezeichnete - übergegangen war, dergestalt, daß man sagen durfte, es seien „viele bundesrätliche Verordnungen in Wahrheit nichts anderes als Verordnungen der obersten Reichsbehörde, die sich um der verfassungsmäßigen Form willen in das Gewand einer Bundesratsverordnung gekleidet haben“. Hiernach wäre es eine Verleugnung von Ergebnissen einer allgemeinen Entwicklung, wenn man nach dem Vorschlage der bayerischen Denkschrift den Reichsrat unter Ausschaltung der Reichsregierung wieder mit der gesamten Verordnungsgewalt bekleiden wollte, ganz abgesehen davon, daß ja die Hauptarbeit bei der Formulierung der Gesetzesentwürfe doch immer bei den Reichsministerien bleiben wird, daher auch die Ausführungsverordnungen technisch am besten von diesen gestaltet werden können und die maßgebliche Beteiligung des Reichsrats nur zu unfruchtbarer Doppelarbeit führen müßte. Die Bismarcksche Verfassung hatte, um noch ein anderes Beispiel zu geben, die Handhabung der Reichsaufsicht zu einem sehr wesentlichen Teile in die Hand des Bundesrats gelegt. Aber schrittweise und zunächst zögernd, dann jedoch mit einer sich steigernden Konsequenz hatte das Reich durch Gründung von Reichsverwaltungsgerichten den Bundesrat aus dem Verfahren der Reichsaufsicht ausgeschaltet. Es war auch hier wieder nur die Krönung eines im Aufbau befindlichen Gebäudes, wenn man in Weimar die schon früher oft verlangte Einsetzung eines Reichsstaatsgerichtshofes vornahm, dem die letzte Entscheidung über Streitigkei-

8 [Carl Bilfinger, Der deutsche Föderalismus in Vergangenheit, Gegenwart und Zukunft, in: VVDStRL 1 (1924), S. 35-59, hier: S. 58: „zum Parikularismus beigetragen"]. 
ten zwischen Reich und Ländern, also auch die Entscheidung in sogenannten Aufsichtskonflikten zugewiesen wurde.

III.

Die unitarische Fortbildung des Reichsverfassungsrechts auf den Gebieten, von denen bisher die Rede war, hätte sich nach dem Gesagten aller Wahrscheinlichkeit nach auch dann vollzogen, wenn uns die Revolution erspart geblieben wäre. Gewiß hätte sich nicht alles auf einmal, nicht alles so glatt und reinlich, wie jetzt, durchgesetzt. Manches, was die Nationalversammlung mit einem Federstriche ins Leben rufen konnte, wäre erst nach harten Kämpfen in den Konferenzsälen der Regierungen und in den Verhandlungssälen der Parlamente entstanden, schließlich aber wäre es doch einmal geboren worden. Allein die Nationalversammlung hat die Gunst der Stunde, die sich ihr bot, nicht nur benutzt, sondern sie hat sie auch mißbraucht. Sie hat bei der Neuregelung des Verhältnisses zwischen Reich und Ländern vielfach nicht nur einen gemessenen Schritt, sondern einen kühnen Sprung getan. Sie hat sich nicht begnügt, die Ausstattung des Reichs mit Zuständigkeiten dort, wo Lücken bestanden, zu ergänzen, sondern sie hat das Reich mit neuen Kompetenzen verschwenderisch beschenkt. Und sie hat den den Ländern traditionell zustehenden Einfluß auf die Willensbildung des Reichs nicht nur geschmälert, sondern nahezu vernichtet. Es fragt sich, ob diese gewalttätige Beschleunigung der unitarischen Entwicklung auf einer richtigen oder auf einer falschen Einschätzung der in Deutschland vorhandenen politischen Kräfte beruhte.

Die für den Inhalt der Weimarer Verfassung in erster Linie verantwortlichen Männer hatten sich in den ersten Wochen der Revolutionszeit in den Glauben versetzen lassen, daß die Umwälzung den Lebenswillen und die Lebenskraft der deutschen Einzelstaaten gebrochen habe. Dieser Glaube hat sich schon nach kurzer Zeit als ein schwerer Irrtum erwiesen. Man wiegte sich in dem Gedanken, die Beseitigung der Dynastien und ihr kampfloser Rückzug habe gezeigt, wie schwach sie im Boden ihrer Länder verwurzelt gewesen; er habe vor allem auch die Eigenständigkeit der Länder selbst an der Wurzel getroffen. Aber nicht nur das erste, sondern auch das zweite war falsch. Die Dynastien hatten doch eben $S$ t a t e n gegründet und befestigt gehabt. Sie hatten diese in langer und zäher Arbeit, vor allem durch die Schöpfung einer in sich durchaus geschlossenen Verwaltung, auf eigene Füße gestellt. Und die Staaten ließen bald erkennen, daß sie zwar schlimmstenfalls auf ihre Dynastien verzichten konnten - manche 
haben es, wie alle Welt weiß, nur sehr ungern und sozusagen nur des Dekorums wegen und unter Vorbehalt des Widerrufs getan -, daß sie aber nicht willens waren, sich selbst aufzugeben. Es war und ist nicht etwa nur eine von Erinnerungen an überlebte Zeiten gespeiste Romantik, die den Fortbestand der Einzelstaaten verlangt, und es sind nicht nur engherzige und lokale wirtschaftliche Interessen, die sich für die Fortdauer einzelstaatlicher Regierungszentren rühren - nebenbei bemerkt, gibt es auch unitarische Romantiker und gibt es Kreise, die an einer unitarischen Entwicklung ein in Zahlen ausdrückbares Geschäftsinteresse besitzen -, sondern es handelt sich hier um Stimmungswerte viel allgemeinerer Natur. Die Landesbevölkerung als solche, und zwar ganz unabhängig von ihrer Stammeszugehörigkeit, die ja nur an einzelnen Stellen und auch da nur eine nebensächliche Rolle spielt, ist durch eine lange Erziehungsarbeit des Landesfürstentums zur Staatlichkeit herangebildet worden, ist zum Staate zusammengewachsen, hat ihr Staatsgefühl vom Landesstaate empfangen und an ihm genährt, legt Wert auf einen ununterbrochenen Zusammenhang mit einer Landesregierung, will von Landesbeamten regiert sein. Deshalb ist der Sitz des Widerstandes gegen Unitarisierung und Zentralisierung durchaus nicht nur in der Landesbürokratie, sondern ebenso in den das Landesvolk repräsentierenden Landtagen anzutreffen. Es zeigt sich, daß das System des Konstitutionalismus in den Einzelstaaten eine bedeutsame Wirkung auf deren innere Kohärenz ausgeübt hat. Auch der durch die Weimarer Verfassung zwar nicht nach ihrem Wortlaute, aber nach ihrem Sinne für die Landesverfassungen geforderte Parlamentarismus hat keineswegs die erwartete Homogenität zwischen Landtagen und Reichstag und keineswegs eine Zersetzung der in den Ländern wirkenden partikularistischen Kräfte herbeigeführt, er hat sich vielmehr geradezu als Stütze föderalistischer oder gar partikularistischen Strebungen erwiesen ${ }^{9}$. Dagegen hat auch der organisatorische Zusammenhang zwischen Reichs- und Landesparteien nichts auszurichten vermocht Ein sozialdemokratischer Abgeordneter oder Minister spricht im preußischen oder bayerischen Landtage

9 Mit Recht bemerkt Wittmayer, [Europäische] Organisationsfragen der Weimarer Verfassung, Zeitschrift für Politik Bd. 13 [1924] S. 231, dem Reichsparlamentarismus sei im Landesparlamentarismus ein gefährlicher Konkurrent und Gegner entstanden; s. auch S. 242, 246. Schon vorher hat sich Bilfinger, Der Einfluß der Einzelstaaten auf die Bildung des Reichswillens (1923) S. 89, in ähnlichem Sinne ausgesprochen. - Die gegenteilige Auffassung von Koch, Deutsche Juristenzeitung 1924 Sp. 76 scheint mir nicht begründet zu sein. Doch dürfte das von ihm geäußerte Bedenken bezüglich der Notwendigkeit des parlamentarischen Systems in den Ländern zuzutreffen. 
eine andere Sprache als im Reichstage. Es ist bezeichnend, daß es nicht Herr vo n Kahr, sondern Herr E is ner gewesen ist, der zum ersten Male dem Reiche den bayerischen Fehdehandschuh vor die Füße geworfen hat!

Der falsche Glaube, daß die Einzelstaaten bereits reif zum Abbau seien, hat sich bitter gerächt. Die Übertreibung des unitarischen Prinzips in der Verfassung hat eine Opposition hervorgerufen, deren stürmische Entladungen das Reich geradezu in eine kritische Lage gebracht haben. Es hilft nichts, wenn man sich über die Maßlosigkeit der an der Reichsverfassung geübten Kritik entrüstet. So wenig man die Haltung der bayerischen Regierung in ihrem Konflikte mit dem Reiche vom Standpunkte des Rechts verteidigen kann, so sehr muß man zugeben, daß dieser Konflikt selbst nur das Symptom einer tiefliegenden Krankheit darstellt. Die bayerische Denkschrift hat vollkommen recht, wenn sie sagt: „Was als Klammer für das neue Reich gedacht war, hat sich als Sprengpulver erwiesen."

Die Weimarer Verfassung ist also in ihrer starken Betonung des Unitarischen der geschichtlichen Entwicklung vorausgeeilt. Ihre Verfasser haben Früchte ernten wollen, die noch nicht gereift waren. Sie haben sich allzusehr von dem Gedanken beherrschen lassen, daß der Bundesstaat überlebt, die Zeit des Einheitsstaates nahe herangekommen sei. Seltsam, daß sie, die doch so gern in westeuropäischen Verhältnissen ihre Vorbilder suchten, so völlig übersehen haben, wie in England föderalistische, in Frankreich rationalistische Tendenzen bestrebt sind, den Einheitsstaat aufzulockern. Die bundesstaatliche Periode des modernen Großstaates ist noch nicht vorüber. Weder in den Vereinigten Staaten noch in den britischen Dominions denkt man daran, die bundesstaatliche Verfassung aufzugeben; in den letzteren ist sie zum Teil vor kurzer Zeit erst recht befestigt worden.

So ist die föderalistische Reaktion in Deutschland zu einem guten Teile innerlich begründet. Diese Reaktion hat aber noch eine weitere Grundlage. Wir haben schon unter der Herrschaft der Bismarckschen Verfassung beobachten können, wie eng in Deutschland das bundesstaatliche Problem mit dem „konstitutionellen“ zusammenhängt. Es war damals offensichtlich, daß jede Erweiterung der Reichszuständigkeit den Einfluß des Reichtags vergrößerte. Denn jedes neue Reichsgesetz erstreckte die Reichsaufsicht auf neue Gebiete; die Handhabung der Reichsaufsicht unterlag aber der Kontrolle des Reichstags. Dasselbe galt für jede Bereicherung der Stellung des Kaisers, die auf Kosten des Bundesrates ging. Denn da der Bundesrat keiner parlamentarischen Verantwortlichkeit unterlag, wohl aber der Reichskanzler, mit dessen Hilfe der Kaiser regierte, so kam eine Verschiebung des organisatorischen Kräfteverhältnisses zugunsten des Kai- 
sers immer auch den Kontrollbefugnissen des Reichstags zugute. Daher die erklärte Feindschaft der konservativen Parteien gegen den Unitarismus. Daher Bismarcks vorsichtige, zuweilen schroff ablehnende Haltung gegenüber unitarischen Tendenzen; sie war sicher viel weniger durch eine Hinneigung zum Föderalismus als durch eine Abneigung gegen den Parlamentarismus bestimmt. Nun hat in der Weimarer Verfassung zusammen mit dem Unitarismus auch der demokratische Parlamentarismus einen entscheidenden Sieg davongetragen. Einen Sieg von so zerstörender Wirkung, daß er jeden Gegner auf dem Schlachtfelde hat liegen lassen. Die Verfassung hat einen Parlamentsabsolutismus in reinster Form begründet. Allein die geschichtliche Erfahrung zeigt, daß sich gegen jeden Absolutismus, mag er ein monarchischer oder ein parlamentarischer sein, von selbst irgendwelche Gegengewichte bilden, Gegenkräfte, die sich in den Dienst der vom Absolutismus bedrohten Freiheit der Bürger stellen. Diese Gegengewichte können sehr verschiedener Art sein. Es kann geschehen, daß die richterliche Gewalt als Schützerin der Freiheit auftritt, indem sie das durch den Parlamentarismus vernichtete Gleichgewicht der Gewalten zu ihrem Teile wiederherzustellen sucht. Sicherlich ist es kein Zufall, daß das richterliche Prüfungsrecht, d. h. das Recht des Richters, die Gesetze auf ihre Verfassungsmäßigkeit zu prüfen, gerade heute, wo das Parlament die Gesetzgebung allein in der Hand hat, weit stärker betont wird als früher. Es kann aber auch sein, daß sich in der Selbst verwaltung ein Mittel findet, dem Absolutismus ein Paroli zu bieten. Die Geschichte des englischen Selfgovernments beweist, welche Rolle die Selbstverwaltung als Hüterin der Freiheit gegenüber der Allmacht des Parlaments zu spielen vermag. Nun ist aber der Föderalismus zu gutem Teile nichts anderes als eine Betonung des Gedankens der Selbstverwaltung in bestimmter Form. Und es ist eine ganz natürliche Erscheinung, daß er in demselben Augenblicke auf den Plan tritt, in dem sich der Unitarismus mit einem freiheitsfeindlichen Absolutismus verbrüdert hat. Also Föderalismus um der Freiheit willen. Daraus erklärt sich auch, daß die an sich so unsympathische Kampfansage der letzten bayerischen Regierung gegen die Reichsgewalt auch in Kreisen, die mit partikularistischen Velleitäten nicht das mindeste zu tun haben, auf Beifall gestoßen ist; es war keineswegs nur die „preußische Reaktion“, die jene Kriegserklärung - nach Preuß‘ Ausdrucke - „mit Hurragebrüll“ als einen Vorstoß gegen „die dreimal verfluchte Verfassung der Republik" aufgenommen hat.

Betrachtet man die jüngste föderalistische Bewegung von diesem Standpunkte aus, so kann man sie nicht ohne weiteres als Ausdruck verkehrter Anschauungen bezeichnen. Was dem gesunden Gedanken der Selbstver- 
waltung dient, kann nicht selbst ganz ungesund sein. Das führt sofort zu einer weiteren Erwägung. Das organisatorische Prinzip, das man mit dem Namen Selbstverwaltung bezeichnet, äußert sich in zwei Richtungen. Selbstverwaltung besteht einmal in einer eigenen, selbständigen Betätigung öffentlicher Gewalt auf einem abgegrenzten Gebiete. Selbstverwaltung besitzt, wer innerhalb eines größeren Ganzen Verwaltung im eigenen Namen betreibt. Selbstverwaltung heißt aber auch Einstellung gesellschaftlicher Kräfte, die dem Ganzen gegenüber ein eigenes Leben führen, in den Dienst des Ganzen. Die Gemeinde hat Selbstverwaltung, soweit ihr der Staat einen Kreis von Geschäften zur eigenen Besorgung überläßt; sie übt aber Selbstverwaltung auch dann aus, wenn sie vom Staate mit Wahrnehmung staatlicher Aufgaben dergestalt betraut wird, daß ihr Organismus mit dem Staatsorganismus verflochten, daß ihre Organe zu Staatsorganen, das heißt im Namen des Staates handelnden Organen gemacht werden. Gerade in diesem zweiten Sinne zeigt sich die gewaltige ethische Bedeutung der Selbstverwaltung als eines Mittels zur Erziehung zum Gemeinschaftssinn. Es ist alte Staatsweisheit, daß man widerstrebende Kräfte am sichersten für den Staat gewinnt, wenn man sie zur Arbeit für den Staat heranzieht. Die brandenburgisch-preußischen Kurfürsten und Könige haben wohl gewußt, was sie taten, als sie den frondierenden Landadel in den Dienst für den Staat hineinzwangen, und es gehörte zu den verhängnisvollen Fehlern der wilhelminischen Ära, daß man die Kräfte der durch die Sozialdemokratie vertretenen Arbeiterschaft künstlich von der Mitarbeit für den Staat ferngehalten hat, statt sie in diese Arbeit einzuspannen. Der Freiher $r$ vom $S$ tein hat nirgends ein wahreres Wort gesprochen als in der Einleitung zur preußischen Städteordnung ${ }^{10}$, wo er rühmt, daß die „tätige Einwirkung auf die Verwaltung des Gemeinwesens den Gemeinsinn errege und erhalte“. Von dieser Seite aus betrachtet, bekommt auch der Föderalismus ein neues Gesicht. Denn die Forderung, den Einzelstaaten ein größeres Feld eigener Betätigung abseits vom Reiche einzuräumen, enthält nur die eine Hälfte des föderalistischen Programms. Die andere besteht in dem Verlangen, den Anteil der Länder an der Willensbildung des Reichs in Gesetzgebung und Verwaltung über das bisherige Maß hinaus zu

10 [Abdruck in: Freiherr vom Stein, Briefe und amtliche Schreiben, hrsg. Walther Hubatsch, Bd. II/2: Das Reformministerium (1807-1808), Stuttgart 1960, S. 948. „... Notwendigkeit, den Städten eine selbständigere und bessere Verfassung zu geben, in der Bürgergemeine einen festen Verständigungspunkt gesetzlich zu bilden, ihnen eine tätige Einwirkung auf die Verwaltung beizulegen und durch diese Teilnahme Gemeinsinn zu erregen und zu erhalten"]. 
steigern. Dieses Verlangen kann natürlich gestellt werden zur Befriedigung des eigennützigen Interesses an der Geltendmachung der einzelstaatlichen Persönlichkeit. Aber ebenso möglich ist es, daß in ihm der Wunsch zum Ausdrucke kommt, Dienst zu leisten an der Reichsgesamtheit, der Wunsch, wie es Bilfing e $\mathrm{r}^{11}$ ausdrückt, „die noch vorhandenen Kräfte der Einzelstaaten möglichst einheitlich in den Dienst des Reiches zu stellen“. Die Erfüllung dieses Wunsches würde in der Tat geeignet sein, den „Gemeinsinn“ der Länder zu erregen und zu erhalten. Folglich wäre ein Föderalismus solcher Prägung nicht einheitsgefährdend, sondern einheitsfördernd; er würde den Partikularismus nicht begünstigen, sondern ihm entgegenwirken; er würde statt des „Sprengpulvers“ eine „Klammer" schaffen. Also Föderalismus nicht nur, wie vorhin, um der Freiheit, sondern auch um der Einheit willen. Das war ja auch der Kern des Föderalismus, wie ihn Bismarck verstanden und vertreten hat! Niemals hat er größere Staatsweisheit bekundet als in dem Augenblicke, als er durch die Einrichtung des Bundesrats das deutsche Landesfürstentum zur selbständigen Mitarbeit am Reiche heranzog. Das hat die Reichseinheit gestärkt, nicht gefährdet. Es ist eine einseitige Auffassung der deutschen Staatsgeschichte, wenn man das Länderstaatstum nur als Quelle der Dekomposition betrachtet. So richtig es ist, daß die Territorialgewalten den Untergang des alten Reiches herbeigeführt haben, so unzweifelhaft ist es doch auch, daß sie Jahrhunderte hindurch das Reich, dessen Bestand von einem im Wesen undeutschen Kaisertum bedroht war, in föderativer Form zusammengehalten haben. Man wird heute gewiß nicht behaupten wollen, die Reichsgewalt sei so stark, daß sie der Mithilfe der Einzelstaaten bei der Erhaltung der Reichseinheit durchaus entraten könnte!

Man kann und muss nach alledem zugeben, daß es neben unberechtigten auch wohlbegründete Ansprüche des deutschen Föderalismus gibt. Und es fragt sich nun, wie diese erfüllt werden können. Bei der Antwort hierauf wird die formelle und die materielle Seite auseinanderzuhalten sein.

IV.

Es ist mißlich, daß sich die von der drängenden Gegenwart geforderten Konzessionen an den Föderalismus, abgesehen von unbedeutenden Din-

11 [Carl Bilfinger, Der deutsche Föderalismus in Vergangenheit, Gegenwart und Zukunft, in: VVDStRL 1 (1924), S. 35-59, hier S. 58: 1. These]. 
gen, nicht ohne eine förmliche Änderung der Verfassungsurkunde, also vermutlich nur unter heftigen parlamentarischen Kämpfen werden verwirklichen lassen. Das Verfassungsrecht des Deutschen Reichs in der Bismarckschen Periode besaß eine wunderbare Beweglichkeit, die es erlaubte, ohne sonderliche Schwierigkeiten den wechselnden Bedürfnissen der bundesstaatlichen Politik Rechnung zu tragen, dergestalt, daß sich je nachdem bald eine unitarische, bald eine föderalistische Biegung der staatsrechtlichen Verhältnisse vornehmen ließ. Das hing zusammen einmal mit der in der Praxis ausgebildeten Methode der „stillschweigenden“, d. h. solcher Verfassungsänderungen, die sich durch einfache Gesetze ohne Änderung des Verfassungstexts vollziehen lassen. Zwar mußten solche Gesetze die für Verfassungsänderungen vorgeschriebenen Formen wahren. Aber die Verfassung kannte für Verfassungsänderungen keine andere Erschwerung, als daß sich im Bundesrate nicht vierzehn Stimmen oder mehr gegen die Änderung erklären durften; eine erhöhte Majorität im Reichstage wurde nicht gefordert. So konnten sich oft fast unvermerkt Verschiebungen in der bundesstaatlichen Struktur des Reichs, sei es in unitarischer Richtung - das war das häufigste -, sei es in föderalistischer vollziehen. Die wichtigsten Erweiterungen der Reichskompetenz und die durchaus unitarisch wirkende Einführung von Stellvertretern des Reichskanzlers sind ebenso, wie die föderalistische Rückbildung der Reichsfinanzverfassung durch die Franckensteinsche Klausel, ${ }^{12}$ von einfachen Gesetzen herbeigeführt worden. Dazu kam, für die Gesetzgebung wie für die Verordnungs- und Verwaltungspraxis von Bedeutung, daß die Verbindung des Bundesratssystems mit dem System der preußischen Hegemonie der Verfassung eine ungemeine Elastizität verlieh. Je nachdem die preußische Vormacht es gut fand, sich vor den unitarischen oder vor den föderalistischen Wagen zu spannen, konnte sie ihre beherrschende Stellung im Bundesrate dazu benutzen, diesen in die eine oder andere Richtung zu lenken. Die preußische Hegemonie war weder ein rein unitaristisches Element der Verfassung, wie manche meinen, noch ein föderalistisches, wie andere denken, sondern sie war gerade ein Instrument, vortrefflich geeignet, die beiden Gegensätze in der Verfassung in harmonischen Zusammenklang zu bringen.

Die Weimarer Verfassung ist von solcher Schmiegsamkeit weit entfernt. Das bedeutet keinen Vorwurf. Im Gegenteil, eine auf demokratisch-parlamentarischer Basis aufgebaute Verfassung, welche die Gesetzgebung in die Hände rasch wechselnder Mehrheiten legt, muß eher „starr“, als „biegsam“

12 [Dazu vgl. Andreas Thier, Franckensteinsche Klausel, in: Handwörterbuch zur deutschen Rechtsgeschichte, 2. Aufl., Berlin 2008, Bd. I, Sp. 1648-1650]. 
sein, wenn anders der verfassungsmäßige Zustand vor dauerndem Wechsel gesichert werden soll. So hat der Art.76 der Reichsverfassung die Änderung der Verfassung an wesentlich schwerere Formen gebunden, als wir früher gewohnt waren. Freilich hat sich das System der „stillschweigenden" Verfassungsänderungen aus der früheren in die jetzige Praxis herübergeschleppt. Allein nach Lage der Dinge wird damit nicht eine Erleichterung für föderalistische, sondern gerade für unitarische Verfassungsänderungen geboten, dies sogar in so hohem Maße, daß die bayerische Denkschrift an diesem Punkte mit einer besonders energischen und, wie ich glaube, berechtigten Kritik eingesetzt hat ${ }^{13}$.

Angesichts der Schwierigkeiten, die sich einer Befriedigung föderalistischer Wünsche auf dem ordnungsgemäßen Wege der Gesetzgebung entgegenstellen, hat man versucht, auf Umwegen zu helfen.

Man hat bei mehreren Gelegenheiten förmliche Verträge zwischen Reich und Ländern geschlossen. Das schien z. B. im Bereiche des Post-, Eisenbahn- und Wasserstraßenwesens sogar durch die Verfassung geboten zu sein; denn diese verlangte sowohl hinsichtlich der Post- und Telegraphenverwaltungen Bayerns und Württembergs, als bezüglich der Staatseisenbahnen, Wasserstraßen und Seezeichen eine „Verständigung“ über die Bedingungen der Übernahme. Dabei hat sich nur leider gezeigt, daß die $\mathbf{Z u}-$ geständnisse, die das Reich den Selbständigkeitsansprüchen der beteiligten Einzelstaaten machte, entweder mager waren und daher nicht befriedigten, oder daß sie, soweit sie Beifall fanden, in der Einräumung höchst bedenklicher, weil dem Sinne der Verfassung zuwiderlaufender Sonderrechte bestanden.

In anderen Fällen hat man geglaubt, durch Regierungs erklär u n g e n mindestens eine Beruhigung schaffen zu können. Bekannt sind die ausführlichen Erklärungen, welche die Reichsregierung der bayerischen Regierung gegenüber am 11. und am 23. August 1922 über die Handhabung der Republikschutzgesetze abgegeben hat, und das damit zusammenhängende Schreiben des Reichskanzlers an den bayerischen Ministerpräsidenten vom 23. August 1922, worin unter anderem versprochen wird, es solle von den noch nicht ausgeführten Zuständigkeiten des Reichs

13 Über die Zulässigkeit und Angemessenheit stillschweigender Verfassungsänderungen hat der im September d. J. in Heidelberg tagende deutsche Juristentag Verhandlungen gepflogen und Beschlüsse gefaßt. Diese werden nebst den Referaten des Grafen zu Dohna und des Verfassers dieser Abhandlung demnächst in Drucke erscheinen. [in: Verhandlungen des Dreiunddreißigsten Deutschen Juristentags, Berlin und Heidelberg 1925]. 
nicht ohne Not und, soweit möglich, nicht ohne Zustimmung des Reichsrats Gebrauch gemacht werden. Noch bekannter ist das „Abkommen“ mit der bayerischen Regierung vom Februar 1924, dem ein spöttischer Mund den Namen des „Homburger Friedens“ beigelegt hat. Hier ließ sich die Reichsregierung zu Versprechungen hinsichtlich der Abberufung des Landeskommandanten, der Verwendung „bayerischer" Truppen außerhalb Bayerns, des Inhalts des Fahneneides herbei. Weniger bekannt, aber nicht weniger wichtig war die den Landesregierungen gemachte Zusage, man werde die in Art. 69 der Verfassung ausgesprochene Verpflichtung, die Gesetzentwürfe vor der Einbringung beim Reichstage zunächst dem Reichsrate vorzulegen, nicht weiterhin durch Provokation von Initiativanträgen aus der Mitte des Reichstags umgehen. Im April 1924 sind Vereinbarungen in Angelegenheiten des Eisenbahnwesens abgeschlossen worden, und der Reichskanzler Marx hat in seiner Rede vom 4. Dezember 1923 geradezu programmatisch den „Weg der Verhandlungen“ als den besten Weg bezeichnet, um das Verhältnis zwischen Reich und Ländern befriedigend zu gestalten.

Über solche vertragsmäßige oder doch vertragsähnliche Abmachungen ließe sich manches sagen. Sie haben einerseits einen nur sehr beschränkten Wert, da sie, sofern sie überhaupt rechtlich bindend sein sollten, doch jedenfalls nur die im Augenblicke am Ruder befindliche, nicht jede künftige Reichsregierung verpflichten. Sie sind auf der anderen Seite politisch bedenklich; es liegt nahe, daß die am Vertrage nicht beteiligten Landesregierungen gegen solche Extratouren recht nachdrücklich Einspruch erheben. Und es besteht die Gefahr, daß die Reichsregierung bei jedem Gesetzentwurfe, den sie einbringt, darauf gefasst sein muß, auf früher abgegebene Zusicherungen allgemeinen Inhalts festgenagelt zu werden. Das wichtigste und entscheidendste ist aber, daß sich solche Bindungen mit der Verfassung überhaupt nicht vertragen. An die verfassungsmäßigen Rechte der Reichsgewalt kann niemals durch Vertrag, sondern nur durch Verfassungsänderung gerührt, und reichsgesetzlichen Bestimmungen, wie etwa die des Wehrgesetzes, können nur durch Reichsgesetz beseitigt oder geändert werden.

Ein dritter Versuch, föderalistischen Wünschen entgegenzukommen, ist gelegentlich in der heutzutage nicht mehr ungewöhnlichen Form der Ausnahme- oder Notverord nung gemacht worden. Besonders die „Ermächtigungsgesetze“ schienen hierzu zu ermutigen. Als ein bezeichnendes Beispiel darf der merkwürdige $\mathbb{} 42$ der dritten Steuernotverordnung vom 14. Februar 1924 angeführt werden. Es heißt dort: „Die Aufgaben der Wohlfahrtspflege, des Schul- und Bildungswesens und der Poli- 
zei werden den Ländern nach Maßgabe näherer reichsrechtlicher Vorschriften zu selbständiger Regelung und Erfüllung überlassen ... Vor der Überlassung an die Länder werden die reichsrechtlichen Vorschriften, die dem Grundsatz des Satz 1 entgegenstehen, aufgehoben werden." Was soll das heißen? Entweder bedeutet die Klausel nichts anderes als ein Programm ohne rechtlich bindende Kraft; dann ist ihre Aufnahme in eine „Verordnung“ wertlos und sinnlos. Oder es soll ein Verzicht des Reichs auf Kompetenzen ausgesprochen werden, die ihm in der Verfassung in bezug auf Wohlfahrtspflege, Polizei, Schul- und Bildungswesen beigelegt worden sind. Dann ist die Klausel verfassungswidrig und nichtig, da das Ermächtigungsgesetz, auf dem die Verordnung beruht, jede Abweichung von den Vorschriften der Verfassung ausdrücklich untersagt hat.

Es zeigt sich also, daß eine Umlenkung der Reichsverfassung selbst in gemäßigt föderalistische Bahnen nur auf geradem Wege bewirkt werden kann. Ohne eine Revision der Reichsverfassung ist hier nichts oder nicht viel auszurichten. In welchem Sinne soll nun diese Revision erfolgen?

\section{$V$.}

Man hat wiederholt gesagt, es werde sich die unitarische Strenge der Weimarer Verfassung mildern und weniger fühlbar machen lassen, wenn man sich entschlösse, die jetzt übliche Häufung der Reichsgeschäfte in der Berliner Zentrale durch ein überlegtes System der De ze n tral is a ti o n zu ersetzen. Namentlich der frühere Reichsminister Ko ch hat sich wiederholt in energischer und eindrucksvoller Weise für diesen Gedanken eingesetzt. Allein ich meine, daß sich hierdurch die berechtigten Ansprüche eines „veredelten“ Föderalismus nur zur Hälfte befriedigen lassen würden. Der Begriff der Dezentralisation läßt in diesem Zusammenhange mehrere verschiedene Bedeutungen zu. Handelt es sich dabei lediglich darum, Geschäfte der Reichsministerien auf Bezirksinstanzen abzuwälzen, die wie etwa die Landesfinanzämter oder Finanzämter gleichfalls Reichsbehörden sind, so bedeutet dies nur eine Verschiebung der Zuständigkeitsordnung innerhalb des Reichsbehördenorganismus. Eine solche hat für das Verhältnis zwischen Reich und Ländern keine Wirkung, oder wenn doch, vielleicht nicht immer eine günstige. Denn einerseits kann sie da oder dort eine föderalistische Empfindlichkeit, welche die Reichsbeamten nun einmal nicht gern in der Lokalinstanz wirken sieht, in unerfreulicher Weise verletzen. Die Dezentralisation kann andererseits, namentlich wenn sie durch Einrichtung reichsministerieller Delegaturen in größeren Einzelstaa- 
ten geschieht, leicht zur Begründung von Sonderrechten führen - die neuste Geschichte des Post- und Eisenbahnwesens zeigt das deutlich - und daher, wie Bilfinger richtig bemerkt hat, dem Partikularismus Vorschub leisten. Anders würde es stehen, wenn man Dezentralisation dadurch vornähme, daß man „Aufgaben des Reichs an die Länder und Gemeinden abgäbe“. Aber auch das wäre in zweierlei Weise möglich. Entweder indem man Landesbehörden und Landesbeamte mit der Vornahme von Geschäften der Reichsverwaltung betraute, dabei aber die Beauftragten der Leitung und Kontrolle einer Reichsinstanz unterstellte. Damit wäre den Einzelstaaten wenig gedient. Denn ein System, das den Ländern keine Verwaltung im eigenen Namen und unter eigener Verantwortlichkeit gibt, sondern ihre Behörden zu „mittelbaren“ Reichsbehörden macht, ein System, das statt einer bloßen „Oberaufsicht“ über die Landeszentralregierungen eine unmittelbare Dienstaufsicht über Landesmittel- und Unterbehörden einführt, ein System, das den Ländern vielleicht sogar ein gutes Teil ihrer Ämterpatronage entzieht, würde ja eher eine unitarische als eine föderalistische Wirkung haben. Ein wirkliches Entgegenkommen gegen den Föderalismus würde also nur in einer solchen „Dezentralisation“ zu finden sein, die eine Abwälzung von Zuständigkeiten des Reichs auf die Länder als staatliche Einheiten enthielte. Damit wäre in der Tat die eine Hälfte des föderalistischen Programms erfüllt. Aber eben nur die eine, und vielleicht nicht die wichtigste. Jeder andere Wunsch, die Einzelstaaten in höherem Grade an den Geschäften des Reichs teilnehmen zu lassen, bliebe unberücksichtigt. Ja, es würde ihm in gewissem Sinne sogar entgegengearbeitet, weil jede Verengerung der Reichskompetenzen naturgemäß auch die Möglichkeiten einer Beteiligung der Länder an Reichsgeschäften verringert.

Es ergibt sich hieraus, daß eine Verfassungsrevision durch Abbau der Reichszuständigkeiten nicht das allerwichtigste Mittel zur Erreichung des gesteckten Zieles sein möchte. Immerhin muß dieser Abbau sehr ernstlich erwogen werden; er läßt sich auch ohne Schaden für die gemeindeutschen Interessen an einer Reihe von Stellen durchführen.

Das gilt zunächst für die Kompetenz zur G e s e t z g e b u n g. Es spricht vieles dafür, daß man von dem, was in den Artikeln 7 bis 10 der Verfassung und in manchen Bestimmungen der Grundrechte dem Reiche überwiesen worden ist, wieder aus der Hand gibt. Armenwesen, Wander- und Jugendfürsorge, Bergbau, Theater- und Lichtspielwesen bedürfen höchstens zum Teil reichsrechtlicher Regelung; soweit dies der Fall ist, ergibt sich die Zuständigkeit des Reichs nach dem schon oben erwähnten Grundsatze der „Konnexität“ meist aus anderen Klauseln der Verfassung. Eine 
Hauptaufgabe scheint mir die glatte Beseitigung des Artikels 9 der Verfassung zu sein, der dem Reiche unter der nichtssagenden und wirkungslosen Voraussetzung des „Bedürfnisses für den Erlaß einheitlicher Vorschriften“ die gesetzgeberische Regelung der gesamten Wohlfahrtspflege und des Schutzes der öffentlichen Sicherheit und Ordnung verstattet. Damit ist der Reichsgesetzgebung ein Gebiet fast ohne, jedenfalls ohne irgendwelche sichere Grenzen erschlossen worden; das Reich kann den Ländern einen großen Teil von Aufgaben entreißen, auf denen sie bisher ungestört und gut gearbeitet haben und wahrscheinlich auch in Zukunft besser arbeiten werden als das Reich. Ebenso verträgt der Artikel 10 mit seiner „Grundsatzgesetzgebung“ eine, wenn auch vorsichtig vorzunehmende, Säuberung. Das Bodenrecht und die Bodenverteilung sollte der Reichszuständigkeit wieder entzogen werden; die bayerische Denkschrift spricht mit Recht von der Gefahr, „daß die mannigfachen natürlichen, wirtschaftlichen und sozialen Verschiedenheiten des Bodens und seiner bisherigen Rechts- und Besitzverhältnisse und die mannigfachen kulturellen Eigenheiten, die sich aus diesen Verschiedenheiten ergeben, zugunsten eines öden Einerlei verschwinden“. In bezug auf die Rechtsverhältnisse der Religionsgesellschaften, Schulen und Landesbeamten sollte den Ländern die einstige Unabhängigkeit ihrer Gesetzgebung zurückgegeben werden, freilich unbeschadet des Rechts des Reichs, die Freiheit des Einzelnen und den Schutz seiner Rechte zu gewährleisten. Man darf nicht einwenden, daß dem Reiche nach Art. 10 ja nur die Aufstellung von „Grundsätzen“ zustehe. Denn abgesehen davon, daß die Grenze zwischen Grundsätzlichem und Nichtgrundsätzlichem flüssig und dem Ermessen des Gesetzgebers preisgegeben ist, so ist, wie die bayerische Denkschrift wiederum sehr richtig sagt, „gerade das Grundsätzliche das Wesentliche und Wichtige“. Ebensowenig darf man sich und andere mit der Beruhigung trösten, daß das Reich in bezug auf konkurrierende Bedarfs- und Grundsatzgesetzgebung Enthaltsamkeit üben könne und, wie oben gezeigt, durch seine Regierung auch versprochen habe. Allein die Einzelstaaten werden nicht ohne weiteres geneigt sein, sich solchen Sirenenklängen gefangen zu geben. Und es ist doch auch zu bedenken, daß, solange der Katalog der Reichsgesetzgebungskompetenzen ungekürzt in der Verfassung stehenbleibt, die Reichszentralstellen vermöge des Rechts der „selbständigen Reichsaufsicht“ in der Lage bleiben, die Landesverwaltungen auf allen dort aufgezählten Gebieten mit begründeten und unbegründeten Anfragen, Anregungen und Ausstellungen nach Belieben zu behelligen und dadurch Verdrießlichkeiten hervorzurufen, die besser vermieden werden. 
Wichtiger noch als die Erwägung, ob eine Wiedereinsetzung der Länder in den Besitz ihrer alten Gesetzgebungsvorbehalte möglich und wünschenswert sei, scheint mir die Frage zu sein, ob die Verwalt u n g s o he it der Einzelstaaten mehr, als in der Verfassung geschehen, geschont werden müsse. Es handelt sich dabei nicht in erster Linie um eine Verminderung des dem Reiche schon durch die Verfassung zugewiesenen Besitzes an eigener unmittelbarer Verwaltung. Hier wird sich Geschehenes schwerlich rückgängig machen lassen. Höchstens in Nebendingen könnte man hier vorgehen; so wäre vielleicht an eine Revision des Art. 97 in bezug auf die reichseigene Strom- und Schifffahrtspolizei zu denken. Es handelt sich ferner auch nicht darum, ob etwa die Verwaltung der Reichssteuern den Ländern zurückzugeben sei, - übrigens eine technisch schwierige Maßregel, über deren Durchführbarkeit und ZweckmäBigkeit ich mich des Urteils enthalte. Denn die reichseigene Verwaltung ist von der Verfassung nur für Zölle und Verbrauchssteuern, nicht für andere Steuern vorgeschrieben; eine Revision der Verfassung steht also hier nur zum Teil in Frage. Wohl aber muß ernstlich geprüft werden, ob nicht die Klausel des Art. 14 zu streichen sei, die es dem Reiche gestattet, den aus dem alten Rechte übernommenen und tief begründeten Grundsatz, daß die Reichsgesetze durch die Landesbehörden auszuführen sind, nach Gutdünken durch einfache Reichsgesetze zu durchbrechen. Während sich früher das Reich neue Verwaltungskompetenzen immer nur durch eine Verfassungsänderung ad hoc aneignen konnte, ist es jetzt in der Lage, ohne größere Anstrengungen Stück für Stück aus der Verwaltungshoheit der Einzelstaaten herauszubrechen. Diese Klausel wird von den Ländern mit Recht als eine ständige Bedrohung des Restbestandes ihrer Staatlichkeit empfunden und sollte als eine Überschreitung der unitarischen „Bedürfnisgrenze" beseitigt werden.

Das Kernproblem der ganzen Verfassungsfrage liegt nun aber auf dem orga $n$ is a to r i s c h e n Gebiete. Und nach Lage der Sache kann es sich hier zunächst nur darum handeln, ob und inwieweit den föderalistischen Bestrebungen durch eine Verstärkung der Stellung des R e i chs r a ts entgegenzukommen sei. Denn der Reichsrat ist die Stelle, an der der Einfluß der Einzelstaaten auf die Willensbildung des Reichs, die Stelle, an der ihre Mitarbeit am Reiche am meisten und am sichtbarsten zutage tritt.

Die radikalste, übrigens weder von der bayerischen noch von der badischen Denkschrift, sondern nur in dem bekannten Bamberger Programm der Bayerischen Volkspartei vertretene Forderung, dem Reichsrate unverkürzt die Rolle des ehemaligen Bundesrates zuzuweisen, in der Form, wie er sie nach der ursprünglichen Bismarckschen Verfassung zu spielen hatte, 
ist unerfüllbar. Wir haben früher gezeigt, daß solche Restitution die Ergebnisse einer schon vor der Revolution fast abgeschlossenen Entwicklung ignorieren würde. Man kann den Reichsrat nicht mehr, wie einst, mit wesentlichen Funktionen der Reichsaufsicht betrauen. Man kann ihn auch nicht wieder zum Hauptträger des Reichsverordnungsrechtes machen. $\mathrm{Ob}$ man, wie die bayerische Denkschrift, verlangt, den Abschluß nicht nur von Bündnissen, sondern auch, wie ehemals, von Verträgen, „die sich auf Gegenstände der Reichsgesetzgebung beziehen“, an die Zustimmung des föderativen Reichsorgans binden sollte, darüber läßt sich eher sprechen. Was die in den Bereich der Gesetzgebung einschlagenden Verträge anlangt, wäre die Forderung sogar selbstverständlich, wenn sich die andere und wichtigere durchsetzen sollte, dem Reichsrate ein volles Mitbestimmungsrecht bei der Reichsgesetzgebung einzuräumen.

Denn das ist ja schließlich die Hauptsache von allem. Hier reichen sich die bayerische und die badische Denkschrift, die im übrigen nicht immer die gleichen Wege gehen, brüderlich die Hand. In der Tat, beläßt man dem Reichsrate im Verfahren der Reichsgesetzgebung seine jetzige bescheidene Stellung oder bessert sie hier nur in Kleinigkeiten aus, so bleibt die ganze Verfassungsrevision auch vom Standpunkte eines maßvollen Föderalismus aus betrachtet eine Halbheit, selbst wenn man auf anderen Gebieten allerlei Konzessionen machen wollte. Denn alle Einflußmöglichkeiten und Einflußrechte, wie sie sein mögen oder ausgeklüngelt werden können, bleiben doch im Sande stecken, wenn sie nicht in einer entscheidenden Mitwirkung an der Gesetzgebung ihre Krönung finden. Sowenig sich vor hundert Jahren die Landtage mit der Rolle einer bloß gesetzesberatenden Körperschaft zufrieden gaben, sowenig werden sich heute die Einzelstaaten mit den Initiativ- und Einspruchsrechten abspeisen lassen, die dem zur Vertretung ihrer Interessen geschaffenen Reichsrate von der jetzigen Verfassung vergönnt sind. Will man zur Ruhe kommen, so muß also wohl der Schritt gewagt werden. Dabei genügt es nicht - obschon auch das eine Verbesserung des geltenden Rechtes wäre -, daß man dem Reichsrate ein absolutes Veto gegen Verfassungsänderungen zuerkennt. Man muß ihm bei jedem Reichsgesetze die Ebenbürtigkeit mit dem Reichstage, die M it wirkung bei der Sanktion der Reichsgesetze gewähren, und zwar ein volles Recht des Mitbeschlusses, nicht überwindbar durch Zweidrittelmehrheiten des Reichstags oder Volksentscheide. Daß man dann dem Reichsrate auch, wie früher dem Bundesrate, bei der Einbringung der Gesetzesvorlagen durch die Reichsregierung die Präzedenz zuerkennen müsste - was die badische und die bayerische Denkschrift verlangen -, wäre keine unbedingte notwendige Folge; es hätte auch heute nicht 
denselben Wert wie früher, da die mit dem Reichstage versippte Reichsregierung doch immer in der Lage bliebe, das Vorrecht des Reichsrats durch Provokation von Initiativanträgen zu umgehen.

Der frühere Reichsminister Koch hat ausgeführt, der Reichsrat würde, wenn er die Gleichberechtigung mit dem Reichstage erhielte, die Stellung einer ersten Kammer einnehmen ${ }^{14}$. Wenn das zuträfe, so würde es meines Dafürhaltens kein Unglück sein. Das Zweikammersystem ist eine sehr nützliche Einrichtung. Es würde dem Grundcharakter der Weimarer Verfassung nicht widersprechen. Bekanntlich war es in dem von P re u ß verfassten ersten Entwurfe vorgesehen. K o c h meint, eine erste Kammer pflege die Gleichberechtigung mit der zweiten nur dann zu erlangen, wenn sie auf geschichtlicher Autorität beruhe oder irgendwie ein besonderes Gewicht an Sachkunde oder wirtschaftlichem Einfluß in sich trage, das der anderen Kammer abgehe. Selbst dann noch sei ihre Gleichberechtigung nicht voll aufzurichten, weil ihr gegenüber die Ministerverantwortlichkeit nicht durchgeführt werden könne. Aber wenn sich im Deutschen Reiche eine erste Kammer als Repräsentation der Einzelstaaten einsetzen ließe, so wäre doch wohl in ihr ein Element von recht beträchtlicher „geschichtlicher Autorität" vertreten, das sich vielleicht später einmal bei einer Zuziehung der jetzt im Reichswirtschaftsrate vertretenen Kreise durch Männer von "Sachkunde und wirtschaftlichem Einflusse“ ergänzen ließe. Und warum soll gegenüber einer ersten Kammer eine Ministerverantwortlichkeit nicht bestehen können? Das französische Beispiel lehrt, daß dies sehr wohl möglich ist. Es stimmt auch nicht, daß der Reichsrat als erste Kammer nur eine Dublette des Reichstags sein würde. Denn obwohl die Landesregierungen, die in ihm vertreten sind, Geschöpfe ihrer Landesparlamente, also mittelbar ebenso von den "Wählermassen“ abhängig sind wie der Reichstag, so ist doch schon die andere Form der Auslese vollauf geeignet, einer so gestalteten Versammlung ein anderes Gesicht zu geben als einer auf unmittelbaren Volkswahlen beruhenden Körperschaft. Wäre dem nicht so, so würde das Zweikammersystem in anderen Bundesstaaten, ja es würde sogar die Institution des Reichsrats in seiner jetzigen Form vollständig sinnlos sein.

Allein es hat keinen Zweck, diese Fragen weiter auszuspinnen. Denn die Sache liegt eben $\mathrm{nicht}$ so, daß die Erhebung des Reichsrats zu einem bei der Gesetzgebung dem Reichstage gleichberechtigten Organ die Einführung einer ersten Kammer bedeuten würde. So haben es sich jedenfalls die Länder, die jenes Ziel verfolgen, nicht gedacht. Sie wollen, daß im Reichs-

14 Deutsche Juristenzeitung 1924, Sp. 79. 
rate auch künftig die Einzelstaaten als solche mit einem ihrer historischen Vergangenheit entsprechenden Gewichte vertreten seien, daß dort nach wie vor, anders als in einer ersten Kammer, nach Instruktionen gestimmt werde, daß die Einrichtung des Reichsrats den in den Ländern regierenden Autoritäten eine Mitregierung im Reiche ermögliche. Daher der Wunsch, dem Reichsrat die Verordnungsgewalt, die Mitwirkung beim Abschlusse von Bündnissen und Staatsverträgen, das Recht auf Auskunft seitens der Reichsregierung über die Führung der Reichsgeschäfte, kurz das Recht zum „Mitwirken und Mitsorgen“, wie es die bayerische Denkschrift ausdrückt, zu verschaffen, überhaupt die „Hebung der verfassungsrechtlichen Stellung des Reichsrats zu der Stellung des früheren Bundesrats" zu bewirken. Bekanntlich war aber der Bundesrat keine erste Kammer, sondern das Hauptorgan der Regierung des Reichs. Auch wenn man also die zahlreichen Nummern dieses Programms bis auf die Gewährung des Sanktionsrechts bei der Reichsgesetzgebung zusammenstreicht, so wird doch auch dieses Recht nach der zugrunde liegenden Idee dem Reichsrate als einem regierenden Kolloquium neben dem Reichsparlamente zufallen.

Erst hieraus ergeben sich nun aber verfassungsrechtliche und verfassungstechnische Probleme der schwierigsten Art, deren Bedeutung sich noch steigern würde, wenn etwa die Stellung des Reichsrats nicht nur im Bereich der Gesetzgebung, sondern auch in dem der Verwaltung erhöht werden sollte. Die Probleme liegen so nahe, daß man kaum anzunehmen wagt, sie seien den Verfassern der süddeutschen Denkschriften, die ihrer nicht einmal in Andeutungen Erwägung tun, völlig entgangen. Um so mehr ist es Pflicht, darauf hinzuweisen. Nicht um die föderalistischen Vorschläge durch Hinweis auf ihre Konsequenzen ad absurdum zu führen, sondern um die Fragen, die sich aus ihnen ergeben, nach Möglichkeit bis ans Ende zu durchdenken.

\section{VI.}

Wenn die deutschen Einzelstaaten durch eine bedeutende Vermehrung der Rechte des Reichsrats wieder zu einer beherrschenden Stellung im Reiche gelangen, so ist es selbstverständlich, daß sie alle gleichmäßig an dem Gewinne Anteil erhalten müssen. Es wird keiner von ihnen dulden können, daß ihm in der Körperschaft, die auf das Niveau eines Hauptregierungsorgans emporgehoben worden ist, Fesseln angelegt sind, die ihn verhindern, das ihm nach geschichtlicher und gegenwärtiger Bedeutung ge- 
bührende Gewicht in die Waagschale zu werfen. Dies geht in erster Linie den Staat Pre u ß n an.

Der preußische Staat hat sich bei der Einrichtung des neuen Reichs und bei der Feststellung des Inhalts der Weimarer Verfassung eine Behandlung gefallen lassen müssen, die man selbst dann nur schwer begreifen kann, wenn man den unitarischen Doktrinarismus der im Reiche damals maßgeblichen Persönlichkeiten einerseits, die Parteigebundenheit der durch die Revolution in Preußen zur Herrschaft gelangten Kreise andererseits in Rechnung zieht. Viel länger als in den deutschen Mittelstaaten hat es in Preußen gedauert, bis sich das, was wir oben den Lebenswillen des Einzelstaats nannten, in Volksvertretung und Regierung wieder eingefunden hat. Nicht bloß Zuschauer aus nächster Nähe sind erstaunt gewesen, wie zaghaft und bescheiden die preußischen Interessen zur Zeit des Weimarer Staatenausschusses, aber auch noch in den Anfängen des Reichsrats vertreten worden sind. Wie tief in den ersten Monaten nach Erlaß der Reichsverfassung der Wille zur Selbstbehauptung im preußischen Staate gesunken war, zeigt am deutlichsten der selbstmörderische Beschluß, den die preußische Landesversammlung am 17. Dezember 1919 gefaßt hat: Preußen wolle, ehe es sich eine eigene neue Verfassung gebe, den Versuch machen, ob sich nicht schon jetzt die Schaffung eines deutschen Einheitsstaats erreichen lasse; es sei bereit, in einem solchen Einheitsstaate aufzugehen, wenn dieselbe Bereitwilligkeit auch bei den anderen Ländern bestehe. Das damals erwartete Echo aus den übrigen Einzelstaaten hat sich freilich nicht hören lassen! Demungeachtet hat sich Preußen zunächst in seiner Politik der Selbstauflösung nicht irremachen lassen; die programmatischen Artikel über die Autonomie der Provinzen in der Novemberverfassung von 1920 sind dessen Zeuge.

Diese Politik der Entsagung ist ja gewiß zu beträchtlichem Teile inzwischen aufgegeben worden. Aber noch immer läßt sich beobachten, daß Preußen dem Reiche gegenüber die seiner Bedeutung entsprechende Haltung nicht einnimmt. Es wagt nicht energisch aufzutreten und überläßt oft in großen Fragen anderen Staaten die von Rechts wegen ihm zukommende Führung. Solche Politik läßt sich allenfalls fortsetzen, wenn sich eine weitere Entwicklung der Reichsverfassung in unitarischer Richtung ohne Hemmnisse vollziehen würde. Sie wird aber in demselben Augenblicke unmöglich, in dem das Gegenteil eintritt. Sobald sich eine Revision der Reichsverfassung in föderalistischem Sinne durchsetzt, sobald die Einzelstaaten einen im Vergleich zum gegenwärtigen Rechtszustande wesentlich verstärkten Einfluß auf das Reichsregiment gewinnen, wird sich Preußen gezwungen sehen, aus seiner Zurückhaltung herauszutreten und das ihm 
nach Umfang, Bevölkerungszahl, politischer und wirtschaftlicher Bedeutung zukommende Gewicht im Reiche zu fordern. Es ist fraglich, ob die bayerische Regierung völlig zufrieden sein wird, wenn sich die von ihr ins Rollen gebrachte Revisionsfrage in dieser Richtung entwickelt!

Preußen wird und muß zunächst verlangen die Beseitigung des für seinen Bestand bedrohlichen Artikels 18 der Reichsverfassung. Dieser Artikel ist in erster Linie als Sturmblock gegen die Existenz des preußischen Großstaats gedacht gewesen; kein anderer Staat wird durch ihn in demselben Maße beunruhigt wie Preußen. Der preußische Staat kann nicht länger dulden, stündlich der Gefahr der Zerpulverung ausgesetzt zu sein, wenn andere Länder sich anschicken, die Hand an das Reichsruder zu legen. Dem „entschiedenen Bekenntnis“ zu Artikel 18, das der Antrag der bayerischen Volkspartei verlangt, wird der preußische Staat ein entsprechendes „Non possumus“ entgegensetzen müssen.

Preußen wird und muß aber unter der gleichen Voraussetzung weiterhin verlangen die Beseitigung der Verfassungsvorschrift, die dem preußischen Staate gebietet, die Hälfte seiner Reichsratsstimmen durch Vertreter der Provinzialverwaltungen abgeben zu lassen. Diese Vorschrift, die das von Natur und Vernunft dem preußischen Staate zukommende Gewicht im Reichsrate künstlich herabsetzt, es im Ergebnis zuweilen fast auf die Ebene des dem bayerischen Staate zufallenden herabdrückt, - die Vorschrift, welche die erwartete Auflösung des preußischen Einheitsstaates in einer wichtigen Beziehung unzeitig vorausnimmt, ist schon heute schwer erträglich. Ihre praktische Bedeutung und Wirkung läßt sich aus den Berichten über die Abstimmungen des Reichsrats statistisch feststellen. Vom März 1922 bis zum Dezember 1923 konnte man - für absolute Genauigkeit kann ich freilich nicht einstehen - außer einer Reihe von Abstimmungen über Unterfragen nicht weniger als dreiundzwanzig Fälle zählen, in denen bei Hauptabstimmungen über Gesetze, Verordnungen oder Vertagungsanträge den preußischen Regierungsstimmen dissentierende Provinzialstimmen entgegengetreten sind. Dabei fand sich manchmal nur ein kleiner Teil, manchmal die Mehrheit, gelegentlich sogar die Gesamtheit der Provinzialvertreter in der Opposition gegen die Staatsregierung zusammen. Der Erfolg ist nicht immer der gewesen, daß die preußischen Staatsstimmen bei der Gesamtabstimmung in die Minderheit gedrängt worden sind. Aber ihr Gewicht hat häufig gelitten, der Druck einer partikularistischen Fronde ist durch Hinzutritt preußischer Provinzialstimmen verstärkt, das Zustandekommen von Reichsgesetzen, für die sich die preußische Regierung eingesetzt hatte, gefährdet worden, so z. B. wenn die Regierungsstimmen den verfassungsändernden Charakter eines Gesetzes ver- 
neinten, die Provinzialstimmen ihn bejahten. In den meisten Fällen handelte es sich um Gesetze oder Verordnungen von großer Bedeutung: über Anpassung des Strafgesetzbuchs an das neue Verfassungsrecht, Mietzinsbildung, Beteiligung der Frauen an der Rechtspflege, Getreideumlage, Republikschutz, Reichskriminalpolizei, das Ermächtigungsgesetz vom Oktober 1923 u. a. m. Diese Paralysierung der preußischen Staatsautorität muß auch von solchen bedauert werden, die in politisch wichtigen Fragen, in denen Staats- und Provinzvertreter auseinandergingen, den Standpunkt der provinziellen Opposition gebilligt haben. Daher ist es bezeichnend, $\mathrm{da} ß$ der erste energische Vorstoß gegen die Provinzialstimmen, eingeleitet durch einen Antrag des Abgeordneten v o n C a m p e vom 2. Januar 1924 (Drucksachen des preußischen Landtags Nr. 7426), von einer Partei ausgegangen ist, die keineswegs durch dick und dünn mit der jetzigen Regierung zu gehen gewillt ist. Der Inhalt des Antrags würde übrigens, wenn zum Gesetz erhoben, die Frage nicht endgültig lösen. Hier kann nicht durch ein preußisches Gesetz, sondern nur durch eine Änderung der Reichsverfassung geholfen werden ${ }^{15}$.

Wird nun nach alledem durch den föderalistischen Angriff auf die Weimarer Verfassung der preußische Staat zu einer kräftigeren Betonung seiner Individualität herausgefordert, so tritt aus dem Hintergrunde wieder das angeblich längst zur Ruhe gelangte "Gespenst" der p reußischen Heg e moni e hervor. Ich würde für meinen Teil darin nicht ein Unglück, sondern die Wiederherstellung eines naturgemäßen Zustandes erblicken. Es ist ein Irrtum, wenn man eine Hegemonie Preußens für „unmöglich" hält, weil sie unvereinbar sei mit den Wandlungen, die sich durch die Revolution vollzogen haben und nicht ohne eine neue Revolution rückgängig zu machen sind. Die preußische Vormachtstellung ist nicht untrennbar mit der monarchischen Staatsform Preußens verbunden. Sie

15 Der Antrag des Abg. von Campe und der übrigen Mitglieder der deutschen Volkspartei will den $₫ 8$ Abs. 2 des preußischen Gesetzes vom 8. Juni 1921 beseitigen. Nach dieser Vorschrift steht den Provinzialvertretern in den Vollsitzungen des Reichstags freies Stimmrecht zu; es soll nur vorher zwischen ihnen und den Regierungsvertretern eine Beratung zwecks Herbeiführung einer einheitlichen Stimmabgabe stattfinden. Die Streichung des Satzes würde also bloß das ausdrückliche Bekenntnis zur Abstimmungsfreiheit der Provinzialvertreter beseitigen, aber kein Mittel angeben, wodurch die Einheitlichkeit der preußischen Stimmabgabe bewirkt werden soll. Das letztere ist auch im Hinblick auf die Reichsverfassung m. E. nicht möglich; denn diese setzt den Eintritt einer Divergenz zwischen Regierungs- und Provinzialstimmen geradezu voraus. Darauf geht ja die Tendenz des Art. 63 Satz 2 der RV hinaus. Die ganze Einrichtung hätte sonst gar keinen Sinn gehabt. 
bedarf nicht unbedingt der militärischen und der Verkehrsmachtmittel, über die der preußische Staat ehemals verfügte. Es ist nicht richtig, zu sagen, die preußische Hegemonie habe nur auf den preußischen Bajonetten beruht; das sollte am wenigsten von Leuten gepredigt werden, die im übrigen der Meinung sind, daß Staaten in Zukunft nur mit geistigen Waffen zu kämpfen und zu siegen haben. Innerhalb eines Bundesstaates, der aus großen und kleinen Einzelstaaten zusammengewachsen ist, der nur unter willkürlicher Zerreißung seines geschichtlich bedingten Gefüges in abgezirkelt gleiche Kantone zerlegt werden kann, wird die Führung notwendig dem größten Einzelstaate zukommen, zumal wenn seine überragende Größe verbunden ist mit der Größe seiner Leistungen und Verdienste um das Ganze $^{16}$. Gewiß ist die Hegemonie in Deutschland heute nicht denkbar in der Form einer Herrschaft des Großen über die Kleinen, einer Ausübung der Staatsgewalt der Vormacht in den Grenzen der anderen Länder. Aber Hegemonie bedeutet nicht notwendig Herrschaft über andere. Hegemonie ist Führung. Hegemonie ist „Inbegriff aller Rechtssätze und Einrichtungen, vermöge deren die führende Macht eines zusammengesetzten Staatswesens dem Leben der Gesamtheit die gewünschte Richtung zu geben und den Stempel des eigenen Geistes aufzudrücken vermag "17. Die Erfahrung hat uns gezeigt, daß allein die innere Autorität des preußischen Rechtsgeistes und der erprobten preußischen Verwaltung ohne äußere Zwangsmittel imstande war, preußisches Recht und preußische Verwaltungsrichtlinien vielfältigster Art zu gemeindeutschem Besitze zu machen. Führertum und freiwillige Gefolgschaft ist etwas durchaus dem germanischen Rechtsgeiste Entsprungenes und Entsprechendes. Und sein ethischer Wert ist dem „eidgenössischen Rechtssinne" 18 der auf der Gleichheit der Einzelstaaten aufgebauten bundesstaatlichen Republiken gewiß ebenbürtig, dem Popanz des Majoritätsprinzips entschieden überlegen. Gibt man dem preußischen

16 Der „echte“ Föderalismus, der sich den wirklich föderalistischen Bundesstaat nur als Zusammensetzung gleichkräftiger Einzelstaaten denken kann, muß natürlich die preußische Hegemonie in jeder Gestalt verdammen. Vgl. insbes. Beyerle, Föderalismus, in der Festschrift der Görres-Gesellschaft für Felix Porsch (1923), S. $138 \mathrm{ff}$.

17 [Unausgewiesenes Selbstzitat aus Heinrich Triepel, Unitarismus und Föderalismus im Deutschen Reiche. Eine staatsrechtliche und politische Studie, Tübingen 1907, S. 111 f.; dazu auch ders., Die Hegemonie. Ein Buch von führenden Staaten, Stuttgart 2. Aufl. 1943, S. 2 Fn.].

18 [Von Triepel wiederholt zitiert: Heinrich v. Treitschke, Das constitutionelle Königthum in Deutschland, in: ders., Historische und politische Aufsätze. Dritter Band: Freiheit und Königthum, 4. Aufl. Leipzig 1871, S. 604]. 
Staate im Rate der Länder eine Stellung, die ihn vor anderen bevorzugt, ohne die anderen zu erdrücken - ob man die Meiststimmenzahl von zwei Fünfteln noch etwas herabsetzen könnte, darüber wäre zu reden -, so wird der preußische Staat in die Lage gesetzt, seine geschichtliche Mission, die er noch nicht ausgespielt hat, auch in Zukunft zu erfüllen. Der preußische Adler wird zwar nicht mehr in Versuchung kommen, seine Fänge in den Boden anderer Staaten einzuschlagen. Aber den Wappentieren anderer Länder voranzufliegen -, das wird er noch können!

Aber damit ist die Frage nicht erledigt. An sich und zunächst bedeutet Hegemonie nur ein Führerverhältnis gegenüber anderen Staaten. Allein die Hegemoniestellung in einem Bundesstaate verleiht dem führenden Staat auch eine besondere Macht gegenüber der Zentralgewalt. Und so erhebt sich bei der Betrachtung des föderativen Systems in Deutschland der Zweifel: ist die bevorzugte Stellung eines konsolidierten Preußens in einem aufgewerteten Reichsrate mit den Interessen des Reichs als Gesamtheit verträglich? Man sieht, es ist die alte preußisch-deutsche F r a ge, die jetzt von neuem ihr Haupt erhebt. Rein verfassungstechnisch gefaßt, ist sie auf den einfachen Nenner zu bringen: ist mit der Erhöhung des preußischen Einflusses auf die Lenkung des Reichs die Gefahr einer in sich unmöglichen Doppelregierung gegeben? Entsteht hier nicht eine Rivalität, für die es an einem Ausgleiche fehlt? Vom preußischen Standpunkt aus betrachtet: was nützt Preußen die dominierende Stellung in dem auf die Gesetzgebung beschränkten Bundesrate, wenn neben beiden eine völlig unabhängige Reichsregierung steht, die ihren starken Rückhalt im Reichstage findet? Vom Standpunkte des Reichs aus gesehen: wie soll sich eine Reichsregierung durchsetzen, wenn sie sich nicht auf die im Bundesrate dominierende preußische Staatsregierung stützen, wenn sie diese Regierung nicht beeinflussen kann?

Nun handelt es sich aber doch hier um Fragen, die keineswegs von vorgestern sind. Die Schwierigkeiten, die sich aus der Notwendigkeit einer Auseinandersetzung zwischen Reichsgewalt und preußischer Staatsgewalt ergeben, haben ja die ganze Zeit der alten Verfassung hindurch bestanden. Bismarcks genial entworfenes System hatte sie allerdings in hohem Maße zu überwinden verstanden. Die Realunion zwischen preußischem Königtum und deutschem Kaisertum, die Kombination von Bundesrat und kaiserlicher Exekutive, von Reichskanzler und preußischer Ministerstellung brachte Reichs- und preußische Regierung von Haus aus in eine innige Verbindung. Als sich die Reichsregierung mehr und mehr von der preußischen emanzipierte, suchte man durch Nebenbehelfe, wie etwa durch die Ernennung hoher Reichsbeamter zu preußischen Bevollmächtigten im 
Bundesrate und durch die Ernennung von Staatssekretären des Reichs zu Mitgliedern des preußischen Staatsministeriums, für ein reibungsloses Neben- und Ineinanderarbeiten der beiden Staatsgewalten zu sorgen. Aber völlig gelungen ist das niemals. Durch die Weimarer Verfassung glaubten manche das preußisch-deutsche Problem aus der Welt geschafft zu haben. Das hat sich sehr bald als ein Irrtum erwiesen. Es war eben, wie später der Minister Koch mit Recht gesagt hat, „eine Fiktion, wenn man Preußen lediglich so behandeln wollte, wie irgendein anderes deutsches Land“. Durch den verschleiernden Nebel der Verfassungsparagraphen trat überall der Riesenleib des alten preußischen Staates hervor, zeigte sich an allen Stellen das feste Gefüge seiner mächtigen Verwaltung. Trotz aller formalen Rechte der Reichsaufsicht kann man es schließlich doch nicht wagen, Reichsgesetze zu machen, wenn man nicht sicher ist, dass sie von der preußischen Verwaltung energisch und sinngemäß ausgeführt werden; das Reich kann keine innere Politik treiben ohne die Gewißheit, daß sich die preußische innere Politik in der gleichen Bahn bewegt. Daher hat es auch seit Weimar trotz der grundsätzlichen Willfährigkeit der preußischen Staatsregierung niemals an Reibungen zwischen dem Reiche und Preußen gefehlt, ja die Schwierigkeiten des Zusammenarbeitens sind - eben weil jene Verbindungsstellen der alten Verfassung fehlten - manchmal sehr viel größer gewesen als früher. Wenn man geglaubt hatte, daß sie sich durch die endlich erreichte Übereinstimmung des parlamentarischen Wahlrechts und die Gleichheit des parlamentarischen Regierungssystems im Reiche und in Preußen würden beseitigen lassen, so war das wiederum ein Irrtum gewesen. Schon die Tatsache, daß die Legislaturperioden im Reiche und Preußen nicht notwendig zusammenfallen, kann bewirken, daß die Parlamente und die Regierungen eine verschiedene Farbe besitzen, und selbst wenn gleichzeitige Neuwahlen im wesentlichen gleichartig ausfallen, so kann doch die bei unseren Parteiverhältnissen unvermeidliche Bildung von Koalitionsregierungen, entweder sofort oder später, in Preußen in dieser, im Reiche in einer anderen Form geschehen. Allerdings gehen die Aussagen über Grad und Häufigkeit von Unstimmigkeiten zwischen Reichs- und preußischer Regierung auseinander. Die einen sprechen von unerträglichen Zuständen; andere meinen, die Sache sei nicht so schlimm, man pflege sich doch gewöhnlich friedlich zu verständigen. Die Wahrheit wird sein, daß die Reibungsflächen je nach der politischen Gesamtlage, den beiderseitigen parlamentarischen Parteikonstellationen, aber auch je nach Charakter und Temperament der beteiligten Ressortminister und Dezernenten verschieden groß sind. Eines aber ist sicher: die Möglichkeit einer gefährlichen Disharmonie zwischen dem Reiche und Preußen wird 
sich um ein Bedeutendes steigern, wenn sich die Entwicklung in der vorhin geschilderten Weise vollziehen sollte.

Schon längst ehe die Frage einer föderalistischen Umbiegung der Verfassung akut geworden ist, hat man nach technischen Mitteln gesucht, um den preußisch-deutschen Dualismus erträglich zu gestalten. Und es ist bezeichnend, daß diese Mittel allesamt aus dem Rüsthause der alten Verfassung und der alten Reichspraxis hervorgezogen sind. Sollte das nicht ein Fingerzeig sein für den Weg, der einzuschlagen ist, wenn sich die Verfassung im ganzen wieder mehr den einstigen Formen nähern wird?

Die Praxis der letzten Jahre hat versucht, ein engeres Zusammenarbeiten zwischen Reich und Preußen durch eine gegenseitige Beteiligung an Kabinettssitzungen herbeizuführen. Ein preußischer Staatssekretär pflegt den Sitzungen des Reichskabinetts beizuwohnen, und umgekehrt finden sich Vertreter von Reichsressorts bei preußischen Kabinettssitzungen ein. Gemeinsame Vertretersitzungen laufen daneben her. Koch hat vorgeschlagen, ${ }^{19}$ diese Einrichtung auszubauen. Der als Gast im Reichskabinett erscheinende preußische Vertreter solle immer ein Minister sein; dieser Minister solle dann auch Preußen im Reichsrate vertreten; am besten sei es, wenn dort die preußische Vertretung durch einen gemeinsamen Minister ohne Portefeuille stattfände. Der Gedanke ist sicher vortrefflich. Nur ist es zweifelhaft, ob das vorgeschlagene Rezept genügen könnte, wenn sich was wir ja hier voraussetzen - die preußische Machtstellung im Reiche weit über den jetzigen Stand erheben würde. Muss man da nicht zu drastischeren Mitteln greifen? Solche sind in der Tat auch bereits vorgeschlagen worden, und zwar wiederum, was betont werden muß, längst ehe die föderative Frage in ihr jetziges akutes Stadium getreten ist. Zwei Lösungen kommen in Betracht. Ich will die eine die präsidentielle, die andere die ministerielle nennen.

Die erste besteht darin, daß man verfassungsmäßig eine Verbindung der Stellungen des Reichspräsidenten und eines zu schaffenden preußischen Staatspräsidenten herbeiführt. Der Gedanke ist vor längerer Zeit von Thoma ${ }^{20}$ vertreten worden. Auf die Gefahr hin, von manchen für ein politisches Kind angesehen zu werden, muß ich erklären, daß ich den Gedanken nicht für innerlich unmöglich halte. Natürlich könnte er nicht in der Form ausgeführt werden, daß der in Preußen ge-

19 [Erich Koch-Weser, Das Verhältnis Preußens zum Reich, in: Deutsche Allgemeine Zeitung Nr. 158 v. 6. April 1921, Beiblatt der Morgen-Ausgabe].

20 [Richard Thoma, Deutsche Verfassungsprobleme, in: Annalen für soziale Politik und Gesetzgebung 6 (1919), S. 409-439, hier: 422]. 
wählte Staatspräsident zugleich als Reichspräsident gekoren zu betrachten wäre - das würden heute die anderen Einzelstaaten nicht mehr hinnehmen -, sondern so, daß der jeweilige Reichspräsident gleichzeitig die Rolle des preußischen Staatspräsidenten zu spielen hätte. Das preußische Selbstgefühl könnte sich mit einer derartigen Bestimmung des preußischen Staatsoberhaupts deshalb zufrieden geben, weil ja das preußische Volk mit etwa vier Siebtel der Stimmberechtigten an der Präsidentenwahl beteiligt ist. Thoma hat ausgerechnet, daß im allerungünstigsten und unwahrscheinlichsten Falle ein Reichspräsident etwa ein Drittel, für gewöhnlich aber einen sehr viel größeren Bruchteil der preußischen Stimmen auf sich vereinigen würde. Einen Sinn würde das Ganze freilich nur haben, wenn man den Präsidenten sowohl im Reiche als in Preußen von allzu starker parlamentarischer Bindung befreien könnte, wenn man z. B. sein Recht der Parlamentsauflösung von ministerieller Gegenzeichnung befreite. Ob das durchzusetzen wäre, bleibe dahingestellt.

Falls man die präsidentielle Lösung für undurchführbar hält, muß man eine Stufe tiefer steigen und es mit der ministeriellen versuchen. Hier haben wir von verschiedenen Seiten bereits Vorschläge erhalten. Koch wünscht Personalunion zwischen dem Reichskanzler, mindestens dem Vizekanzler und dem preußischen Ministerpräsidenten, dazu noch zwischen dem Reichsminister des Inneren und dem preußischen Innenminister, oder die Angliederung eines gemeinsamen Ministers ohne Portefeuille an beide Kabinette. Anschütz und Bilfinger begnügen sich mit der Personalunion zwischen Reichskanzler und Ministerpräsident; der erstere erachtet es für eventuell angezeigt, daß der Reichspräsident eine Anzahl von Ministern als Anwälte des Reichs mit Stimmrecht ins preußische Staatsministerium abordne. Stre se m a n n hält es für denkbar, daß der Reichskanzler eines der preußischen Ministerien bekleidet und daß gleichzeitig der preußische Ministerpräsident einen Sitz im Reichskabinett erhält ${ }^{21}$. Ich muß es mir versagen, auf diese einzelnen Vorschläge, die ich alle für erwägenswert halte, genauer einzugehen. Sicher ist jedenfalls eines: jeder von ihnen kann nur unter der Voraussetzung erfüllt werden, daß der Parlamentarismus, sei es in Preußen, sei es im Reiche, sei es an beiden Stellen, zu großen Opfern bereit ist. Ob sich Reichstag und Landtag freiwillig

21 Vgl. zu all diesem Thoma, Annalen für soziale Politik und Gesetzgebung Bd. 6 S. 422. - Koch, Deutsche Allg. Ztg. Nr. 158 vom 6. April 1921; Deutsche Juristenzeitung 1921 Sp. 292. - Anschütz, Das preußisch-deutsche Problem (1922) S. $21 \mathrm{f}$. - Bilfinger, Föderalismus a.a.O. S. 57, 59. - Stresemann, Sitzg. des Reichstags vom 9. August 1923, StenBer. S. 11776. 
dazu bequemen werden, sich Minister von einer ihrem Einflusse entzogenen Stelle aufdrängen und nehmen zu lassen, mit anderen Worten: ob sie geneigt sind, wichtige Ministerien halb und halb zu „entpolitisieren“, das ist eine Frage, die man im gegenwärtigen Augenblicke nicht ohne große Kühnheit mit Ja beantworten kann.

Man sieht, die durch den neuesten föderalistischen Vorstoß teils geschaffenen, teils aufgedeckten Probleme sind verwickelter, als manche wähnen. Es ist heute, wie immer: Jeder Stein, der auf dem glatten Boden des deutschen Verfassungslebens angestoßen wird, bringt einen zweiten ins Rollen. Und immer wieder ist es schließlich die preußisch-deutsche Frage, die sich als letzte Schwierigkeit auftürmt. Ohne daß sie in irgendeiner Form entschieden wird, ist das föderative Problem als ganzes nicht zu lösen. Aber ist jene Frage überhaupt restlos lösbar? Oder haben wir es nicht vielmehr hier mit einem der unüberbrückbaren inneren Gegensätze zu tun, mit denen wir Deutschen vom Schicksal schwerer belastet sind als andere Nationen, schwerer belastet auch deshalb, weil wir sie tiefer empfinden als andere und zugleich weniger geschaffen sind, ihrer durch radikale Mittel Herr zu werden? Vielleicht müssen wir uns mit dem Worte trösten, das, so banal es klingt, doch ein großes Korn Wahrheit enthält, und das in einem anderen, aber ähnlichem Zusammenhange von Montesquieu ausgesprochen worden ist: daß der Wagen irgendwie laufen wird, weil er laufen muß. In der Tat, da Preußen und das Reich zusammengehen m ü s se n, so we r$\mathrm{d}$ e $\mathrm{n}$ sie auch zusammengehen. Und es bleibt nur die Aufgabe einer mit technischen Hilfen arbeitenden Gesetzgebung, dies zu befördern, Störendes beiseite zu schieben. Auch solche Gesetzgebung freilich ist nichts Einfaches, und mancher mag zweifeln, ob unsere Zeit den Beruf dazu besitzt. Vor zwei Menschenaltern ward uns der Staatsmann geschenkt, dem der große Wurf gelang. Es ist bitter zu wissen, daß die Gottheit eine solche Gunst einem Volke nicht zweimal in hundert Jahren gewährt. 
Teil III: Grundauffassung 1927/1929 


\title{
Text 10 \\ Staatsrecht und Politik. Rede beim Antritte des Rektorats ${ }^{1}$
}

\author{
Hochansehnliche Versammlung! \\ Verehrte Kollegen! \\ Liebe Kommilitonen!
}

Für den Rektor einer Universität bietet es einen eigenen Reiz, sich in der Reihe seiner Vorgänger nach den Männern umzusehen, die zugleich im Bereiche der Wissenschaft seine Vorgänger gewesen sind. Auch für den Gelehrten können ja in besonderem Sinne die Goetheschen Worte ${ }^{2}$ gelten:

Wohl dem, der seiner Väter gern gedenkt,

Der froh von ihren Taten, ihrer Größe,

Den Hörer unterhält und, still sich freuend,

Ans Ende dieser schönen Reihe sich

Geschlossen sieht.

Allerdings - unter den Männern der Wissenschaft wird es manchen geben, der den Anspruch erhebt, nicht an das Ende, sondern an den Anfang einer Reihe gestellt zu werden. Ein anderer wird umgekehrt davor zurückschrecken, sich selber einen Platz in einem wissenschaftlichen Stammbaume anzuweisen, weil er nicht zu einem Vergleiche der eigenen Leistungen mit den Leistungen der Voreltern herausfordern möchte; es ist ja fast gewiß, daß hierbei der Lebende Unrecht erhält. Indes - der Stolze muß sich doch sagen, daß selbst ein Ahnherr immer auch ein Enkel ist. Der Bescheidene aber wird der Gefahr, die er fürchtet, entgehen, wenn er die Hörer nicht in erster Linie von Taten und Größe einzelner Ahnherren unterhält, sondern mehr von wissenschaftlichen Strömungen, von denen jene beherrscht wa-

1 [In: Beiträge zum ausländischen öffentlichen Recht und Völkerrecht, Heft 1, Berlin und Leipzig 1927; Rede beim Antritte des Rektors der Friedrich-Wilhelms-Universität zu Berlin am 15. Oktober; Triepel war 1926/27 Rektor der Friedrich-Wilhelms-Universität zu Berlin. Dazu statistisch nüchtern: Heinrich Triepel, Bericht über das Amtsjahr 1926/27 erstattet bei der Rektoratsübergabe am 15. Oktober 1927, Berlin 1927].

2 [Johann Wolfgang v. Goethe, Iphigenie auf Tauris, I.3, V 151-155, in: Hamburger Ausgabe Bd. V, S. $16 \mathrm{f}$.]. 
ren, und wenn er dazu die Richtungen der Gegenwart, in deren Banne er sich selber fühlt, in Beziehung setzt, wenn er also sozusagen die Ahnentafel aus der Sphäre des Subjektiven in die des Objektiven erhebt.

Von den Juristen, die den Berliner Rektormantel getragen, können wir Staatsrechtslehrer nur zwei ganz für uns in Anspruch nehmen: Friedrich Julius Stahl und Rudolf von Gneist. Denn Theodor Schmalz, der erste Rektor unserer Universität, war in seinen Interessen ebensosehr, ja vielleicht noch mehr der Staatswirtschaft und anderen juristischen Disziplinen als dem Staatsrechte zugewandt. August W il he l m Hefft e r, trotz seiner verdienstlichen Leistungen im Privatfürstenrecht und im Völkerrecht, war doch in der Hauptsache Prozessualist und Kriminalist. Die Bedeutung unseres Wilhelm Kahl liegt zunächst auf kirchenrechtlichem und strafrechtlichem Gebiete. Otto von Gi erke endlich, dessen immer überragende Gestalt, seit er geschieden ist, ${ }^{3}$ uns fast von Jahr zu Jahr mehr ins Gewaltige wächst, war ein viel zu universaler Geist, als daß wir ihn in den schmalen Rahmen eines Einzelfachs einspannen dürften, auch wenn gerade unser Staatsrecht seiner Gedankenarbeit besonders fruchtbare Anregungen zu verdanken hat. Stahl aber und Gneist gehören völlig zu uns. Obwohl sie beide vom römischen Rechte ausgegangen sind, und obwohl sie sich auch später keineswegs in den Netzen eines engen Spezialistentums haben fangen lassen, so liegt doch bei beiden der wissenschaftliche Schwerpunkt durchaus auf dem Gebiete des öffentlichen Rechts.

Wir müssen der lockenden Versuchung widerstehen, eine genauere Parallele zwischen den zwei hervorragenden Männern zu ziehen. Nach fast allen Seiten des Charakters und der Lebensauffassung verschiedene Naturen, sind sie nur in dem einen völlig gleich gewesen: darin, daß sie ihre Wissenschaft in eine ganz nahe Verbindung mit politischen Zielen gebracht haben. Freilich, auch hierbei welche Gegensätze zwischen den beiden! Stahl das anerkannte Haupt und der geistige Führer einer politischen Partei; Gneist zwar äußerlich in das Gefüge einer Partei eingestellt, aber ihr innerlich keineswegs in allem hingegeben. Stahl mit der vollen Kraft des fanatischen Dogmatikers stets aufs Ganze gehend, niemals bereit, $\mathrm{Zu}$ geständnisse zu machen; Gneist beweglicher und schmiegsamer, immer bedacht, das große Reformwerk nicht zu gefährden, dem seine Lebensarbeit galt. Stahl im Grunde viel mehr Politiker als Gelehrter; nicht mit Unrecht hat Lenz von ihm gesagt: „Politik war, was er als Lehrer, wie als Mit-

3 [Otto v. Gierke (1841-1921)]. 
glied der Fakultät und als Schriftsteller trieb. “4 Bei Gneist steht doch der Forscher und Gestalter im Vordergrunde, nur daß es eine politische Aufgabe ist, die ihn bei der Wahl des Stoffs und öfters auch bei dessen Gliederung und Deutung bestimmt. Stahl wie Gneist sind Jünger der historischen Rechtsschule gewesen, und beide standen unter dem Einflusse Hegels. Trotzdem bekämpft Stahl die Hegelsche Philosophie, wie er sagt, wegen des Mangels an allem geschichtlichen Prinzip, ja er nennt sie deshalb einmal eine absolute und verderbliche Irrlehre; aber er sucht doch wieder seine Stütze in Hegel, sobald er glaubt, sittliche und politische Wahrheiten durch ihn verkündigt zu hören. Gneist hat seine eigentümliche, ihn immer leitende Auffassung vom Verhältnisse zwischen Staat und Gesellschaft auf dem Umwege über Lorenz von Stein von Hegel bezogen. Indes weder in politischen Anschauungen, noch in der Methode hat er sich von der Hegelschen Philosophie entscheidend bestimmen lassen. Dies alles ließe sich ohne Mühe noch länger fortspinnen. Allein für unsere heutige Betrachtung soll es uns nur auf die Feststellung ankommen, daß die staatsrechtliche Arbeit der beiden Männer ihren Charakter ganz wesentlich durch die Verbindung juristischen Denkens mit politischen Idealen und Zwecksetzungen erhalten hat.

Nur wenige Jahre, nachdem Gneist in der Schrift über die Bildung der Geschworenengerichte ${ }^{5}$ zum ersten Male seine berühmt gewordene politische Forderung, englische Selbstverwaltung auf deutschen Boden zu verpflanzen, aufgestellt hatte, erschien Carl Friedrich Gerbers Buch über die öffentlichen Rechte. Es enthielt das scharf umrissene Programm einer neuen Schule, die sich zur Aufgabe machte, die Wissenschaft des Staatsrechts von allem Politischen zu reinigen. An die Stelle des politischen und staatsphilosophischen Raisonnements, so heißt es wörtlich, hat die juristische Konstruktion zu treten. ${ }^{6}$ Der Sinn ist: das Rechtliche kann nur aus dem Rechtlichen begriffen werden. Bei einer rechtswissenschaftlichen Betrachtung kann das Politische nur Material, niemals Zweck sein. Es gilt, im Staatsrechte die ganze Summe allgemeiner juristischer Begriffe anzuwenden, die in ihrer Einfachheit und ursprünglichen Reinheit im Privatrechte zergliedert worden sind, entweder unmittelbar

4 [Max Lenz, Geschichte der königlichen Friedrich-Wilhelms-Universität zu Berlin Bd. II/1, Halle 1918, S. 125].

5 [Rudolf v. Gneist, Die Bildung der Geschworenengerichte in Deutschland, Berlin 1849].

6 [Carl Friedrich Gerber, Über öffentliche Rechte, Tübingen 1852, S. 27: „Wo politisches und staatsphilosophisches Raisonement die Stelle der juristischen Construction vertreten muß, gebürt die letzte Entscheidung immer der Gewalt“.]. 
oder, wo dies wegen des verschiedenen materiellen Gehalts nicht geht, in der Weise, daß man sie nach den im Privatrechte entwickelten Grundsätzen exakter Interpretation und Konsequenz verändert. Der Nutzen dieser Methode wird dann von Gerber sofort an einem besonderen Probleme anschaulich gemacht, indem die ,juristische Natur" der öffentlichen Rechte des Monarchen, der Beamten, der Untertanen herausgestellt wird. Dabei begegnen uns eine Reihe von Konstruktionen, die in der Folgezeit eine große Rolle gespielt haben: so z. B. die Auffassung des Monarchenrechts als „eigenen“ und „ursprünglichen“ Rechts, die Behauptung, daß die sogenannten Freiheitsrechte der Untertanen keine Rechte seien, daß vielmehr in ihnen nur gewisse Wirkungen objektiver Rechtssätze über die Ausübung der Staatsgewalt ausgedrückt werden sollten. Aus der begrifflichen Konstruktion werden auch sogleich praktische Folgerungen gezogen, so etwa die, daß sich von den öffentlichen Rechten der Bürger fast kein einziges zur gerichtlichen Verfolgbarkeit eigne.

Die neue Methode, die übrigens auf ältere Anregungen Albrechts zurückgeführt werden kann, ist von Gerber nachher noch in seinen reizvoll geschriebenen Grundzügen des deutschen Staatsrechts ${ }^{7}$ angewendet worden. Dann hat sie Laband, Gerbers geistiger Testamentsvollstrecker, wie ihn Landsberg ${ }^{8}$ treffend genannt hat, übernommen und mit vollendeter Künstlerschaft gehandhabt. Und Labands deutsches Staatsrecht, dessen erster Band genau vor fünfzig Jahren erschienen ist, ${ }^{9}$ hat mehr als eine Generation deutscher Publizisten vollständig beherrscht, hat auch über Deutschlands Grenzen hinaus, namentlich in den romanischen Ländern, Einfluß gewonnen. Kaum einer von uns Älteren hat in seinen Anfängen nicht im Banne der Gerber-Labandschen Schule gestanden. Ihre Wirkung ist auch weder durch die kräftige Opposition Gierkes ${ }^{10}$ und Edgar Loenings ${ }^{11}$, noch durch den mutigen, nur nicht ganz richtig angesetzten Angriff Stoerks ${ }^{12}$ gehemmt worden.

7 [Carl Friedrich Gerber, Grundzüge eines Systems des deutschen Staatsrechts, Leipzig 1865].

8 [Ernst Landsberg, Geschichte der Deutschen Rechtswissenschaft Bd. III/2, München 1910, S. 833].

9 [Paul Laband, Das Staatsrecht des Deutschen Reichs Bd. I, Tübingen 1876].

10 [Otto v. Gierke, Labands Staatsrecht und die deutsche Rechtswissenschaft, München 1883].

11 [Edgar Loening, Die konstruktive Methode auf dem Gebiet des Verwaltungsrechtes, in: Schmollers Jahrbuch 11 (1887), S. 117-145].

12 [Felix Stoerk, Zur Methodik des öffentlichen Rechts, Wien 1885]. 
Für die Schule handelt es sich bei der Behandlung staatsrechtlicher Probleme schlechterdings um nichts anderes als um die Analyse öffentlichrechtlicher Verhältnisse durch Feststellung ihrer „juristischen Natur“, um die Auffindung der allgemeinen Rechtsbegriffe, denen sie untergeordnet sind, und um die Entwickelung der Folgerungen, die sich aus den gefundenen Prinzipien ergeben. Jene Analyse bedeutet ganz allgemein eine Ausbreitung der logischen Elemente, aus denen sich der Begriff eines Rechtsinstituts zusammensetzt. Jede teleologische Betrachtung wird verpönt; denn der Zweck, dem ein Rechtsinstitut dient, liegt jenseits seines Begriffs. Daraus ergibt sich von selbst, daß dem Staatsrechte alle politischen Erwägungen, da sie Zweckerwägungen enthalten, fernzuhalten sind. Den Ehrentitel „streng juristisch“ legt die Schule nur solchen staats- und verwaltungsrechtlichen Schriften bei, die eine Berührung mit dem Politischen meiden wie den Verkehr mit dem Gottseibeiuns. Wer sich dieser gelegentlich fast ketzerrichterlichen Tyrannei nicht beugt, wird im besten Falle ignoriert. Der Erfolg ist gewesen, daß die der konstruktiven Periode vorangehende Literatur lange Zeit fast der Vergessenheit anheimgefallen ist, darunter neben vielen verdienterweise verschollenen Büchern manches gute und wertvolle. Mit dem bei aller Positivität doch auch "politisch“ denkenden Robert von Mohl wußte die konstruktive Staatsrechtslehre ebensowenig etwas anzufangen, wie die neue verwaltungsrechtliche Richtung mit Lorenz von Stein und mit Gneist. Auch die kleinen, aber feinen staatsrechtlichen Schriften von Ferdinand von Martitz haben, weil sie als zu „politisch“ galten, nicht die verdiente Würdigung erfahren. Jahrzehntelang arbeitet die Staatsrechtslehre fast ausschließlich mit begrifflichen Konstruktionen. Vor allem die ganze Literatur, die sich mit der Bismarckschen Reichsverfassung beschäftigt, die Literatur, die es unternimmt, die „juristische Natur“ des Reichs, der Länder und ihrer Verbindung, den „rechtlichen Charakter" der Sonderrechte, des Kaisertums, des Bundesrats, der Reichslande, der Schutzgebiete zu ergründen. Überhaupt aber die Literatur, die sich mit verfassungs-, verwaltungsoder völkerrechtlichen Einrichtungen, mit dem „Wesen“ der Regentschaft, des Protektorats, der Realunionen usw. befaßt. Es ist eine lange Reihe von Schriften, an denen noch spätere Geschlechter die Fülle des aufgewendeten Scharfsinns bewundern werden, auch wenn sie, wie zu befürchten steht, über das Verhältnis von Mühe und Ertrag skeptischer denken werden als die Zeitgenossen. Freilich haben schon damals manche Leute den Kopf geschüttelt über den Gegensatz zwischen gewissen juristischen Konstruktionen und den Wirklichkeiten des politischen Lebens. Aber es focht die Häupter und Anhänger der deutschen Schule nicht an, wenn ihnen ein 
Mann wie der französische Jurist Duguit zurief: „Il n'y a pas deux vérités sociales“. Anschütz hat einmal gesagt, was für den Historiker und Politiker „in Wahrheit wahr ist“, brauche nicht wahr zu sein für staatsrechtliche Betrachtung. Noch im Jahre 1913 hat Anschütz die preußische Hegemonie in Deutschland zwar im Sinne einer historisch-politischen Bewertung der Dinge anerkannt, im Sinne des Staatsrechts aber energisch abgeleugnet. Das war, vom Standpunkte der Schule gesehen, ganz folgerichtig, da diese die Hegemonie nicht als einen Rechtsbegriff verwenden konnte.

Nun ist freilich das Wort Politik vieldeutig, und so konnte das Verhältnis der konstruktiven Publizistik zum „Politischen“ verschieden gestaltet sein.

Man kann unter Politik staatliches $\mathrm{H}$ a $\mathrm{ndeln}$ verstehen, kann etwa, wie Bluntschli, als Politik auffassen die Leitung des Staats und die Einwirkung auf die Staatsangelegenheiten, die „bewußte Staatspraxis“. Wo man den Trennungsstrich zwischen dem wahrhaft Politischen und anderem staatlichen Tun zu ziehen habe, vielleicht unter Verwertung des Integrationsgedankens, den Rudolf $\mathrm{S}$ mend mit Glück in die staatsrechtliche Begriffswelt eingeführt hat, braucht uns hier nicht zu beschäftigen. Denn jedenfalls verträgt politische Staatstätigkeit ebenso wie die bloß technische Verwaltung eine Beurteilung nicht nur nach Gesichtspunkten der Zweckmäßigkeit, sondern auch nach solchen des Rechts. Das Staatsrecht hat ja im Grunde gar keinen anderen Gegenstand als das Politische. Der Staatsrechtslehrer kann also gar nicht darauf verzichten, politische Vorgänge oder Absichten mit den Maßstäben des öffentlichen Rechts zu messen. Zwar haben im 17. Jahrhundert die politischen Praktiker an den fürstlichen Höfen zuweilen erklärt, es sei nicht statthaft, Angelegenheiten des Staats und der Fürsten vor Studenten zu verhandeln und Professoren darüber entscheiden zu lassen. Selbst Carpzov hat einmal zugegeben, daß daran etwas Richtiges sei. Aber das Verlangen, die Staatsgelehrten sollten sich nicht um schwebende politische Verhandlungen kümmern, ist von ihnen niemals befolgt worden, um so weniger, als sich gerade die Höfe und die Regierungen erbetener und unerbetener Gutachten der Professoren immer gern bedient haben - vorausgesetzt, daß sie zu ihren Gunsten lauteten. Die Literatur des deutschen Staatsrechts besteht zu einem sehr großen Teile aus Streitschriften über politisch bedeutsame Fragen - von der Zeit Ludwigs des Bayern bis zur jüngsten Gegenwart. An den Kämpfen zwischen Königtum und römischer Kurie, zwischen der kaiserlichen und der ständischen Partei im Reiche, an den Streitigkeiten über das Gesandtschaftsrecht der Kurfürsten oder über den Vorzug der Erbtöchter, an den niemals abreißenden Kompetenz-, Territorial- und Sukzessionshändeln des 
alten Reichs haben sich die besten staatsrechtlichen Köpfe Deutschlands mit Eifer beteiligt, von Lupold von Bebenburg bis Reinkingk und Limnäns, von Pufendorf, Leibniz, Thomasius und Peter Ludewig bis Pütter. Und die Staatsrechtslehrer des 19. Jahrhunderts haben es ihnen gleichgetan, von Klüber bis Hermann Schulze, von Welcker bis Hänel und Laband. Denn auch Laband hat es nicht verschmäht, zu politischen Tagesfragen von rechtlicher Bedeutung, etwa zum lippeschen Thronstreite ${ }^{13}$ oder zur Frage der Einführung direkter Reichssteuern, in Streitschriften Stellung zu nehmen. Es ist nicht zu leugnen, daß manchmal die wissenschaftliche Objektivität des Publizisten, der literarisch in die politischen Kämpfe seiner Zeit hineingezogen wurde, nicht nur verdächtigt - das war stets und ist auch heute selbstverständlich -, sondern wirklich in Gefahr gebracht worden ist. Wir Heutigen dürfen aber doch wohl ohne Überhebung sagen, daß wir auf diesem Gebiete gewissenhafter sind als viele unserer staatsrechtlichen Vorfahren im 17. und 18. Jahrhundert, die in der Verbindung von Forscher- und Sachwaltertätigkeit oft skrupelloser waren, als es sich ziemte. Und weil wir gewissenhafter sind, so sind wir auch freier. Während die bedeutendsten publizistischen Schriften des 17. Jahrhunderts, aus der Feder eines Chemnitz, eines Pufendorf, eines Leibniz, wegen ihres politischen Charakters unter Pseudonymen erschienen sind, treten wir heute mit offenem Visiere für unsere Überzeugung ein. Irre ich nicht, so war Böhlaus Schrift über die Kompetenz-Kompetenz des Norddeutschen Bundes aus dem Jahre $1869^{14}$ die letzte rein staatsrechtliche Monographie, die sich mit dem Mantel der Anonymität bekleidet hat. Freilich haben wir, die wir im Schatten des Rechtsstaats fechten, auch nicht mehr zu befürchten, daß wir wegen unserer Theorien um Amt und Brot gebracht werden oder gar das Schicksal eines Algernon Sidney erleiden, der dem Scharfrichter überliefert wurde, weil er die gemäßigte Monarchie für besser erklärt hatte als die absolute. Zwar haben wir Heutigen statt mit fürstlicher Ungnade mit dem Stirnrunzeln der ungekrönten Könige der Presse und des Parlaments zu rechnen. Allein das ficht uns nicht sonderlich an, weil wir wissen, daß wir im Grunde doch mit jedem, der an der Freiheit der Meinungsäußerung interessiert ist, in stillem Bunde stehen, und daß ein Bündnis wie eine Ehe ohne gelegentlichen Streit langweilig zu werden droht. Je-

13 [Paul Laband, Der Streit über die Thronfolge im Fürstentum Lippe, Berlin 1896; ders., Direkte Reichssteuern. Ein Beitrag zum Staatsrecht des Deutschen Reiches, Berlin 1908].

14 [Hugo Böhlau, Kompetenz-Kompetenz. Erörterungen zu Art. 78 der Verfassung des Norddeutschen Bundes, Leipzig 1869]. 
denfalls aber - wenn wir von unvermeidlichen Menschlichkeiten absehen, so hat es der Wissenschaft nichts geschadet, sondern es hat ihr unendlich genützt, daß ihre Jünger die politischen Ereignisse ihrer Zeit in das Stoffgebiet juristischer Untersuchung gezogen haben. Gerade durch Gutachten und Streitschriften behält der Theoretiker die Fühlung mit der Praxis, und gerade aus dieser Verbindung strömen der Wissenschaft heute wie einst die fruchtbarsten Anregungen zu.

Es würde sich lohnen, in diesem Zusammenhange auch die Beteiligung der Staatsrechtslehrer am p o l i t i s c h e n L e b e n ins Auge zu fassen. Ich kann nur kurz die eigenartigen Wandlungen streifen, die sich hier im Laufe der Zeit vollzogen haben. In der Periode des ständischen und der des absoluten Beamtenstaats finden wir die Professoren der Rechtsgelehrtheit, die Staatsrechtslehrer in erster Reihe, sehr häufig als Berater der Fürsten in den Hofräten und Geheimen Ratskonsilien, oder wir sehen sie wirken als Räte „von Haus aus“ oder als Beamte im Dienste landständischer Korporationen. Oft von vielen Seiten umworbene Männer, werden sie in den Angelegenheiten der äußeren und inneren Politik auch dann angegangen, wenn man sie nicht dauernd an ein Amt zu fesseln vermag. Die Einführung der konstitutionellen Verfassungen bringt die Publizisten auf die Bänke der Parlamente. In den ersten Jahrzehnten parlamentarischen Lebens ziehen die Staatsrechtslehrer in Scharen in die Landtage der deutschen Einzelstaaten ein. Von den bekannten Namen der Wissenschaft fehlt hier kaum einer: Karl Salomo Zachariä, Rotteck, Welcker, Jordan, Mohl, Bluntschli, Stahl, Heinrich Albert Zachariä, Poezl, ganz zu schweigen von den Kleineren, wie Behr, Dresch, Schunck oder Moy de Sons, und von den staatsrechtlich gefärbten Historikern, wie Dahlmann, Waitz, Droysen, Duncker, Sybel, später auch Treitschke. Es ist ganz auffallend, wie sehr sich dies Bild etwa seit der Zeit der Gründung des Norddeutschen Bundes und des Deutschen Reichs verändert hat. Nur Gneist und Hänel sind noch lange Jahre dem parlamentarischen Leben treu geblieben, eine Weile auch Marquardsen und Georg Meyer. Von den Männern, deren Wirksamkeit das deutsche Staatsrecht in den letzten Jahrzehnten des 19. Jahrhunderts beherrscht hat, sind weder Laband noch Seydel, weder Loening noch Zorn, weder Binding noch Brie, weder Jellinek noch Otto Mayer gewählte Volksvertreter gewesen. Gerber hat nur dem konstituierenden Reichstage von 1867 angehört; andere haben sich mit der politisch geruhsameren Rolle des Mitglieds einer Ersten Kammer oder eines Staatsrats begnügt. Welcher Gegensatz zwischen der Beteiligung der Staatslehrer am Frankfurter Parlamente und ihrer Teilnahme an der Weimarer Nationalversammlung! In Weimar finden wir, wenn wir den Begriff des Staatsrechtslehrers nicht 
sehr weit fassen, als Abgeordnete nur zwei aus unserer Reihe; Hugo Preuß hat an der Herstellung der neuen Reichsverfassung als Beauftragter der Regierung, nicht als Abgeordneter teilgenommen. Nun ist der Rückzug der Publizisten aus dem politischen Leben gewiß auf Gründe sehr verschiedener Art zurückzuführen. Die zunehmende Verdrängung des Persönlichen durch das Parteigemäße, der grundsätzlichen Erörterungen durch einen handwerksmäßigen Betrieb politischer Geschäfte, die stärkere Betonung des Wirtschaftlichen bei der Parteibildung haben den Parlamenten einen Rahmen gegeben, in den sich der Professor nur schwer noch einfügen mag. Allein ich glaube nicht fehlzugreifen, wenn ich die parlamentarische Enthaltsamkeit der neueren Publizistenschule auch mit ihrer inneren Einstellung zum Politischen als solchem in Verbindung bringe. Der naturrechtliche Nationalismus, der einen großen Teil der Staatslehre bis tief in das 19. Jahrhundert beherrscht hat, setzt den Gelehrten in ein anderes Verhältnis zu dem auf Wille und Tat abgestellten politischen Leben als eine Gedankenrichtung, deren Vertreter sich auf die Bildung von Begriffen und auf das Argumentieren aus dem System beschränken wollen.

Wir haben es nun aber heute nicht mit der Beziehung der Professoren des Staatsrechts zur Politik, sondern mit der Beziehung ihrer Wissenschaft zum Politischen zu tun. Richten wir unseren Blick wieder auf den Kampf, den die konstruktive Schule gegen die politisch gefärbte Publizistik, vor allem gegen die Tendenzliteratur der vor- und nachmärzlichen Zeit eröffnete, so sehen wir, daß sich der Angriff in erster Linie auf die Methode unserer Wissenschaft bezog. Das Staatsrecht soll nicht mehr politisch behandelt werden. Geht man dem nach, so macht wieder die Mehrdeutigkeit des Ausdrucks „Politik“ einige Schwierigkeiten.

Man hat noch bis vor wenigen Jahrzehnten unter Politik die Lehre vom Staate schlechthin verstanden, ungefähr in dem Sinne, wie sie von der Antike aufgefaßt worden ist. So bezeichnet etwa Waitz die Politik als die wissenschaftliche Erörterung der Verhältnisse des Staats mit Rücksicht sowohl auf die historische Entwicklung der Staaten überhaupt wie auf die staatlichen Zustände und Bedürfnisse der Gegenwart. Darnach wäre das Staatsrecht ein Teil einer umfassenden Wissenschaft Politik, und es würde sich fragen, ob Staatsrecht mit oder ohne Rücksicht auf die anderen Teile dieser Staatswissenschaft zu betreiben sei. Die Frage bleibt aber die gleiche oder verschiebt sich doch nur äußerlich, wenn man davon ausgeht, daß sich der ehemals einheitliche Begriff der Politik inzwischen aufgelöst hat, und daß der Staat nunmehr der Gegenstand verschiedener Wissenschaften geworden ist, von denen die eine ihn nach seiner rechtlichen Seite untersucht, während ihn andere von einem geschichtlichen oder gesellschaftli- 
chen oder psychologischen oder irgendeinem andern Standpunkte aus betrachten. Ob es dabei auch eine Politik in einem engeren Sinne, d. h. eine wissenschaftliche Lehre vom Staatsinteresse geben könne, ist streitig, darf uns aber zunächst gleichgültig sein. Denn die Frage ist allein die, ob es methodisch richtig ist, wenn sich die Wissenschaft des Staatsrechts überhaupt in Beziehung zu anderen Wissenschaften setzt, die es mit dem Staate zu tun haben. Jedermann würde dies wohl ohne Bedenken bejahen, wenn es nicht von der neuesten Richtung, die sich gern als die konsequente Fortentwicklung der Gerber-Labandschen Schule bezeichnet, im Interesse der Methodenreinheit leidenschaftlich bekämpft würde. Die von Kelsen ${ }^{15}$ geführte jung-österreichische Schule, von der erkenntnistheoretisch unanfechtbaren Gegenüberstellung des Seins und des Sollens ausgehend, will aus der Jurisprudenz im allgemeinen und aus dem Staatsrechte insbesondere, da es sich hier um eine $n$ o $r$ m a t i $v$ e Wissenschaft handele, alle kausalen Erwägungen ausschließen. Mit besonderer Feindseligkeit werden p olit is che Erörterungen, da sie Zweckerörterungen seien, als rechtsfremd abgewiesen. Während noch Laband zugegeben hatte, daß die Zwecke eines Rechtsinstituts von Einfluß auf seine juristische Gestaltung und von Wert für sein Verständnis sein können, wird ein derartiger Gedanke von Kelsen als „metajuristisch“ - wie der unschöne Ausdruck lautet - mit dem Anathem belegt. Auf diese Weise wird natürlich und absichtlich das Recht als bloße Form jedes Inhalts entleert. Kelsen ist soweit gegangen, den Staat überhaupt nur als einen Rechtsbegriff, als einen Zurechnungspunkt gewisser Handlungen zu bezeichnen; schließlich hat er ihn mit der Rechtsordnung selbst, also mit einem System von Normen gleichgesetzt.

Nun war die kritische Sonderung der rechtslogisch gewonnenen und der kausalwissenschaftlichen Erkenntnisse unleugbar ein Verdienst. Eine andere Frage aber ist es, ob die schroffe Einseitigkeit, mit der die jüngste Richtung die Rechtslehre auf das Formale beschränken will, der Wissenschaft zum Segen gereicht. Angenommen, wenn auch nicht zugegeben, daß der Jurist, soweit er formallogische Begriffsarbeit durch gesellschaftliche, historische, ethische oder andere Erwägungen ergänzt, nicht mehr Jurisprudenz, sondern Soziologie oder Geschichte oder sonst etwas treibe, so scheint es sich ja nur um eine Frage der Etikettierung zu handeln, die für die Sache ohne Belang sein würde. Aber gerade jene Ergänzung ist es, gegen die man eifert. Die Meister der neuen Schule jagen jeden Gedanken,

15 [Damals war gerade u.a. erschienen: Hans Kelsen, Allgemeine Staatslehre, Berlin 1925]. 
der nicht als normlogisch approbiert werden kann, aus dem Bereiche der Jurisprudenz hinaus, wie die Zunftmeister den Bönhasen ${ }^{16}$ aus dem städtischen Weichbilde. Daß man Staatsrecht in solcher methodischen Exklusivität betreiben kann, ist gewiß. Aber es geschieht doch schließlich um den Preis einer Verarmung unserer Wissenschaft, die den Ruhm der Methodenreinheit wahrlich teuer bezahlen müßte. Im übrigen ist, wie Adolf Menzel sehr richtig sagt, Methodensynkretismus kein Majestätsverbrechen! Wohin wären wir gekommen, wenn wir Kirchenrecht ohne Kirchengeschichte, Handelsrecht ohne Rücksicht auf Volks- und Privatwirtschaft betrieben hätten! Ebensowenig aber läßt sich Staatsrecht ohne Rücksicht auf das Politische betreiben. Schon Pufendorf hat sich erzürnt über die Staatsrechtslehrer, die die deutsche Verfassung behandelten, ohne die res civiles, d. h. die Politik, zu kennen. Sie eignen sich, höhnt er, zu ihrem Geschäfte wie der Esel zum Saitenspiele. ${ }^{17}$ Was würde der alte Kämpfer zu den modernsten Staatsgelehrten sagen, die von Politik nicht einmal etwas verstehen wollen! Der logische Purismus, der die Jurisprudenz von der Berührung mit anderen Wissenschaften abschließt, der sie zu einer esoterischen, nur den Eingeweihten verständlichen Lehre macht, der alle staatlichen Einrichtungen: Verfassung, Parlament, Königtum, Selbstverwaltung und vieles andere nur als blutleere Schemen erscheinen und ihren ethischen Gehalt unbegriffen läßt, muß notwendig zu einer Verdorrung der Staats- und Rechtslehre führen. Hoffen wir, daß die nächste Generation unserer Publizisten, dem Leben zugewandter als die letzte, gerade mit Energie daran gehen wird, die Normen des Staatsrechts in die innigste Beziehung zu setzen zu den politischen Kräften, die sie schaffen und ausgestalten, und die ihrerseits wieder vom staatlichen Rechte gemeistert werden - eine Aufgabe, die bei uns erst langsam in Angriff genommen ist und von der ausländischen Staatsrechtslehre, vor allem der angelsächsischen, weit besser erfüllt wird als von der deutschen.

Es ist nun aber nicht einmal richtig, daß die Rechtswissenschaft, auch wenn man sie im engsten Sinne versteht, um ihres Gegenstands willen genötigt sei, sich auf logisch-formale Konstruktionen zu beschränken. Die normlogische Schule hat sich auf einen zwar nicht falschen, aber willkür-

16 [alter norddeutscher Ausdruck für: Pfuscher].

17 [Samuel Pufendorff, Über die Verfassung des Deutschen Reiches, hrsg. Harry Breslau, Berlin 1870, S. 25: „Aber wer ohne von der Geschichte Deutschlands und der Politik die geringsten Kenntnisse zu besitzen sich die Darstellung eines so unregelmäßigen Staatsgebildes zur Aufgabe stellt, der besitzt ebenso viel Talent dazu, als der Esel zum Saitenspiel."]. 
lich verengten Rechtsbegriff zurückgezogen. Daß der Sinn des Rechts ein Sollen, nicht ein Sein ist, kann vernünftigerweise nicht bestritten werden. Aber unsere Wissenschaft hat es nicht nur mit dem transzendentalen Gehalte des Rechts, sondern mit empirisch gegebenen Rechtsordnungen zu tun, die aus Regeln für ein geordnetes Zusammenleben von Menschen bestehen, die werden und vergehen, die nach Ort und Zeit verschieden gestaltet sind. Deshalb ist trotz allem und allem jede Rechtsordnung für sich etwas „Gegebenes“, also ein „Sein“, und diese Gegebenheit kann gar nicht ohne Rücksicht auf die sozialen Beziehungen, die das Recht normiert, begriffen werden. Ferner: die Regeln des rechtlichen Sollens sind immer der Ausdruck universeller Wertungen, und sie beziehen sich ihrem Sinne nach auf Objekte, die als Mittel zur Verwirklichung bestimmter Zwecke gedacht sind. Man kann daher zum Verständnisse der Rechtssätze überhaupt nicht gelangen, ohne sich ein Bild von den Zweckbeziehungen zu machen, um die es sich beim Rechtlichen handelt, von den Interessen, deren Anerkennung, Mißbilligung, deren Ausgleich die erste Aufgabe oder, wenn man will, die Voraussetzung der Rechtsordnung bildet. Nennen wir nun „politisch“ - das ist abermals eine neue Bedeutung des vielschillerigen Wortes - alles, was sich auf die Staatszwecke oder auf deren Abgrenzung gegenüber individuellen Zwecken bezieht, so ist es klar, daß eine allseitige Erfassung der Normen des Staatsrechts ohne Einbeziehung des Politischen gar nicht möglich ist.

Bei Lichte besehen, ist es auch nur eine Selbsttäuschung, wenn die konstruierende Jurisprudenz der Meinung lebt, sie vermöge den gesamten Stoff der Rechtsordnung ohne Urteile wertenden Charakters zu beherrschen. Sehen wir uns doch das Verfahren, das man juristische Konstruktion zu nennen pflegt, etwas genauer an. Zunächst einige ganz einfache Beispiele. Man konstruiert, wenn man den Theaterbesuchsvertrag als einen Werkvertrag auffaßt, d. h. als einen Vertrag über die Herstellung einer Werkleistung, nämlich der Aufführung; man tut es, um auf das Verhältnis die Bestimmungen des Bürgerlichen Gesetzbuchs über Werkverträge anzuwenden. Oder, wenn ich ein staatsrechtliches Beispiel anführen darf, es gibt Juristen, die die Abdankung eines Staatsoberhaupts als einen Regierungsakt konstruieren, um den Akt unter die Vorschrift der Verfassung zu bringen, daß Regierungshandlungen des Staatschefs der Gegenzeichnung eines Ministers bedürfen. Worin besteht nun eine derartige Konstruktion? Es ist seltsam, daß darüber ganz verschiedene Erklärungen abgegeben wer- 
den. Max Rümelin, ${ }^{18}$ der den Gegenstand, wie ich glaube, am schärfsten untersucht hat, begreift unter Konstruktion die Einordnung einer Einzelerscheinung in das System unter Analysierung und Synthese ihrer Begriffselemente. Ich will mir diese Definition aneignen. Nur möchte ich, etwas anders, als es Rümelin tut, als Konstruktion nicht die Verknüpfung eines Tatbestands mit einer Rechtsfolge, sondern die zum Zwecke dieser Verknüpfung vorgenommene Einordnung eines Tatbestands oder einer Rechtsfolge in das System ansehen. Die Konstruktion bezieht sich immer auf rechtliche Erscheinungen oder Vorgänge, die nicht ohne weiteres durch Subsumtion unter einen feststehenden Begriff gebracht werden können. Wenn man einen Stockschlag unter den Begriff der Körperverletzung bringt, so ist das bloße Subsumtion, keine Konstruktion. Die Konstruktion ist nur die Vorstufe für eine noch vorzunehmende Subsumtion; ihr Zweck ist, die konstruierte rechtliche Erscheinung, sozusagen, subsumtionsreif zu machen. Dagegen halte ich es, auch hier anders als Rümelin, für gleichgültig, ob der Begriff, unter den eine Erscheinung gebracht wird, schon bekannt ist oder erst neu gebildet wird. Zahlreiche Begriffe, die uns heute geläufig, die zum Teil schon zu gesetzlichen Begriffen geworden sind, hat die Wissenschaft ursprünglich zum Zwecke der Konstruktion gebildet - man denke an das Rechtsgeschäft oder an dingliche und persönliche Rechte oder an Staatenbund und Bundesstaat; es war Konstruktion, wenn Georg Jellinek ${ }^{19}$ den Begriff der "Staatsfragmente" aufgebracht hat. Voraussetzung ist nur, daß der neue Begriff dazu dienen soll, systemfördernd zu wirken, vielleicht eine Erscheinung der Unterstellung unter andere, bereits geläufige Begriffe zu entziehen und ihr eben dadurch einen Platz im Systeme anzuweisen.

Dabei wird man aber wohl zwei Arten oder auch zwei Stufen der Konstruktion auseinanderzuhalten haben. Die erste begnügt sich damit, den bekannten Rechtsstoff als eine Einheit darzustellen, indem sie die einzelnen Rechtssätze als Ausflüsse höherer Prinzipien und diese wieder, immer aufwärts steigend, als Ableitungen aus einem an die Spitze der großen Pyramide gestellten Begriffe auffaßt. Sie will das Einzelne als Teil des Ganzen, das Ganze in seinem inneren Zusammenhange und Zusammenhalte aufzeigen. Sie ist Konstruktion um ihrer selbst willen. Man kann sie als die be gr e if e nd e oder, um eine bekannte Formel Max Webers zu variieren, als verstehende Konstruktion bezeichnen. Ein zweiter Schritt, der

18 [Max v. Rümelin, Zur Lehre von der juristischen Konstruktion, in: Archiv für Rechts- und Wirtschaftsphilosophie 16 (1922/23), S. 345-355].

19 [Georg Jellinek, Ueber Staatsfragmente, Heidelberg 1896]. 
nicht immer getan wird, aber freilich sehr nahe liegt, besteht dann darin, daß man aus der postulierten Einheit des Rechtssystems die Befugnis entnimmt, von den gefundenen Prinzipien neue Rechtssätze herzuleiten, also eine Ausfüllung der Lücken des bekannten Rechtsstoffs vorzunehmen. Vom Standpunkte des konstruierenden Juristen handelt es sich freilich dabei um Ausfüllung nur scheinbarer Lücken, da für ihn Konsequenz und Analogie bloß logische Operationen sind, die lediglich feststellen, was im vorhandenen Rechtsstoffe schon enthalten ist. Hier wird also die Konstruktion zur Rechtsfindung verwendet. P h i l i p p $\mathrm{Heck}$ hat das als Inversionsmethode bezeichnet. ${ }^{20}$ Wir wollen das Vorgehen die lückenfüllende Konstruktion nennen. Ob eine juristische Konstruktion nur die erste Stufe erreichen will oder eine Lückenergänzung im Auge hat, ist nicht immer sofort zuerkennen. Die Gerber-Labandsche Schule ist jedenfalls im vollen Sinne konstruktiv. Bei ihrer Fortsetzung in der Kelsenschen Schule kann man oft zweifeln, da hier die Jurisprudenz nicht mehr als eine praktische Wissenschaft aufgefaßt wird, der die Aufgabe gesetzt ist, die Rechtsanwendung durch Deutung des bestehenden und Gewinnung neuen Rechts vorzubereiten.

Es scheint mir an dem Mangel an einer Unterscheidung zwischen verstehender und lückenfüllender Konstruktion zu liegen, daß man sich nicht einig ist, auf welchen geschichtlichen, namentlich geistesgeschichtlichen Grundlagen die konstruktive Jurisprudenz beruhe. Man hat gesagt, die Verdrängung der politisierenden Methode des Staatsrechts durch die konstruktive Richtung erkläre sich daraus, daß die Zeit, in der unsere Nation noch um neue verfassungsrechtliche Formen zu ringen hatte, durch eine Periode verfassungspolitischer Ruhe abgelöst worden sei. Das trifft sicher bis zu gewissem Grade zu. Aber es würde doch eben nur das Staatsrecht angehen, während sich die Vorherrschaft des Konstruktiven in der zweiten Hälfte des vorigen Jahrhunderts auf allen Gebieten der Rechtswissenschaft geltend machte. Wie ist das zu erklären? Viele führen es auf die Auswirkungen der historischen Rechtsschule, andere auf den Einfluß Hegels zurück - was übrigens nicht notwendig einen Gegensatz bedeuten würde. Ich halte beides nicht für richtig oder doch nur für halb richtig.

Es ist unzweifelhaft, daß wir selbst bei den Häuptern der geschichtlichen Rechtsschule eine konstruktive Verfahrensart in der Darstellung des geltenden Rechtes finden. Savignys berühmte Monographie über den

20 [Philipp Heck, Das Problem der Rechtsgewinnung, Tübingen 1912, S. 13]. 
Besitz $^{21}$ gilt ja vielen als Musterbeispiel für konstruierende Jurisprudenz, und Albrechts Gewere ${ }^{22}$ bildet dazu ein germanistisches Gegenstück. Aber sollte bei Savigny die Neigung zur Konstruktion nicht eher ein Teil des naturrechtlichen Rückstandes sein, den man in seinem Gedankenbau vorzufinden mit Recht geglaubt hat? Im übrigen war seine Methode sicherlich weit mehr verstehende, als lückenfüllende Konstruktion, vielleicht ausgenommen den letzten Teil seines Systems, ${ }^{23}$ das internationale Privatrecht. Das Begriffliche herauszustellen und es zum System zu gestalten, macht nach Savigny die Jurisprudenz der Würde einer Wissenschaft teilhaftig. Erst Puchta und Keller sind bewußt und energisch von den konstruierten Begriffen deduktiv zur Lösung der vom Rechte nicht geregelten Einzelfälle herabgestiegen. Aber gerade bei Puchta war es doch wohl der besondere Einfluß der dialektischen Philosophie, der hierbei eine Rolle spielte. Freilich hat es auch ein Mann wie Eich horn nicht verschmäht, zu konstruieren, z. B. aus der „Natur“ des Deutschen Bundes als eines völkerrechtlichen Vereins die Unmöglichkeit der Einführung eines Bundesgerichts zu erweisen. Indes die Grundgedanken der historischen. Schule führen nicht zur konstruktiven Methode hin, sondern von ihr hinweg. Das Dogma von der logischen Geschlossenheit des Rechts ist naturrechtliches Erbgut und nicht, wie viele glauben, auf dem Boden der historischen Schule erwachsen. Deren konsequenteste Vertreter, man denke etwa an Wilhelm Arnold, waren ausgesprochene Gegner der Konstruktion. Wenn andere die konstruktive Methode annahmen, so geschah es trotz des Grundprinzips der Schule. Denn nach diesem ist ja das Recht das Leben des Volkes, von einer bestimmten Seite angesehen. Wie kann man von hier aus zu einer logischen Ableitung der Rechtssätze aus erfundenen Begriffen gelangen? Manigk ${ }^{24}$ hat überzeugend dargetan, daß zwischen der historischen Schule und der modernen Zweckjurisprudenz keineswegs eine unüberbrückbare Kluft aufgetan sei. Zwar mußte die historische Schule jedem Versuche entgegentreten, Lücken des Rechts durch subjektive Werturteile auszufüllen. Wohl aber vermochte sie die rechtsschöpferische Kraft objektiver, in der Gesellschaft vorhandener, also uni-

21 [Friedrich Carl v. Savigny, Das Recht des Besitzes. Eine civilistische Abhandlung, Gießen 1803].

22 [Wilhelm Eduard Albrecht, Die Gewere als Grundlage des älteren deutschen Sachenrechts, Königsberg 1828].

23 [Friedrich Carl v. Savigny, System des heutigen Römischen Rechts Bd. VIII, Berlin 1849].

24 [Gemeint sein könnte: Alfred Manigk, Savigny und der Modernismus im Recht, Berlin 1914]. 
verseller Wertgedanken anzuerkennen; denn auch diese sind Ergebnisse einer Geschichte und stehen im Flusse der Geschichte. Was insbesondere das Verhältnis des Staatsrechts zum Politischen anlangt, so mag es stimmen, daß der quietistische Zug, der der historischen Rechtsschule anhaftete, eine Abneigung wenigstens gegen politisches Raisonnement, „das den Geist der Neuerungssucht atmet“, im Gefolge gehabt hat. Und die Hauptvertreter der antipolitischen Richtung im Staatsrechte, Gerber und Laband, kamen ja von der historischen Schule her. Allein sie waren doch schon einigermaßen entartete Kinder der großen Mutter. Über Gerber, der bezeichnenderweise Puchta, nicht Savigny seinen Meister nannte, hat Gierke das harte Urteil gefällt, er habe mit seinen romanistischen Konstruktionen die deutsche Seele im deutschen Rechte getötet. ${ }^{25}$ Das Beispiel Gneists aber, der doch gewiß ein Sohn der historischen Rechtsschule gewesen, beweist uns, daß auch diese ein Verhältnis zum Politischen gewinnen konnte.

Mit der Rückführung der konstruktiven Jurisprudenz auf Hegel steht es ähnlich. Kein Zweifel, daß Hegel auf die Juristen in der ersten Hälfte des vorigen Jahrhunderts, zum Teil noch länger, einen starken Einfluß geübt hat. Namentlich das öffentliche Recht und neben dem Strafrecht besonders das Staats- und Völkerrecht zeigen die Spuren - Maurenbrecher, der jüngere Pütter, Heffter, Fricker, endlich Otto Mayer, neben manchem, der nur äußerlich von Hegel berührt worden ist. Ganz sicher lassen sich auch einzelne Elemente der Hegelschen Philosophie in den Gedanken der konstruktiven Jurisprudenz wiederfinden. Wenn sich Ihering in seiner jüngeren, stark konstruktiven Schaffenszeit wie Puchta und andere von dem Glauben tragen ließ, daß die „höhere“ Jurisprudenz kraft der inneren Dialektik der Rechtsverhältnisse zur Produktion neuen Rechtsstoffs führe, so ist das offenbar ganz hegelisch gedacht gewesen. Einzelne Begriffsbildungen, die im konstruktiven Staatsrechte eine Rolle gespielt haben, lassen sich unmittelbar auf Hegel zurückführen. Ja, Hegel hat ausdrücklich der positiven Rechtswissenschaft, freilich mit einem deutlichen Tone der Geringschätzung, die Aufgabe zugewiesen, die Zusammenstellung, Konsequenz, Zerspaltung der gegebenen Rechtsbestimmungen durch Deduktion aus ihren positiven Daten vorzunehmen. Aber das ist nach ihm doch alles nur eine Sache der äußeren Ordnung, eine Sache des Verstandes, es hat mit dem wirklichen Begreifen, mit der Vernunft nichts zu tun. So sind die Hegelschen Konstruktionen und die Konstruktionen der Jurisprudenz

25 [Otto v. Gierke, Deutsches Privatrecht. Erster Band: Allgemeiner Teil und Personenrecht, Leipzig 1895, S. 92]. 
gar nicht miteinander vergleichbar. Wer das Gegenteil annimmt, verwechselt die formale Logik mit Hegels metaphysischer Logik, das Begriffliche im gewöhnlichen Sinne mit dem Hegelschen Begriffe, der ja der lebende, sich in unaufhaltsamem Gange entwickelnde Geist des Wirklichen ist. Hegels Konstruktion ist also nur verstehende Konstruktion, und zwar ist sie, auch soweit sie sich auf das Recht bezieht, Geschichtskonstruktion, nicht Rechtskonstruktion; Staat und Recht werden eingereiht in die Entfaltung des Geistes in der Geschichte. So führt Hegels Konstruktion über das Recht hinaus, sie dient nicht der begrifflichen Systematik des Rechtes selbst. Es ist daher ganz bezeichnend, daß von den letzten Ausläufern des Hegelianismus im öffentlichen Rechte nur Otto Mayer, aber weder Lorenz von Stein noch Gneist, die historisch gerichteten Hegelianer, juristische Konstruktion im technischen Sinne gepflegt haben. Und umgekehrt hat die neueste Gestaltung der konstruktiven Staatsrechtslehre, die Kelsensche Normlogik, nicht den geringsten Zusammenhang mit Hegel. Wie sollte das auch möglich sein bei einer Schule, die bewußt unhistorisch ist, während Hegel doch die schöpferische Selbstbewegung des Geistes zur Denknotwendigkeit stempelt, also eben historisch gerichtet ist, - bei einer Schule, die zuletzt den Staat ganz im Rechte verschwinden läßt, während doch bei Hegel das Recht völlig im Staate aufgegangen ist. In der Tat sucht die normlogische Schule selber ihren Ausgangspunkt nicht bei Hegel, sondern bei Kant, - ob mit Recht oder Unrecht, möge hier dahingestellt bleiben. Die Vorliebe für das System und den Glauben an die Lückenlosigkeit des Systems hat die konstruktive Rechtslehre nicht nur mit Hegel, sondern mit der ganzen idealistischen Philosophie, vielleicht überhaupt mit der Philosophie gemeinsam.

Die Hauptsache ist nun aber, daß es konstruierende Juristen längst vor der historischen Rechtsschule und längst vor Hegel, ja man kann sagen, daß es sie gegeben hat, seitdem man überhaupt das Bedürfnis nach innerer Ordnung des Rechtsstoffs empfunden und befriedigt hat, nur daß die Konstruktion nicht immer bewußt als Methode oder als einzige Methode gehandhabt, daß sie oft nur als Systembildnerin oder aus didaktischen Gründen verwendet worden, daß sie oft nur als verstehende, nicht als lückenfüllende Konstruktion aufgetreten ist. Konstruiert haben schon die römischen Juristen - wie köstlich hat uns Ihering ${ }^{26}$ den Konstrukteur Paulus geschildert! -, konstruiert haben Glossatoren wie Postglossatoren, die Scholastik wie der Ramismus, die Synthetiker und Systematiker des 16.

26 [Rudolf v. Jhering, Scherz und Ernst in der Jurisprudenz. Eine Weihnachtsgabe für das juristische Publikum, Leipzig 1883]. 
Jahrhunderts wie das Naturrecht und die Aufklärung. Gerade im Naturrechte finden wir die Konstruktion in bedeutendem Ausmaße. Nur vollzieht sie sich hier, sozusagen, zuerst auf einer anderen Ebene, indem erst das natürliche Recht als solches durch aprioristische Begriffsbildungen und Deduktionen gemeistert und das Ergebnis für das positive Recht nur dann verwendet wird, wenn der Jurist das Naturrecht zur Ausfüllung der Lücken des positiven Rechts verwenden will. Nicht alle, aber die meisten Naturrechtslehrer haben diesen zweiten Schritt getan. Was ist es anderes als lückenfüllende Konstruktion, wenn z. B. Hug o Groti us die Unveräußerlichkeit der Domänen - es war umstritten, ob das Staatsgut vom Landesherrn veräußert werden durfte oder nicht - dadurch erweisen will, daß er das Recht des Landesfürsten am Domanium als Nießbrauch auffaßt, und wenn ihn Leyse $r$ dadurch zu widerlegen sucht, daß er den Herrscher auf Grund des ursprünglichen Staatsvertrags zum wahren Eigentümer stempelt? Gewiß sind in der naturrechtlichen Jurisprudenz logische Deduktionen aus dem Begriffe oft friedlich neben Zweck- und Werterwägungen gelagert. Um bei dem Beispiele der Domänenfrage zu bleiben, so schließt sich Pufendorf auf der einen Seite der These des Grotius und seiner Begründung an, weist aber doch daneben darauf hin, daß es für den Staat notwendig sei, für die ökonomischen Bedürfnisse des jeweiligen Regierungsnachfolgers zu sorgen und deshalb das Domanium der Verfügungsgewalt des Landesherrn zu entziehen. Jedenfalls ist es aber sicher, daß die konstruktive Methode der Rechtsfindung dem Naturrechte ganz geläufig gewesen ist. Nur hat das Naturrecht an Stelle der römischen Rechtsbegriffe, aus denen heraus die deutschen Staatsrechtslehrer ursprünglich die öffentlichen Rechtsverhältnisse konstruiert hatten, eine andere Konstruktionsbasis gesetzt. Gewisse Spielarten der naturrechtlichen Konstruktion aus der Zeit der Aufklärung können geradezu als unmittelbare Vorläufer der konstruktiven Lehrart des 19. Jahrhunderts bezeichnet werden. Das gilt vor allem für die axiomatische Methode des Heineccius, die bei der Behandlung jedes Rechtsinstituts die Definition an die Spitze stellt, daraus dann Axiomata deduziert und aus diesen wieder die Einzelheiten ableitet; es wird z. B. aus dem Begriffe der Ehe das Axiom der Konsensehe entwickelt, und hieraus werden allerhand weitere Schlüsse für die Einzelheiten gezogen. Dahin gehört aber auch die logisch-demonstrative Methode Christian Wolffs und seiner Schule und endlich die Lehre von der Natur der Sache als Mittel zur Ausfüllung von Rechtslücken, eine Lehre, die wir am Ende der Aufklärungsperiode bei $\mathrm{R} \mathrm{u} \mathrm{n} \mathrm{d} \mathrm{e} \mathrm{im} \mathrm{deut-}$ schen Privatrecht, bei Kle inschrod im Strafrecht, bei Gönner im Staatsrecht finden. Gerade diese Methoden haben, was Landsberg in seiner 
Geschichte der deutschen Rechtswissenschaft ${ }^{27}$ sehr fein beobachtet und herausgearbeitet hat, die Brücken gebildet, die vom abstrakten Vernunftrecht des 18. Jahrhunderts zur Konstruktionsjurisprudenz des 19. Jahrhunderts herübergeführt haben.

Alle jene im einzelnen sehr verschiedenen Arten der Rechtsdarstellung und Rechtsfindung können mit keiner bestimmten Philosophie in Zusammenhang gebracht werden. Im Gegenteil, sie versuchen sich alle mit den Weltanschauungen und Erkenntnisformen ihres Zeitalters in Einklang zu setzen. Sie stehen ebenso mit dem Begriffsrealismus der Scholastik in Verbindung wie mit der abstrahierenden Richtung der Aufklärung und des kantischen und nachkantischen Idealismus, wie endlich mit der positivistischen Verengerung des allgemeinen Denkens in den letzten Menschenaltern, mit einer Denkweise, die nicht über den Stoff hinaussieht und nur für gültig hält, was sie aus dem Stoffe herausziehen kann. Gemeinsam haben alle Spielarten der Konstruktionsjurisprudenz nur eine gedankliche Grundlage. Es ist eine, wenn ich so sagen darf, juristische Berufsanschauung. Die konstruktive Methode will dem Bedürfnisse des Theoretikers und Praktikers entgegenkommen, G e w i ß h e it über die Rechtssätze zu schaffen, nach denen sich das gesellschaftliche Leben zu richten hat. Rechtsgewissheit ist notwendig zur Beruhigung des vom Rechte in seinen Interessen getroffenen Bürgers, sowie zur Beruhigung des Gewissens des Rechtsforschers und der rechtsprechenden Obrigkeit. Die Unfehlbarkeit aber des logischen Schlusses, die Evidenz seiner Ergebnisse, scheint allein imstande zu sein, jene Beruhigung zu schaffen. Und so glaubte man die beste juristische Methode zu finden in der Operation mit kristallscharfen Begriffen und granitharten Deduktionen, die eine feste Berechenbarkeit der Resultate verbürgt.

Daher auch der beliebte Vergleich der Jurisprudenz mit der Mathematik, die Bezeichnung der Rechtsfindung als „Rechnen mit Begriffen“, die Forderung, daß die Rechtslehre einem jeden das Seine „mit mathematischer Genauigkeit“ zu bestimmen habe. Die Verwandtschaft der Rechtswissenschaft mit der Mathematik ist von Leibniz bis Wolff und Kant immer wieder behauptet worden. Andeutungen darüber finden sich sogar bei $S$ a vi g n y. Aber auch in neuerer Zeit tritt der Gedanke namentlich bei den Philosophen, so bei Wundt und bei Cohe n auf, und Kels e n, der Schüler Cohens, nennt die Jurisprudenz eine Geometrie der tota-

27 [Ernst Landsberg, Geschichte der Deutschen Rechtswissenschaft, 4 Bde., München 1890-1910]. 
len Rechtserscheinungen, ${ }^{28}$ wenn er auch zugibt, daß das Gleichnis nicht in allen Punkten zutreffe. Es hat eine Zeit gegeben, in der man die Sache ganz wörtlich genommen und sogar staatsrechtliche Fragen durch Rechenexempel zu lösen versucht hat. Ein berühmter Streit drehte sich darum, ob bei einem Dissens zwischen den drei Kurien des alten Reichstags der Kaiser der Mehrheit beitreten und ihre Beschlüsse zum Reichsgesetze erheben, ob er also z. B. mit Kurfürstenkollegium und Reichsfürsten zusammen über ein entgegenstehendes Votum der Reichsstädte hinweggehen könne. Hierbei stützten sich manche auf die von Reinkingk verteidigte Lehre, daß Kaiser und Reichstag die Majestät pro partibus indivisis besäßen, der Kaiser also eine Hälfte, jeder der drei Stände ein Sechstel innehabe. Daraus leitete man dann mit mathematischer Sicherheit ab, daß der Kaiser und zwei Reichsstände zusammen mit zehn Zwölfteln, ja sogar, daß der Kaiser, wenn er nur einen Stand auf seiner Seite habe, mit acht Zwölfteln mehr müsse ausrichten können als die restlichen zwei oder vier Zwölftel. Noch P üt ter hat sich gegen solchen Unfug zur Wehr setzen müssen.

Wie steht es nun aber in Wirklichkeit mit der apodiktischen Gewißheit, die mit der intellektualistischen Methode der formalen Logik erzielt werden soll? Sie ist nicht mehr als ein trügerischer Schein. Noch kein Jurist hat mit ihr allein ein vernünftiges Ergebnis erzielt, und es ist Selbstbetrug, wenn er glaubt, mit ihr allein zum Ziele gekommen zu sein. Denn die scheinbar rein logische Analyse und Synthese der Begriffe kann, wenn anders sie sinnvoll sein soll, ohne Unterstützung durch Werturteile gar nicht vorgenommen werden. Es würde kein logisches Fehlurteil sein, wenn man den Vertrag, durch den sich jemand die Benutzung einer Theaterloge sichert, als einen Mietvertrag konstruieren wollte. Daß man es nicht tut, liegt daran, daß man bei jenem Vertrage nicht das Sitzen in der Loge, sondern das Schauen und Hören der Vorstellung als das Wesentliche betrachtet. Was aber wesentlich oder unwesentlich ist, läßt sich nur durch ein Werturteil feststellen. Selbst bei ganz einfachen Subsumtionen kommen wir häufig ohne Zweckerwägungen und Werturteile nicht aus. In der früheren Reichsverfassung war bestimmt, daß für die „Bekleidung“ der Truppen die Grundfarben und der Schnitt der preußischen Armee maßgebend seien. Ob die Offiziershandschuhe zur Bekleidung gehörten oder nicht, und ob die Einführung brauner, statt weißer Handschuhe in der preußischen Armee von den andern Kontingenten nachgeahmt werden mußte, desgleichen ob man die Handschuhe unter den Begriff der "Ausrüstung“

28 [Hans Kelsen, Hauptprobleme der Staatsrechtslehre, Tübingen 1911, S. 93]. 
zu stellen hatte, von der eine andere Stelle der Verfassung sprach - ich glaube, die Frage hat in der Tat Kopfzerbrechen gemacht -, das ließ sich nicht aus einem mit den Mitteln der Logik gefundenen Begriffe der Kleidung oder Ausrüstung, sondern nur unter Zuhilfenahme von Zweckerwägungen entscheiden. Erst recht sind aber die aus Anlaß einer juristischen Konstruktion vorgenommenen Begriffsbildungen und Begriffseinordnungen nicht ohne teleologische Zutaten zu vollziehen. So ergibt es sich denn leicht, daß der Konstruierende dazu verführt wird, in einen Begriff von Anfang an hineinzulegen, was er nachher aus ihm herausziehen möchte, daß er also bona fide ein gewünschtes Ergebnis erschleicht. Gerade im Staatsrechte lassen sich Hunderte von Konstruktionen finden, bei denen in solcher Weise ein als nützlich erachtetes Resultat herbeigeführt wird. Ein Beispiel statt vieler: Ein junger Staatsrechtslehrer beschäftigte sich einst mit der schon vorhin berührten Frage, ob die Abdankung des Monarchen der Gegenzeichnung eines Ministers bedürfe. Sie bedarf ihrer nur, wenn sie ein Regierungsakt ist. Um sie nun als solchen erscheinen zu lassen, zerlegte sie der Jurist in zwei Akte: den Antrag des Monarchen an den Staat, ihn aus seiner Stellung zu entlassen - diesen Antrag stellt der Herrscher als Individuum -, und die Gewährung der Entlassung - diese nimmt er als Staatsorgan vor. Was er aber in dieser Eigenschaft tut, ist kontrasignaturbedürftig. Eine so gekünstelte Konstruktion wird wenige befriedigen. Der Jurist wäre auch nie auf sie verfallen, wenn er nicht mit aller Gewalt zu einem in seinen Augen politisch notwendigen Ergebnisse hätte gelangen wollen. In Wirklichkeit ist die Abdankung eine Erklärung, die der Monarch nicht namens des Staats, sondern gegenüber dem Staate abgibt, sie ist also ganz sicher kein Regierungsakt. Will man sie also, dem Wortlaute der Verfassung zuwider, an eine Gegenzeichnung binden, so läßt sich das vi elle i ch t dadurch bewirken, daß man unter Zuhilfenahme politischer Interessenwertungen den Rechtssatz der Verfassung, der sich nur auf echte Regierungsakte bezieht, analog auf Fälle ausdehnt, in denen es angemessen erscheint, daß eine das Staatswohl stark berührende persönliche Entschließung des Staatsoberhauptes ebenso behandelt wird wie ein Regierungsakt. Ich glaube freilich nicht, daß die Analogie in diesem Falle berechtigt sein würde, weil ich es gerade im Staatsinteresse für unbedingt geboten halte, das Staatsoberhaupt ganz frei darüber entscheiden zu lassen, $\mathrm{ob}$ es sein Verbleiben im Amte oder sein Ausscheiden für notwendig erachtet.

Die konstruktive Begriffsjurisprudenz im Staatsrechte hat sich aber nicht nur bei bescheidenen Einzelfragen bewußt oder unbewußt mit politischen Zweckerwägungen verbunden. Es ist keine Übertreibung, wenn 
ich sage, daß die Mehrzahl der für das Staatsrecht maßgebend gewordenen Staatstheorien, die ja größtenteils juristische Konstruktionen gewesen sind, im Hinblick auf politische Ziele aufgestellt und zur Rechtfertigung politischer Akte verwendet worden ist. Die Lehren vom Staats- oder Gesellschaftsvertrage, von der Souveränität, von der Gewaltenteilung sind nicht nur Erzeugnisse theoretischer Spekulation, sondern von Anbeginn Stützen für staats- oder kirchenpolitische Bestrebungen gewesen. Dies läßt sich bis in die neueste Zeit verfolgen. Die Lehre von der juristischen Persönlichkeit des Staats wie ihr Gegenstück, die privatrechtliche Staatskonstruktion, waren, was schon Albrecht richtig gesehen hat, Programmstücke politischer Parteien. Die Konstruktion des Monarchenrechts als eines eigenen Rechts an der Staatsgewalt, der Begriff des Trägers der Staatsgewalt, die Formulierung des Bundesstaatsbegriffs sind als Krücken für politische Bewegungen verfertigt oder doch benutzt worden. Selbst L a b a nd s Lehre vom Gegensatze des Gesetzes im materiellen und formellen Sinne, ${ }^{29}$ scheinbar politisch ganz neutral, ist in Gedanken an den preußischen Budgetkonflikt der sechziger Jahre entstanden, hatte sicher eine politische Tendenz, und die Leidenschaftlichkeit, mit der sie von Hänel ${ }^{30}$ bekämpft wurde, besaß einen politischen Hintergrund. In Labands Reichsstaatsrecht hat Gierke mit Recht einen „unverkennbar absolutistischen Zug“ erblickt, und etwas Ähnliches ließe sich auch in O t to M a y e r $\mathrm{s}^{31}$ angeblich ganz unpolitischen verwaltungsrechtlichen Konstruktionen entdecken.

Freilich in allen diesen Fällen hat sich schließlich gezeigt, daß sich aus Begriffen die widersprechendsten Folgerungen ziehen lassen, weil man die Begriffe, ohne logisch falsch zu verfahren, weiter oder enger fassen kann, und weil ihre sogenannte "Richtigkeit" meist nur von der Breite des Induktionsbodens abhängt, aus dem sie entsprossen sind. Auf den Staatsvertrag hat $\mathrm{Hob}$ be s seinen Staatsabsolutismus ebenso zu stützen vermocht wie die Monarchomachen oder Milto n und Sidne y ihr Widerstandsund Absetzungsrecht und wie Rous seau seine demokratische Lehre. Die organische Staatstheorie konnte von G o e n n e r als Ausgang für absolutistische, von den Romantikern für feudalständische, von $\mathrm{Hugo}$ Pre u ß für demokratische Folgerungen benutzt werden. Den Souveränitätsbegriff hat B od in so formuliert, daß er eine außen- und innenpoliti-

29 [Paul Laband, Das Staatsrecht des Deutschen Reiches, Bd. 2, Tübingen 1877, S. $1 \mathrm{ff}$. ( $(56)$; ders., Das Budgetrecht nach den Bestimmungen der preußischen Verfassungsurkunde, Berlin 1871].

30 [Albert Hänel, Das Gesetz im formellen und materiellen Sinne, Leipzig 1888].

31 [Otto Mayer, Deutsches Verwaltungsrecht, 2 Bde., Leipzig 1895/96]. 
sche Stütze für das französische Königtum bildete. In Deutschland modelte man ihn um, damit man aus ihm das Widerstands- und Bündnisrecht der Reichsstände entwickeln konnte; R e in kin g k, der den Kaiser hiergegen schützen wollte, leitete seinen Souveränitätsbegriff aus einer dafür günstigen Formel der Postglossatoren ab. Je nachdem man die Majestas so oder so konstruierte, wurde das Recht des Kaisers, dem Reichshofrate eine mit dem Reichskammergerichte konkurrierende Stellung anzuweisen, von den einen anerkannt, von den andern bestritten. Die Rheinbundsfürsten nahmen eine gewaltsame Verrenkung des Souveränitätsbegriffes vor, um ihre Landstände zerbrechen zu können, und die Formel, mit der die Wiener Schlußakte von 1820 das monarchische Prinzip auf die Souveränität der Fürsten zurückführt, ist ein klassisches Beispiel für eine politisch beeinflusste juristische Konstruktion. „Da der Deutsche Bund“, heißt es dort, „aus souveränen Fürsten besteht, so muß dem hierdurch gegebenen Grundbegriffe zufolge die gesamte Staatsgewalt in dem Oberhaupte des Staats vereinigt bleiben." Die Konstruktion des Bundesstaats war immer abhängig von der Begriffsbestimmung der Souveränität, und je nachdem man die Souveränität als Begriffsmerkmal des Staats behauptete oder leugnete, konnte man die Möglichkeit eines Bundesstaats überhaupt verneinen oder bejahen. Neuerdings halten es viele für ausgeschlossen, ein Völkerrecht auch nur zu denken, ehe nicht der hinderliche Souveränitätsbegriff über Bord geworfen ist, ${ }^{32}$ während ich mich für meine Person anheischig mache, die Souveränität der Staaten, natürlich so wie ich sie konstruiere, geradezu als Voraussetzung für ein zwischenstaatliches Recht zu erweisen.

So zeigt sich, daß die normlogische Staatsrechtsschule ganz mit Recht behauptet, es habe die bisherige Doktrin politische Zweck- und Wertgedanken für ihre Begriffsbildungen mitverwendet, und zwar oft im Widerspruche mit ihrer methodischen Grundauffassung. Nur ziehen wir aus dieser Tatsache einen anderen Schluß als der intellektualistische Purismus. Wir sind nicht der Meinung, daß die teleologische Erwägung aus der Rechtswissenschaft zu verbannen sei. Wir denken vielmehr, daß sie, statt sich hinter der Maske des Logischen zu verbergen, in voller Offenheit ihren Platz in der Rechtslehre suchen und behaupten müsse. Da das Recht selbst nichts ist als ein Komplex von Werturteilen über Interessenkonflikte, so ist die teleologische Methode die dem Gegenstande der Rechtswissenschaft adäquate Methode. Auch im Staatsrechte scheuen wir daher

32 [Das zielt wohl gegen Hans Kelsen, Das Problem der Souveränität und die Theorie des Völkerrechts. Beitrag zu einer reinen Rechtslehre, Tübingen 1920]. 
nicht, sondern fordern wir die Verbindung der politischen Erwägung mit der logisch-formalen Begriffsarbeit. Wir ziehen zwar heute einen schärferen Trennungsstrich zwischen rein politischen und rechtlichen Erwägungen, als es die liberale Publizistik zur Zeit der Rotteck und Welcker, die konservative durch Stahl und andere getan hat; wir wünschen keine Rückkehr der Tage, in denen man Staatsrecht durch Politik ersetzte. Erst recht verabscheuen wir es, wenn politische Tendenz das geltende Recht verfälschen will. Aber wir gehen dem Politischen so wenig aus dem Wege, daß wir uns sogar außerstande erklären, das Recht ohne Rücksicht auf das Politische auszulegen. Dabei sind wir weit davon entfernt, die juristische Konstruktion als solche zu verachten. Im Gegenteil, wir erkennen in ihr, vielleicht nicht das einzige, aber doch ein wertvolles, bisher jedenfalls noch nicht übertroffenes Mittel zur Systembildung, ohne das wir uns eine Herrschaft über den Stoff schwerlich hätten erobern können. Gerade wir Publizisten haben ihr in dieser Richtung vieles zu verdanken. Die konstruktive Methode Otto Mayers hat uns die schier unübersehbare Masse des Verwaltungsrechts erst recht eigentlich wissenschaftlich meistern lassen. Wir beugen uns also vor der verstehenden Konstruktion. Wir schätzen die Konstruktion sogar, wenn auch mit einigem Vorbehalt, soweit sie eine Vorbereitung sein will für die zweite Hauptaufgabe des Juristen, für die Ergänzung des Rechtsstoffs durch Gewinnung neuer Rechtssätze. Denn sie liefert uns bequeme Schubfächer, in denen wir die zu prüfenden Rechtserscheinungen vorläufig unterbringen können, ehe wir sie nach Grundsätzen wertender Interessenabschätzung endgültig beurteilen. Die Konstruktion kann uns also als „Subsumtions- und Analogiehypothese“ dienen. Aber wenn sie eine größere als diese heuristische Rolle spielen will, wenn sie sich anmaßt, selber lü cken füllende Funktionen zu übernehmen, oder wenn sie sich gar gebärdet, die allein seligmachende Methode zu sein, dann werfen wir ihr den Fehdehandschuh hin.

Es ist nicht zu verkennen, daß die Zweckjurisprudenz der Gefahr ausgesetzt und zuweilen sogar unterlegen ist, einem flachen Relativismus oder einem rohen Utilitarismus zu verfallen; selbst Ihering ist der Gefahr nicht immer entronnen. Vor allem für das Staatsrecht scheint eine Methode bedenklich zu sein, die alle Auslegung und Lückenfüllung auf Wertungen stützt. „Ein Staat“, sagte Gerber, „der auf Meinungen gegründet ist, kann nur eine unsichere und schwankende Existenz haben."33 Allein ist denn das formallogische Verfahren weniger auf „Meinungen“ gestützt? Es ist

33 [Carl Friedrich v. Gerber, Über öffentliche Rechte, Tübingen 1852, S. 27: „Ein Staat, der nicht auf Rechte, sondern auf Meinungen...."]. 
kein Zweifel - und das bitte ich namentlich Sie, meine Herren Kommilitonen, stets zu bedenken -, daß gar manche in der Tracht des rein Juristischen wandelnde Begriffe und Axiome des öffentlichen Rechts nichts anderes sind als Ausdrucksformen politischer, ja parteipolitischer Tendenzen. Aber die teleologische Jurisprudenz ist gezwungen, Farbe zu bekennen. Sie macht kein Hehl daraus, daß ihre Ergebnisse abhängig sind von Werturteilen. Denn eine Interessenjurisprudenz, die sich zur Aufgabe setzt, Interessen gegeneinander ,abzuwägen“, muß, wenn sie nicht auf halbem Wege stecken bleiben will, die Maßstäbe nennen, nach denen sie die Abwägung vollzieht. Die Zweckjurisprudenz macht indessen, meist sogar dem ungeschulten Auge, deutlich, wo sie sich an der Grenze der subjektiven und der objektiven Interessenwertung befindet. Daß freilich ihre Aufgabe darin besteht, die Maßstäbe, an die sie sich hält, in der Sphäre des Objektiven zu suchen, steht fest. Wir alle sind dem Irrtum unterworfen, und es kann uns begegnen, daß wir subjektives Meinen mit objektivem Gelten verwechseln. Aber solcher Irrtum ist leichter aufzudecken als der Fehler einer logischen Konstruktion. Unsere Pflicht sehen wir jedenfalls im Staatsrechte wie im Privatrechte - denn es gibt nur eine juristische Methode -, unsere Pflicht sehen wir darin, daß wir uns bei Auslegung und Lückenfüllung zunächst an die Wertungen halten, die wir im Gesetze ausgedrückt sehen. Läßt uns dieses im Stich, so sind wir verpflichtet, die Maßstäbe anzulegen, die wir im Rechtsbewußtsein der rechtlich verbundenen Gemeinschaft finden. Selbst wenn wir einmal am letzten Ende in die eigene Brust greifen, wenn wir, wie es die klassisch gewordene Vorschrift des Schweizerischen Zivilgesetzbuchs ${ }^{34}$ fordert, nach der Regel entscheiden, die wir als Gesetzgeber aufstellen würden, so handeln wir doch nicht nach individueller Willkür. Auch der Gesetzgeber hat seine Normen nicht nach Willkür, sondern nach sachlich begründeter Erwägung aufzustellen. So sollte es vielleicht noch besser heißen: wir entscheiden im Notfalle so, wie wir als Gesetzgeber entscheiden $m$ ü $ß$ t e n. Unser Bewußtsein ist ja doch nur ein Teil eines überindividuellen Geistes. Greifen wir in unsere Brust, so greifen wir zugleich nach ewigen Sternen. Auch für die Interessenjurisprudenz bleibt der oberste Leitstern die Rechtsidee, die ewige Ger e ch t i g k e it. Ihr allein zu dienen, ist unsere Pflicht, ihr treu zu dienen, soll unser Gelöbnis sein.

34 [Schweizerisches Zivilgesetzbuch vom 10. Dezember 1907, $\mathbb{1} 1$. 


\section{Text 11 \\ Die Staatsverfassung und die politischen Parteien. Rektoratsrede $^{1}$}

\section{Vorwort}

Die nachfolgenden Ausführungen geben den Inhalt einer Rektoratsrede wieder, die ich am 3. August 1927 in der Aula der Berliner Universität bei der Feier gehalten habe, welche, wie in jedem Jahre, zur Erinnerung an König Friedrich Wilhelm III., den Stifter der Universität, veranstaltet worden ist. Dem von verschiedenen Seiten geäußerten Wunsche, die Rede durch eine Veröffentlichung im Buchhandel weiteren Kreisen zugänglich zu machen, glaubte ich trotz mancher Bedenken nicht entgegentreten zu sollen. Dagegen habe ich der Versuchung, bei dieser Gelegenheit manches breiter darzulegen, was in einem Vortrage nur angedeutet werden konnte, ohne Schwanken widerstanden. Denn wenn ich einmal ans Ergänzen gegangen wäre, hätte es vermutlich kein Halten mehr gegeben, und aus der Rede wäre ein Buch geworden. Dies zu schreiben, bin ich zur Zeit, mit anderen Aufgaben beschäftigt, nicht imstande.

Berlin, im Dezember 1927

\section{I.}

Nach einem alten, uns ehrwürdig gewordenen Brauche feiern wir auch in diesem Jahre den Geburtstag des königlichen Stifters der Berliner Universität. Nach ihm ist unsere Hochschule genannt, sein Name prangt in golde-

1 [Öffentlich-rechtliche Anhandlungen, Heft 10, Berlin 1928; Rektoratsrede vom 3. August 1927; Triepel war zum damaligen Zeitpunkt Mitglied der DNVP. Reden zur Gedächtnisfeier des Stifters der Berliner Universität wurden in der Weimarer Republik noch ziemlich regelmäßig gehalten. Der Theologe Karl Holl beispielsweise sprach 1925 „Über Begriff und Bedeutung der ,dämonischen Persönlichkeit'“. Triepels Nachfolger, der Altphilologe Eduard Norden, sprach 1928 über „Heldenehrungen“. Danach gab es mehrere Jahre keine Gedächtnisreden. Der erste nationalsozialistische Rektor Eugen Fischer sprach dann aber 29. Juli 1933 auf der Erinnerungsfeier über den „Begriff des völkischen Staates, biologisch betrachtet".]. 
nen Lettern über dem Portale des stattlichen Hauses, das er uns zu Eigentum gegeben hat. Sein Bildnis ist unserm Siegel und der Schaumünze an der Amtskette des Rektors eingeprägt. So ist uns schon in äußeren Zeichen die Erinnerung an Friedrich Wilhelm III. immer lebendig, an einen Herrscher, der gewiß nicht zu den größten der preußischen Könige, aber sicher zu ihren redlichsten und gütigsten gehört hat. Unverlöschlich ist aber auch unser Dank für die Tat, - denn es war eine Tat -, die in einer Zeit drückendster Not des Vaterlandes die Grundlagen und den Rahmen für eine der vornehmsten Bildungsstätten der Nation geschaffen hat.

In der berühmten Denkschrift vom Juli 1809, in der Wilhelm von Humboldt ${ }^{2}$ dem Könige den Antrag auf Begründung der Universität vorlegte, sprach er die Überzeugung aus, die preußische Politik, die trotz aller Bedrängnisse fortfahre, die wissenschaftlichen Einrichtungen zu unterstützen und zu verbessern, werde auf ganz Deutschlands intellektuelle und moralische Richtung den entschiedensten Einfluß ausüben. Wir Heutigen bewundern in solchen Worten nicht nur und nicht einmal in erster Linie den Scharfblick und die Sehergabe des Staatsmannes, sondern vor allem die schlichte Sicherheit, in der sich der Glaube des preußischen Patrioten an die Unzerstörbarkeit der sittlichen Kräfte seines Staates auszudrücken vermochte. In dieser Zuversicht aber war der König eins mit seinem Minister. Glücklich das Volk, dessen Führer nicht allein stark sind im Wollen, sondern die auch von dem lebendig machenden Glauben an die Zukunft der Nation und des nationalen Staates getragen werden!

Wie die preußische Politik nach der Katastrophe von 1806, so hat sich auch die deutsche Politik nach dem Zusammenbruche von 1918 zur Aufgabe gestellt, durch geistige Kräfte zu ersetzen, was uns an physischen verlorengegangen ist. ${ }^{3}$ Es ist heute noch nicht an der Zeit, ein Urteil darüber zu fällen, ob die deutsche Kulturpolitik in den Jahren nach der Revolution der preußischen zu Anfang des vorigen Jahrhunderts ebenbürtig ist an Tiefe der Problemerfassung, wie an Sicherheit in Setzung der Ziele und Wahl der Mittel. Aber so verschieden auch im einzelnen über diese oder jene Maßregel gedacht werden mag, so wird doch immer rühmlich bleiben der Ernst und die Energie, mit der auf jenem Gebiete die Arbeit in Angriff genommen worden ist. Die Opferwilligkeit der staatlichen Gewalten in

2 [Wilhelm von Humboldt, Antrag auf Errichtung der Universität Berlin, in: ders., Werke in fünf Bänden, hrsg. Andreas Flitner / Klaus Giel, Darmstadt 1964, Bd. IV, S. 113-120].

3 [Anlehnend an eine ungesicherte Formulierung Friedrich Wilhelms III.; dazu vgl. Max Lenz, Geschichte der Universität zu Berlin. Bd. I, 1910, S. 78 f.]. 
Reich und Ländern, in den Grenzen natürlich der durch die Verhältnisse eingeengten Opferfähigkeit, ist heute gewiß nicht geringer als vor hundert Jahren, und namentlich die deutschen Universitäten haben trotz der großen Zahl unerfüllter Wünsche doch immer noch Grund zur Dankbarkeit. Die Furcht, daß der Bestand der einen oder der anderen Hochschule der Rücksicht auf Sparsamkeit im Staatshaushalte zum Opfer gebracht werden würde, hat sich zum Glück als unbegründet erwiesen.

$\mathrm{Ja}$, in gewisser Hinsicht gehen die Bemühungen um Förderung der geistigen Kultur heute mehr in die Breite, als es vor hundert Jahren sein konnte. Der Anteil nämlich, den die Gesellschaft an der Sicherung des geistigen Besitzstandes des Volkes nimmt, ist größer als einst. Zwar hat auch Humboldt schon gelehrt, die Nation werde selber aufgeklärter und gesitteter werden, wenn sie zur Begründung der Aufklärung und Sittlichkeit in der heranwachsenden Generation tätig mitwirke; sie werde am Schulwesen mehr Interesse nehmen, wenn dieses auch in pekuniärer Hinsicht ihr Werk und ihr Eigentum sei. Aber für die finanzielle Ausstattung der Universitäten, wenigstens für die neu zu begründende Berliner Hochschule, zog er hieraus doch nur die eine Folgerung, daß ihr Unterhalt nicht aus den königlichen Kassen, sondern aus bestimmten, ihr als Eigentum zu überweisenden Domänen bestritten werden sollte. Würde seine Forderung nicht alsbald von seinem Nachfolger Schuckmann hintertrieben, sondern erfüllt worden sein, so hätte dies für sich allein die Hochschule schwerlich in ein näheres Verhältnis zur Nation gebracht. Heute sehen wir nun, wie diese Nation, oder um deutlicher zu sprechen, wie die Kreise der Gesellschaft, die dazu in der Lage sind, dem Staate freiwillig zur Hand gehen, um aus Eigenem der wissenschaftlichen Forschung auf Universitäten und anderen hohen Schulen die äußeren Mittel zu liefern, deren diese bei der technisch verfeinerten und auf technische Behelfe mehr als jemals angewiesenen Art ihrer Arbeit nicht entraten können. Daß dies heute möglich ist, während es vor hundert Jahren unmöglich gewesen wäre, erklärt sich zwar leicht aus den ökonomischen und sozialen Umschichtungen, die sich in der Zwischenzeit vollzogen haben. Aber die Tatsache als solche ist doch immerhin auf unserem Gewinnkonto zu buchen.

Man darf allerdings nicht außer Augen lassen, daß die neue Form, in der sich der Anteil der Gesellschaft am Gedeihen der Wissenschaft bekundet, auch ihre Gefahren hat. Nicht jede Stiftung zugunsten der Wissenschaft geschieht aus reiner Freude an reiner Wissenschaft. Mancher, der etwas gibt, will auch etwas dafür haben. Dabei braucht noch nichts Schlimmes zu sein. Im Gegenteil. Wenn etwa die chemische Industrie bedeutende Mittel zur Errichtung oder Erhaltung chemischer Forschungsinstitute auf- 
bringt in der Absicht, sich selbst damit zu fördern, so ist das nicht nur unbedenklich, sondern es kommt sogar der Allgemeinheit in hohem Grade zugute, und dies selbst dann, wenn die Geldgeber die Forschung nach bestimmten Zielen hinzulenken bestrebt sind. Aber es liegt wesentlich anders, wenn auf den Gebieten der Geisteswissenschaften dem Gelehrten eine Unterstützung gegeben wird, um ihn mehr oder weniger deutlich in eine Richtung zu steuern, die bestimmten wirtschaftlichen, sozialen, außen- oder innenpolitischen Strebungen genehm ist. Hier muß zum Fluche ausschlagen, was ein Segen sein könnte. Als sich Schuckmann dagegen wandte, daß unsere Universität mit Domanialbesitz ausgestattet werde, sprach er die zynischen Worte: „Wie exaltiert auch die Köpfe sein mögen, so behalten doch die Mägen immer ihr Recht gegen sie ... Wem die Herrschaft über die Mägen bleibt, der wird auch mit den Köpfen fertig. “4 Die Anstalten der Bildung, das war die Meinung, müssen allein unter der Herrschaft des Staates, also auch in unmittelbarster finanzieller Abhängigkeit vom Staate stehen. Das war das genaue Gegenteil von den Ideen Humboldts, ${ }^{5}$ dessen letzter Plan gerade dahin ging, das gesamte Erziehungswesen aus der Umklammerung durch den Staat zu lösen und alle Schulen, wie er einmal schrieb, „bloß von der Nation besolden zu lassen." Allerdings dachte sich Humboldt unter der "Nation“ etwas anderes und Einheitlicheres als eine durch den Kampf vielspältiger Interessengruppen aufgelockerte Gesellschaft. Und ihn würde ein Grauen befallen haben, wenn er sich hätte vorstellen können, daß die „Besoldung“ der Schulen an Stelle des Staates von mannigfachen lnteressentenverbänden, vielleicht von solchen, die sich mit politischen Parteien decken oder mit ihnen verschwistert sind, besorgt werden sollte.

Wir werden uns alle darüber einig sein, daß die Wissenschaft ihren Adel verlieren müßte, wenn sie in wirkliche Abhängigkeit von politischen Parteien geriete. Deshalb drängt sich die bange Frage auf, ob nicht solche Abhängigkeit in der Gegenwart beinahe unvermeidlich geworden ist. Zwar finden wir in den Grundrechten auch der neuesten Verfassungen den tröstlichen Satz: „Die Wissenschaft und ihre Lehre sind frei.“ Allein weder Forschung noch Lehre können die Förderung, ja die Unterhaltung durch

4 [Zitat, wie auch die Konfrontation Humboldt/Schuckmann evtl. angeregt von Adolph Wagner, Die Entwicklung der Universität Berlin 1810-1896, Berlin 1896, S. 10].

5 [Dazu vgl. Wilhelm v. Humboldt, Ideen zu einem Versuch, die Gränzen der Wirksamkeit des Staats zu bestimmen. Kap. VI: Über öffentliche Staatserziehung, in: Werke in fünf Bänden, hrsg. Andreas Flitner / Klaus Giel, Darmstadt 1960, Bd. I, S. $103 \mathrm{ff}$.$] .$ 
persönliche Kräfte und sachliche Mittel entbehren, die der Staat zur Verfügung stellt. „Der Staat nimmt an ihrer Pflege teil“, sagt die Weimarer Verfassung. Und so müßte die gestellte Frage, die für uns eine Schicksalsfrage ist, bejaht werden, wenn es zuträfe, daß der moderne Staat und insbesondere der deutsche, die Natur eines Parteienstats, wie der neueste Ausdruck lautet, angenommen habe, d. h. eines Staats, der die politischen Parteien so fest in seine Organisation einbaut, daß staatliches Wollen und Handeln in entscheidenden Dingen immer auf Wollen und Handeln von Parteigemeinschaften beruht. Ist das richtig? Ich möchte heute allein auf diese letzte, wenn ich so sagen darf, präjudizielle Frage eine Antwort suchen, und werde es den Hörern überlassen, die für uns wichtigen Folgerungen im stillen zu ziehen. Mein Thema lautet also: Das Verhältnis von Staat und Partei, oder genauer von staatlicher Verfassung und polit is che r Partei. Es ist freilich ein weites Feld, auf das wir uns damit begeben, und wir werden es nur mit flüchtigen Schritten durchmessen können.

\section{II.}

Geschichtlich angesehen, hat sich das Verhalten des Staats gegenüber den politischen Parteien in einer vierfachen Stufenfolge bewegt. Wir können von einem Stadium der Bekämpfung, dann von einem Stadium der Ignorierung sprechen. An dieses schließt sich die Periode der Anerkennung und Legalisierung, und als letzte würde die Ära der verfassungsmäßigen Inkorporation folgen, die uns freilich zunächst noch in Existenz und Eigenart problematisch ist.

Diese Entwicklung hat sich in einer verhältnismäßig kurzen Zeitspanne, nämlich in nicht viel mehr als einem Jahrhundert, vollzogen. Denn die politischen Parteien in dem Sinne, wie wir den Begriff heute verstehen, sind fast nirgends älter als ein Jahrhundert. Natürlich hat es politische Parteien als Gesinnungsgemeinschaften von jeher gegeben, und auch Parteien im Sinne von Gruppen, die ein gemeinsames auf den Staat bezogenes Interesse einem Gegner gegenüber zu verwirklichen streben, finden sich in jedem Zeitalter und in jeder Staatsform. Aber die politische Partei, wie wir sie uns heute denken, als eine in fester Form vereinsmäßig gestaltete Kampfgenossenschaft, die zur Erreichung politischer Ziele eine Macht über den Staat zu gewinnen strebt, ist doch erst ein Erzeugnis der modernen Repräsentativverfassung. Die politische Partei setzt eine Volksvertretung als Kampffeld und ein parlamentarisches Wahlrecht als Kampfmittel voraus. 
Daher denn die Geschichte der englischen Parteien etwa im Zeitalter der glorreichen Revolution, die Geschichte der amerikanischen Parteien mit der Entstehung der Verfassung der Vereinigten Staaten, die Geschichte der Parteien des kontinentalen Europa mit den auf die französische Revolution zurückgehenden Verfassungsbildungen anhebt.

Bei diesem Zusammenhange zwischen Repräsentativverfassung und Parteientwicklung könnte es auf den ersten Blick überraschen, daß sich der konstitutionelle Staat, jedenfalls auf dem europäischen Festlande und namentlich in Deutschland, amtlich und offiziell dem Parteiwesen vorerst ablehnend gegenüberstellt. Man ist versucht, zu denken, daß die Parteibildung, wie sie die Repräsentativverfassung zur Voraussetzung hat, so andererseits deren notwendige Folge darstelle. In Wahrheit ist, wie wir noch sehen werden, Parteibildung und Parteiherrschaft nur mit einer ganz bestimmten, aber nicht mit jeder Auffassung und Ausprägung des Systems der Volksvertretung verknüpft. Es gab und gibt Wahlsysteme, die ohne Anteilnahme und Wahlkämpfe politischer Parteien funktionieren können. In der Jugendzeit des süddeutschen Konstitutionalismus finden wir nur ganz schüchterne Ansätze einer politischen Parteibildung, und noch im Jahre 1848 sind zur deutschen Nationalversammlung in vielen Wahlkreisen Abgeordnete als Männer allgemeinen Vertrauens gewählt worden, ohne von einer organisierten Partei als Kandidaten aufgestellt gewesen zu sein. Wenn dem aber so war, so konnten sich die Regierungen, während sie das parlamentarische Wesen notgedrungen dulden mußten, dem Parteiwesen erfolgreich widersetzen. Noch in der Mitte des 19. Jahrhunderts hat die parteifeindliche Politik der deutschen Bundesregierungen durch die bekannten, übrigens dem französischen Rechte entlehnten „Verbindungsverbote" die politischen Vereine überhaupt und die organisierten Parteien insbesondere in der Entfaltung ihrer Kräfte empfindlich hemmen können. Die polizeistaatlich befangenen Anschauungen der Bureaukratie, die eine selbständige Parteipolitik als unzulässige Einmischung in das Vorbehaltsgebiet obrigkeitlicher Betätigung empfand, begegneten in jener Zeit nicht einmal einem starken Widerspruche der öffentlichen Meinung, sogar nicht in den Landtagen. Es mutet uns heute wie ein Märchen an, wenn wir hören, daß im hessischen Landtage vom Jahre 1834 Heinrich von Gagern mit knapper Not einem Ordnungsrufe entging, nachdem er die Regierung als Repräsentantin einer Partei bezeichnet und empörte Entgegnungen der schwer beleidigten Regierungsvertreter hervorgerufen hatte. Der deutsche Bürger der Biedermeierzeit betrachtete die Parteien als eine Gefahr für die Ruhe des Staates, ja, er war nicht abgeneigt, das Parteiwesen als eine moralische Verirrung anzusehen. Und war er ein Demokrat, 
so konnte er sich auf den Klassiker der demokratischen Lehre, auf Jean Jacques Rousseau, berufen, der die Parteien als ein fremdartiges Einschiebsel zwischen der Masse der Bürger und ihrer Gesamtheit, als ein Mittel, den allgemeinen Willen zu fälschen, betrachtet hatte.

Freilich, der Bürger und Politiker jener Zeit war in aller Regel kein Demokrat, sondern ein liberaler Mann. Aber gerade die Dogmatik des bürgerlichen Liberalismus, dessen Ideen die neuen Verfassungen geschaffen hatten und in ihrer Entwicklung bestimmten, lehnte das Parteiwesen entweder völlig ab, oder sie bekämpfte doch jedenfalls den Einfluß der Parteiorganisationen auf die Willensbildung der Parlamente mit aller Entschlossenheit.

Nach der Auffassung, die dem System der Volksrepräsentation zugrunde gelegt worden, ist der Volksbote kein Vertreter, kein Mandatar, kein Delegatar seiner Wähler oder seines Wahlkreises, sondern ein Vertreter des ganzen Volkes. Das war bereits im 18. Jahrhundert in England die herrschende Meinung. Dem Einflusse Sieyès, Mouniers, Talleyrands ist es zu danken, daß sich die französische Nationalversammlung in den entscheidenden Juliverhandlungen des Jahres 1789 auf denselben Boden stellte. „Un Députéc, sagte Sieyes, „est nommé par un baillage au nom de la totalité des baillages; un Député l'est de la nation entière; tous les citoyens sont ses commettants." Daher muß der Abgeordnete ohne Instruktion, ohne imperatives Mandat in die Versammlung kommen. Er ist Herr seiner eigenen Meinung. Und am besten ist es, wenn er sich seine Meinung erst bildet in der Beratschlagung mit den anderen. Aus der freien Diskussion ergibt sich die gemeine Meinung. Diese ist, sagt Sieyès einmal, das Ergebnis eines Drängens und Stoßens, bei dem sich die nützlichen und die schädlichen Ansichten scheiden. Die einen sinken, die anderen bewegen sich fort, bis sie endlich alle gereinigt zu einer einheitlichen Meinung zusammenschmelzen. Diese Anschauung, die Carl Sch mitt ${ }^{6}$ mit Recht die geistesgeschichtliche Grundlage des modernen Parlamentarismus überhaupt genannt hat, beherrscht die ganze liberale Doktrin. Wir finden sie bei Burke, Bentham und John Stuart Mill, wie bei Guizot und Benjamin Constant. Auf ihr beruht aber auch das positive Recht des jungen Konstitutionalismus. Auf sie gehen die fast stereotyp gewordenen Sätze der deutschen Verfassungen zurück: „Der Gewählte ist als Abgeordneter nicht des einen Wahlbezirks, sondern des ganzen Landes anzusehen.“ „Die Abgeordneten folgen bei ihren Abstimmungen nur ihrer eigenen gewissenhaften Über-

6 [Carl Schmitt, Die geistesgeschichtliche Lage des heutigen Parlamentarismus, 2. erw. Aufl. München 1926]. 
zeugung; sie sind nicht an Aufträge oder Vorschriften irgendeiner Art und Quelle gebunden." Das ist von vornherein und in erster Linie als eine scharfe Absage an alle Parteigebundenheit, an alle Parteidisziplin gemeint gewesen.

Es fehlt auch nicht an technischen Mitteln - sie werden namentlich durch Vorschriften über die parlamentarische Geschäftsbehandlung geschaffen -, um die Parteibildung in der Volksvertretung zu verhindern oder sie zu paralysieren, mindestens sie nicht sichtbar zu machen. In Bayern wie in Sachsen richtete sich die Sitzordnung in der Abgeordnetenkammer nach dem Lose; in den verschiedenen Klassen, aus denen sich die württembergische zweite Kammer zusammensetzte, entschied das Amtsoder das Lebensalter über die Reihenfolge der Sitze. Ähnliche Bestimmungen galten in Sachsen-Weimar-Eisenach, in Kurhessen und anderwärts. Wie man über diese Dinge dachte, zeigt eine Stelle in R obert Mohl's Württembergischen Staatsrecht, wo es heißt: „Die Bestimmung der Sitzordnung ist keineswegs ein zu kleinlicher Gegenstand für eine Verfassungsurkunde, indem dadurch die äußere Abscheidung der politischen Parteien verhindert wird. Eine Vermischung der Angehörigen verschiedener Ansichten wird der Leidenschaftlichkeit weniger Gegenstand und weniger Halt geben, als eine geschlossene Masse derselben. Es wird auch dem einzelnen erleichtert, seiner Überzeugung in den Fällen zu folgen, in welchen er von der Meinung oder von den Beschlüssen seiner Partei ab-

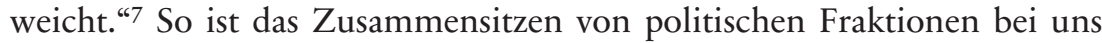
erst seit 1848 und erst allmählich zur Regel, aber keineswegs zu einer allgemein gebilligten Einrichtung geworden. Noch im Jahre 1872 schrieb Mohl: die feste Verbindung der einer Parteiabschattung angehörigen Mitglieder einer repräsentativen Versammlung zu einer sog. Fraktion, d. h. zu einem besonders beratenden und die Teilnehmer durch Mehrheitsbeschlüsse bindenden Vereine, sei „ein nach allen Seiten schädlicher Auswuchs und Unfug, ein Beweis von unfertiger staatlicher Erziehung". ${ }^{8}$ Der Abneigung gegen Fraktionsbildung und Fraktionseinfluß entsprang auch die zuerst in Frankreich aufgekommene, dann in Deutschland vielfach eingebürgerte Einrichtung, daß die Kammern durch das Los in Abteilungen zerlegt wurden, denen man die Vorberatung von Gesetzentwürfen oder die Prüfung von Wahlen anvertraute. Die Institution hat sich der Form

7 [Robert v. Mohl, Staatsrecht des Königreichs Württemberg, 1834, 2. Aufl. Tübingen 1846, Bd. I, S. 723].

8 [Robert v. Mohl, Die Parteien im Staat, in: ders., Encyklopädie der Staatswissenschaften, 2. Aufl. Tübingen 1872, S. 648-658, hier: 654]. 
nach im deutschen Reichstage bis zur Revolution erhalten. Auch das Verbot, in der Verhandlung Reden abzulesen, die vorher formuliert worden sind, gehört in diesen Zusammenhang; der Abgeordnete hat sich eben seine Meinung in der Beratschlagung im Plenum, nicht in einem Fraktionszimmer zu bilden. Benjamin Constant hielt gerade diese scheinbare Äußerlichkeit für so wichtig, daß er sie zweimal zum Gegenstande ausführlicher Erörterung gemacht hat.

Die Entwicklung des Parlamentarismus hat nun aber allmählich weitab von seinem grundsätzlichen Ausgangspunkte geführt. Die ständig fortschreitende Verstärkung des demokratischen Gedankens hat die Eigenständigkeit des Parlaments, die Originalität seiner in Beratung und Debatte geborenen Beschlüsse, die Unabhängigkeit der Abgeordneten von außerparlamentarischen Einflüssen, die Freiheit von fraktioneller Beherrschung geschmälert und schließlich fast vernichtet. Die Parteiorganisation greift den Parlamentarismus von außen und von innen an. Sie bemächtigt sich des Wählers und treibt ihn mehr und mehr in ihre Netze. Sie bemächtigt sich des Parlamentsverfahrens in allen seinen Stadien und Richtungen. Der Zusammenhang der außerparlamentarischen, Distrikt und Land umfassenden Parteien mit ihren parlamentarischen Exponenten, den Fraktionen, wird immer enger. Die Beschlüsse der Volksvertretungen werden in Beratung und Abstimmung der Fraktionen vorbereitet. Die Diskussion im Plenum, manchmal sogar in den Ausschüssen, wird zur leeren Form. Der Parlamentsbeschluß ist, wenn das Parlament eine homogene Mehrheit besitzt, ein Parteibeschluß, bei Parteizersplitterung ein Parteienkompromiß. Und der Abgeordnete ist nicht mehr ein Vertreter des Volkes, sondern ein Vertreter seiner Partei, er fühlt sich als solcher und handelt als solcher. Von der Freiheit der Überzeugung, der Rede und der Abstimmung ist kaum ein Rest übriggeblieben. Der Abgeordnete ist nicht nur abhängig von der Stimmung seiner Wähler und der außerparlamentarischen Parteiorganisation, der er sein Mandat verdankt, sondern er ist abhängig von der Fraktion, die ihn einer harten Disziplin unterwirft, ohne deren Erlaubnis er in den öffentlichen Sitzungen den Mund nicht öffnen darf, die den Inhalt seiner Reden, sein Verhalten in den Ausschüssen vorschreibt, die, von seltenen Ausnahmefällen abgesehen, seine Abstimmung leitet.

Das Eigentümliche ist nun aber, daß das geschriebene Recht diese Entwicklung zunächst vollständig ignoriert hat. Gewiß hat die sozusagen amtliche Abneigung der Regierungen gegen das Parteiwesen vor der harten Wirklichkeit des politischen Lebens kapitulieren müssen. Man bekämpft vielleicht eine einzelne Parteibildung, sucht sie sogar durch Ausnahmegesetze zu zerstören, ehe man die Nutzlosigkeit solcher Maßregeln einsieht. 
Aber man bekämpft nicht das Parteiwesen als solches. Im Gegenteil, man nimmt Fühlung mit den Parteien, man verhandelt mit ihnen, sucht sie zu beeinflussen, stützt sich auf bestimmte Parteien, sucht schließlich sogar auf die Parteibildung selbst und das Verhältnis der Parteien zueinander, bald trennend, bald verbindend, einzuwirken. Aber für den Gesetzgeber ist bis vor einigen Jahrzehnten der Begriff der Partei nicht vorhanden gewesen. Der Ausdruck „Partei“ findet sich in keiner Verfassungsurkunde, in keinem Gesetze. Sogar die Geschäftsordnungen der Parlamente scheinen in dieser Periode von dem Bestehen der politischen Parteien und Fraktionen nichts zu wissen. Nicht einmal in England, wo doch früher als irgendwo anders das Parteiensystem das parlamentarische Wesen beherrscht. Die Standing Orders und die Sessional Orders des Unterhauses deuten mit keinem Worte an, daß die ganze Verhandlungsweise des Parlaments durch die Parteien, ihre Führer, ihre „Einpeitscher" bestimmt wird. „Von der Einteilung in Parteien“ sagt S id ne y L ow, ${ }^{9}$ "und von der Tatsache, daß die Reichsexekutive ein Ausschuß aus einer Partei ist, wird auch vom Unterhause selbst keine Notiz genommen." Der Kongreß der Vereinigten Staaten kennt noch heute keine Fraktionen. In Frankreich und Deutschland blieben die Fraktionen, obwohl sie längst entwickelt waren, eifrig arbeiteten und eifersüchtig auf Parität bei der Zusammensetzung der Ausschüsse hielten, doch für die Geschäftsordnung bis vor nicht langer Zeit ein unbekannter Begriff, ebenso der durch die Praxis entwickelte, aus den Vertrauensmännern der Fraktionen zusammengesetzte Seniorenkonvent, und im deutschen Reichstage glaubte man an der Fiktion festhalten zu müssen, daß die durch das Los gebildeten Abteilungen die Mitglieder der Kommissionen bestimmten, während dies doch längst schon von den Fraktionen in die Hand genommen worden war.

Unter dem Drucke der Verhältnisse hat sich nun diese Einstellung des offiziellen Staates seit einiger Zeit wesentlich geändert. Gesetze, Verordnungen, Geschäftsordnungen beginnen, das Parteiwesen und die Parteiorganisation, die außer- wie die innerparlamentarische, förmlich anzuerkennen. Das kann mittelbar, der Jurist sagt in solchen Fällen: durch konkludente Willenserklärungen, geschehen. So ist z. B. in Kanada und in Australien die gesetzliche Einrichtung getroffen, daß der Führer der parlamentarischen Oppositionspartei einen beträchtlichen Zuschuß zu seinen Abgeordnetengebühren, also eine Art Gehalt empfängt; er wird dadurch geradewegs zum Träger eines staatlichen Amtes gestempelt. Mehr und mehr auch sprechen die Gesetze ausdrücklich von den Parteiorganisationen außerhalb

9 [Sidney Low, Die Regierung Englands, Tübingen 1908]. 
des Parlaments, geben ihnen allerlei Rechte, ja, sie greifen sogar in das Leben der Parteien durch manche zwingenden Vorschriften ein.

Am frühesten und zugleich am umfassendsten tritt die neue Haltung des Gesetzgebers in den Staaten der amerikanischen Union zutage. Hier hat sich die Einrichtung ausgebildet, daß die Aufstellung der Kandidaten für öffentliche, durch Wahlen zu besetzende Ämter in eingehenden gesetzlichen Bestimmungen geregelt, daß also eine von Haus aus ganz freie Tätigkeit der Partei auf dem für ihr Leben wichtigsten Gebiete durch staatliche Normen geregelt wird. Das geschah durch die Einführung der sogenannten „Primary Elections“, der Vorwahlen, - ein Institut, das in der deutschen Literatur bisher nur geringe Beachtung gefunden hat. Es taucht schon seit der Mitte der Sechziger Jahre da und dort auf, zuerst in Kalifornien und im Staate New York. Seitdem das Australian Ballot System, das geheime Wahlrecht, das übrigens schon an sich durch die Einführung amtlicher Stimmzettel den Parteien einen "gesetzlichen Status“ verlieh, große Verbreitung gefunden und die längst eingerissene Wahlkorruption ins Gigantische gesteigert hatte, verbreitete sich auch die gesetzliche Organisation der Vorwahlen, die der Korruption Einhalt tun sollte. Die Bewegung begann etwa 1885, wurde seit 1895 lebhafter und hat allmählich fast die ganze Union ergriffen. Das System ist jetzt in mehr als vierzig Staaten eingebürgert. Ursprünglich fakultativ, bald aber obligatorisch geworden, spielt es bei der gewaltigen Zahl der durch Wahlen besetzten Stellen eine außerordentliche Rolle. Obwohl neuerdings wieder stark angefeindet, wird es doch von den meisten gepriesen und wird vermutlich nicht wieder aus dem amerikanischen Rechte verschwinden. Mit der staatlichen Regelung der Vorwahlen wollte man die Allmacht des Parteiboß oder der von ihm beherrschten Conventions brechen, d. h. der Parteibehörden, die, aus dem spontan gebildeten Caucus hervorgegangen, sich zu förmlichen Parteiregierungen mit tyrannischer Herrschaft entwickelt hatten. Man will jetzt die Parteiangehörigen selber zu Worte kommen lassen, will ihnen ermöglichen, die Nominierung korrupter Kandidaten zu verhindern, will die Berufspolitiker entthronen und die Macht der Interessentengruppen brechen, von denen sie bezahlt werden. Zu diesem Zwecke läßt man die Parteimitglieder entweder die Conventions wählen - so nach dem ursprünglichen System, oder man gibt ihnen die unmittelbare Nominierung der Kandidaten in die Hand - das ist die heute durchaus herrschende Form der Vorwahlen, die Form der „Direct Primaries“. So wird also jetzt der Parteiangehörige zweimal zur Urne gerufen. Das erstemal innerhalb der Partei, um den Parteikandidaten zu wählen, das zweitemal, um bei der eigentlichen Wahl dem aufgestellten Kandidaten zum Siege über den Kan- 
didaten der Gegenpartei zu verhelfen. Und im ersten wie im zweiten Falle ist es das Staatsgesetz, das den Wahlgang regelt. Die Erfahrung hat gezeigt, daß die Parteimitglieder die ihnen durch die Vorwahl gebotene Einflußmöglichkeit stark ausnützen. Die Beteiligung ist bei den Vorwahlen manchmal viel stärker als bei den Hauptwahlen. Es wird von Fällen berichtet, in denen ein Kandidat bei der Vorwahl achtmal mehr Stimmen als bei der Hauptwahl erhalten hat, dort 220000, hier nur 28000; wenn er doch schließlich den Kandidaten der Gegenpartei geschlagen hat, - so wird auch bei dieser die Wahlbeteiligung in der Hauptwahl stark nachgelassen haben. Häufig lassen die Wählerziffern bei einer Vorwahl schon im Voraus den Ausgang der Hauptwahl erkennen, obwohl natürlich Überraschungen nicht ausgeschlossen sind. Darum wird aber auch auf die Vorbereitung und Durchführung der Primaries eine ungewöhnliche Mühe verwendet. Die Kosten sind zuweilen ungeheuer, und so scheint es, als ob sich hier doch wieder ein neues Tor für das Eindringen der Korruption aufgetan habe.

Die Gegner der neuen Einrichtung haben anfänglich versucht, deren Verfassungsmäßigkeit anzuzweifeln. Sie haben sich auf den Grundsatz der Vereins- und Versammlungsfreiheit berufen. Aber die Gerichte haben ihnen unrecht gegeben, gelegentlich mit Begründungen, die einem europäischen Juristen reichlich „smart“ erscheinen. Heute zweifelt in den Vereinigten Staaten kaum noch jemand daran, daß der Staat das Recht habe, mit seinen Gesetzen aufs tiefste in die Autonomie der Parteien einzugreifen. In der Tat regeln die Vorwahlgesetze ganz eingehend Ort und Zeit der Primaries, die Formen der Kandidatennominierung und die Art der Abstimmung, die Wahlkosten und die Modalitäten ihrer Aufbringung, die Organisation und die Zuständigkeit der Wahlleiter, denen zuweilen geradezu obrigkeitliche Funktionen, das Recht zu Eidesabnahmen und Zwangsmaßregeln übertragen sind. Ja, die Gesetze müssen auch notgedrungen über die Feststellung der Parteizugehörigkeit der Bürger, über Parteiwechsel, über Bildung neuer Parteien - die natürlich im Interesse des alten Zweiparteiensystems möglichst erschwert wird -, über Parteinamen und Parteiembleme, über die ständigen Parteibeamten Vorschriften erlassen. Das ganze Parteiwesen wird auf diese Weise zum Gegenstande der Gesetzgebung gemacht, und wenn sich Parteispaltungen ereignen, so haben die Staatsgerichte die Aufgabe, über Legitimität oder Illegitimität von Parteiorganisationen zu entscheiden. Das Ganze gilt als der Sieg in einem „Kreuzzuge“ der Demokratie gegen Parteimißbräuche. Aber nicht etwa in dem Sinne, daß man mit den Auswüchsen des Parteiwesens dieses selbst habe treffen wollen. Im Gegenteil: das demokratische Prinzip soll inner- 
halb der Partei gestärkt, die Partei soll gereinigt werden, auf daß sie mit um so besserem Rechte zum Eckpfeiler der gesamten Staatsorganisation gestaltet werden könne.

In Deutschland ist der Staat bei der Legalisierung des Parteiwesens nicht entfernt mit der Eindringlichkeit vorgegangen, wie es in den Vereinigten Staaten geschehen ist. Aber der Prozeß hat doch auch bei uns schon vor der Revolution begonnen und ist nach dem Umsturze in beschleunigtem Tempo fortgeschritten. Irre ich mich nicht, so war Württemberg das erste Land, in dem die einstige Zurückhaltung des Gesetzgebers gegenüber den Parteien aufgegeben worden ist. Die Geschäftsordnung der württembergischen Abgeordnetenkammer vom Sommer 1909 handelt in aller Ausführlichkeit von den „Mitgliedervereinigungen“, d. h. den Fraktionen, von ihren „Vollmitgliedern“ und „ständigen Gästen“, verlangt die verhältnismäßige Berücksichtigung der Parteien bei den Wahlen der Schriftführer, der Kommissionen, bei der Handhabung der Redeordnung und sonst; in der Begründung erklärt die Kammer, daß „zu dem anderwärts noch üblichen Versteckspiel mit der Tätigkeit der Fraktionen kein Anlaß vorliege“. Sie hat deshalb auch als erste den Ältestenrat offiziell eingeführt. Nach der Revolution ist das alles in den Geschäftsordnungen des Reichstags und der meisten Landtage nachgeahmt worden. Württemberg ist auch der erste Staat in Deutschland gewesen, der dem Verhältniswahlverfahren bei den Wahlen zum Landtage Eingang und damit den Parteiorganisationen die förmliche Anerkennung durch das Gesetz verschafft hat. Dieses Wahlsystem ist ja nunmehr das gemeindeutsche geworden. In den Wahlgesetzen werden die Parteien noch manchmal in schamhafter Verhüllung als „Wählervereinigungen“ oder "Wählergruppen“ bezeichnet. Aber meistens treten sie doch schon mit voller Namensnennung auf den Plan, gelegentlich, wie in Thüringen, sogar in der Verfassung. Die Verkleidung ist ja auch ganz sinnlos geworden. Denn das ganze System stützt sich darauf, daß organisierte Parteien um den Wahlsieg ringen. Bei der Listenwahl, die die normale Wahlform bildet, wird die Mitwirkung der Parteien durch Aufstellung und Einreichung der Wahlvorschläge, also ein amtlicher Verkehr zwischen Wahlbehörde und Partei geradezu gefordert. Vor allem treibt das System der gebundenen Liste den Wähler mit aller Macht in den Parteiring hinein. Die Partei wird schließlich bei der Wahl alles, der Einzelwähler dagegen eine Null. Zur bloßen Statistenfigur wird freilich auch der Parteikandidat. Sein Name braucht heute nach vielen Wahlgesetzen auf den Stimmzetteln gar nicht mehr zu erscheinen. Noch das Reichswahlgesetz von 1920 verordnete, die Angabe einer Partei auf dem Stimmzettel werde nicht beachtet; im Jahre 1922 wurde zunächst gestattet, daß der Stimmzet- 
tel an Stelle der Namen oder neben ihnen die Angabe der Partei enthalte; nach der neuesten Regelung müssen die Stimmzettel die Partei anführen und dürfen nur die ersten vier Kandidaten mit Namen nennen. Jedenfalls sind nunmehr die Parteien zu einem gesetzlich anerkannten Status gelangt. Sie sind in den Mechanismus des Wahlverfahrens und der parlamentarischen Geschäftsbehandlung als notwendige Glieder einbezogen. Besonders lebhaft kümmert sich in Österreich der Gesetzgeber um sie. Das Wahlgesetz für den Nationalrat und die Landtagswahlordnungen können sich gar nicht genug darin tun, die Parteien bei der Wahlvorbereitung, bei der Besetzung der Wahlbehörden und der Berufungskommissionen, bei der Überwachung des Wahlvorgangs zu beteiligen. In Deutschland zeigt sich, wie in Amerika, allerdings zunächst noch durch Erwägungen technischer Art veranlaßt, eine Neigung, die Parteibildung, und zwar im Sinne einer Stabilisierung des Parteienbestandes, von Staats wegen zu kontrollieren. Die Einreichung von Wahlvorschlägen wird erleichtert, wenn glaubhaft gemacht ist, daß die bereits vorhandenen Parlamentsparteien hinter ihnen stehen. Das braunschweigische Wahlgesetz zählt die acht Parteien, die es für beachtlich hält, sogar mit Namen auf. In Sachsen wird neuerdings eine neugebildete Partei zur Wahlbewerbung nur zugelassen, wenn sie 3000 Mark beim Landeswahlleiter einzahlt. Diese verfallen zugunsten der Staatskasse, wenn es die junge Parteigruppe nicht wenigstens zu einem Sitze im Landtage bringt. In Hamburg gilt seit kurzem das gleiche, und auch in anderen Ländern, z. B. in Hessen und in Danzig, ist man im Begriffe, eine ähnliche Einrichtung einzuführen.

Nur an einer Stelle hat der Prozeß fortschreitender Legalisierung der Parteien bisher noch haltgemacht, und zwar gerade an dem Punkte, an dem in der Gegenwart der Parteieinfluß als ein funktionelles Element des staatlichen Lebens am deutlichsten in Erscheinung tritt, - bei der Bildung und Beherrschung der R e gi e r u ng. Es gibt keine Verfassung, die auch nur andeutungsweise den Tatbestand, den man parlamentarische Parteiregierung nennt, formalisiert. Nur Österreich hat hier merkwürdige Erscheinungen aufzuweisen. Nach den Verfassungen aller Bundesländer, mit einziger Ausnahme Vorarlbergs, werden dort die Mitglieder der Landesregierungen, abgesehen vom Landeshauptmann oder seinem Stellvertreter, durch Wahlen der Landtage gebildet, die das Verhältnis der Parteien berücksichtigen müssen - eine Einrichtung, die zu der, vom Standpunkte des Parlamentarismus gesehen, geradezu grotesken Folge führt, daß die oppositionelle Minderheit der Volksvertretung in der Regierung vertreten ist und ihre Verantwortlichkeit teilt. In der Republik Österreich selbst hat einmal im Jahre 1920 ein Gesetz vorgeschrieben, daß die Mitglieder des 
Kabinetts von der Nationalversammlung im Wege der Verhältniswahl zu bestimmen seien. Freilich ist diese sogenannte "Proporzregierung" samt dem Gesetze, das sie eingerichtet hatte und das sich nur aus einer besonderen politischen Konstellation erklären ließ, sehr bald wieder verschwunden. Auch im Deutschen Reiche hat einmal ein Gesetz, eines der berüchtigten Ermächtigungsgesetze vom Jahre 1923, indem es seine Geltung auf die Fortdauer der derzeitigen "parteipolitischen Zusammensetzung“ der Reichsregierung abstellte, die Parteigebundenheit der Regierung zum Ausdrucke gebracht. Aber auch dieses Gesetz war eine Eintagsfliege. Im übrigen findet sich weder in England, dem Mutterlande der parlamentarischen Parteiregierung, noch auf dem Kontinente eine Verfassung oder ein Gesetz, das der Partei mit nackten Worten die Rolle eines Elements im Staatsorganismus an dessen zentraler Stelle eingeräumt hätte. In dem einzigen Satze der Weimarer Verfassung, der das Wort „Partei“ enthält, im Artikel 130, heißt es: „Die Beamten sind Diener der Gesamtheit, nicht einer Partei." Die Klausel stellt sich als eine deutliche Wendung gegen den Gedanken des Parteienstaates dar; sie dürfte auch praktisch auszuwerten sein, da sich aus ihr ohne Schwierigkeit das Verbot einer parteipolitisch gefärbten Ämterpatronage herauslesen läßt. Vielleicht ist es nicht ohne Interesse, den Wortlaut des Satzes in Parallele zu stellen mit der bekannten These des monarchischen Staatsrechts, nach der die Beamten Diener des Staates sind, nicht Diener des Fürsten, wobei dieser nicht als Staatsorgan, sondern als Privatperson gedacht wird. Denn es erhellt unter dieser Voraussetzung aus der Gleichung Fürst und Staat - Partei und Staat, daß die Verfassung die Partei als etwas Nichtstaatliches betrachtet, also eine Identifizierung von Partei und Regierung ausdrücklich ablehnt.

Diese auffallend offizielle Ignorierung des tatsächlich doch vorhandenen Parteiregimes bringt uns nun zu der letzten Frage, die wir aufzuwerfen haben. Ist der moderne Staat, was sein Verhältnis zu den Parteien anlangt, in ein viertes Stadium getreten, in die Periode des Parteienstaates, also eines Staats, der sich auf den Parteien aufbaut? Die Frage wird von manchen ohne weiteres bejaht, darunter von Staatslehrern hohen Ranges. Hören wir etwa Friedrich von Wieser: „Das Wesen der Demokratie ist die Überantwortung des Staates an die politischen Parteien ... Die Parteiverfassung ist ein wesentlicher Bestandteil der Staatsverfassung. Indem die demokratische Staatsverfassung der siegenden Partei die Macht zuteilt, ist sie eine Anweisung auf deren Parteiverfassung..." ${ }^{10}$ Die Parteiverfassung ist bestimmt, die „abstrakte Formel“ der Staatsverfassung konkret auszufül-

10 [Friedrich Wieser, Das Gesetz der Macht, Wien 1926, S. 433 f.]. 
len. Oder Richard Thoma: Die politische Partei verfolgt den Zweck und soll ihn „im Sinne parteienstaatlichen Verfassungsrechts"11 verfolgen, die Herrschaft in die Hand ihrer Führer zu bringen. „Der ideelle Staatswille der Demokratie ist der auf Volksbewilligung oder -duldung beruhende Wille der jeweils herrschenden Parteiorganisationen."12 Gustav Radbruch $^{13}$ erklärt, die Parteien, vor kurzem noch hinter den Kulissen, seien jetzt als wichtige „Organe“ des Staats auf die Bühne des Staatsrechts getreten. Und Otto Koellreutte ${ }^{14}$ sagt: „Der deutsche Parteienstaat ist verfassungsmäßig heute Wirklichkeit geworden.“ Ist diese Anschauung richtig?

Man kann, wie ich meine, auf die Frage nicht mit einem glatten Ja oder Nein antworten. Es kommt hier, wie so oft, darauf an, ob man die Dinge vom Standpunkte des formalen Rechts oder nach Gesichtspunkten politischer Dynamik beurteilen will.

Eine rein juristische Anschauungsweise wird den Begriff des Staatsorgans, wenn er sich nicht ins Nebelhafte verflüchtigen soll, nur so fassen dürfen, daß man darunter eine Person oder eine Gruppe versteht, deren Wille von Rechts wegen als staatlicher Wille zu gelten hat. In diesem Sinne ist die Partei noch nirgends oder fast noch nirgends, jedenfalls noch nicht in Deutschland, ein Staatsorgan, oder sie ist es doch höchstens insofern, als sie unter der Firma der "Wählergruppe“ - die sich aber nicht mit einer Partei zu decken braucht - im Mechanismus des Wahlverfahrens mit Zuständigkeiten von technischer Bedeutung betraut ist. In der Sphäre der Gesetzgebung und Regierung, im Bereiche der staatlichen „Integration“, auf den es uns letztlich doch allein ankommt, ist die Partei eine extrakonstitutionelle Erscheinung, ihre Beschlüsse sind, vom Standpunkte des Rechts aus gesehen, unverbindliche und unmaßgebliche Äußerungen eines dem Staatsorganismus fremden sozialen Körpers. Wenn man also erklärt, der moderne Staat sei auf den Parteien „aufgebaut“, so ist das eine

11 [Richard Thoma, Der Begriff der modernen Demokratie in seinem Verhältnis zum Staatsbegriff, in: Erinnerungsgabe für Max Weber, hrsg. Melchior Palyi, München 1923, Bd. II, S. 37-64, hier: 61].

12 [Thoma, Der Begriff der modernen Demokratie, S. 63].

13 [Gustav Radbruch, Der Mensch im Recht, in: ders., Rechtsphilosophie II. Gesamtausgabe, hrsg. Arthur Kaufmann, Heidelberg 1993, Bd. II, S. 467-476, hier: 473: „Die Parteien, vor kurzem noch hinter den Kulissen, sind jetzt als wichtige Organe des Staates auf die Bühne des Staatsrechts und der Staatsrechtswissenschaft getreten."].

14 [Otto Koellreutter, Die politischen Parteien im modernen Staate, Breslau 1926, S. 86]. 
rechtlich unhaltbare Behauptung. Wie könnte auch die Rechtsordnung die staatliche Willensbildung an zentraler Stelle förmlich abhängig machen vom Willen gesellschaftlicher Organisationen, die nach Existenz, Umfang und Charakter die unberechenbarsten aller Massenzusammenhänge darstellen, die plötzlich entstehen und vergehen oder ihre Grundsätze wechseln können, die manchmal nach wenigen Jahrzehnten von ihren Grundlagen nichts mehr übrig haben als ihre Namen, die in gewissen Staaten nach ganz inkommensurablen, zuweilen nach politisch ganz nebensächlichen Prinzipien gebildet, die ihrer Natur nach durchaus auf Eigennutz gestellt sind und deshalb schon von Hause aus der Einbeziehung in eine organische Staatsgemeinschaft widerstreben, die nicht einmal immer den Staat als solchen bejahen, deren vornehmste Tätigkeit in gegenseitigem Kampfe besteht! Nur der Bolschewismus und der Facismus haben den Staat wirklich auf Parteien aufgebaut. Aber doch eben jeder nur auf einer Partei, so daß sie, wie es Robert Michels sis treffend ausgedrückt hat, zu Staaten gewordene Parteien oder zu Parteien gewordene Staaten darstellen. Vielleicht läßt sich auch ein echter Parteienstaat denken in Ländern, in denen das Parteiwesen in einem Zweiparteiensystem erstarrt ist, und wo die Parteien weder durch Klassen, noch durch Weltanschauungs-, noch durch andere unüberbrückbare Gegensätze getrennt sind, wie im England des klassischen Parlamentarismus oder wie in den Vereinigten Staaten von Amerika. Aber im allgemeinen liegt in dem Gedanken des Parteienstaats ein schwer auflösbarer Widerspruch. Jedenfalls ist er für uns keine rechtlich anerkannte Größe.

Vor allem aber, der Parteienstaat ist solange rechtlich undenkbar, als der Parlamentaris m u s vom positiven Rechte nach den Ideen ausgerichtet bleibt, die seiner Entstehung zugrunde gelegen haben. In der Tat hält auch der moderne Gesetzgeher noch immer mit Strenge fest an dem Dogma des Liberalismus, wonach der Parlamentswille gebildet wird aus den Erklärungen frei und selbständig entscheidender Männer. Alle, auch die neuesten Verfassungen verwerfen klipp und klar das imperative Mandat.

15 [unausgewiesenes Zitat aus Robert Michels, Zur Soziologie des Parteienwesens in der modernen Demokratie. Untersuchungen über die oligarchischen Tendenzen des Gruppenwesens, Vorwort zur zweiten Auflage von 1924, Wiederabdruck hrsg. Werner Conze, Stuttgart 1970, S. XXX: „Ich habe es mir auch versagen müssen, die zwei großen Parteibewegungen: den Bolschewismus und den Faschismus mehr als nur gelegentlich mit in den Bereich meiner in diesem Bande dargelegten Untersuchungen zu ziehen. [...] Einmal sind beide Bewegungen im Besitze der Staatsmacht und somit, wie man will, zu Staaten gewordene Parteien oder zu Parteien gewordene Staaten."]. 
Sie erklären heute wie einst die Abgeordneten für Vertreter des gesamten Volkes, die an Aufträge nicht gebunden, nur ihrem Gewissen verantwortlich sind, von ihren Wählern nicht abberufen werden können. Das sind keine leeren „Redensarten“, kein „unverbindlicher Gesetzesinhalt“, sondern es sind ernst gemeinte verpflichtende Willenserklärungen des Verfassungsgesetzgebers. Solange sich das geschriebene Recht von dieser Linie nicht abdrängen läßt, kann der Parteienstaat eine rechtliche Legitimität nicht erlangen.

Aber freilich, es hieße den Kopf in den Sand stecken, wenn man leugnen wollte, daß die Wirklichkeit des politischen Lebens mit dem Bilde, das vom positiven Rechte gezeichnet wird, in aller Regel ${ }^{16} \mathrm{n}$ i c h t übereinstimmt. In Tat und Wahrheit sind es eben doch die politischen Parteien, denen die Regierung des Staates ausgeliefert ist. Sie sind es, die die leitenden Regierungshäupter stellen, die einzelnen Ministerposten besetzen, die Kabinette stützen, überwachen, gängeln, stürzen, in deren Bureaus die große Politik gemacht, die Entscheidung über das Zustandekommen der Gesetze gefällt wird. Sie sind es, denen mehr und mehr der Einfluß auf die Verwaltung, namentlich die Ämterpatronage in die Hand gespielt worden ist. Natürlich in den verschiedenen Ländern in verschiedenem Ausmaße. Die Eigenart der Verwaltungsgliederung, die Zahl der durch Wahlen zu besetzenden Ämter, die Stärke historischer Überlieferungen, dies und anderes kann das Bild im einen Staate so, im anderen anders gestalten. Richten wir unsern Blick nur auf Deutschland, so können wir gar nicht übersehen, daß auch hier der Parteienstaat zur Tatsache geworden ist. Er zeigt sich in der Regierung, er zeigt sich in der Verwaltung. Die Einführung des Verhältniswahlsystems bei den Gemeindewahlen und den Wahlen zu zahlreichen Verwaltungsämtern der sozialen Versicherung und anderen hat sogar die kommunale Selbstverwaltung und die Selbstverwaltung der öffentlichen Genossenschaften den politischen Parteien überantwortet. Wie die Staatsverwaltung unter Parteieinfluß geraten ist, weiß jedermann. Da ist nichts abzuleugnen oder zu beschönigen. Gelegentlich kommt es sogar in Gesetzesbestimmungen mit einer, man möchte sagen naiven Offenheit zum Ausdrucke, etwa in dem preußischen Gesetze über die neue Provinz Oberschlesien vom 14. Oktober 1919, wo verlangt wird, daß der dem Oberpräsidenten zugesellte Beirat „unter Berücksichtigung der in Oberschlesien bestehenden Parteibildungen" zusammenzusetzen sei.

Diese Erscheinungen sind nichts Willkürliches oder Zufälliges. Es hat sich hier vielmehr ein ganz natürlicher Prozeß vollzogen. Er bildet die bei-

16 [Im Originaldruck: ,in alle Wege“]. 
nahe logische Folge einer Staatsanschauung, die der Entwicklung der letzten Zeit ihr Gepräge gegeben hat. Der atomistische Individualismus beherrscht den Werdegang der modernen Demokratie. Wenn die öffentliche Gewalt letzten Endes in die individualistisch aufgelockerte Masse verlegt wird, so schafft sich diese, da sie als Masse nicht wollen und handeln kann, die Organisationen, durch die sie einen Willen zu erzeugen vermag. Wenn insbesondere das Wahlrecht zur Volksvertretung rein individualistisch gestaltet wird, kann die Masse ihr Recht gar nicht ausüben, ohne sich irgendwie in Gruppen zu gliedern. Diese Gliederung ist durch die Bildung der politischen Parteien erfolgt und konnte wohl aus Gründen, die hier nicht näher darzulegen sind, zunächst kaum anders erfolgen. Das politische Parteiensystem ist die Selbstorganisation, die sich die Massendemokratie geschaffen hat.

So stehen sich also hier nach liberalen Prinzipien geformtes Recht und massendemokratische Wirklichkeit unversöhnlich gegenüber. Noch behauptet das erste seine ererbte Stellung. Noch vermag es sich auch im rechtlichen Leben durchzusetzen. Noch zögern die Staatsgerichtshöfe, anzuerkennen, daß ein Abgeordneter durch Parteidiktat gezwungen werden könne, sein Mandat niederzulegen, oder daß er bei einem Ausschlusse aus der Partei sein Mandat von selber verliere. Obgleich das württembergische Wahlgesetz den bedenklichen Satz enthält, ein Abgeordneter verliere seinen Landtagssitz durch Austritt aus der politischen Vereinigung, in deren Auftrag er auf eine Vorschlagsliste gesetzt worden sei, so hat sich doch der württembergische Staatsgerichtshof geweigert, daraus den Schluß zu ziehen, daß die Partei durch Exklusion ihres Vertreters ein Landtagsmandat vernichten könne. Und wenn der Österreichische Verfassungsgerichtshof gelegentlich in einem entgegengesetzten Sinne entschieden hat, so war er dazu durch die „parteienstaatliche“ Fassung einer einzelnen Gemeindewahlordnung genötigt. Noch hat das liberale Dogma seine Anhänger auch in demokratischen Kreisen; als Beweis mögen die interessanten Ausführungen des jetzigen Reichstagspräsidenten $\mathrm{Pa}$ u 1 L ö be über Parlamentsreform dienen, in denen es als der „eigentliche Zweck“ des Parlaments bezeichnet wird, daß im parlamentarischen Kampfe der eigene Gedankengang an der Kritik des andern geprüft, Irrtümer ausgemerzt, fremdes Geistesgut verarbeitet und aufgenommen werde. Aber im Grunde handelt es sich doch hier um ein Rückzugsgefecht des Liberalismus gegen die Massendemokratie. Schon mehren sich die Stimmen, die nach dem imperativen Mandate als der letzten Konsequenz des demokratischen Gedankens rufen. Würde diese Forderung erfüllt, dann würde allerdings der alte Par- 
lamentarismus durch den Parteienstaat endgültig überwunden worden sein.

Ob das ein Glück wäre? Die wenigsten werden die Frage bejahen. Es scheint doch, als ob die überwiegende Meinung in Europa die Kluft, die sich zwischen Recht und Wirklichkeit aufgetan, und ebenso die Wirklichkeit selbst als das Symptom einer Krankheit betrachtet, daß ihr die Parteiherrschaft und der Parteienstaat als eine Entartung des staatlichen Körpers erscheinen. Freilich, der Ärzte, die sich um den Leidenden bemühen, sind viele, und es dürfte noch keinem gelungen sein, ein wirksames Heilmittel zu entdecken oder eine sichere Prognose über den Krankheitsverlauf zu stellen. Es kann sein, daß sich der Verfall in Staaten mit einer dem Parteigetriebe völlig entrückten Exklusivgewalt - aber wie viele solcher Staaten gibt es heute noch? - langsamer vollzieht, oder daß er hier gelegentlich aufgehalten werden kann, etwa wenn sich die Parteien als unfähig zu einer Regierungsbildung erweisen und der Staatschef einzugreifen in der Lage ist. Es kann sein, daß durch eine Einengung des staatlichen Aufgabenkreises die Angriffsfläche für die Parteien verkleinert wird. Aber die Möglichkeit der „Entpolitisierung“ von Verwaltungszweigen hat ihre Grenzen, und die Maßregel ist oft nur ein trügerischer Schein, da es die politischen Parteien verstehen, auch etwas, was nicht „politisch“ ist, zu etwas Politischem zu machen. Deshalb ist es unter den heutigen Verhältnissen auch verfrüht, wenn man vorschlägt, den Staat auf künstlich geschaffenen Gebilden, mögen sie berufsständisch oder sonstwie organisiert sein, neu aufzubauen. Denn noch ist die Macht der Parteien so groß, daß sie alle solchen neuen Organisationen ebenso durchfressen würden, wie sie es mit den alten naturgewachsenen, den Gemeinden und anderen, getan haben es müßten denn jene auf einer so großen Einfachheit und einer so vollständigen Gleichheit der Interessen ihrer Mitglieder beruhen, daß es in ihrem Kreise keine Gegensätze gäbe, die von den politischen Parteien als Einbruchsstelle benutzt werden könnten.

Die alten liberalen Ideen vom Wesen des repräsentativen Staates werden sich, so starke sittliche Werte auch in ihnen enthalten sind, schwerlich wieder durchsetzen. Daher kann eine Abkehr vom Parteienstaate nur geschehen entweder durch eine Entwicklung aus der Massendemokratie heraus oder durch deren Überwindung. Es ist denkbar, und viele sehen dies schon im Werden, daß sich eine Veredelung der „egalitären“ Demokratie durch ihre Umwandlung in eine Führeroligarchie vollzieht, so, daß an Stelle der unverantwortlichen Parteiorganisationen und der noch unverantwortlicheren, vielfach anonymen Mächte, die sich hinter ihnen verbergen, selbständige und daher verantwortliche Staatsleiter treten. Die Partei wäre 
dann nicht mehr ein echtes Staatsorgan, sondern sie wäre, wie Georg Jellinek es ausgedrückt haben würde, auf die Rolle eines bloßen „Kreationsorgans" ${ }^{\text {17 }}$ herabgedrückt. Aber eine reinliche Lösung des Problems dürfte dadurch schwerlich gewonnen sein. Denn eine sichere Schutzwehr gegen das Vordringen des Parteienstaates wird erst dann aufgerichtet sein, wenn die atomistisch-individualistische Staatsauffassung, aus der er geboren ist, aufgegeben und durch eine organische ersetzt worden ist.

Solcher Wandel vollzieht sich nicht in wenigen Jahren. Er läßt sich auch nicht diktieren. Ebensowenig lassen sich die politischen Parteien der Gegenwart durch Dekrete beseitigen. Ob gut oder böse, sie sind doch nun einmal geschichtlich gewordene Lebensformen. Aber auch ihre Stunde wird schlagen. Schon sehen wir allenthalben andere gemeinschaftsbildende Kräfte am Werke. Diese werden allmählich in natürlicher Entwicklung zu einer neuen Gliederung des Volkes führen, die aus einer seelenlosen Masse eine lebendige „Einheit in der Vielheit“ gestaltet. Viele werden solche Voraussage eine romantische Illusion nennen. In meinen Augen wäre es kein Schimpf, als Romantiker zu gelten. Aber ich denke im übrigen, es sind keine Märchen- und keine Spukgestalten, sondern sehr leibhaftige Wesen, die im Begriffe stehen, sich aus der mechanisierten Gesellschaft der Gegenwart zu organischen Formen zu gestalten. Wenn es gelingt, die sich mit elementarer Gewalt aus dem Schoße des Volks herausringenden Kräfte einer personell und territorial reich gegliederten neuen Selbstverwaltung wirtschaftlicher und geistiger Art in den Dienst des Staates zu zwingen, der durch sie nicht zerstört, sondern zusammengehalten werden soll, - wenn der Staat nicht abgebaut, sondern im Gegenteil von unten her aufgebaut sein wird, dann wird er zum echten Organismus geworden sein, „wo alles sich zum Ganzen webt, eins in dem andern wirkt und lebt" ${ }^{18}{ }^{18}$ Möge ein glückliches Geschlecht mit leiblichen Augen sehen, was uns Heutigen nur im Geiste als ein schönes Bild der Zukunft vorschweben kann!

17 [Georg Jellinek, Allgemeine Staatslehre, 4. Aufl. Berlin 1922, S. 544 f.].

18 [Johann Wolfgang v. Goethe, Faust I, V 443-44, in: Hamburger Ausgabe Bd. III, S. 22]. 


\section{Text 12 \\ Wesen und Entwicklung der Staatsgerichtsbarkeit ${ }^{1}$}

Es herrscht in unserer Vereinigung der gute Brauch, daß den Berichterstattern ein weites $\mathrm{Ma}$ von Freiheit gelassen wird in Bezug auf den Umfang ihrer Darlegungen, und die Art, wie sie diese gestalten. Solche Freiheit gedenke ich reichlich auszunutzen. Vor allem dadurch, daß ich den Wortlaut des uns gestellten Themas nicht ausdehnend, sondern einschränkend auslege. Allerdings hat zu meiner Genugtuung schon dieser Wortlaut eine gewisse Grenze gezogen. Die Aufgabe soll offenbar nicht bestehen in einer Ausbreitung des ganzen Stoffs von Rechtssätzen über die „Staatsgerichtsbarkeit", der im Rechte des Inlands und Auslands zu finden ist, - auch nicht in einer erschöpfenden Behandlung der großen Praxis und der zahlreichen Einzelfragen, die auf jenem Gebiete aufgeworfen worden sind oder aufgeworfen werden können, - auch nicht in einer systematischen Durchdringung des reichen Materials, endlich auch nicht in ausführlichen Vorschlägen zur Änderung oder Fortbildung des bestehenden Rechts. Das alles würde in der zur Verfügung stehenden Zeit nicht geschehen können, es würde zudem in diesem Kreise hervorragender Sachkenner weithin überflüssig sein, schon weil es in der Literatur nicht an systematischen Arbeiten, wenigstens über große Teile des zu besprechenden Rechtsinstitutes mangelt. Ich darf, um nur einiges zu nennen, auf die aus neuerer Zeit stammenden Abhandlungen von Kels e $\mathrm{n}^{2}$ über Verfassungsgerichtsbarkeit in Österreich, von $S \mathrm{ch}$ indle $\mathrm{r}^{3}$ über Verfassungsgerichtsbarkeit in den Vereinigten Staaten und in der Schweiz, auf den stoffreichen Aufsatz

1 [In: VVDStRL 5, Berlin und Leipzig 1929, S. 2-29; Vortrag am 23. April 1928 auf der 5. Tagung der Vereinigung der Deutschen Staatsrechtslehrer in Wien].

2 [Aus Kelsens zahlreichen damaligen Publikationen könnte Verschiedenes gemeint sein. Dazu etwa Hans Kelsen, Österreichisches Staatsrecht. Ein Grundriss entwicklungsgeschichtlich dargestellt, Tübingen 1923; Die Vollendung der österreichischen Bundesverfassung, in: Zeitschrift für Politik 15 (1925), S. 301-319, hier bes. S.317ff; Die Verfassung Österreichs, in: Jahrbuch des Öffentlichen Rechts 15 (1927), S. 51-103; Wesen und Entwicklung der Staatsgerichtsbarkeit, In: VVDStRL 5, Berlin 1929, S. 30-88].

3 [Dietrich Schindler, Die Verfassungsgerichtsbarkeit in den Vereinigten Staaten von Amerika und in der Schweiz, in: ZSR 44 (1925), S. 19 ff.]. 
von E is wald t ${ }^{4}$ über die Staatsgerichtshöfe in den deutschen Ländern, auf meine eigene kleine Monographie ${ }^{5}$ über die Streitigkeiten von Reich und Ländern in der Festschrift für Ka h 1 hinweisen, ganz zu schweigen von den Lehrbüchern, den Kommentaren und den zahlreichen älteren Schriften über Staatsgerichtshöfe und Ministerverantwortlichkeit. Wollen Sie also von mir keinen Bericht über alle Seiten der als „Staatsgerichtsbarkeit" bezeichneten Einrichtung erwarten, sondern nur einige grundsätzliche Bemerkungen über deren Wesen und Entwicklung, wie es unsere Tagesordnung vorschreibt. Aber auch die „Entwicklung“ des Instituts werde ich nicht in einer fortlaufenden pragmatischen oder dogmengeschichtlichen Schilderung behandeln; sondern die geschichtliche Entwicklung soll mir nur dazu dienen, um aus ihr etwas Grundsätzliches über das Wesen der Sache zu entnehmen oder grundsätzliche Auffassungen hierüber in ihr bestätigt zu finden.

Wenn ich also mit dem Thema in Hinsicht auf seinen Umfang wohl zufrieden sein kann, so bin ich dies nicht ebensosehr in bezug auf das hier gebrauchte Wort „Staatsgerichtsbarkeit“. Die Bezeichnung wird freilich in der neuesten Literatur mehrfach verwendet, z. B. von $S \mathrm{~m}$ e $\mathrm{nd}$ in seinem kürzlich erschienenen schönen Buche. ${ }^{6}$

Aber gut kann ich den Ausdruck nicht finden. Er ist mißverständlich, schon weil er auf einen Gegensatz hindeutet, der heute kaum noch eine Rolle spielt; nach unserer Gerichtsverfassung sind alle Gerichte Staatsgerichte. Vor allem aber kann er dazu verführen, den Begriff der Einrichtung, auf den er sich bezieht, rein formal, nämlich als die von Staatsgerichtshöfen ausgeübte Gerichtsbarkeit zu bestimmen. Gewiß ließe sich ein solcher formeller Begriff denken. Man hat nicht ganz mit Unrecht die Verwaltungsgerichtsbarkeit, wenigstens nach preußischem Rechte, definiert als Vornahme von Verwaltungsakten in Form der Rechtsprechung durch Verwaltungsgerichte. Man könnte als Gegenstück dazu eine Staatsgerichtsbarkeit konstruieren als Vornahme von Regierungsakten in der Form der Rechtsprechung durch Staatsgerichtshöfe, und das wäre in gewissem Sinne ganz richtig. Allein einmal hätte es doch nur dann einen Wert, wenn man zuvor den Gegensatz zwischen Regierung und Verwaltung genügend ent-

4 [Wolfgang Eiswaldt, Die Staatsgerichtshöfe in den deutschen Ländern und Art 19 RVerf., in: Annalen des Deutschen Reiches für Gesetzgebung, Verwaltung und Volkswirtschaft 59 (1926), S. 299 ff.].

5 [Heinrich Triepel, Streitigkeiten zwischen Reich und Ländern. Beiträge zur Auslegung des Artikels 19 der Weimarer Reichsverfassung, Tübingen 1923].

6 [Rudolf Smend, Verfassung und Verfassungsrecht, München 1928]. 
wickelt hätte; sobald man sich aber an diese Aufgabe macht, begibt man sich sofort auf eine Bahn, auf der nur mit sachlicher Sinndeutung etwas zu erreichen ist. Ferner aber ist für die sog. Staatsgerichtsbarkeit die Benutzung besonderer Staatsgerichtshöfe zur Rechtsprechung über gewisse Fragen nicht das Wesentliche. Auf der einen Seite ist nicht jede Entscheidung eines Staatsgerichtshofs ein Akt der,,Regierung“, auch nicht jede ein Akt der Rechtsprechung in Regierungssachen, nicht einmal jede überhaupt Rechtsprechung, d. h. Rechtsstreitentscheidung; ich darf auf das hinweisen, was ich in der Festschrift für Kahl über den „Zwangsausgleich“ ausgeführt habe. Und soweit die Staatsgerichtshöfe Rechtsprechung üben, kann in diesem Rahmen auch Verwaltungsgerichtsbarkeit erscheinen, oder Strafgerichtsbarkeit, oder beides zugleich, wie beim Staatsgerichtshofe zum Schutze der Republik, oder Disziplinargerichtsbarkeit, wie etwa nach dem Hamburger Senatsgesetze, oder sogar gelegentlich Zivilgerichtsbarkeit; man denke an gewisse Möglichkeiten, die sich aus der Bestimmung in Art. 18, Abs. 7 der Weimarer Reichsverfassung ergeben. Staatsgerichtsbarkeit ist nicht Staatsgerichtshofsgerichtsbarkeit, sondern manchmal nur ein kleiner Teil davon. Das schweizerische Bundesgericht ist Zivilgericht, Strafgericht, Kompetenzkonfliktshof und Verfassungsgericht in einer Person, und es gibt Oberhäuser, die, zu Staatsgerichtshöfen „konstituiert“, sowohl Straf- wie Verfassungsgerichtsbarkeit ausüben können. Auf der anderen Seite gehören oft Entscheidungen, die in einem Lande von einem Staatsgerichtshofe gefällt werden, in einem anderen Lande in den Zuständigkeitsbereich eines Verwaltungsgerichts oder eines ordentlichen Gerichts oder einer parlamentarischen Körperschaft. Die Prüfung der Verfassungsmäßigkeit von Gesetzen kann ebensowohl einem ordentlichen Gerichte wie einem Staatsgerichtshofe obliegen, und die Entscheidung über die Legitimation der Parlamentsmitglieder - die ich nicht als Gegenstand bloßer Verwaltungsgerichtsbarkeit ansehe - wird bald von den Kammern, bald von einem Staatsgerichtshofe, bald von einem besonderen Wahlprüfungsgerichte gefällt; in Elsaß-Lothringen war es ein Senat des Oberlandesgerichts Colmar, in Danzig ist es der oberste Gerichtshof, der über Einsprüche gegen die Gültigkeit der Parlamentswahlen zu entscheiden hat. Ja, auch im selben Lande können sich Gerichte verschiedener Art in die "Staatsgerichtsbarkeit" teilen; wir wissen ja, wie bei uns im Reiche der Staatsgerichtshof, das Reichsgericht, der Reichsfinanzhof, das Wahlprüfungsgericht auf jenem Gebiete konkurrieren.

Es ist also doch wohl wertvoller, wenn wir die "Staatsgerichtsbarkeit“ nicht nach dem Subjekte, sondern nach dem Gegenstande der Entscheidung bestimmen. Und eben deshalb möchte ich wünschen, daß sich statt 
jenes Ausdrucks eine auf das Sachliche abstellende Bezeichnung einbürgere. Hä n el spricht in unserem Zusammenhange von „organischer Rechtspflege“, Fle in er und andere von „Staatsrechtspflege“. Aber das erste umschreibt den Gegenstand unvollständig, das zweite zu umfassend. Denn nicht alle staatsrechtlichen Fragen, die gerichtsförmig erledigt werden, gehören in den Bereich, den wir im Auge haben: so ist z. B. die Rechtsprechung über Fragen der Staatsangehörigkeit ${ }^{7}$ Verwaltungsgerichtsbarkeit, nichts anderes. Ich halte den Ausdruck „Verfassungsgerichtsbarkeit " für den besten, weil er auf das abzielt, was nach meiner Auffassung das Wesentliche an der Einrichtung darstellt. Auch ist er bereits quellenmäßig geworden; die österreichische Bundesverfassung hat ihn, meines Wissens als erste, in die Gesetzessprache eingeführt.

Allerdings muß ich auch hier wieder sogleich gegen eine formale Ausdeutung des Begriffes Widerspruch erheben. Verfassungsgerichtsbarkeit ist Gerichtsbarkeit in Fragen der Verfassung und zum Schutze der Verfassung. Aber Verfassung ist in diesem Zusammenhange nicht die Verfassung im formellen Sinne, nicht das Verfassungsgesetz oder die Verfassungsgesetze, nicht die Verfassungsurkunde. Ich halte es nicht für förderlich, wenn Kelsen in der erwähnten Abhandlung den Unterschied zwischen Verfassungs- und Verwaltungsgerichtsbarkeit darin erblicken will, daß jene die Verfassungsmäßigkeit, diese die „bloße“ Gesetzmäßigkeit von Rechtsakten zu prüfen habe, oder wenn M e r k $1,{ }^{8}$ in dem gleichen Gedankengange, als Aufgabe der Verfassungsgerichtsbarkeit den Schutz ,der höchsten Stufe der Rechtsordnung" bezeichnet. Abgesehen davon, daß diese Begriffsbestimmung vielerlei unberücksichtigt läßt, was meines Erachtens zur Verfassungsgerichtsbarkeit gehört, so muß doch bemerkt werden, und wird auch von Kels e n ausdrücklich zugegeben, daß im letzten Grunde jede Gesetzwidrigkeit der Vollziehungsakte einschließlich der Verordnungen eine Verfassungswidrigkeit bedeutet, da die Forderung der Gesetzmäßigkeit der Verordnungen in der Regel, die Forderung der Gesetzmäßigkeit der Vollziehung häufig durch formales Verfassungsrecht ausgesprochen ist. Somit ergibt sich die rechtstheoretische Grenze zwischen Verfassungsund Verwaltungsgerichtsbarkeit lediglich aus dem Unterschiede zwischen unmittelbarer und mittelbarer Verfassungsmäßigkeit. Ich meine, daß damit nur wenig gewonnen ist, und daß sich auf diesem Wege nicht nur der Gegensatz der Verfassungs- zur Verwaltungsgerichtsbarkeit, sondern auch

7 [Dazu vgl. Heinrich Triepel, Internationale Regelung der Staatsangehörigkeit, in: ZaöRV 1 (1929), S. 185-199].

8 [Gemeint ist vielleicht: Adolf Merkel, Allgemeines Verwaltungsrecht, Wien 1927]. 
ihr Gegensatz zu anderen Arten der Gerichtsbarkeit, etwa zur Straf- oder Disziplinargerichtsbarkeit, so gut wie ganz verflüchtigt.

Verfassungsgerichtsbarkeit ist nicht bloß Gerichtsbarkeit in Fragen der formellen Verfassung. Wer möchte behaupten, daß die Entscheidung über eine Ministeranklage nur dann Verfassungsgerichtsbarkeit sei, wenn der Minister wegen Verletzung der Verfassung, nicht aber, wenn er wegen Verletzung eines Gesetzes angeklagt worden ist? Oder daß die Wahlprüfungsgerichtsbarkeit keine Verfassungsgerichtsbarkeit darstelle, weil oder wenn der Richter dabei das Wahlgesetz, nicht die Verfassung anzuwenden habe? Die Verfassungsgerichtsbarkeit ist Gerichtsbarkeit in Sachen der materiellen Verfassung. Es kann sein, daß das positive Recht eines einzelnen Staats gewisse prozessuale Einrichtungen nur auf den Schutz des formellen Verfassungsrechts gemünzt hat. Ob das zutrifft oder nicht, ist eine Sache der Gesetzesauslegung. Aber das Institut im ganzen genommen, geschichtlich, politisch, rechtlich betrachtet, ist ein Institut, das der Verfassung als dem Inbegriffe der den staatlichen Verband zur Einheit konstituierenden Ordnung in gerichtsförmiger Weise Bestand und Gewähr verschaffen soll. "Gewährleistung" oder ,gerichtlicher Schutz" der Verfassung - so wird der Zweck der Einrichtung klar und zutreffend in manchen Verfassungsurkunden des vorigen Jahrhunderts bezeichnet.

Mit dieser Formulierung habe ich ungefähr schon umschrieben, was ich als das Wesen der Verfassung und damit der Verfassungsgerichtsbarkeit ansehe. Verfassung ist Ordnung, rechtliche Ordnung. Sie ist ein in sich geschlossenes System der Rechtssätze, die den Versuch machen, das staatliche Leben zu regeln, soweit es in der Selbsterhaltung und ständigen Selbsterneuerung jenes Verbandes besteht, den wir Staat nennen. Nicht alles staatliche Leben wird von der Verfassung normiert, nicht jede Tätigkeit des Staats in Justiz und Verwaltung. Die Verfassung hat es nur mit den Vorgängen zu tun, in denen sich das geistige Erlebnis der staatlichen Gemeinschaft in seiner Totalität vorbereitet, vollzieht, erneuert, - in Fordern und Gewähren, in Kampf und Verständigung. Verfassung ist, um mit Smend ${ }^{9}$ zu sprechen, die Rechtsordnung des staatlichen Integrationsprozesses. Sie ist also das Recht, das sich des W e s e n $\mathrm{t}$ li ch e $\mathrm{n}$ im staatlichen

9 [Rudolf Smend, Verfassung und Verfassungsrecht, in: ders., Staatsrechtliche Abhandlungen und andere Aufsätze, Berlin 1955, S. 189: „Die Verfassung ist die Rechtsordnung des Staates, genauer des Lebens, in dem der Staat seine Lebenswirklichkeit hat, nämlich seines Integrationsprozesses. Der Sinn dieses Prozesses ist die immer neue Herstellung der Lebenstotalität des Staates, und die Verfassung ist die gesetzliche Normierung einzelner Seiten dieses Prozesses."]. 
Leben zu bemächtigen strebt. Was freilich „wesentlich“ ist, was nicht, das hängt, wie ich glaube, von Wertungen ab, die zeitlich und örtlich bedingt sind. Das Ganze der Integrationsvorgänge läßt sich zwar in absoluten Kategorien formeller Art, wie denen der persönlichen, funktionellen oder sachlichen Integration meistern, wie es Smend so anschaulich getan hat; aber ihr Inhalt wird durch Wertungen bestimmt, die nicht immer die gleichen sind, die vielmehr im Fluss geschichtlicher Entwicklung stehen.

Dasselbe gilt meiner Ansicht nach für den Begriff des Polit is chen, den wir in die Betrachtung einzuführen haben. Über diesen Begriff ist in neuerer Zeit viel Interessantes und Wertvolles gesagt worden, namentlich von $\mathrm{S}$ mend und Carl Schmitt. So bestechend die Erklärung des Politischen bei Carl Schmitt erscheint - ich denke vor allem an seine „Freund-Feind-Theorie“ in dem bekannten geistreichen Aufsatze ${ }^{10}$, , so vermag ich ihm doch nicht zu folgen. Von anderem abgesehen schon deshalb nicht, weil er das Wesen des Staats vom Politischen ableitet, während doch eine natürlichere, auf Sprachgefühl und Geschichte gestützte Auffassung suchen wird, das Wesen des Politischen aus dem Staatlichen heraus zu entwickeln. Ich kann mich aber auch nicht damit befreunden, daß zwischen „Politischem“ und „Rechtsstaatlichem“ ein Gegensatz geschaffen wird. Von dem dezisionistischem Standpunkte aus, von dem Carl $\mathrm{Schmitt}$ und Hermann Heller ausgehen, liegt es natürlich nahe, das Politische lediglich in dem über die Existenzform des Staates letztlich Entscheidenden zu erblicken, während alles bürgerlich-rechtsstaatliche, weil es vorzugsweise in Hemmungen und Kontrollierungen der staatlichen Gewalten besteht, als unpolitisch danebengestellt wird. Ich leugne keineswegs diesen Gegensatz, d. h. den Gegensatz zwischen ,souveräner“ Dezision und bloßer Gewaltenkontrolle als solchen, ich halte es sogar für wertvoll, daß er schärfer als früher herausgearbeitet wird. Aber mir scheint, es sei willkürlich, das „Politische“ in Gegensatz zum „Rechtsstaatlichen“ zu bringen. Rechtsstaatliches Denken ist nicht unpolitisches Denken, sondern eine besondere Art des politischen Denkens, und die bürgerlich-rechtsstaatlichen Bestandteile einer Verfassung gehören auch zu ihrem ,politischen System“.

Der Anschauung $S \mathrm{~m}$ en d s vom Wesen des Politischen stehe ich näher. Allerdings gebe ich mich auch ihr nicht ganz gefangen. Er hat meine eigene Bestimmung des Politischen: ,,alles, was sich auf einen Staatszweck bezieht“, oder: „was sich auf die Staatszwecke oder deren Abgrenzung gegen-

10 [Carl Schmitt, Der Begriff des Politischen, in: Archiv für Sozialwissenschaft und Sozialpolitik 58 (1927), S. 1-33]. 
über individuellen Zwecken bezieht“, getadelt. Ich meine, daß diese allerdings sehr weite und ein wenig farblose Definition ihr Recht hat und in manchen Zusammenhängen auch ausreicht. Aber ich bekenne gern, daß ein Bedürfnis besteht, aus dem weiteren einen engeren Begriff herauszuschälen, ja ich halte dies in bezug auf den Gegenstand, den wir heute behandeln, sogar für notwendig. Es gibt im staatlichen Leben verschiedene Intensitätsgerade des Politischen. Wir sprechen ja auch von ,hochpolitischen“ Angelegenheiten und von einer ,hohen“ oder "großen“ Politik, und setzen dem die Angelegenheiten oder Aktionen gegenüber, bei denen entweder die Verbindung mit staatlichen Zwecken eine losere oder die Bewertung des Staatszwecks, um den es sich handelt, eine geringere ist - wobei wiederum keine absoluten, sondern geschichtlich bedingte Maßstäbe angewendet werden müssen. Und es ist in der Tat richtig, daß in einem engeren und spezifischen Sinne politisch nur das ist, was mit den höchsten, obersten, entscheidendsten Staatszwecken, was mit der staatlichen „Integration" in Verbindung steht, was sich auf den Staat als schöpferische Macht bezieht, was, wie H e g el sagt, den „Standpunkt der höchsten konkreten Allgemeinheit" ${ }^{\text {11 }}$ darstellt. So ist denn auch der Gegenstand der Verfassung und damit der Gegenstand der Verfassungsgerichtsbarkeit in diesem Sinne politisch zu nennen.

Darin liegt nun aber im Grunde das ganze Problem der Verfassungsgerichtsbarkeit beschlossen. Die Verfassungsgerichtsbarkeit bezieht sich auf Streitigkeiten, die ihrer Natur nach, weil sie politisch sind, einer Entscheidung in prozeßförmiger Art widerstreben. Ich mußte, während ich diesen Vortrag vorbereitete, oft an die berühmte, so vielfach mißverstandene, aber einen großen Wahrheitskern enthaltende These Rudolph Soh m s denken: das Wesen des Kirchenrechts steht mit dem Wesen der Kirche in Widerspruch. ${ }^{12}$ Natürlich darf man, von inneren Gründen ganz abgesehen, für unser Gebiet keinen voll entsprechenden Satz aufstellen. Das Wesen des Politischen steht nicht mit dem Wesen des Rechts in Widerspruch. Im Gegenteil: nach der Grundanschauung, von der ich ausgehe, ist ja das Verfassungsrecht gerade das Recht für das Politische. Obwohl es zweifellos Politisches gibt, was nicht rechtlich, mindestens nicht gesetzlich geregelt werden kann und nirgends auf der Welt in dieser Weise gere-

11 Georg Wilhelm Friedrich Hegel, Grundlinien der Philosophie des Rechts, in: Theorie-Werkausgabe, Frankfurt 1970, Bd. VII, S. 474 (\$303).

12 [Rudolph Sohm, Kirchenrecht Bd. I, Leipzig 1892, S. 1: „Das Kirchenrecht steht mit dem Wesen der Kirche im Widerspruch. Das Wesen der Kirche ist geistlich; das Wesen des Rechts ist weltlich.“]. 
gelt worden ist, so ist doch alle s Verfassungsrecht „politisches“ Recht. Daher bilden die Verfassungsstreitigkeiten nicht etwa als Rechtsstreitigkeiten einen Gegensatz zu politischen Streitigkeiten. Einen solchen Gegensatz halte ich für völlig schief. Das Politische aus dem Begriff der Verfassungsstreitigkeiten herausnehmen, heißt die Schale ihres Kerns berauben. Verfassungsstreitigkeiten sind immer politische Streitigkeiten. Wenn man Verfassungsstreitigkeiten auf den Rechtsweg verweist, so ist das keine „Entpolitisierung", wie W it t m a y e ${ }^{13}$ meint; man kann Verfassungsstreitigkeiten gar nicht entpolitisieren. Trotz alledem, oder auch eben deshalb darf man, ohne paradox zu werden, den Satz aussprechen: das Wesen der Verfassung steht bis zu einem gew is sen Grade mit dem Wesen der Verfassungsgerichtsbarkeit in Widerspruch.

In der Welt des Politischen nämlich, die auch die Welt der Verfassung ist, drängt von Hause aus alles auf Durchsetzung des eigenen Willens durch eigene Macht. Um so stärker, je „politischer" die Sphäre ist, in der sich die Handelnden bewegen. Die fast naturgemäße Entscheidung politischer Streitigkeiten ist Entscheidung durch Kampf, durch Unterdrückung des gegnerischen Willens, in zweiter Linie durch Verständigung, wenn der Kampf nicht lohnt oder aussichtslos erscheint. Je ,politischer“ die Frage, je mehr das Irrationale im staatlichen Leben, je mehr das Daimonion des Staates in Betracht kommt, um so stärker und um so begreiflicher ist die Abneigung, sich das Gesetz des Handelns von fremder Entscheidung vorschreiben zu lassen. Daher im völkerrechtlichen Verkehr der zähe Widerwille gegen obligatorische Schiedsgerichtsbarkeit, jedenfalls in Fällen, in denen die Streitigkeit stärkere politische Bedeutung hat; daher der Vorbehalt bezüglich der Lebensinteressen und des Ehrenpunktes in allgemeinen Schiedsabkommen. Innerhalb des Sonderlebens des Staates herrscht die gleiche Erscheinung. Politische Gegensätze werden, auch wenn sie auf einen rechtlichen Nenner gebracht werden können, lieber unüberbrückt gelassen, als der Entscheidung eines Dritten unterworfen; ein „Vereinigungsverfahren" wird dem gerichtlichen vorgezogen. Wenn eine Streitfrage erledigt werden muß, zieht man den Zwangsausgleich der Rechtsstreitentscheidung vor. Und zwar den Zwangsausgleich, bei dem der Wille der einen Partei den der andern überwindet. Das alles ist ganz unabhängig von der Staatsform. In der konstitutionellen Monarchie ist es der Fürst, der der Volksvertretung, in der parlamentarischen Monarchie ist es die Volksver-

13 [Gemeint sein könnte: Leo Wittmayer, Reichsverfassung und Politik, Tübingen 1923; ders., Die Zukunft der modernen Demokratie, in: ZgStW 79 (1925), S. 1639]. 
tretung, die dem Monarchen ihren Willen aufzuzwingen sucht; in der Demokratie werden die Minderheit und ihre organisatorischen Exponenten von der Mehrheit an die Wand gedrückt. Es ist bezeichnend, daß in den Vereinigten Staaten die dort eingebürgerte Verfassungsgerichtsbarkeit, die doch, wie wir sehen werden, stark objektiviert gehalten ist, gerade von der konsequenten Demokratie angefochten wird; es war eine Forderung in dem bekannten Programm La Follettes von 1924, daß ein mit Zweidrittelmehrheit gefaßter Kongreßbeschluß gesetzesfeindliche Entscheidungen des obersten Bundesgerichtes müsse überrennen können. Je stärker ausgebildet der ,politische Instinkt“, desto größer die Abneigung gegen Verfassungsgerichtsbarkeit. Es ist schwerlich ein Zufall, daß diese Institution in Mittel- und Kleinstaaten mehr ausgebildet ist als in Großstaaten, daß der „politischste“ Staat der Welt, daß England kaum eine Spur davon, jedenfalls kein Verständnis dafür besitzt, daß der preußische Großstaat es nicht einmal zu einem Gesetze über die Durchführung von Ministeranklagen gebracht hat. Und es ist nicht nur eine kleinlich denkende Bürokratie, die sich, wie einst gegen die Einführung der Verwaltungsgerichtsbarkeit, so damals und später auch gegen die Einführung einer Verfassungsgerichtsbarkeit gesträubt hat. Vielmehr zählt diese gerade Männer von größtem politischem Format zu ihren Feinden. In klassischer Form hat Bismarck den Grund seiner Gegnerschaft in einer Rede vor dem Abgeordnetenhause am 22. April 1863 enthüllt: Es darf nicht ,,von dem einzelnen Urteilsspruche eines Gerichts, wie er sich nach der subjektiven Ansicht der Stimmenden herausstellt, die politische Zukunft des Landes, die Machtverteilung zwischen der Krone und dem Landtage, sowie zwischen den Häusern des Landtags abhängig gemacht werden. Diese staatsrechtliche Frage kann nur von der Gesetzgebung, nur von der Verständigung zwischen den Faktoren der Gesetzgebung entschieden werden. "14 Als Parallele darf diesem Ausspruch des deutschen der eines französischen Politikers zur Seite gesetzt werden: „L'esprit subtil“, sagt Benjamin Constant, „l'esprit subtil de la jurisprudence est opposé à la nature des grandes questions qui doivent être envisagées sous le rapport public, national, quelquefois même européen."

Obwohl sich nun das politische Element der Verfassung der Unterstellung unter ein prozeßförmiges Verfahren widersetzt, haben wie doch eine Verfassungsgerichtsbarkeit erhalten. Freilich um den Preis, daß dieses Rechtsinstitut in so vieler Hinsicht unausgeglichen, brüchig, schillernd,

14 [Horst Kohl (Hg.), Die Politischen Reden des Fürsten Bismarck, Stuttgart 1892, Bd. II, S. 172]. 
widerspruchsvoll erscheint. Es bedarf der Erklärung, wie es zu einer Verfassungsgerichtsbarkeit gekommen ist.

Daß die Verfassungsgerichtsbarkeit in Deutschland, Österreich und der Schweiz stärker als irgendwo anders entwickelt worden ist, liegt zum Teil natürlich daran, daß dem germanischen Staatsdenken die Notwendigkeit eines Rechtsschutzes auch für das öffentliche Recht immer lebendig geblieben ist. Der Deutsche hält es nicht für ein Unding, mit der öffentlichen Gewalt, und wäre sie die höchste, um sein Recht Prozeß zu führen. Es ist urdeutsch gedacht, wenn wir in einer Verfassung des Kantons Uri ähnlich auch in der von Unterwalden nid dem Wald - lesen: „Glaubt sich Jemand durch einen Landesgemeindebeschluß in seinen Privatrechten benachteiligt, so kann er das ordentliche Gericht anrufen. Dasselbe hat die Streitfrage zwischen dem Volke und dem Rechtssuchenden gewissenhaft nach den Akten zu entscheiden." Was aber die Verfassungsstreitigkeiten in einem engeren Sinn, d. h. die Streitigkeiten zwischen den politischen Gewalten selber anlangt, so war es wichtig, daß der deutsche Konstitutionalismus der Frühzeit, in der die Grundlagen für die Verfassungsgerichtsbarkeit gelegt worden sind, unmittelbar an ständische Gedanken- und Organisationsformen anknüpfen konnte. Dem ständischen Wesen und der dualistischen Struktur des ständischen Staates entsprach ja die Auffassung, daß sich Regierung und Stände wie zwei Vertragsparteien gegenüberstanden, deren Zwistigkeiten durch Schieds- oder Richterspruch geschlichtet werden konnten. So hat bei der Einsetzung des württembergischen Staatsgerichtshofs die Erinnerung an das alte württembergische Landgericht sicher eine Rolle gespielt. Ganz ständisch gedacht war es, wenn die kurhessische Verfassung von 1831, die altenburgische aus demselben Jahre und die braunschweigische von 1832 Kompromißgerichte vorsahen, von denen die Streitigkeiten zwischen Regierung und Landtag über die Auslegung der Verfassung entschieden werden sollten. Während diese Gerichte für jeden Streitfall besonders gebildet werden mußten, stellte die gleichzeitig entstandene Verfassung des Königreichs Sachsen für solche Fälle bereits einen permanenten Staatsgerichtshof zur Verfügung; die oldenburgische Verfassung von 1852 gestattete die Wahl zwischen Schiedsgericht und Staatsgerichtshof. Ständischen Ideen entsprang die paritätische Art, in der die Staatsgerichtshöfe überall gebildet wurden. Ständisch gedacht war endlich die gelegentlich auftretende Parität zwischen Fürst und Landtag bei Anklagen vor dem Staatsgerichtshofe; in Württemberg z. B. konnte die Anklage wegen Versuchs des Verfassungsumsturzes oder wegen Verfassungsverletzung von den Ständen gegen Minister und Departementschefs, von der Regierung gegen einzelne Mitglieder der Stände und ihres Ausschusses er- 
hoben werden, - eine Einrichtung, die manchmal auch außerhalb Deutschlands, z. B. in der niederländischen Verfassung begegnet.

Für die Entwicklung der Verfassungsgerichtsbarkeit in den deutschen Ländern war aber außerdem von Bedeutung, daß sie einen Ersatz zu bilden hatte für den Schutz, den der aufgelöste Reichsverband den ständischen Gerechtsamen, aber auch den Landesfürsten gegenüber den Ständen durch die Reichsgerichtsbarkeit geboten hatte. Sogar die Ministeranklage konnte unter diesem Gesichtspunkte betrachtet werden; wenn die Stände früher ihren Landesherrn wegen Missetat oder Rechtsanmaßung vor der Reichsjustiz hatten belangen können, so schufen sie sich in der neuen Verfassung ein Mittel, statt des souverän gewordenen Landesfürsten seinen Minister vor ein Gericht, und zwar nunmehr ein Landesgericht zu ziehen. Es war dann ganz folgerichtig, wenn manche Kleinstaaten, nachdem der Deutsche Bund das Bundesschiedsgericht geschaffen hatte, diesem Bundesorgan schon in ihren Konstitutionen die Verfassungsstreitigkeiten überwiesen, wie Reuß j. L. im Jahre 1850, Oldenburg - wenigstens zur zweitinstanzlichen Entscheidung - im Jahre 1852. Bald nach der Gründung des Norddeutschen Bundes haben die Verfassungen von Reuß ä. L. und Schaumburg-Lippe den Bund für jene Aufgabe in Aussicht genommen, wobei freilich übersehen wurde, daß die Bundes-, wie auch die nachmalige Reichsverfassung, den Bundesrat für Verfassungsstreitigkeiten nur als Vergleichsinstanz bestellt, deren „Erledigung“ aber auf den Weg der Reichsgesetzgebung verwiesen hatte. Heute, wo Art. 19 der Weimarer Verfassung einen echten gerichtlichen Schutz für Verfassungsstreitigkeiten bietet, hat es wieder einen Sinn erhalten, wenn sich manche Einzelstaaten, wie Sachsen und Braunschweig, den Luxus eines eigenen Staatsgerichtshofs sparen, oder wenn sie ihren Staatsgerichtshof nicht als Gericht für Verfassungsstreitigkeiten im engeren Sinne verwenden, wie Württemberg, Baden und Hessen. Im einen wie im anderen Fall schieben sie dann stillschweigend die Erledigung dieser Streitigkeiten dem Staatsgerichtshofe für das Deutsche Reich zu. Manche Kleinstaaten tun dies in ihren Verfassungen ausdrücklich: so Lippe und Mecklenburg-Strelitz. Schaumburg-Lippe und Lippe haben den Reichsstaatsgerichtshof sogar zur Entscheidung über Ministeranklagen bestellt, was ihnen durch $₫ 15$ des Reichsgesetzes über den Staatsgerichtshof ermöglicht worden ist.

Bedeutungsvoller als der Hinweis auf die verfassungshistorischen Grundlagen der Verfassungsgerichtsbarkeit ist die Aufdeckung der ideengeschichtlichen Wurzeln, aus denen sie entsprossen ist. Es herrscht kein Zweifel, daß es die von der Aufklärung geborenen und gespeisten Gedanken des Rationalismus gewesen sind, die hier Pate gestan- 
den haben, die Anschauungen, die insbesondere der bürgerliche Liberalismus, namentlich wieder dessen rechtsstaatliche Ausprägung, in Deutschland und den anderen europäischen Staaten gehegt und gepflegt hat. Vor allem war es die rationalistische Theorie der Gewaltenteilung, die für die Verfassungsgerichtsbarkeit bestimmend geworden ist.

Allerdings, diese Theorie ist niemals ganz einheitlich gewesen. Und je nach der Abschattierung, die sie erfuhr, konnte sie der Verfassungsgerichtsbarkeit förderlich oder abträglich werden.

In ihrer strengsten Form betont die Lehre von der séparation des pouvoirs vor allem die gegenseitige $S$ elbständigke it der drei Gewalten. Das gilt in erster Linie für Legislative und Exekutive in ihrem Verhältnisse zur richterlichen Gewalt. Zwar soll die Freiheit des Bürgers, der die Gewaltentrennung dienen will, auch durch die Unabhängigkeit der richterlichen Gewalt, ja gerade durch sie gegen Legislative und Exekutive geschützt werden. Aber doch nur insofern, als keine der beiden die Funktion der Rechtsprechung sich anmaßen oder den einzelnen Richter abrufen darf. Denn auf der andern Seite ist es dem Richter verwehrt, sich in die Sphäre der Gesetzgebung oder der Vollziehung einzumischen. Der Richter ist an das gebunden, was die gesetzgebende Gewalt geschaffen, und hat als gültig hinzunehmen, was die Verwaltung in ihrer Sphäre bestimmt hat. Daher die Ablehnung des richterlichen Prüfungsrechts gegenüber Gesetzen und die Abneigung gegen eine Judikatur in Verwaltungssachen. Als die eigentümliche Domäne des Richters gilt die Zivil- und Strafjustiz. Deshalb, und weil die richterliche Gewalt an dem politischen Spiel der anderen Gewalten keinen Anteil zu nehmen hat, ist sie „en quelque façon nulle“, spielt sie, nach Ernst von Meiers etwas frivolem Ausdrucke, die Rolle des heiligen Geistes in der Trinitätslehre. ${ }^{15}$ Darum ist sie auch nicht dazu da, Streitigkeiten zwischen Legislative und Exekutive zu entscheiden. Zwischen „Prärogative“ und Legislative, sagt John Locke, gibt es keinen Richter. Für Exekutive und Legislative gilt der Satz, daß „le pouvoir arrête le pouvoir"; es ist ihre Sache, wie sie sich vertragen und auseinandersetzen, und irgendwie werden sie es vernünftigerweise tun, wofern der Staatswagen nicht stillestehen soll. Wenn also z. B. das Oberhaus auf Anklage des Unterhauses über die Minister zu Gerichte sitzt, so ist das nach Montesquieus gewiß ungeschichtlicher, aber dem rationalistischen Einschlag sei-

15 [Ernst von Meier, Französische Einflüsse auf die Staats- und Rechtsentwicklung Preußens im XIX. Jahrhundert, Bd.I, Leipzig 1907, S. 67: „Unter den drei Gewalten spielt auch bei Montesquieu die richterliche einigermaßen die Rolle des heiligen Geistes in der Trinitätslehre: sie ist den beiden anderen nicht ebenbürtig."]. 
ner Lehre entsprechender Auffassung keine Ausübung richterlicher Gewalt, sondern eine Kontrollfunktion des Parlaments gegenüber der Regierung, die ganz allein in jenes System der Gewichte und Gegengewichte gehört, das für das Verhältnis von Legislative und Exekutive eingerichtet ist. Man sieht, von diesem Ufer konnte keine Brücke zur Verfassungsgerichtsbarkeit geschlagen werden.

Es ließ sich aber von dem Ausgangspunkte der konstitutionellen Doktrin noch ein anderer Weg beschreiten. Man konnte bei der Lehre von der Gewaltenteilung den Nachdruck statt auf die schroffe Gegensätzlichkeit der drei Gewalten auf ihre gemeinsame Ableitung aus dem einheitlichen Gesamtwillen der Nation und damit auch auf die Notwendigkeit legen, sie im Interesse der Einheitlichkeit des staatlichen Lebens in Harmonie untereinander und mit einem Gesamtwillen zu bringen. Daraus entsprang der Gedanke an ein pouvoir modérateur oder régulateur, ein pouvoir arbitre, ein pouvoir judiciaire des autres pouvoirs, der Gedanke an ein Organ des Ausgleichs zwischen den konstituierten Gewalten und zwischen ihnen und dem pouvoir constituant. Nach der liberalen Doktrin B e n ja m in Co n stants war die königliche Gewalt mit dieser Aufgabe betraut. Aber vor und nach seiner Zeit ist man auf den Gedanken gekommen, die ausgleichende und entscheidende Funktion auf eine gerichtliche oder gerichtsähnliche Instanz zu übertragen. F i ch tes Idee des Ephorats, die er eine Zeitlang gehegt hat, gehört in diesen Zusammenhang. In Amerika hat sie durch Franklins Council of Censors in der pennsylvanischen Verfassung einen organisatorischen Ausdruck gefunden. In Frankreich war es vor allem Si e y è s, der an der Idee einer eigenen Verfassungsgerichtsbarkeit jahrzehntelang mit Zähigkeit festgehalten hat. Seine berühmte Rede vom 2. Thermidor des Jahres III enthielt unter anderem die Forderung, es müsse eine ,jurie constitutionnaire“ eingeführt werden, und wenn er auch damals nicht damit durchdrang, so ist es ihm doch später in der Konsularverfassung von 1799 gelungen, den „Sénat conservateur“ als ein Verfassungsgericht einzusetzen, das über die Verfassungsmäßigkeit sowohl der Akte des Corps législatif, wie der des Gouvernements zu entscheiden hatte. Die Verfassungen von 1802 und 1804 haben dies beibehalten, und obwohl die Institution von der harten Faust des ersten Bonaparte arg verstümmelt worden war, hat man doch unter dem zweiten Kaiserreich im Jahre 1852 noch einmal an die alte Tradition angeknüpft. In der Mehrzahl der europäischen Staaten haben sich jene Gedanken nur in bescheidenem Umfange ausgewirkt. Sie sind höchstens darin zu erkennen, daß man öfters die Entscheidung über Ministeranklagen nicht dem Oberhause, sondern einem besonderen Staatsgerichtshofe übertrug. Doch ist ihr Einfluß noch in der 
Mitte des 19. Jahrhunderts in Deutschland zu beobachten, vor allem in der Frankfurter Nationalversammlung. Die Verfassung der Paulskirche unternahm es in einem bisher unerhörten Ausmaße, die Streitigkeiten zwischen den politischen Gewalten der Entscheidung eines grundsätzlich zu diesem Zwecke eingesetzten Gerichtshofs zu unterwerfen. Allerdings scheute sich die Verfassung, den letzten Schritt zu tun; denn sie ließ die Zuständigkeit des Reichsgerichts zur Entscheidung von Verfassungsstreitigkeiten in der obersten Schicht des deutschen Verfassungslebens, d. h. von Streitigkeiten zwischen den Häusern des Reichstags und der Reichsregierung und zwischen ihnen selbst von einer kompromissarischen Einigung der Streitteile abhängen. Allein im Verhältnisse zwischen Reichsgewalt und Landesgewalten wurde solche Einschränkung nicht gemacht. Und der Grundgedanke war jedenfalls der, es solle, wie es Max Duncker nachmals ausgedrückt hat, durch eine hoch und freigestellte richterliche Gewalt, die in Fragen des Rechts auch über dem Reichstage und dem Reichsoberhaupte stehe, ,wie einst der Großrichter von Aragonien über König und Ständen"16, alles öffentliche Wesen in Deutschland auf dem Boden des Rechts erhalten werden. Man sieht aus den von Duncker gewählten historischen Beispielen, wie sich hier ständische Ideen mit modernen liberal-rechtsstaatlichen vermählten.

Es gab aber auch noch andere Wege, um von dem Prinzip der Gewaltenteilung ausgehend $\mathrm{zu}$ einer Verfassungsgerichtsbarkeit zu gelangen. Man konnte sich nämlich darauf stützen, daß die $r$ i c h t e $\mathrm{r} l$ i c h e $\mathrm{G}$ e w a 1 t als solche schon von Haus aus dazu bestimmt sei, ein Gegengewicht sowohl gegen Legislative wie gegen Exekutive zu bilden. Man konnte ihr folglich von vornherein die Rolle eines pouvoir modérateur zuweisen, um die andern Gewalten in dem Rahmen zu halten, der allen Gewalten durch die Verfassung gezogen war, allerdings in erster Linie, soweit es galt, die Exekutive zur Verfassungstreue zu zwingen. Dazu bedurfte es also keines besonderen Staatsgerichtshofs, sondern man konnte sich der ordentlichen Gerichte bedienen, nur daß man vielleicht um der Bedeutung der Sache willen eine oberste Instanz mit der Urteilsfällung betraute. So übertrug denn die erste französische Verfassung von 1791 die Entscheidung über die Anklagen gegen die Minister der Haute Cour nationale; die holländische Verfassung bestellte dafür den Hoogen Rad, die belgische den Kassationshof, manche deutsche Einzelstaaten ihre Oberappellationsgerichte. Man besann sich aber auch darauf, daß der Hauptzweck der Ge-

16 [Max Duncker, Zur Geschichte der deutschen Reichsversammlung in Frankfurt, Berlin 1849, S. 50]. 
waltenteilung gewesen war, für die Freiheit des Bürgers einen Schutz zu bieten. Wenn daher die Regierung die ihr von der Verfassung gegenüber dem Bürger gezogenen Grenzen überschreitet, so ist es Sache des Richters, sie in ihre Schranken zu weisen. Freilich wählte man auch für diese Aufgabe häufig besonders gebildete Gerichte, Staatsgerichtshöfe. So entstand, obwohl mit mancherlei einengenden Verklausulierungen, die Gerichtsbarkeit des schweizerischen Bundesgerichts zur Entscheidung über Beschwerden wegen Verletzung verfassungsmäßiger Rechte der Bürger, die Zuständigkeit des Reichsgerichts der Frankfurter Verfassung zur Annahme von Klagen deutscher Staatsbürger wegen Verletzung der durch die Reichsverfassung ihnen gewährten Rechte, die Zuständigkeit des österreichischen Reichsgerichts, über Beschwerden der Staatsbürger wegen Verletzung der ihnen durch die Verfassung gewährleisteten politischen Rechte zu entscheiden. Es war aber endlich auch möglich, die Sache ganz radikal anzufassen. Verfassungswidrige Willkür der Exekutive kann nicht gebrochen werden, wenn sich die Exekutive auf verfassungswidrige Willkür des Gesetzgebers zu stützen vermag. Der Richter ist dazu berufen, den Bürger in seiner Freiheit auch gegen den Gesetzgeber zu schützen. Und zwar hat jeder Richter diese Aufgabe zu erfüllen, nicht bloß ein Staatsgerichtshof. Von diesem Gedanken haben sich in den Vereinigten Staaten von Amerika die Einzelstaaten wie die Union bestimmen lassen. Sie haben den Schutz der Verfassung gegen Verletzung durch Exekutive u n d Legislative der ordentlichen Gerichtsbarkeit anvertraut. Die Begründung für diese Gestaltung der Verfassungsgerichtsbarkeit ist in klassischer Form von Alexander Hamilton im „Federalist“ gegeben worden. Die große Aufgabe des Richters und seine einzige besteht darin, Recht anzuwenden. Was aber der Gesetzgeber, der, wie der Richter, nur ein Delegatar der Verfassung oder des souveränen Volkes ist, zum Gesetzesinhalte macht, kann nicht Recht sein, wenn es der Verfassung widerspricht. Die Gerichte dürfen verfassungswidrige Gesetze nicht zur Grundlage eines Urteils machen. Indem sie die Verfassung dem verfassungswidrigen Gesetz vorziehen, erfüllen sie ihren Beruf, Recht und nur das Recht anzuwenden, und erweisen sie sich zugleich als das natürliche ,intermediate body“ zwischen Volk und Legislative, als ein Bollwerk der Freiheit gegen Übergriffe der Legislative. In dieser Konstruktion liegt auch die Erklärung für die ganz singuläre Form, in der die Amerikaner die Verfassungsgerichtbarkeit technisch behandeln. Sie ist bei ihnen nicht, wie anderwärts, als ein Prozeß gestaltet, in dem Exekutive und Legislative, oder Bürger und Exekutive, oder Bundesgewalt und Landesgewalt als Parteien auftreten. Vielmehr entscheidet der Richter „Zwischen der Verfassung und dem Gesetze.“ Über die Verfas- 
sungsmäßigkeit staatlicher Akte wird immer nur als über eine Inzidientfrage in Prozessen entschieden, in denen die Gerichte ihre normale Funktion als Zivil- und Strafgerichte erfüllen. Der Richter kommt niemals in die Lage, einen Staatsakt, insbesondere ein Gesetz aufzuheben; er erklärt nur möglicherweise, daß ein Gesetz, weil es verfassungswidrig und damit ungültig sei, nicht angewendet werden könne; wie Tocqueville einmal gesagt hat: la loi ne se trouve blessée que par hasard. Das Verfahren ist unter den objektiven Verfahrensarten - so möchte ich das nennen - die objektivste. Die Verfassungsgerichtsbarkeit ist nicht mehr ein eigenes Institut, sondern ein Akzessorium zur ordentlichen Gerichtsbarkeit. Da hier die politischen Gewalten niemals unmittelbar in den Rechtsstreit verwickelt werden, so hat die größtmögliche „Entpolitisierung“ stattgefunden. Freilich sind die Amerikaner in dieser Beziehung fast völlig isoliert geblieben. Nur das norwegische Recht steht ungefähr auf demselben Boden. Als vor etwa zwanzig Jahren durch $\mathrm{C} h$ a r l e s B e n o ist und andere der Versuch gemacht wurde, die amerikanische Einrichtung nach Frankreich zu verpflanzen, mußte dies an der ganz anders eingestellten traditionellen Auffassung der Franzosen von der Gewaltentrennung scheitern.

Alle diese, in doktrineller Grundlegung und organisatorischer Ausführung so verschiedenen Versuche, die politischen Kräfte im Staate durch das Mittel der Verfassungsgerichtsbarkeit auszubalanzieren oder zu neutralisieren, haben nun doch niemals - selbst wenn sie es sich zum Ziele setzten - vermocht, dieser Gerichtsbarkeit ihren politischen Cha$\mathrm{r}$ a k t e $\mathrm{r}$ zu nehmen. Naturam expellas furca, tamen usque recurret. ${ }^{17}$

Der politische Grundzug der Verfassungsgerichtsbarkeit zeigt sich am deutlichsten in der Art, wie das Institut der gerichtlichen Entscheidung über Ministeranklagen - oder Anklagen gegen republikanische Staatschefs - entwickelt worden ist. Das Verfahren hatte ja ursprünglich einen vorwiegend strafrechtlichen Charakter, dem Vorbilde des englischen Rechtsgangs beim Impeachment entsprechend. Es hat diesen Charakter in manchen Staaten bis heute behalten. Ein politisches Element hat ihm freilich immer und überall, der Natur der Sache nach, angehaftet; denn es ist stets ein Mittel politischen Kampfes gewesen. Dem entspricht die Organisation der Gerichtsbarkeit und das Verfahren. Auch wo der Minister vor ein Strafgericht gestellt wird, ist dieses Gericht selten das ordentliche Gericht, vielmehr gewöhnlich ein Staatsgerichtshof, dessen Besetzung unter Mitwirkung der Legislatur erfolgt, manchmal sogar zum Teil aus Mitglie-

17 [Horaz, Episteln I 1,24: Auch wenn Du die Natur gewaltsam austreibst, kehrt sie doch zurück.]. 
dern der Legislatur, oft geradezu nur aus einer Kammer des Parlamentes besteht, wie es das englische Beispiel gelehrt hatte. Zwar sagt die italienische Verfassung von 1848: „Il Senato... costituito in Alta Corte di Giustizia... non è corpo politico", und das ist gewiß nicht ohne praktische Bedeutung insofern, als vielerlei, was für den Senat als politischen Körper gilt, auf den Senat als Staatsgerichtshof nicht anwendbar ist: Pairsschub, Vertagung und Schluß durch den König, Prinzip der Diskontinuität, Beschlußfähigkeitsziffer und anderes. Aber trotz allem bleibt der Senat immer ein Teil der politischen Gewalt, ja er wird zur richterlichen Funktion in unserem Falle gerade berufen, weil er politisch orientiert ist, weil man von ihm erwartet, daß er seine politische Erfahrung benutzen wird, um bei der Urteilsfällung die politische Seite der Straftat, sei es als schärfend, sei es als mildernd zu würdigen. Er ist ein politisches Gericht „pel suo spirito“, sagt L u z z a t t i. Denn in Italien, wie in Frankreich urteilt der Senat nicht über die Straftaten, die der Minister während seiner Amtsführung, sondern über die, die er in seiner Amtsführung begangen hat. Daraus erklärt sich auch die uns befremdliche Erscheinung, daß - wiederum dem Prozeß vor dem House of Lords auf Impeachment entsprechend - dem Verfahren vielfach ein diskretionäres Element beigemischt ist. Es ist Benjamin Constants Einfluß, der sich hier ausgewirkt hat. „Politisches Recht“, sagt seine Lehre - und um politisches Recht handelt es sich in unserem Falle - verlangt seiner Natur nach ein weites Maß von Freiheit in der Anwendung. Der politische Zweck der Ministeranklage besteht weniger darin, die Minister zu bestrafen, als sie zu beseitigen. Werden die Pairs zu Richtern über die Räte der Krone bestellt, so sollen sie nicht wie gewöhnliche Richter nach formalem Rechte urteilen, sondern „d'après leurs lumières, leur honneur et leur conscience“. Die Verfassung der hundert Tage, die von Constant redigiert worden ist, bestimmte in der Tat: „La Chambre des Pairs... exerce, soit pour caractériser le délit, soit pour infliger la peine, un pouvoir discrétionnaire." Die Charte von 1830 stand auf demselben Standpunkte, und das heutige französische Recht läßt mindestens die Möglichkeit einer entsprechenden Auslegung zu. Auch die belgische Verfassung erklärt, es solle - bis zum Erlasse eines Gesetzes, das niemals ergangen ist - die Deputiertenkammer für die Anklage, der Kassationshof für die Kennzeichnung des dem Minister zur Last gelegten Delikts und für die Festsetzung der Strafe ganz freies Ermessen besitzen. So hat denn auch im Jahre 1830 die französische Pairskammer die Minister Karls X., so hat im Jahre 1918 der Senat den früheren Minister des Innern Malvy wegen Verbrechen bestraft, von denen der Code pénal nichts wußte, und mit Strafen belegt, die dort, jedenfalls für solche Verbrechen, nicht vorgesehen waren. 
Der Senat hat sich im Jahre 1918 zur Rechtfertigung seines Verfahrens auf sein ,pouvoir souverain“ berufen, und das hat nur vereinzelten Widerspruch hervorgerufen. Diskretionär aus politischen Gründen ist ja schon immer die Entscheidung der Kammer, ob sie einen Minister anklagen will oder nicht. In Italien hat das oft eine große Rolle gespielt, weil es sich dort darum handelt, ob ein Beschluß der Kammer, einen Minister $n$ i c h t vor den Senat als die Alta Corte zu bringen, der ordentlichen Strafgerichtsbarkeit Raum läßt oder nicht. Als im Jahre 1895 Giolitti wegen Siegelbruchs und Aktenbeseitigung, im Jahre 1897 Crispi wegen Teilnahme an Amtsveruntreuung angeschuldigt, von der Kammer aber nicht angeklagt worden waren, hat der Kassationshof beide Male erklärt: mache die Kammer von ihrem Anklagerechte keinen Gebrauch, so sei das ein Zeichen, daß entweder das behauptete Verbrechen nicht begangen worden, oder daß sich die Kammer von der $S$ ta ats rais on bestimmen lasse, ihr Recht nicht auszuüben. Und die gleiche Staatsraison entscheide darüber, ob die Kammern und ob die Alta Corte beschließen wollen, der ordentlichen Justiz freien Lauf zu lassen. Tun sie es nicht, so haben die Gerichte zu schweigen. Zehn Jahre später, im Falle Nasi (1907) hat sich der Kassationshof sogar auf den Standpunkt gestellt, daß die ordentliche Gerichtsbarkeit schon von Haus aus schon durch das Anklagerecht der Kammer in bezug auf reati ministeriali, das Wort im technischen Sinne genommen, ausgeschlossen sei. Klage die Kammer nicht an, so gebe sie zu erkennen, daß sie aus politischen Gründen überhaupt einen Prozeß und ein Urteil vermieden sehen möchte, weil es im besonderen Falle der Gesellschaft nützlicher sei, einen Verbrecher der Strafe zu entziehen, als der Gerechtigkeit Genüge zu tun. Man hat diese Entscheidung eine „rechtsfeindliche Blasphemie“ genannt; vermutlich mit Recht. Jedenfalls ist durch sie die Kammer, die den Fall Nasi bereits an die ordentliche Gerichtsbarkeit abgegeben hatte, in die Notwendigkeit versetzt worden, nachträglich doch noch die Anklage beim Senat zu erheben, damit nicht ein schweres Verbrechen der gerechten Sühne entzogen werde, und der Senat hat den Angeklagten dann auch verurteilt. Man sieht, wie hier sogar die Justiz bemüht ist, dem „Politischen“ zu einem Siege über das Strafrecht zu verhelfen.

Im allgemeinen hat ja nun aber bekanntlich die gerichtliche Geltendmachung der Ministerverantwortlichkeit ihren kriminellen Charakter nach und nach verloren, und in gleichem Grade, in dem dies geschah, ist sie allmählich v $\quad$ o 11 l $\mathrm{i}$ g zu einer, „justice politique“ geworden. Namentlich in Deutschland. Als Gegenstand der Anklage erscheint mehr und mehr, statt eines Verbrechens im Sinne des Strafrechts, die Verletzung der Verfassung und des Gesetzes schlechthin, gelegentlich auch, wie früher im Groß- 
herzogtum Baden, so noch heute in den Republiken Baden, Hessen und Mecklenburg-Schwerin „schwere Gefährdung der Sicherheit oder Wohlfahrt des Staates". Im einen wie im anderen kommt ein politischer Gedanke zum Ausdruck. Denn auch wo Verfassungs- oder Gesetzesverletzung in ganz allgemeiner Wendung zum Klaggrunde gemacht wird, ist doch offenbar die Meinung die, daß nicht wegen jeder Verletzung jeder einzelnen Bestimmung der Verfassungsurkunde oder eines gewöhnlichen Gesetzes Klage soll erhoben werden dürfe, sondern nur wegen Verletzung der politischen Bestandteile des Verfassungsrechts, politisch in dem Sinne genommen, den wir vorhin zu umschreiben versucht haben. Und wie mit dem Klaggrunde, so steht es mit den Strafen. Nach amerikanischem Muster beschränkt man sich im wesentlichen auf Amtsentziehung, nur selten erschwert durch Aberkennung der Fähigkeit, öffentliche Ämter fortan zu bekleiden; ein wenig Disziplinarrechtliches haftet heute, soweit das deutsche Recht in Betracht kommt, nur den einschlagenden Vorschriften der oldenburgischen Verfassung an. Man sieht, Benjamin Constant hat recht behalten: es kommt nicht so sehr darauf an, den Minister zu bestrafen, als ihn unschädlich zu machen. Daher steht den Kammern auch das Recht zu, die Klage zurückzunehmen, wenn jenes Ziel nicht mehr als politisch erstrebenswert gilt, und es ist durchaus politisch gedacht, wenn die Verfassungen von Baden, Hessen und Mecklenburg-Schwerin dem Landtage zwar die Erhebung der Anklage nur mit Zweidrittelmehrheit, die Rücknahme der Klage aber mit einfacher Mehrheit gestatten; daß Württemberg das Gegenteil vorschreibt, ist ein Zeichen unpolitischer Formenstrenge. Politisch ist es gedacht, wenn manche Verfassungen das Anklagerecht der Volksvertretung erlöschen lassen, nachdem sich diese ihres Rechts mehrere Jahre lang verschwiegen haben; so die Verfassungen von Baden, Hessen, Thüringen, Mecklenburg-Schwerin und Oldenburg, auch im Auslande findet man das mehrfach. Es hat mit der strafrechtlichen Verjährung gar nichts zu schaffen. Auch die Anklage gegen gewesene Minister ist ihres strafrechtlichen Charakters mehr und mehr entkleidet und zu einer rein politischen Maßregel geworden; die Staatsgerichtshöfe sind hier jetzt gewöhnlich auf die bloße Feststellung beschränkt, daß der Angeklagte die Verfassung verletzt habe. In dieser Feststellung liegt heute vielfach das beinahe alleinige Ziel des Anklageverfahrens überhaupt. Denn der politische Zweck, den Minister gegen den Willen des Staatsoberhaupts aus dem Amte zu bringen, konnte in der konstitutionellen Monarchie, wenn überhaupt, nur durch das Mittel verfassungsgerichtlichen Verfahrens erreicht werden; in der parlamentarischen Monarchie und Präsidentschaftsrepublik gibt es einfachere und rascher wirkende politische Methoden, um zu jenem Ziele 
zu gelangen. Daher denn hier die Ministeranklage zu einem ganz seltenen Ereignisse geworden ist. Wenn man das Institut gleichwohl beibehalten hat, so erklärt sich das zum Teil aus den „erziehlichen“ Absichten der Verfassungen, von denen Richard Schmidt ${ }^{18}$ einmal in bezug auf frühere Verhältnisse gesprochen hat. Es erklärt sich noch mehr aus der unklaren Konstruktion eines Gegensatzes von parlamentarisch-politischer und juristischer Ministerverantwortlichkeit, am meisten aber vielleicht aus dem Bedürfnisse, über die bedeutsamsten Fragen des Verfassungslebens in schweren Streitfällen auf das Begehren einer großen nationalen Anklagejury durch einen Gerichtshof ein für die Zukunft verbindliches Feststellungsurteil fällen zu lassen. Aus diesem Grunde haben denn auch wohl kleine Republiken mit direktorialem Regierungssystem die Einrichtung beibehalten. Sie hat dort an sich den allergeringsten Sinn. Die Schweiz kennt sie nicht; Sachsen, Braunschweig, Mecklenburg-Strelitz haben sie mit Recht in ihre neuen Verfassungen gar nicht aufgenommen.

Ein Skeptiker könnte versucht sein, auch die "Staatsgerichtsbarkeit“, die sich als Verfassungsgerichtsbarkeit in einem engeren Sinne darstellt - unser Reichsgesetz von $1921^{19}$ spricht hier ex professo von einem Verfahren in "verfassungsrechtlichen Streitigkeiten“ - in den Staaten mit modernem Verfassungszuschnitt, namentlich in solchen mit parlamentarischem Regierungssystem als überholt zu betrachten. Es ist in der Tat unbestreitbar, daß eine parlamentarisch stark gebundene Regierung, selbst wenn sie den Parlamentsparteien gegenüber eine selbständige Meinung besitzt, doch nicht leicht wagen wird, als Kläger gegen die Volksvertretung aufzutreten, umgekehrt ist es sicher, daß die Volksvertretung heute einen Verfassungsdisput mit der Regierung nicht in einem Prozeßverfahren auszutragen braucht, wenn sie es nicht will; sie kann ja ihren Gegner auf höchst unprozessuale Weise auf die Knie zwingen. Es mag auch sein, daß diese sehr nüchterne politische Erwägung einen der Gründe bildet, weshalb in den außerdeutschen Staaten, den alten wie den neuen, eine Verfassungsgerichtsbarkeit, bei der sich das Parlament und die Regierung als solche in Parteirollen gegenüberstehen, vollkommen unbekannt ist. Aber damit ist die Sache nicht erledigt. Denn erstens sind Regierung und Parlament nicht die einzigen möglichen Gegner in Verfassungsstreitigkeiten, und zweitens

18 [Vielleicht: Richard Schmidt, Staatsverfassung und Gerichtsverfassung. Betrachtungen zum Problem der Gemeindegerichtsbarkeit, Tübingen 1908].

19 [Abdruck bei Heinrich Triepel (Hg.), Quellensammlung zum Deutschen Reichsstaatsrecht, 4. Aufl. 1926, S. 164 ff.]. 
liegen die Gründe, von denen sich die Staaten in bezug auf Annahme oder Ablehnung der Verfassungsgerichtsbarkeit bestimmen lassen, viel tiefer.

Die Staaten unterstellen auf der einen Seite einer besonderen Verfassungsgerichtsbarkeit nur das, was nach ihrer Auffassung politischen Charakter besitzt. Was sie als außerhalb der politischen Welt stehend erachten, schieben sie, sofern sie es gerichtsbar machen wollen, der ordentlichen oder der Verwaltungsgerichtsbarkeit zu. Daraus erklärt sich, wie ich meine, die verschiedene Behandlung, die die einzelnen Verfassungen dem $B$ ü rge $r$ in bezug auf die Verfassungsgerichtsbarkeit angedeihen lassen. $\mathrm{S} \mathrm{m}$ e $\mathrm{d} \mathrm{d}^{20}$ hat uns bei unserer letzten Zusammenkunft in München in eindrucksvoller Weise die integrierende Funktion von verfassungsmäßigen Grundrechten auseinandergesetzt. Aber gerade hier scheint mir deutlich zu werden, wie sehr alle Integration von geschichtlich wechselnden Wertungen abhängig ist. Integrierend ist, was ein Volk in einer bestimmten Periode seiner staatlichen Entwicklung als existenzkonstituierend ansieht. Die liberal-rechtsstaatliche Auffassung, von der die Verfassungen des 19. Jahrhunderts in ihrer Mehrzahl beherrscht wurden, sah in den Grund- und Freiheitsrechten viel mehr eine Beschränkung des Staatlichen, als einen Teil des Staatlichen, und es wird sich daraus erklären, daß die meisten Staaten die Streitigkeiten über Grundrechtsverletzungen nicht als Verfassungs-, sondern höchstens als Verwaltungsstreitigkeiten behandelten. Natürlich darf nicht übersehen werden, daß für die Verschiedenheit der Rechtsbildung in diesem Punkte auch manche rein rationale und organisationstechnische Elemente eine Rolle spielen: auf der einen Seite die Furcht vor Überlastung der Staatsgerichtshöfe, auf der anderen der Mangel ausreichender Verwaltungsgerichtbarkeit und anders mehr. So läßt sich nicht mit allgemeinen Wendungen erklären, warum gerade die Schweiz oder Österreich oder der Freistaat Bayern ihren Bürgern das Recht der Verfassungsbeschwerde bei ihren Staatsgerichtshöfen eingeräumt, während andere Staaten dies abgelehnt haben, oder warum die bundesgerichtliche Praxis in der Schweiz in bezug auf den Umfang der von ihr geschützten Bürgerrechte zu einem anderen Ergebnisse gekommen ist als die österreichische Praxis. Das bedürfte einer viel gründlicheren Untersuchung, als sie hier geboten werden kann. Bei der Auslegung des Art. 19 der deutschen Reichsverfassung wird man davon ausgehen können, daß dieser Artikel an die liberal-rechtsstaatliche Entwicklung der Verfassungsgerichtsbarkeit im Deutschland des 19. Jahrhunderts anknüpft, und daß er deshalb unter

20 [Rudolf Smend, Das Recht der freien Meinungsäußerung, in: VVDStRL 4, Berlin 1928, S. 44-74]. 
„Verfassungsstreitigkeiten“ in den Ländern die Streitigkeiten zwischen Bürger und Staat über Besitz oder Berücksichtigung individueller Rechte nicht begreifen will, auch derer nicht, die in einer Verfassungsurkunde zugesichert oder gewährleistet worden sind.

Auf der anderen Seite - der Staat stellt nicht a lles Politische, oder nicht alles, was er als politisch ansieht, unter die Verfassungsgerichtsbarkeit. Im Gegenteil, immer macht sich die Tendenz des Politischen, vor allem des „Hochpolitischen“ geltend, sich der Erfassung durch Richter und Prozeß zu entziehen. Die berühmte „Lücke“ der Reichsverfassung, d. h. der Mangel einer Verfassungsgerichtsbarkeit für Streitigkeiten zwischen den höchsten Organen des Reichs - Reichstag, Reichsrat und Reichspräsident - ist schwerlich aus bloßer Vergeßlichkeit ungeschlossen geblieben. $\mathrm{Da}$ man die Staatsgerichtsbarkeit des Reichs für alle Verfassungsstreitigkeiten in den Ländern zur Verfügung hält, beruht gewiß in erster Linie auf der Berücksichtigung alter Tradition und säkularer Forderungen. Aber es deutet doch auch darauf hin, daß die Verfassung das staatliche Leben der Länder politisch geringer einschätzt als das Verfassungsleben des Reichs. Sie gewährt den Einzelstaaten etwa dasselbe, was der Einheitsstaat in Form der Verwaltungsgerichtsbarkeit den Gemeinden zum Austrag organisatorischer Rechtsstreitigkeiten zu gewähren pflegt. Und wenn die Bismarcksche Reichsverfassung die Entscheidung der Streitigkeiten zwischen Reich und Ländern dem föderalistischen Bundesrate, also einer mehr schiedsgerichtlich und diplomatisch verfahrenden Körperschaft übertrug, während die Weimarer Verfassung dafür den Staatsgerichtshof bereitgestellt hat, so ist das zweite zwar ein Fortschritt im Sinne des rechtsstaatlichen Prinzips, aber es läßt doch erkennen, daß die Bismarcksche Verfassung die politischintegrierende Bedeutung der Einzelstaaten höher gewertet hat, als es die heutige Verfassung tut. Es ist außerordentlich bezeichnend, daß sich Preußen im Jahre 1867 einer Verfassungsgerichtsbarkeit für Streitigkeiten zwischen Bund und Ländern widersetzt, daß im Jahre 1919 gerade Preußen die Einführung dieser Institution gefordert hat. Die politische Vormacht des deutschen Bundesstaate hatte als eine unerträgliche Beschränkung empfunden, was das in eine Abwehrstellung gedrängte Preußen gerade als Schutzwehr begehren mußte!

So viel an Politischem nun auch der Verfassungsgerichtsbarkeit entronnen ist, so bleibt doch noch genug davon dem Art. 19 der Reichsverfassung und dem Ausführungsgesetzte von 1921 verfangen. Der politische Charakter der Einrichtung zeigt sich weniger in der Organisation des Staatsgerichtshofs - diese ist sogar, soweit Verfassungsstreitigkeiten im engeren Sinne in Betracht kommen, so „unpolitisch“ wie möglich gestaltet 
worden - als in den Regeln über seine Zuständigkeit und über sein Verfahren. Und die Erkenntnis des politischen Charakters wird für die Auslegung jener Regeln und für die Handhabung des Verfahrens von Bedeutung sein. Ich muß mich auf ein paar Andeutungen beschränken. Einiges ist schon vorhin gesagt worden.

Für die Streitigkeiten zwischen Reich und Ländern enthält der Art. 19 eine so eindeutige Kompetenzbestimmung, daß eine einschränkende Auslegung des allerdings sehr umfassenden Wortlauts kaum möglich sein wird. Ich darf mich in dieser Hinsicht auf meine Ausführungen in der Festschrift für Kahl beziehen. Für die Deutung des Wortes „Verfassungsstreitigkeiten innerhalb eines Landes" haben wir freiere Hand, und wir können hier verwerten, was wir durch unsere allgemeinen Betrachtungen gewonnen haben.

Eine Verfassungsstreitigkeit ist, wie wir sahen, immer eine Streitigkeit, die es mit der Verfassung im materiellen Sinne zu tun hat. Daraus folgt aber noch nicht ohne weiteres, daß jedermann, für den es etwas ausmacht, wie das Verfassungsrecht ausgelegt wird, an einem gerichtlichen Verfahren teilnehmen kann, das die Verfassung doch als ein außerordentliches Mittel zum Schutze der Verfassung eingerichtet hat. Als Partei kann sich an solchem Verfahren nur beteiligen, wer an dem durch die Verfassung geregelten Leben des Staates beteiligt ist. Beteiligt hieran sind freilich heute nicht nur die Regierung und die Volksvertretung in ihrem Gegen- und Zusammenspiel. Der Staatsgerichtshof für das Deutsche Reich hat vollkommen recht, wenn er auch die Landtagsmitglieder, die Fraktionen, die Parlamentsminderheiten, in Fragen des Wahlrechts sogar die außerparlamentarischen Parteien, die nach unserm Wahlsystem nun einmal eine rechtlich umschriebene Funktion bei der Konstituierung der politischen Gewalten besitzen, mit Parteifähigkeit ausstattet, und wenn er andeutet, daß er in Wahlangelegenheiten auch dem einzelnen Staatsbürger Parteifähigkeit zuerkennen würde. Er würde wohl auch, und zwar mit Recht, als parteifähig ansehen eine Volksgruppe, die gegen die Landesregierung wegen verfassungswidriger Einschränkung des Rechtes auf Volksbegehren vorgehen will, selbst wenn in der Landesverfassung nicht ausdrücklich, wie in Mecklenburg-Schwerin geschehen, bestimmt ist, daß durch Volksbegehren ein Verfassungsstreitverfahren eingeleitet werden kann. Dagegen halte ich es für unrichtig, wenn der Staatsgerichtshof die Parteifähigkeit reichsritterschaftlichen Familien zuspricht, die um die Anerkennung ihrer Autonomie kämpfen, oder öffentlich-rechtlichen Korporationen, wie den Landeskirchen, die über die Aufwertung ihrer Ansprüche auf Staatsleistungen prozessieren wollen, oder Gemeinden, die gegen den Erlaß eines Einge- 
meindungsgesetzes vorgehen. Die Eigenschaft, ein „anerkanntes Organ des Staatskörpers" zu sein, macht eine Körperschaft noch nicht zu einem Elemente des Verfas s ung g lebens, d. h. der den staatlichen Zusammenhalt konstituierenden und aufrechterhaltenden Vorgänge. In den angeführten Fällen hätten die Rechtsschutzmöglichkeiten anderswo gelegen, bei der ordentlichen oder der Verwaltungsgerichtsbarkeit; allenfalls wäre der Streit auf einem Umwege, durch Inanspruchnahme der Reichsaufsicht, in das Bett der Verfassungsgerichtbarkeit zu leiten gewesen. Vermutlich ist die entgegenkommende Haltung des Staatsgerichtshofes daraus zu erklären, daß er jene anderen Möglichkeiten nicht als gegeben oder im Einzelfalle als verbaut betrachtet hat. (In der Tat hatte die sächsische Landeskirche in ihrem Aufwertungsstreit zunächst die Reichsaufsicht in Bewegung setzen wollen, war aber vom Reichsminister des Inneren auf Art. 19 der Reichsverfassung hingewiesen worden.) Die Weitherzigkeit des Staatsgerichtshofs in der Anerkennung der Parteifähigkeit wird ihm, fürchte ich, noch zu schaffen machen; schon haben z. B. die Beamtenorganisationen ihren Anspruch angemeldet, gegebenenfalls als Klägerinnen zugelassen zu werden.

Ob der Staatsgerichtshof im Rechte ist, wenn er außer der Landesverfassung auch die Reichsverfassung als möglichen Gegenstand einer Verfassungsstreitigkeit „innerhalb eines Landes“ ansieht, kann zweifelhaft sein. Er will es annehmen für solche Vorschriften der Reichsverfassung, die „auf die Landesverfassung oder auf landesverfassungsmäßige Normen einwirken und insoweit eine Ergänzung der Landesverfassung bilden“. Das scheint mir reichlich formalistisch gedacht zu sein. Ich meine, daß allerdings Reichsverfassung und Reichsgesetz den Gegenstand einer Verfassungsstreitigkeit innerhalb seines Landes bilden können. Aber nur wenn und soweit sie Normen enthalten, nach denen sich einzelstaatliches V e r $\mathrm{f}$ assu $\mathrm{ng}$ l lebe $\mathrm{n}$ zu richten hat. Daß dies heute in nicht ganz geringem Maße der Fall ist, brauche ich in diesem Kreise nicht darzulegen.

So ergibt sich in der Tat nicht nur aus dem Landesrecht, sondern auch aus dem Reichsrechte der Umfang der Verfassungsgerichtsbarkeit für die Länder. Das gilt auch in dem Sinne, daß die Zuständigkeit des Reichsstaatsgerichtshofs letztlich immer durch Auslegung des Art. 19 der Reichsverfassung zu bestimmen ist. Gewiß ist es den Einzelstaaten unverwehrt, die Zuständigkeit ihrer eigenen Staatsgerichtshöfe einzuengen. Viele, ich erinnere nur an Bayern und sein Gesetz von 1920, aber auch an Thüringen, Oldenburg, Lübeck haben es getan, indem sie in Anknüpfung an die alte Tradition nur Regierung und Volksvertretung als Parteien zulassen. Aber es wird dadurch, wie $\mathrm{Naw}$ i a s ky und andere mit Recht annehmen, 
der Weg vor den Reichsstaatsgerichtshof für andere Streitigkeiten, die Verfassungsstreitigkeiten im Sinne des Art. 19 sind, nicht verbaut. Wenn dies einem Lande unbequem ist, so muß es die Zuständigkeit seines Staatsgerichtshofs durch Landesgesetz erweitern; in Bayern ist man damit zur Zeit am Werke.

Meine Aufgabe war es, über das Wesen der Staatsgerichtsbarkeit zu sprechen. Nicht über das V e rf a h r e n vor den Staatsgerichtshöfen. Aber ich muß doch wenigstens mit kurzen Worten darauf hinweisen, daß das Wesen der Verfassungsgerichtsbarkeit, wie ich es zu entwickeln versucht habe, auch für das Verfahren maßgebend sein muß. So sehr es vom Gesetze den Verfahrensweisen des ordentlichen Prozesses angenähert sein mag, so sehr wird doch eine verständige Praxis der Parteien und der Gerichte dessen eingedenk sein, daß es bei politischen Prozessen solcher Art „politisch“ herzugehen hat. Es kommt nicht immer darauf an, daß ein Prozeßgegner als Leichnam auf dem Schlachtfelde liegen bleibt. Am wenigsten kann dies das Ziel in den Fällen sein, wo der Staat zwischen den verschiedenen politischen Gewalten geführt wird. Hier muß das Ziel häufiger der Ausgleich von Gegensätzen, die Harmonisierung gestörter Einheitlichkeit, auf der Grundlage einer vom Gerichte herbeigeführten Klärung der Rechtslage, bilden. Ein guter Staatsgerichtshof wird nicht bloß aus Bequemlichkeit, sondern aus politisch richtiger Einstellung gern einen Vergleich herbeizuführen suchen, wie etwa in dem 1922 begonnenen Prozesse des Staatsrats gegen die Regierung in Preußen. Er wird vielleicht die Entscheidung absichtlich unvollständig halten, um eine Tür für weitere Verhandlungen offen zu lassen; so ist es neuerdings in dem sehr interessanten Urteile über die Donauversinkung geschehen. Aus guten politischen Gründen lassen die Parteien oft einen Prozeß versanden. So in der Streitsache Sachsen gegen Reich wegen des Einmarsches im Jahre 1923; auch jetzt scheint es in dem Verfahren der Fall zu sein, das von Preußen gegen das Reich über die Gültigkeit des Gesetzes vom 9. April 1927 in Sachen der Biersteuergemeinschaft angestellt worden ist. Es war politisch zweckmäßig, daß die Urteile des Staatsgerichtshofs bisher ausschließlich Feststellungsurteile gewesen sind und deshalb eine demütigende Vollstreckung nicht zuließen. Natürlich läßt sich selbst gegen das Reich, wenn es im Prozesse unterlegen ist, ein theoretisch ausgeklügeltes Vollstreckungsverfahren denken, und es hat sogar Gesetzentwürfe und Gesetze gegeben, die eine Vollstreckung gegen die Zentralgewalt eines Bundesstaats genau geregelt haben - ich erinnere an das Ergänzungsgesetz zur Erfurter Unionsverfassung, das ich in mei- 
nem Buche über die Reichsaufsicht ${ }^{21}$ auszugsweise abgedruckt habe, und an das geltende österreichische Recht. Allein solche Dinge kann man sich immer nur bis zu einem Punkte ausdenken, wo die Sache anfängt, politischer Unsinn zu werden. In normalen Zeiten ist selbst bei Leistungsurteilen eine Vollstreckung überflüssig, weil der Unterlegene entweder freiwillig leisten oder einen politisch gangbaren Weg der Verständigung mit dem Sieger suchen wird.

Das führt mich schließlich zu einer letzten Betrachtung. Je politischer die Angelegenheiten sind, die der Verfassungsgerichtsbarkeit unterstellt werden, umso angemessener wird für diese eine Verfahrensart sein, die dem ordentlichen Prozesse am unähnlichsten ist. Je weniger im Verfahren von Klage, von Parteien, von Einlassungszwang, von Klageabweisung und von Verurteilung, von Kassation staatlicher Akte die Rede ist, um so leichter lassen sich politische Fragen, die zugleich Rechtsfragen sind, erledigen. Ich sprach schon vorhin von o b jektiven Verfahren. Der Ausdruck wird nicht mißverstanden werden. Was ich meine, deckt sich zum Teil mit dem, was J os e ph-Barthé 1 ém y als richterliche Prüfung der Verfassungsmäßigkeit von Gesetzen „par voie d'exception“, im Gegensatz zur annullierenden Prüfung „par voie d'action“, bezeichnet. Die Amerikaner haben für Verfassungsstreitigkeiten das objektivste Verfahren eingeführt, das sich denken läßt; sie haben den Vorteil freilich erkauft mit dem Nachteil, daß ihre Verfassungsgerichtsbarkeit eine Gelegenheitsgerichtsbarkeit ist, die keine grundsätzlichen Lösungen bringt. Wir Deutsche können uns rühmen, in dem Verfahren des Art.13, Abs. 2 der Reichsverfassung für einen immerhin beträchtlichen Teil der Verfassungsstreitigkeiten ein objektives Verfahren geschaffen zu haben, das nach allgemeinem Urteil ausgezeichnet funktioniert. Auch der bekannte Entwurf eines Gesetzes über die Prüfung der Verfassungsmäßigkeit von Vorschriften des Reichsrechts über den ich nicht im einzelnen sprechen kann - bewegt sich in den Bahnen eines objektiven Verfahrens. Sollten wir daran gehen, den Beschlüssen des Heidelberger und des Kölner Juristentags entsprechend, den Art. 19 der Verfassung auf alle Verfassungsstreitigkeiten innerhalb des Reichsorganismus auszudehnen, so wird dafür zu sorgen sein, daß gerade hierbei nach Möglichkeit ein objektives Verfahren durchgeführt werde. Daß freilich der Verfassungsgerichtsbarkeit auch beim objektivsten Verfahren immer ein politischer Erdenrest ankleben wird, brauche ich nur anzudeuten. Es kann sein, daß die Objektivität des Verfahrens durch eine politisch auf-

21 [Heinrich Triepel, Die Reichsaufsicht. Untersuchungen zum Staatsrecht des Deutschen Reiches, Berlin 1917]. 
gezogene Organisation des entscheidenden Gerichtshofs wettgemacht wird, daß Parteiregierungen für parteipolitisch abgestempelte Richter sorgen, daß die Verteilung der Richterstellen nach den Stärkeverhältnissen der Parteien im Parlament erfolgt, daß man, wie 1871 in den Vereinigten Staaten geschehen, um eine politisch erwünschte Entscheidung in einem Einzelfalle zu erzielen, eine Art Richterpairsschub vornimmt. Auch in der Haltung der Prozeßparteien kann das politische Element eine bedenkliche Rolle spielen. Es ist möglich, daß ein an sich politisch harmloser Ziviloder Strafprozeß nur deshalb angestrengt wird, weil in ihm die Verfassungsmäßigkeit eines Gesetzes geprüft werden muß, und daß der Prozeß in Wahrheit nicht von dem, der als Kläger auftritt, sondern von einer politischen Partei oder einer Minderheitsfraktion des Parlaments, die hinter dem Kläger steht, geführt und finanziert wird. Solche Dinge lassen sich nicht vermeiden, weil, was mit Politik zusammenhängt, niemals künstlich von ihr gelöst werden kann. Immerhin, so viel ist gewiß: je „objektiver“ das Verfahren organisiert wird, um so geringer ist die von Vielen so sehr gefürchtete Gefahr, daß sich der Richter an die Stelle der „Regierung“ setzt, die Gefahr, daß man zu einem „Government of the judiciary“ gelangt.

Indessen, ich unterlasse es, auf Fragen de lege ferenda einzugehen. $\mathrm{Ob}$ man sich für einen weiteren Ausbau der Verfassungsgerichtsbarkeit, für Stillstand der Bewegung oder gar für Abbau entscheidet, das hängt von Grundüberzeugungen ab, über die wir hier schwerlich zu einer Einmütigkeit gelangen werden. Es gibt unter uns in bezug auf den Rechtsstaat Skeptiker und Enthusiasten, wie es sie schon vor Menschenaltern gegeben hat. Auch unter uns wird der eine, wie einst $S$ arwe y oder Fricker oder K l o e p p el, die Verfassungsgerichtsbarkeit als einen, ,vollkommenen Widersinn“ erklären, ein anderer wird mit $\mathrm{Hän}$ el sagen: es könne „,der Standpunkt des Rechts keiner politischen Erwägung zu Liebe die Forderung fallen lassen, auch für die Rechtsstreitigkeiten der obersten Organe des Staats den Weg Rechtens zu organisieren“. Ich mache für meine Person keinen Hehl daraus, daß ich mich mehr den Enthusiasten des Rechtsstaats als den Skeptikern zuneige. Wir sind meiner Ansicht nach dem bürgerlichen Rechtsstaate noch längst nicht entwachsen, und wir haben heute den allergeringsten Anlaß, ihn schon zu den Toten zu werfen. Auch in der Sphäre des Politischen hat er seine Rolle nicht ausgespielt, und es besteht namentlich in einem Staate mit vielgliedriger Teilung der politischen Gewalten das Bedürfnis, die schwächeren unter ihnen gegen die stärkeren durch das Recht und in der Form rechtens zu schützen, - so etwa die Länder gegen das Reich, den Reichsrat gegen das Reichsparlament. Gewiß, das 
Wesen der Verfassung steht weithin mit dem Wesen der Verfassungsgerichtsbarkeit in Widerspruch, und es gibt eine, freilich schwer feststellbare Grenze für die gerichtsförmige Erledigung verfassungsrechtlicher Streitigkeiten. Allein der Versuch muß gemacht werden, die vorhandene Disharmonie, soweit es möglich ist, harmonisch aufzulösen.

\section{Leitsätze des Berichterstatters}

1. Das Wesen der Staats-, besser: Verfassungsgerichtsbarkeit ist nicht in formaler Weise zu bestimmen. Es handelt sich um gerichtsförmige Entscheidung von Streitigkeiten über die Verfassung, wobei Verfassung in einem materiellen Sinne zu verstehen ist.

2. Verfassungsstreitigkeiten sind immer politische Streitigkeiten. In dieser Tatsache liegt das Problematische der ganzen Einrichtung.

3. Die Einführung der Verfassungsgerichtsbarkeit in das Staatsrecht des 19. Jahrhunderts beruht, abgesehen von dem Einflusse ständischer Erinnerungen, auf der Herrschaft des liberal-rechtsstaatlichen Rationalismus, vor allem auf der Theorie der Gewaltentrennung. Diese Theorie konnte aber in sehr verschiedener Weise organisatorisch ausgedeutet und entwickelt werden, weshalb sehr verschiedene Formen der Verfassungsgerichtsbarkeit entstanden sind.

4. Der politische Charakter der Verfassungsgerichtsbarkeit zeigt sich am deutlichsten in der Ausgestaltung des gerichtlichen Verfahrens auf Ministeranklage. Er ist aber auch bei der Einrichtung des Verfassungsstreitverfahrens im engeren Sinne deutlich erkennbar und muß bei der Auslegung und Handhabung der Normen über Gegenstand, Parteien und Verfahren in erster Linie berücksichtigt werden.

5. Ein „objektives Verfahren“ ist bei der Erledigung von Verfassungsstreitigkeiten das dem Gegenstande angemessenste Verfahren. 
Teil IV: Übergang zur „nationalen Revolution“? 


\section{Text 13 \\ Die Entscheidung des Staatsgerichtshofs im Verfassungsstreite zwischen Preußen und dem Reiche ${ }^{1}$}

I. Das Urteil des StGH v. 25. Okt. 1932, über das in der DJZ. wiederholt berichtet wurde, liegt jetzt im vollen Wortlaute vor. Diese Tatsache rechtfertigt es, daß hier nochmals zu der Entscheidung, deren große rechtliche und politische Tragweite offensichtlich ist, kritisch Stellung genommen wird, obwohl sich das Bild, das nach der mündlichen Begründung des Vorsitzenden gewonnen werden konnte, bei der Einsicht in die ausgearbeiteten Entscheidungsgründe kaum verschoben hat. Ich bin genötigt, mich kurz zu fassen. Insbes. muß ich die prozessuale Seite der Angelegenheit, über die doch manches zu sagen wäre, ganz beiseitelassen. Auch bitte ich mir nachzusehen, daß ich auf die in der Literatur, der älteren wie der jüngsten, geäußerten Meinungen nirgends eingehe, auch nicht auf den Kommentar, mit dem ein Mitglied des StGH. - ein ungewöhnlicher Vorgang - die Urteilsgründe nachträglich zu erläutern und zu ergänzen unternommen hat ${ }^{2}$.

Um das Ergebnis vorauszunehmen: ich halte die Entscheidung des $\mathrm{StGH}$. zum großen Teile für unrichtig. Das muß, um der Sache willen, in aller Offenheit ausgesprochen werden. Ich will versuchen, meine abweichende Auffassung zu begründen. Der Tatbestand darf bei den Lesern als bekannt vorausgesetzt werden.

II. Irre ich nicht, so ist die erste Fehlerquelle der Entsch. darin zu sehen, daß das Verhältnis, in dem die beiden Absätze des Art. 48 RVerf. zueinander stehen, verkannt worden ist. Es war gewiß selbstverständlich, daß der StGH. zu prüfen hatte, ob die V. des RPräs. v. 20. Juli 1932 mit Abs. 1 wie

1 [In: Deutsche Juristen-Zeitung 37 (1932), Sp. 1501-1508; die Literatur zum sog. „Preußenschlag“ und Staatsgerichtshofprozess ist hier nicht zu sondieren. Laut eines Berichts in der Vossischen Zeitung vom 11. November 1932 (Abdruck in: Briefwechsel Schmitt-Smend, 2012, S. 168-170) widersprach Triepel in der Diskussion einem Vortrag Schmitts in der „Deutschen Gesellschaft“. Schmitt erwähnt Triepels Stellungnahme im Tagebuch (Tagebücher 1930 bis 1934, hrsg. Wolfgang Schuller, Berlin 2010, S. 233) unpolemisch und weiß schon am 5. Dezember: „Triepel hat einen Aufsatz gegen das Leipziger Urteil geschrieben“ (Tagebuch, 2010, S. 242).].

2 RuPr. VerwBl. 53, S. $541 \mathrm{ff}$. 
mit Abs. 2 jenes Art. in Einklang zu bringen sei. Denn die V. hatte sich auf beide Bestimmungen berufen. Daß dies zweckmäßig war, habe ich von Anfang an bezweifelt; in früheren Fällen war man vorsichtiger gewesen (s. RGBl. 1920 S. 343, 477). Aber was geschehen war, war geschehen, und wenn Preußen mit seiner Klage die V. im ganzen angriff, so war es nicht zu umgehen, daß sich der StGH. mit beiden Absätzen des Art. 48, wie er sagt, "gesondert" beschäftigte. Denn daß der StGH. auch zur Entsch. von Streitigkeiten zwischen dem Reiche und einem Lande über eine Reichsexekution, wovon Art. 48 Abs. 1 handelt, berufen ist - in welchem Umfange wird freilich noch zu prüfen sein -, kann doch wohl angesichts der Entstehungsgeschichte und des Geistes der Weimarer Verf. nicht bestritten werden. Wer das Gegenteil annimmt, der muß des Glaubens sein, die Verf. habe die Länder jedes rechtlichen Schutzes gegen die schwerste Gewaltmaßregel des Reichs berauben wollen, während die Bismarcksche Verf. trotz ihrer Abneigung gegen alles, was Verfassungsgerichtsbarkeit heißt, die Verhängung der Reichsexekution immerhin von der Entsch. eines judicium parium, einem Beschlusse des Bundesrats, abhängig gemacht hatte (Art. 19).

Nun folgt aber aus der Notwendigkeit, die JuliV. auf ihre Übereinstimmung mit jenen beiden Absätzen „gesondert“ zu prüfen, noch nicht, daß man die beiden Bestimmungen voneinander isoliert. Es ist zwar richtig, daß sich der vom Abs. 1 geregelte Tatbestand nicht mit dem des Abs. 2 deckt. Dort ist Voraussetzung für das Eingreifen des Reichs die Pflichtverletzung eines Landes, hier die Störung und Gefährdung der öffentlichen Sicherheit und Ordnung. Es ist daher gewiß, daß eine „begriffliche Vermischung" der beiden Vorschriften unzulässig sein würde, und ebenso gewiß, daß jede von ihnen einen anderen geschichtlichen Vorläufer besitzt. Allein darum darf der innere Zusammenhang nicht übersehen werden, der zwischen beiden besteht. In beiden Bestimmungen handelt es sich um das Recht des Reichs, bei außergewöhnlichen Ereignissen, die den Bestand der staatlichen Ordnung gefährden, mit außergewöhnlichen Mitteln vorzugehen, nur daß in Abs. 1 der Bestand der bundesstaatlichen Ordnung als solcher zum Gegenstande besonderen Schutzes gemacht wird. In beiden Fällen ist es der RPräs., dem die Befugnis gegeben wird, die gestörte staatliche Ordnung wiederherzustellen. In beiden Fällen ist es der Reichstag, dem die Kontrolle des RPräs. und die letzte Entsch. über den Bestand seiner Maßregeln zugewiesen ist. Trotz des „begrifflichen“ Gegensatzes ist es sehr wohl denkbar, daß ein und derselbe Tatbestand unter beide Bestimmungen zu bringen ist, was übrigens der $\mathrm{StGH}$. ausdrücklich zugegeben hat. Deshalb kann gelegentlich der Abs. 2 helfen, wenn etwa aus besonde- 
ren Gründen der Abs. 1 versagen sollte 3 . Es wird also nicht zu kühn sein, wenn man verlangt, daß bei der Auslegung der beiden Absätze auf ihre innere Zusammengehörigkeit Rücksicht genommen werde.

III. Dies gilt zunächst für die Auslegung des Abs. 1. Nach seinem Wortlaut würde eine Reichsexekution in jedem Falle möglich sein, in dem ein Land eine ihm „nach der RVerf. oder den Reichsgesetzen obliegende Pflicht" nicht erfüllt. Also auch, wenn das Land eine AusführungsV. nicht erläßt, die es aufgrund eines Reichsgesetzes erlassen müßte, oder wenn es dem Staatsangehörigkeitsgesetze zuwider ein Einbürgerungsgesuch zurückweist. Das ist natürlich nicht der Sinn der Vorschrift. Es kann sich, wie im Abs. 2, nur um etwas „Erhebliches“, um schwere Pflichtverletzungen handeln, genauer um solche, die eine Gefahr für den Bestand der bundessstaatlichen Ordnung in sich schließen. Der Abs. 1 will ebenso wie Abs. 2 die Verfassung, diese nicht im formellen, sondern im materiellen Sinne genommen, schützen. Er will die Erfüllung „verfassungsmäßiger Bundespflichten“ sichern, wie es das Modell des Abs. 1, der Art. 19 der Bismarckschen Verf., schärfer als es in der Kopie geschehen, formuliert hatte. Ist das aber richtig, so ergibt sich daraus sofort eine Schranke für die Urteilsgewalt des StGH., nämlich genau dieselbe, die ihm wie anderen Gerichten bei der Entsch. von Streitfällen nach Abs. 2 des Art. 48 gezogen ist. Denn wenn es streitig wird, ob die Voraussetzungen zur Anwendung des Abs. 1 gegeben waren, so ist immer zu entscheiden, ob das Land eine schwere Verletzung einer Bundespflicht begangen hat. Das ist zwar, wie der StGH. richtig sagt, eine Tat- und eine Rechtsfrage zugleich. Aber damit ist nicht bewiesen, daß der StGH. d i e s e Tat- und Rechtsfrage beantworten, daß er das Werturteil, das der RPräs. mit seinem Beschlusse über die Vornahme der Reichsexekution abgibt, durch sein eigenes Werturteil ersetzen dürfte. Der Exekutionsbeschluß gehört zu den „Handlungen, die den Zusammenhalt des Ganzen, die Erhaltung der Lebensfähigkeit des Bundesstaats überhaupt zum Ziele haben. ... Die Bewertung der Interessen, die für ihre Ausübung bestimmend ist, kann, wenn die Einheitlichkeit und Zielsicherheit der Staatslenkung gewahrt bleiben soll, der Prüfung eines außerhalb der Regierung stehenden Organs nicht unterstellt werden, ebenso wenig wie die Interessenabschätzung, die anderen hochpolitischen

3 Vgl. meine Schrift: Streitigkeiten zwischen Reich und Ländern [Beiträge zur Auslegung des Artikels 19 der Weimarer Reichsverfassung, Tübingen], 1923, S. 64. Ich lege Wert darauf, daß man diese Stelle meiner Schrift nicht unterdrückt, wenn man mich als Schwurzeugen für die Ansicht anruft, daß jede Reichsexekution eine Entsch. des StGH. voraussetzt. 
Akten ... vorangeht" ${ }^{4}$ Damit will ich die richterliche Kontrolle auf diesem Gebiete keineswegs völlig ausschalten; das stünde ja in schroffem Widerspruche zu dem, was ich vorhin ausgeführt habe. Dem StGH. muß es freistehen, zu prüfen, ob in dem einzelstaatlichen Verhalten, gegen welches das Reich vorgeht, objektiv betrachtet, überhaupt eine Pflichtverletzung gefunden werden $\mathrm{k}$ a $\mathrm{n} \mathrm{n}$. Und ferner: freies Ermessen ist nicht Willkür. Es gilt auch für Handlungen des RPräs. und andere „actes de gouvernement" der Grundsatz, daß Ermessensüberschreitung und Ermessensmißbrauch den Akt fehlerhaft machen und vom Richter korrigiert werden können. Der StGH. darf also dem Reiche in den Arm fallen, wenn es unter Mißbrauch des Art. 48 Abs. 1 - um ein in diesem Falle wörtlich zu nehmendes Bild zu brauchen - mit Kanonen nach Spatzen schießt. Aber darüber, ob ein Land eine schwere Gefährdung der bundesstaatlichen Ordnung unter Verletzung seiner verfassungsmäßigen Bundespflichten, z. B. seiner Treuepflicht, begangen habe, hat der RPräs., und nur er, nach pflichtmäßigem Ermessen zu entscheiden.

Der StGH. hat die Frage, ob er bei V.en auf Grund des z we it e n Abs. des Art. 48 das Ermessen des RPräs. überprüfen könne, wie schon bei früherer Gelegenheit, so auch diesmal beiseitegeschoben und konnte es tun, da er die Voraussetzungen des Abs. 2 als gegeben erachtete. Seine innere Einstellung wird indes in einem Urteil v. 5. Dez. 1931 wenigstens angedeutet. Der StGH. zitiert hier eine größere Zahl eigener Entscheidungen, in denen er festgestellt habe, daß er bei Notv.en der Länder zwar prüfen dürfe, ob ein ungewöhnlicher Notstand vorhanden und ob der Erlaß der V. dringend erforderlich gewesen sei, daß jedoch hierbei „dem Ermessen der zu einem schnellen und entschlossenen Handeln verpflichteten Regierung ein gewisser Spielraum belassen und ihr Vorgehen so lange als berechtigt angesehen werden müsse, als sich nicht das Gegenteil aus den Verhältnissen der betreffenden Zeit heraus einwandfrei ergebe“. Und er fügt hinzu: „Man kann die Ansicht vertreten, daß Entsprechendes auch hier (nämlich bei Art. 48 Abs.2) zu gelten habe" (RGZ. 134, Anhang S. 44). Unterstellt man, daß der StGH. mit dieser vorsichtigen Wendung seinen eigenen Standpunkt angegeben habe, so würde er m. E. für Abs. 1 des Art. 48 notwendig zu dem gleichen Ergebnisse haben kommen müssen, wenn er sich nicht durch die schroffe Scheidung zwischen Abs. 1 und Abs. 2 den Weg verbaut hätte - ganz abgesehen von der Frage, ob sich die von mir vertretene Anschauung nicht auch ohne Zuziehung des Abs. 2 als richtig dartun ließe.

4 Vgl. meine Streitigkeiten S. 94 ff., bes. 99 f. 
In Wirklichkeit hat der StGH. die Meinung, es handele sich bei der Frage, ob die JuliV. in Abs. 1 des Art. 48 die erforderliche Stütze finde, um eine „reine Ermessensfrage“, als unrichtig abgelehnt, ohne zu prüfen, ob nicht wenigstens zum Teil in der Frage eine Ermessenfrage enthalten sei. Und er hat weiter, in bezug auf gewisse Äußerungen eines preuß. Ministers, festgestellt, daß diese die Grenze der gebotenen - d. h. doch wohl nach dem Sinne der Verf. gebotenen - Zurückhaltung nicht derart überschritten habe, daß darin eine Pflichtverletzung des Landes gegenüber dem Reiche erblickt werden könne. Ich lasse mich nicht dazu verleiten, mich darüber auszusprechen, ob ich mich dieser Beurteilung anschließe; ich würde mir damit gerade das anmaßen, was ich selbst dem höchsten Richter des Reichs nicht zugestehe. Denn der angeführte Satz der Entsch. enthält ein Maß- und Werturteil, das m. E. nur dem RPräs. zusteht und durch kein Urteil eines Gerichtshofs ersetzt werden kann!

IV. So notwendig es ist, zur Auslegung des Abs. 1 des Art. 48 den Abs. 2 heranzuziehen, so notwendig ist das Umgekehrte. Und zwar ganz gleichgültig, ob man im Einzelfalle die Anwendbarkeit des Abs. 1 bejaht oder mit dem StGH. verneint.

Der StGH. legt auf die Geschichte der Entstehung des Abs. 1 einen gewissen Wert. Aber diese Geschichte beginnt nicht erst in der Weimarer Nationalversammlung. Vielmehr stammt die Bestimmung aus der Bismarckschen RVerf. (Art. 19), und diese hatte sie wieder aus der Verf. des Nordd. Bundes übernommen - von den Vorbildern im Rechte des alten Reichs und des Deutschen Bundes zu schweigen. Nun hieß es in Art. 19 der Nordd. BVerf. ausdrücklich: „Die Exekution kann bis zur Sequestration des betreffenden Landes und seiner Regierungsgewalt ausgedehnt werden." Die RVerf. von 1871 hat diesen Satz weggelassen. Aber das ist, wie Del b rü ck bei Beratung der Novemberverträge im Reichstage festgestellt hat, hauptsächlich aus „internationaler Konvenienz" gegenüber den süddeutschen Staaten, d. h. deshalb geschehen, weil man nicht schon in der Verf. ein „unfreundliches Bild aufrollen" wollte. Daher war anzunehmen, daß das, was die Nordd. Verf. verordnet hatte, auch nach der RVerf. von 1871 gelte, und die Wissenschaft des Staatsrechts hat hieran, von verschwindenden Ausnahmen abgesehen, niemals gezweifelt; selbst $\mathrm{Max} v$. Seydel hat in den allgemeinen Chor eingestimmt ${ }^{5}$. Es ist erlaubt, anzunehmen, daß die heutige RVerf., die gewiß nicht föderalistischer aufgezogen ist als die Bis-

5 Vgl. meine Reichsaufsicht [Die Reichsaufsicht. Untersuchungen zum Staatsrecht des Deutschen Reiches, Berlin 1917] S. 673 f. 
marcksche, in diesem Punkte die Erbschaft der RV. von 1871 angetreten hat. Dabei ist zu bedenken, daß es diese letztere mit fürstlichen Regierungen zu tun hatte! Nach alledem ist der weitere Schluß gestattet und geboten: eine Maßnahme, die von der Verf. selber als ein zulässiges Mittel bundesstaatlichen Zwanges angesehen wird, kann unmöglich als schlechthin rechtswidrig bezeichnet werden. Man kann dagegen nicht die „begriffliche Scheidung" der beiden Abs. des Art. 48 ins Feld führen. Wir wissen ja, die beiden Tatbestände decken sich nur zum Teil. Ich sage nicht mehr als dies: was die Verf. überhaupt als möglich ansieht, kann nicht für eine nach dem Grundgedanken der Verf. schlechterdings unmögliche Maßregel ausgegeben werden. Man müßte denn dartun können, daß die Verf. nur im Falle des Abs. 1 jene Maßregel als zulässig habe erklären wollen, was sich nicht dartun läßt. Folglich: es ist auch nach Art. 48 Abs. 2 in das Ermessen des RPräs. gestellt, unter außergewöhnlichen Umständen die "Sequestration“ der Regierungsgewalt und zwar der ganzen Regierungsgewalt, d. h. deren Beschlagnahme zur vorläufigen Verwahrung anzuordnen.

Das wird vom StGH. im Grunde mit dürren Worten anerkannt. Er sagt: der RPräs. konnte es angesichts der außergewöhnlichen politischen Gefahrenlage für geboten erachten, „die staatlichen Machtmittel des Reichs und des größten deutschen Landes in einer Hand zusammenzufassen“. Ist das nicht dasselbe wie das, was ich eben ausgeführt habe?

Allein nun kommt der Bruch, der sich durch die Entsch. hindurchzieht. Nach dem StGH. finden die Maßnahmen des Art. 48 Abs. 2 ihre unüberschreitbare Grenze in den Bestimmungen der Verf., „die nicht lediglich die Zuständigkeiten der verschiedenen Reichsorgane gegeneinander abgrenzen“. Die V. v. 20. Juli ist also zulässig, soweit sie als eine bloße „V e r schiebung von Zuständigkeiten“, als eine „Übertragung von Geschäften und Befugnissen von der Landesregierung auf ein Reichsorgan“ aufgefaßt werden kann, dagegen nicht, soweit sie in „andere Vorschriften" der RVerf. eingreift, von den sieben in Art. 48 Abs. 2 ausdrücklich als suspendierbar bezeichneten Grundrechtsartikeln abgesehen. $\mathrm{Zu}$ den Vorschriften der RVerf., die bloße Abgrenzungen enthalten, gehört nach dem StGH. der Art. 5, aber nicht der Art. 17, der dem Lande eine eigenwüchsige Landesregierung gewährleiste, und nicht die Art. 60 u. 63, wonach die Länder im Reichsrate nur durch Mitglieder ihrer Regierungen vertreten sein können. Zwar könne man Befugnisse der preußischen $\mathrm{Mi}$ nister in „Landesangelegenheiten“ nach Art. 48 vorübergehend von der Landesstaatsgewalt abtrennen und einem RKomm. als Reichs or ga n übertragen, z. B. die Entlassung und Ernennung von Beamten. Aber die Vertretung des Landes Preußen im Reichsrate und Reichstage, überhaupt 
gegenüber dem Reiche sowie gegenüber dem Landtage und Staatsrate könne nicht auf einen RKomm. übergehen, da dieser eben ein Reichsorgan und dem Reiche verantwortlich sei.

In dieser Deduktion ist Richtiges mit Unrichtigem verbunden. Es unterliegt auch für mich keinem Zweifel, daß die Verf. als solche auch für den RPr. als Diktator unantastbar ist. Wie könnte es anders sein! Die Diktatur ist ja gerade um der Verf. willen, zu ihrem Schutze geschaffen. Daher ist es auch sicher, daß der Diktator die Eigenständigkeit der Länder grundsätzlich zu achten hat. Diese wird übrigens nicht durch Art. 17 „gewährleistet“". Art. 17 verlangt von den Ländern die Angleichung ihrer Verfassungsform an die des Reichs, enthält aber nichts von einer Garantie der „Selbstständigkeit" der Länder. Diese wird vielmehr vorausgesetzt, und sie wird nicht nur hier, sondern in jedem Artikel vorausgesetzt; denn sie ist die tragende Grundlage für das ganze Gebäude des Reichs. Aber andererseits ist die Diktatur gerade in ihrem innersten Wesen selber eine Verfassungsanomalie, und es ist die eigentümliche Dialektik der Einrichtung, daß sie das, was sie schützen soll, eben um es zu schützen, angreifen muß, folglich auch - im Rahmen des Diktaturzwecks - angreifen darf. Das erkennt auch der StGH. an, indem er dem Diktator Zuständigkeitsverschiebungen zwischen Reich und Ländern, also gerade diejenige Maßnahme gestattet, die einen Stoß in das Herzstück der Verf. bedeutet! Ist denn aber die vorübergehende Beiseiteschiebung einer Landesregierung und ihre Ersetzung durch einen RKomm. etwas anderes als eine "Zuständigkeitsverschiebung", d. h. ein Vorgang, bei dem das Reich einen Akt vornimmt, der nach der Kompetenzordnung der Verf. normalerweise nur von höchsten Landesorganen vorgenommen werden könnte? Wenn der Diktator Landesbeamte ernennen und entlassen darf, so darf er etwas tun, was eigentlich nur die Landesregierung tun dürfte. Hiervon unterscheidet sich die Einsetzung von obersten Regierungsorganen zwar dem Grade, aber nicht der Art nach. Der StGH. hat nichts dagegen einzuwenden, daß der Diktator den Landesgesetzgeber ersetzt, selbst wenn er dabei der Landesverfassung widersprechende Sätze einführt. Mich dünkt, daß sich solche Zuständigkeitsverschiebung nicht einmal dem Grade nach von der Bestellung einer Landesregierung unterscheidet.

Damit ist auch die Frage entschieden, ob eine V. nach Art. 48 die mattgesetzte Landesregierung von der Vertretung des Landes im Reichsrate und von der Vertretung gegenüber höchsten Reichs- und Landesorganen überhaupt ausschließen dürfe. Natürlich wäre es eine Anomalie, wenn die Vertretung eines Landes im Reichsrate durch das Reich selbst wahrgenommen werden würde. Vielleicht wäre es sogar eine Anomalie, wenn das 
Reich einen rechtlichen Einfluß auf die Instruktion von Reichsratsbevollmächtigten gewinnen würde - übrigens keine größere, als sie einstmals bestand, als der vom Kaiser zu ernennende und abzuberufende Statthalter von Elsaß-Lothringen die reichsländischen Stimmen im Bundesrate instruierte, ja, nicht einmal größer, als sie in der Instruktion der preußischen Bundesratsstimmen durch ein Staatsministerium bestand, dessen Vorsitzender gleichzeitig Reichskanzler war. Allein der vom RPräs. eingesetzte Kommissar ist eben, solange er amtiert, provisorische Landesregierung. Der StGH. bedient sich einer unrichtigen Konstruktion, wenn er den Kommissar als Reichsorgan auffaßt. Der Kommissar ist Landesorgan, seine im Rahmen des Auftrags vorgenommenen Akte sind Akte der Landesstaatsgewalt. Nur die Einsetzung des Kommissars ist Reichsakt, wird im Namen des Reichs vorgenommen; was der Kommissar selber verfügt, das verfügt er im Namen des Landes. Die „Zuständigkeitsverschiebung“ besteht nicht darin, daß während des Provisoriums Landesverordnungen, Verfügungen, Rechtsgeschäfte vom Reiche vorgenommen werden, sondern darin, daß das Reich eine Regierung, die an sich von andern Landesorganen bestellt werden müßte, von sich aus bestellt. Der rechtliche Sachverhalt ist in den zahllosen anderen Fällen, in denen sich ein korporativer Verband die Bestellung eines Organs von außen her gefallen lassen muß, niemals anders aufgefaßt worden. Der vom König ernannte Bürgermeister von Frankfurt a. M. wurde Gemeindeorgan, der vom König von Bayern ernannte Bischof ein Kirchenorgan, der vom Kaiser ernannte Festungskommandant erhielt ein Landes-, kein Reichsamt ${ }^{6}$. Der für eine in ihrer Verwaltung herabgekommene Gemeinde eingesetzte Staatskommissar vertritt in Verfügungen und Rechtsgeschäften die Gemeinde, nicht den Staat. Das Entsprechende muß auch in unserem Falle gelten.

Ich komme hiernach zu dem Schlusse, daß es dem RPräs. nicht verwehrt ist, im Falle des Art. 48 Abs. 2 einen Reichskommissar vorübergehend zur Ausübung der Landesregierung zu bestellen. Und zwar der ganzen Regierung. Das Ergebnis, mit dem die Entsch. des StGH. schließt, ist gerade deshalb so unbefriedigend, weil es eine unmögliche Teilung der Regierungsgewalt für möglich hält, ja verlangt. Denn bei Lichte besehen läßt sich „Regierung“ überhaupt nicht teilen. Man kann die gesetzgebende Gewalt, man kann die Verwaltung nach Gegenstand und Richtung aufteilen. Aber Regierung ist ihrem Wesen nach oberste Leitungs- und Entscheidungsgewalt im Dienste der Zusammenfassung staatlicher Kräfte zur Einheit. Sie ist daher selbst eine Einheit, die sich nicht spalten läßt. Der StGH.

6 Vgl. meine Reichsaufsicht S. 227, 244. 
sucht den Riß durch gute Ratschläge für eine Verständigung zu schließen. Aber keine Verständigung hilft darüber hinweg, daß hier getrennt worden ist, was nicht getrennt werden kann. Schon jetzt hat sich herausgestellt, daß die Durchführung des Urteils einen auch nur für kurze Dauer unerträglichen Zustand geschaffen hat und die Quelle neuer unerquicklicher Streitigkeiten geworden ist. Die Entsch. gleicht dem Urteile der Porzia im Kaufmann von Venedig. Nimm du dein Pfund Fleisch, aber vergieße dabei keine Tropfen Blut!? Der Scharfsinn des Lesers mag sich an der Frage mühen, ob das Reich oder die preußischen Minister die Rolle des betrogenen Shylock spielen. Denn mit dem, was ihnen das Gericht zugesprochen, kann keine der beiden Parteien etwas anfangen, d. h. wirklich „regieren“.

V. Selten ist an einem höchstrichterlichen Urteile so herbe Kritik geübt worden, wie in diesem Falle. Man konnte hören, wie sich der Unmut bis zu starken Zweifeln an der Einrichtung der Verfassungsgerichtsbarkeit gesteigert hat. Streitigkeiten von so eminent politischer Bedeutung seien nicht für richterliche Entscheidung geeignet. Man muß hier vor Übertreibungen dringend warnen. Die Rechtsstreitigkeiten des Art. 19 der RVerf. sind unzweifelhaft auch politische Streitigkeiten. Aber das macht sie nicht schlechthin unfähig, dem Urteil eines Richters unterworfen zu werden. Wenn man die jetzige Gelegenheit benutzen will, um zukünftige Entwicklungen ins Auge zu fassen, so kann es, wie mir scheint, nur in dem Sinne geschehen, daß man eine Gestaltung unserer bundesstaatlichen Verhältnisse erstrebt, die noch mehr als bisher dem Gedanken gerecht wird, daß sich Reich und Länder nicht wie unabhängige „Mächte“ gegenüberstehen. Nicht das Reich für sich ist ein Staat, und nicht die Länder für sich sind Staaten. In der $\mathrm{Z}$ u s a m me n a r beit von Reich und Ländern lebt der deutsche Staat. Wird das in einer künftigen Verfassung noch schärfer ausgeprägt als jetzt, dann werden Streitigkeiten zwischen Reich und Ländern von selbst entpolitisiert, d. h. politisch entgiftet werden. Den StGH. aber soll man nicht antasten. Er ist ein Grundpfeiler unseres Rechtsstaats, und

7 [William Shakespeare, Der Kaufmann von Venedig IV/ 1 (Übers. A. W. v. Schlegel, Shakespeare' s dramatische Werke, Berlin 1856, Bd. VI, S. 259): Porzia: „Ein Pfund von dieses Kaufmanns Fleisch ist dein. / Der Hof erkennt es, und das Recht ertheilt es." Shylock (die Wage erhebend): „O höchst gerechter Richter! - Na, ein Spruch! / Kommt, macht euch fertig.“ Porzia: „Wart noch ein wenig: eins ist noch zu merken. / Der Schein hier giebt dir nicht ein Tröpfchen Blut, / Die Worte sind ausdrücklich, ein Pfund Fleisch. / Nimm denn den Schein, und nimm du dein Pfund Fleisch; / Allein vergießest du, indem du's abschneidst, / Nur ein Tröpfchen Christenblut, so fällt / Dein Hab' und Gut, nach dem Gesetz Venedigs, / Dem Staat Venedig zu."]. 
wir haben heute den geringsten Anlaß, auch nur einen einzigen Stein aus diesem Gebäude herauszubrechen. Nach guter deutscher Rechtsgewohnheit kann auch der „Umstand“ ein Urteil „schelten“. Wir wollen uns dies Recht nicht verkümmern lassen. Aber es ziemt sich auch, den Hut zu ziehen vor einem Gerichte, das, unbekümmert um alle politischen Folgen, wie tief wir sie beklagen mögen, dem Rechte und nur ihm zu dienen sucht. Das Wort: Fiat justitia, pereat mundus, ist ein hartes, vielleicht gefährliches Wort. Aber der königliche Gerichtsherr, ${ }^{8}$ der es sich einst zum Wahlspruche erkoren, hat damit doch ein Richterideal aufgestellt.

8 [Triepel beruft sich hier auf den preußischen „Soldatenkönig“ Friedrich Wilhelm I., der mit Schreiben vom 1. November 1730 die Verurteilung von Hans Herrmann von Katte verschärfte und ihn zum Tode („mit dem Schwert“) verurteilte.]. 


\section{Text 14 \\ Die nationale Revolution und die deutsche Verfassung ${ }^{1}$}

Die große Bewegung, die in diesen Wochen das deutsche Volk bis in seine Tiefen aufgerüttelt hat, und in deren Mitte wir noch stehen, ist von ihren Führern, ${ }^{2}$ man könnte sagen amtlich, als die nationale oder die deutsche Revolution bezeichnet worden. Das ist mit Fug und Recht geschehen. Denn der tiefste Sinn der Bewegung und zugleich das, was ihr allein die Legitimation verleiht, ist die Auflehnung der deutschen Seele gegen den zweifachen Druck, der auf dem deutschen Volke lastet, gegen die Ketten, die seiner freien Bewegung im Leben der Völker geschmiedet worden sind, und gegen alles Undeutsche, was die Reinheit seiner geistigen Haltung getrübt hat oder zu trüben droht. Die Revolution ist eine kulturelle Revolution. Wenn ich nicht irre, so ist ihr auch dieser Name bereits von führender Seite beigelegt worden.

Von dieser kulturellen Bedeutung der Umwälzung soll im folgenden nicht gesprochen, oder richtiger, da sich auch die Staatsverfassung als Ausdruck des geistigen Lebens der Nation, also seiner Kultur darstellt, es soll hier nur eine einzelne Seite dieser kulturellen Aufstandsbewegung ins Auge gefasst werden. Natürlich ist das nur eine äußerliche Isolierung. Denn der Geist, aus dem eine Verfassung gewoben wird, kann kein anderer sein als der, mit dem sich eine nationale Bewegung auf den Gebieten der Wirtschaft, der Schule, der Kunst, der Literatur, kurz auf den Gebieten des Kulturlebens überhaupt umgestaltend auswirkt. Und wenn es, wie zu hoffen ist, gelingt, auf jenen anderen Gebieten einen unleugbar vorhandenen Radikalismus einzudämmen - einen Radikalismus, der seiner innersten Natur nach undeutsch ist und deshalb die nationale Bewegung in ihrem Kern verfälschen würde -, so wird es auch gelingen, die verfassungsrechtliche Gestaltung der deutschen Zukunft auf dem Boden wachsen zu lassen, auf dem sie allein gedeihen kann, und das ist der deutsche Boden.

1 [In: Deutsche Allgemeine Zeitung. Ausgabe Groß-Berlin 72 (1933), Nr. 157 vom 2. April 1933, S.1-2; Triepel antwortet mit seinem Artikel auf das „Ermächtigungsgesetz" v. 23./24. März 1933 und Hitlers rechtfertigende Reichstagsrede.].

2 [So von Hitler in seiner Reichstagsrede vom 23. März 1933 zur Begründung des Ermächtigungsgesetzes, in: Reichstagsprotokolle. 2. Sitzung v. 23. März 1933, S. $25-$ 32]. 
Dass die nationale Revolution in erster Linie die Verfassung des deutschen Staates ergriffen hat, kann nicht zweifelhaft sein. Dies ist noch nicht überall zum Bewusstsein gekommen. Mancher vermag sich überhaupt eine Revolution nicht ohne Barrikadenkämpfe und Straßenschlachten vorzustellen. Es gibt aber zum Glück auch Revolutionen ohne solche Zutaten. Und das Eigentümliche an der Umwälzung des Jahres 1933 ist, dass sie sich in ihrem Hauptstück - von ungesetzlichen oder in ihrer Gesetzlichkeit bestreitbaren Einzelakten muss und kann dabei abgesehen werden durchaus im Rahmen des geltenden Verfassungsrechts vollzogen hat. Sie ist eine legale Revolution. Das klingt wie ein Widerspruch und ist doch keiner. Legal ist, was sich in den Formen abspielt, die von den geltenden Gesetzen vorgezeichnet sind, revolutionär, was das geltende Recht in grundstürzender Weise verwandelt. Und so kann derselbe Akt legal und doch revolutionär sein. ${ }^{3}$

Die Novemberrevolution von 1918 war eine illegale Revolution. Sie zwang die legitimen Obrigkeiten zur Abdankung oder setzte sie ab. Sie entthronte die Fürsten, aber auch den Reichstag und die Landtage, sie hob die Reichsverfassung und die Landesverfassungen aus den Angeln. Die Revolution von 1933 hat in allem das Gegenteil getan. Sie hat die Weimarer Verfassung formell nicht beseitigt, Reichstag und Reichsrat nicht zerstört, den Bestand der Länder nicht angetastet, den Reichspräsidenten nicht abgesetzt. Vielmehr hat sie Reichstag und Reichsoberhaupt sozusagen für sich eingefangen. Der Reichstag hat in den Formen des Artikels 76 der Verfassung das Ermächtigungsgesetz beschlossen, das den Weg für staatsrechtliche Umbildungen freimacht, der Reichstag hat ihm zugestimmt, der Reichspräsident hat es unterschrieben. Der Inhalt des Gesetzes steht unzweifelhaft zu den Grundgedanken der Weimarer Verfassung in vollem Widerspruch. Denn wenn ein verfassungsänderndes Gesetz das ganze System des in einer Verfassungsurkunde vorgezeichneten konstitutionellen Lebens auf vier Jahre in Schlummer versetzt - wobei so gut wie sicher ist, dass das Schlummernde nicht wieder geweckt werden wird -, so ist dies ein in sich revolutionärer Akt. Und doch ist er in formeller Legalität vor sich gegangen, woran auch die Tatsache nichts ändert, dass sich ein Teil der

3 [Triepels Deutung der „nationalen Revolution“ als „legale Revolution“ wurde vom nationalsozialistischen Schrifttum gerne aufgenommen. Während Triepel aber die Legalität auch als Mahnung betonte, verlegte der Nationalsozialismus den Akzent mehr auf die Legitimität der "Revolution“. Dass Triepel die „legale Revolution“ von der „illegalen Revolution“ von 1918 polemisch absetzt, ist freilich sehr problematisch.]. 
dem Gesetz Zustimmenden nur unter dem Druck der Besorgnis vor illegaler Revolution oder Bürgerkrieg zur Zustimmung bereitgefunden hat.

Eine legale Revolution ist nichts Neues. Mindestens nicht in Deutschland. Unser Volk hat im Laufe eines Jahrhunderts mehrere legale Revolutionen erlebt, misslungene und gelungene. Im Jahre 1803 hat der Reichsdeputationshauptschluss und das ihn bestätigende Reichsgesetz den deutschen Staatenbestand in rücksichtslos revolutionärer Weise, aber auf legalem Wege, vereinfacht. Wäre der Versuch der Reichsgründung von 1848 geglückt, so wäre die größte Revolution Deutschlands seit dem Westfälischen Frieden vollzogen gewesen; die Versammlung der Paulskirche aber war in legaler Form zu ihrem Werk berufen worden. Man hat Bismarck oft einen großen Revolutionär genannt. Er war es auch. Allein es gehört zu seinen größten Ruhmestiteln, dass er die Gründung des Norddeutschen Bundes und des Reichs nicht mit Gewalt, sondern durch Vertrag und Gesetz - also legal - vorgenommen hat. Es lässt sich geradezu behaupten, dass es germanischem Rechtssinn entspricht, wenn die Deutschen ihre Staatsumwälzungen in legaler Form bewirken. Mir ist in diesen Wochen oft ein Gespräch durch den Kopf gegangen, das ich im Herbst 1918 mit einem bekannten demokratischen Politiker geführt habe. Am 28. Oktober 1918 hatte die bereits wankende Regierung des kaiserlichen Deutschland die drohende illegale Revolution durch eine legale abzudingen versucht. Zwei Reichsgesetze, von einem erläuternden Erlass des Kaisers an den Reichskanzler begleitet, unternahmen es, das parlamentarische Regierungssystem in Deutschland einzuführen. Jener Politiker, der sich auch bei ernsten Gelegenheiten gern des kaustischen Berliner Witzes bediente, sagte mir damals: „So etwas ist nur in Deutschland möglich! Revolution durch kaiserliche Kabinettsorder!“ Das sollte Spott sein. Aber es lag ernste Wahrheit darin. Richtig war, dass jene Gesetze einen vollkommenen Bruch mit dem Geiste der Bismarckschen Verfassung, also eine Revolution bedeuteten. Und richtig war, dass es echte deutsche Art ist, Revolutionen in aller Form rechtens zu veranstalten. Auch heute könnte ein Spötter sagen: „Nur in Deutschland möglich! Revolution durch den Stimmzettel und durch Gesetz auf Grund des Artikels 76 der Verfassung!" Aber auch diesmal würde im Scherz vollster Ernst enthalten sein.

Aus der Tatsache unzerstörbaren deutschen Rechtssinns ziehe ich nun in verfassungspolitischer Hinsicht für die Zukunft, die nahe wie die ferne, Folgerungen, die dem Manne des Rechts und dem warmen Verehrer deutschen Rechtsgeistes neben allen Sorgen, die ihn bedrücken, tröstliche Gewissheiten bringen. 
In seiner Abrechnung mit der sozialdemokratischen Partei im Reichstage hat der Reichskanzler gesagt: „Wenn wir nicht das Gefühl für das Recht hätten, dann wären wir nicht hier, und Sie säßen auch nicht da. "4 Darin liegt zunächst die Berufung auf die Legalität der Revolution. „Wir hätten es nicht nötig gehabt, weder zu einer Wahl zu schreiten, noch diesen Reichstag heute einzuberufen, noch diese Vorlage (das Ermächtigungsgesetz) hier einbringen zu lassen." Also: Wir hätten Gewalt brauchen können, aber wir haben es vorgezogen, dem Rechte treu zu bleiben. In dem ersten Satz liegt aber noch mehr. Der Kanzler legt Wert darauf, sein Gefühl für das Recht überhaupt zu betonen. Wir nehmen ihn beim Worte. Das Ermächtigungsgesetz hat ihm in bündigster Form die Reichsverfassung zur Verfügung gestellt. Auch den Teil, der die Überschrift „Grundrechte und Grundpflichten des deutschen Volkes“ trägt. In diesem Kapitel steht manches Wunderliche, manches Kompromisslerische und manches „Marxistische“. Soll es ausgemerzt werden, so weinen wir ihm keine Träne nach. Aber es ist dort auch vieles enthalten, das echtes altes deutsches Rechtsgut darstellt. Darunter manches „Freiheitsrecht“, das man nicht mit einer Handbewegung als Erzeugnis eines überlebten „Liberalismus“ abtun darf, was vielmehr Jahrhunderte, bevor das Wort „liberal“ erfunden wurde, in schweren Kämpfen von tapferen Männern germanischen Blutes in Deutschland, in den Niederlanden, in England dem Despotismus weltlicher und kirchlicher Gewalten abgetrotzt worden ist. Diese Freiheitsrechte können zwar in Not- und Ausnahmesituationen angetastet, aber sie können nicht dauernd vernichtet werden. Der deutsche Bauer und der deutsche Arbeiter, aber auch der deutsche Handwerker und der deutsche Gelehrte, sie alle wollen „als freies Volk auf freiem Grunde stehen“.5

4 [Hitler am 23. März 1933 im Reichstag in der Antwort auf die Rede von Otto Wels, in: Reichstagsprotokolle, 2. Sitzung vom 23. März 1933, S. 35].

5 [Goethes Vers vom „freien Grund mit freiem Volk“ (Faust II, V 11580, in: Hamburger Ausgabe Bd. III, S.348), von Triepel frei zitiert, wurde immer wieder politisch vereinnahmt. So zitierte Ernst Rudolf Huber ihn 1944 als „Vision der Volksund Staatserneuerung“ in einem Vortrag Goethe und der Staat (in: Nationalstaat und Verfassungsstaat. Studien zur Geschichte der modernen Staatsidee, Stuttgart 1965, hier: S. 27). Wolfgang Mommsen bemerkte dazu in einer frühen Rezension (in: Der Staat 6 (1967), S. 113-117, hier: 114): „Nebenbei sei bemerkt, dass Huber unseres Erachtens die Szene in ,Faust II', in welcher Faust dem Meere ein neues Land abgewinnt, um darauf, ein freies Volk auf freiem Grunde' anzusiedeln, ganz ungerechtfertigt als eine Glorifizierung großer nationaler Tat deutet. Im Gegenteil, alles löst sich doch in Nichts auf; Fausts Tat erweist sich als eine bloße Chimäre, als ein Werk bloßer Selbstbespiegelung."]. 
Auch in dem, was den Kern einer Staatsverfassung ausmacht, in dem Aufbau der staatlichen Gewalten, wird sich deutsches Rechtsdenken bewähren können. Die Gestaltung der künftigen Verfassung lässt sich vorläufig nur in unsicheren Umrissen vorausdenken. Aber eines ist doch wohl sicher. Der wuchtige Stoß der nationalen Revolution hat sich gegen den demokratisch-parlamentarischen Parteienstaat gerichtet. Dieser ist dem Stoße erlegen, und es gehört keine Sehergabe dazu, um zu prophezeien: der Tote wird nicht wieder auferstehen. Er wird es um so weniger, je rascher gelingt, was gelingen muss - ein heikler Punkt, der indessen in aller Öffentlichkeit erörtert werden muss - wenn es gelingt, der jetzt zum Siege gelangten Partei das Kleid einer Partei abzustreifen und sie zu verwandeln in eine das ganze Volk umfassende Gemeinschaft, der sich ein jeder in Freiheit einzuordnen imstande ist. Fast scheint es, als ob die Zerstörung des Parteienstaates nur dadurch geschehen kann, dass eine Partei zunächst alle anderen vernichtet. Aber der Sieger wird sein wahres Ziel erst erreicht haben, wenn er selbst in der nationalen Gemeinschaft aufgegangen ist.

Dem Tode geweiht ist aber auch der das Volk atomisierende Individualismus, auf dessen Acker der Parlamentarismus des 18. Jahrhunderts allein emporwuchern konnte. Die künftige Verfassung, die aus dem Schoße der Diktatur - denn diese kann und wird nichts Endgültiges sein - geboren werden soll, wird den Staat aufzubauen haben auf den Elementen einer körperschaftlichen Selbstverwaltung. Und dies ist die Stelle, wo die neue Rechtsgestaltung anknüpfen kann an wertvollste Stücke deutscher Überlieferung. Denn anders als Italien, das sich seinen „State corporative“ künstlich aus dem Nichts schaffen musste, haben wir das Glück, die Bausteine längst zu besitzen, die wir zum Werke brauchen, und wir werden hoffentlich nicht wieder in die alte Sünde verfallen, die Elemente unserer Verfassung aus dem Auslande zu beziehen. Kein Land der Welt ist so reich wie wir an Formen und Arten einer genossenschaftlichen Verfassung, die schon jetzt in den Dienst des gemeinen Wesens gestellt ist oder in Zukunft gestellt werden kann. Es sind nur Beispiele, wenn wir Innungen, Gewerkschaften, Berufsgenossenschaften, Kammern aller Art, Betriebs- und Wirtschaftsräte, die Verbände der sozialen Fürsorge und nicht zuletzt die Gemeinden niederer und höherer Ordnung erwähnen. Eine der nächsten Aufgaben wird es sein müssen, zu prüfen, welche von ihnen und in welcher Zusammenschichtung sie geeignet sind, in Gemeinschaft mit den noch lebensfähigen und lebenswilligen Ländern den Grundstock zu bilden, auf dem sich als eine Krone der Selbstverwaltung die Volksvertretung der Zukunft wird aufbauen lassen.

Dabei scheint mir zweierlei der Beachtung wert zu sein. 
Wenn sich nicht das alte Spiel des Parteienstaats erneuern soll, so dürfen Auswahl und Gestaltung der korporativen Keimzellen des Staats nur so geschehen, dass sie weder Angriffsfläche, noch, wie leider bisher, Instrument politischen Parteitreibens sein können. Die „Reinigung“ der Selbstverwaltung darf nicht nur darin bestehen, dass die Ämter der Selbstverwaltungskörper von ungeeigneten Trägern befreit werden, sondern noch mehr darin, dass man jene Körperschaften durch richtigere Zuständigkeitsabgrenzung verhindert, etwas anders zu tun als sachliche und fachliche Arbeit zu leisten. Auf Kampfgenossenschaften, mögen sie politische oder wirtschaftliche Ziele verfolgen, kann sich kein Staat aufbauen, und die Gewerkschaften zum Beispiel können als Bausteine der neuen Verfassung nicht eher verwendet werden, als sie den Charakter der Kampfgenossenschaften abgestreift haben.

Zum andern: Selbstverwaltung darf nicht mehr betrachtet werden als Gegensatz zur Staatsverwaltung, sondern als eine besondere Form der Staatsverwaltung selbst, nämlich als diejenige, bei der das Volk in freier Arbeit an der Tätigkeit des Staates teilnimmt, um dadurch zu staatlichem Gemeinsinn erzogen zu werden. Nur so hat der Freiherr vom Stein, nur so haben Männer wie Lorenz $v$. Stein und Gneist das Wesen der Selbstverwaltung verstanden. In besonderer Weise gilt dies für die Länder im künftigen Reiche. Der Sinn des Bundesstaats liegt darin, dass die Einzelstaaten nicht bloße Bezirke für die Tätigkeit einer zentralisierten Reichsbürokratie, sondern mit Eigenleben erfüllte "Glieder" des Reiches sind, aber eben deshalb nicht etwas anderes als das Reich, sondern Fleisch und Blut vom Reiche selbst. In dem Zusammenwirken von Reich, Ländern und Selbstverwaltungskörper soll der eine unteilbare deutsche Staat seine Arbeit für die deutsche Zukunft verrichten.

Vor sechs Jahren habe ich in einer Rektoratsrede, die sich mit dem Missgebilde des Parteienstaats beschäftigte, ${ }^{6}$ folgendes gesagt: „Wenn es gelingt, die sich mit elementarer Gewalt aus dem Schoße des Volks herausringenden Kräfte einer personell und territorial reich gegliederten neuen Selbstverwaltung wirtschaftlicher und geistiger Art in den Dienst des Staates zu zwingen, der durch sie nicht zerstört, sondern zusammengehalten werden soll, - wenn der Staat nicht abgebaut, sondern im Gegenteil von unten her aufgebaut sein wird, dann wird er zum echten Organismus geworden sein, wo ,alles sich zum Ganzen webt, eins in dem andern wirkt und lebt'.“ Ich fügte hinzu: „Möge ein glückliches Geschlecht mit leibli-

6 Die Staatsverfassung und die politischen Parteien, 1927, 2. Aufl. 1930 [in diesem Band S. 219]. 
chen Augen sehen, was uns Heutigen nur im Geiste als ein schönes Bild der Zukunft vorschweben kann!" Heute lebe ich des fröhlichen Glaubens, dass mir ein gnädiges Geschick noch vergönnen wird, selbst zu sehen, was ich damals nur als schönen Traum zu deuten wagte. 


\section{Text 15 \\ Im Namen der Schriftleitung ${ }^{1}$}

Die Umwälzung der deutschen Verfassung, die sich in den letzten Wochen vollzogen hat und in naher Zukunft weiter auswirken wird, stellt auch die Wissenschaft des Staatsrechts vor große neue Aufgaben. Denn die Staatsrechtslehre kann sich nicht damit begnügen, sich ordnend und wertend um den Rechtsstoff zu mühen, den eine abgeschlossene Entwicklung geschaffen hat. Es ist heute vor allem ihres Amtes, eine im Werden begriffene verfassungsrechtliche Neubildung Schritt für Schritt verstehend und helfend, hier anfeuernd, dort warnend zu begleiten

Das Archiv des öffentlichen Rechts ist zu der Zeit begründet worden, da das Deutsche Reich Kaiser Wilhelms I. und Bismarcks auf die Höhe seiner Macht gelangt war. In einer ununterbrochenen Arbeit von beinahe fünf Jahrzehnten ist es unserer Zeitschrift dank dem Weitblicke ihrer Begründer und der treuen Mitarbeit vieler hervorragender Gelehrter möglich gewesen, einen bedeutenden Anteil zu nehmen an dem rühmlichen Aufschwung der deutschen Staatsrechtswissenschaft und durch sie an der Durchbildung der öffentlichen Rechtseinrichtungen unseres Volkes. In der langen Reihe der Bände des Archivs spiegeln sich Aufstieg und Niedergang, Glück und Not des Reichs, Zusammenbruch und erste Aufbauversuche, aber auch der Wechsel der Staatsanschauungen und die Wandelungen in der Methode staatsrechtlicher Arbeit. Eine neue Zeit verlangt neue Kräfte und neue Werkzeuge für deren Wirkung, und sie darf doch nicht achtlos beiseiteschieben, was von überkommenem Gedankengute brauchbar ist zur Einfügung in den geistigen Neubau der Zukunft. Die gegenwärtigen Herausgeber des Archivs sind sich der schweren Verantwortung bewußt, die ihnen die neue Lage auferlegt. Sie brauchen mit keiner Tradition zu brechen. Wie ihre Vorgänger und sie selbst den Gang der Verfassungsgestaltung in der Vergangenheit, so wollen sie auch die große Bewegung der Gegenwart mit dem sittlichen Ernste und der strengen Wahrhaftigkeit verfolgen, die sich für eine wissenschaftliche Zeitschrift geziemen. Als deutsche Männer sind sie durchdrungen von dem festen Glauben an die

1 [In: Archiv des öffentlichen Rechts 63 (1934), S.1-2; dazu vgl. Lothar Becker, ,Schritte auf einer abschüssigen Bahn'. Das Archiv des öffentlichen Rechts (AöR) und die Staatsrechtswissenschaft im Dritten Reich, Tübingen 1999]. 
unzerstörbaren Kräfte der deutschen Nation und leben der frohen Zuversicht, daß das Reich der Zukunft den altüberlieferten Schatz deutscher Rechtsgedanken als treuer Hüter bewahren und ihn, den Erfordernissen der Zeit entsprechend, mehren werde zum Heile des Vaterlandes. 
Teil V: Letzte Texte 


\section{Text 16 \\ [Nachruf] Viktor Bruns $\dagger^{1}$}

Nachdem in den letzten Jahren der Tod wiederholt schmerzlich empfundene Lücken in den Kreis der Mitarbeiter unserer Zeitschrift gerissen, hat diese jetzt den schwersten Verlust erfahren, den sie und das Institut, unter dessen Verantwortung sie erscheint, erleiden konnten. Am 18. September 1943 verstarb der Direktor des Instituts, sein und der Zeitschrift Begründer und langjähriger erster Leiter. Einer tückischen Krankheit, der er lange Zeit hindurch heroischen Widerstand geleistet hatte, ist er nach schwerem Leiden erlegen.

Bruns wurde am 30. Dezember 1884 in Tübingen geboren. Er entstammte von Vaters- wie von Muttersseite Gelehrtenfamilien, deren Glieder in mehreren Generationen Lehrstühle an deutschen Hochschulen rühmlich bekleidet haben. Sein Vater war der namentlich als Kriegschirurg berühmt gewordene Professor der Medizin Paul Bruns, seine Mutter war eine Tochter des bekannten Theologen und Kanzlers der Universität Tübingen Karl von Weizsäcker. Viktor Bruns studierte in Tübingen und Leipzig die Rechtswissenschaft, bestand 1908 in Tübingen die erste Staatsprüfung für den Justizdienst und promovierte ebendort 1910 auf Grund einer Dissertation über den „Besitzerwerb durch Interessenvertreter“ (erschienen bei J. C. B. Mohr 1910). Noch im gleichen Jahre wurde er, ohne den Umweg über die Privatdozentur gemacht zu haben, als außerordentlicher Professor an die Universität Genf berufen. Im Jahre 1912 nahm er einen Ruf als Extraordinarius in der Juristenfakultät der Universität Berlin an, in deren Mitte er dann 1920 zum ordentlichen Professor aufgestiegen ist. Während des ersten Weltkriegs war er mehrere Jahre in Stuttgart als Zivilreferent beim Stellvertretenden Generalkommando des XIII. Armeekorps tätig gewesen.

1 [In: Zeitschrift für ausländisches öffentliches Recht und Völkerrecht 11 (1942), S. 324a-324d; Triepel hat knappe biographische Würdigungen und Nekrologe für Ferdinand von Martitz, Wilhelm Kahl, Philipp Zorn, Ernst Schmitz, Karl Binding und Bruns verfasst: für Lehrer, Kollegen und Schüler. Dieser Nekrolog, einer der wenigen späten Texte, wurde auch deshalb aufgenommen, weil Triepel sich hier zum Institut für ausländisches öffentliches Recht und Völkerrecht äußert, das 1924 gegründet wurde und heute im Heidelberger Max Planck-Institut fortlebt, in dessen Schriftenreihe die vorliegende Triepel-Textsammlung steht.]. 
Bruns ist wie viele deutsche Lehrer des Völkerrechts erst nach längerer Arbeit auf anderen Gebieten der Rechtswissenschaft in nähere Fühlung mit dem internationalen Rechte gelangt. Er war zunächst, wie seine Erstlingsschrift zeigt, Zivilist und hat auch jahrelang, in Genf wie in Berlin, zivilrechtliche Vorlesungen gehalten, hat auch als Vertreter des römischen und bürgerlichen Rechts seinen Sitz in der Kommission für die erste juristische Staatsprüfung eingenommen. Den Übergang zum Völkerrechte bildete für ihn das Staatsrecht. Aus den Jahren 1918 bis 1922 stammen verschiedene Monographien und Aufsätze, die sich mit Fragen des deutschen Verfassungsrechts beschäftigen; wir erwähnen von ihnen nur die interessante Studie über „Sondervertretung deutscher Bundesstaaten bei den Friedensverhandlungen" aus dem Jahre 1918. Allmählich ist dann Bruns in Lehre und Forschung fast ausschließlich dem Völkerrechte dienstbar geworden. Von seiner unablässigen Arbeit auf diesem Felde legen nicht nur die im Buchhandel erschienenen Schriften, unter anderen über „Die Volksabstimmung im Saargebiet“ und „Deutschlands Gleichberechtigung als Rechtsproblem“ (beide aus dem Jahre 1934), sondern vor allem eine ungewöhnlich große Reihe von Beiträgen zu wissenschaftlichen und politischen Zeitschriften beredtes Zeugnis ab. Wohl die wertvollsten von ihnen hat unsere Zeitschrift bringen können. Wir weisen vor allem auf die tiefdringende und neue Wege einschlagende Abhandlung über „Völkerrecht als Rechtsordnung“ hin, von der ein erster Teil in Band I (1929), ein zweiter in Band IV (1934) erschienen ist, ferner auf den Aufsatz über „Die Tschechoslowakei auf der Pariser Friedenskonferenz" in Band VII (1937) und seine Fortsetzung in Band VIII (1938); der Aufsatz hat zu einer lebhaften Polemik Anlaß geboten. Noch während des jetzigen Krieges und auf ihn bezüglich ist die Untersuchung: „Der britische Wirtschaftskrieg und das geltende Seekriegsrecht" (Band X, 1940) und die in dem jetzt erscheinenden Bande enthaltene Antikritik: „Die britische Seesperre und die Neutralen" verfaßt worden. Manche dieser Arbeiten sind aus Vorträgen entstanden, die Bruns gehalten hat, vor allem in der Akademie für Deutsches Recht, in deren Ausschuß für Völkerrecht er lange Zeit den Vorsitz führte, ferner in einem von der Deutschen Gesellschaft für Wehrpolitik und Wehrwissenschaften, deren Ehrenmitglied er war, eingesetzten, dem Studium seekriegsrechtlicher Fragen gewidmeten Ausschusse, aber auch im Auslande, so an der Académie de droit international im Haag und am Johnsoninstitut in Stockholm. Er war ein geschätzter Vortragsredner und ließ sich auch gern für solche Aufgabe gewinnen. Alles, was Bruns geschrieben hat, ist von tiefem wissenschaftlichem Ernste getragen und beruht auf eindringenden juristischen und historischen Vorarbeiten. Er war 
kein eilfertiger Schriftsteller, sondern ließ alles erst gründlich ausreifen, ehe er zur Feder griff. Überall tritt bei ihm die hohe Achtung vor der Heiligkeit der Rechtsidee zutage, deren Wirksamkeit er mit großem Nachdrucke auch für die gegenseitigen Beziehungen der Staaten forderte, wie er denn auch in vielen Veröffentlichungen einen heißen Kampf für die unserm Vaterlande so lange versagte Gleichberechtigung im Kreise der Nationen geführt hat.

Die Fülle seiner Kenntnisse auf dem Gebiete des Völkerrechts und die Lauterkeit seiner Gesinnung fand ihre amtliche Anerkennung vor allem darin, daß Bruns mehrfach die Rolle eines Mitglieds internationaler Schieds- oder Gerichtshöfe oder eines Staatsvertreters in internationalen Prozessen zufiel. Seit langer Zeit stand er auf der Liste der Mitglieder des Ständigen Schiedshofs im Haag. Von 1927 bis 1931 war er deutscher Richter am Deutsch-polnischen und am Deutsch-tschechoslowakischen Gemischten Schiedsgericht, in den Jahren 1928, 1931 und 1932 nationaler Richter in Rechtsstreitigkeiten der Freien Stadt Danzig beim Ständigen Internationalen Gerichtshof im Haag, und noch in heißen Sommerwochen des Jahres 1942 leitete er, schon recht krank und den körperlichen Anstrengungen fast erliegend, als Vorsitzender die Verhandlungen des Schiedsgerichts, das in Wien tagte, um Streitigkeiten zwischen Bulgarien und Rumänien zu schlichten, die aus der Abtretung der Süd-Dobrudscha entstanden waren. Die Deutsche Reichsregierung betraute ihn wiederholt mit ihrer Vertretung vor der Cour permanente de justice internationale im Haag: im Jahre 1931 im Verfahren wegen der deutschösterreichischen Zollunion, 1933 im Prozesse wegen der Anwendung der polnischen Agrarreform auf die deutsche Minderheit, auch war er 1937 in dem deutsch-litauischen Schiedsprozeß über die Staatsangehörigkeit von Memeldeutschen als Staatsvertreter tätig. Seit Ausbruch des gegenwärtigen Krieges fungierte er als Richter am Berliner Oberprisenhof.

Das Herzstück aber von Bruns' wissenschaftlicher Lebensarbeit bildet neben seinem Lehramt an der Universität die zu Ende des Jahres 1924 erfolgende Gründung und die langjährige Direktion des der Kaiser WilhelmGesellschaft zur Förderung der Wissenschaften angehörigen Instituts für ausländisches öffentliches Recht und Völkerrecht, eines der wenigen geisteswissenschaftlichen Institute dieser für die deutsche Wissenschaft so bedeutsamen Vereinigung. Die Bruns eigene unvergleichliche organisatorische Begabung zeigte sich in der sozusagen aus dem Nichts erfolgenden, an kein Vorbild angelehnten Errichtung und Ausgestaltung der Anstalt. Der gründlich erwogene Plan ging auf Herstellung einer Einrichtung, die erstlich der wissenschaftlichen Vorberatung und Unterstützung einer auf 
Völkerrecht basierenden Staatspraxis, insbesondere der wissenschaftlichen Beihilfe bei der Vorbereitung großer internationaler Schiedsprozesse dienen und als Gutachter- und Auskunftsstelle namentlich den Zentralbehörden zur Verfügung stehen sollte. Sodann aber war das Institut, um mit Bruns' eigenen Worten zu sprechen, „dazu bestimmt, durch Gemeinschaftsarbeit einer größeren Anzahl wissenschaftlich besonders geschulter und befähigter Mitarbeiter das für die Theorie wie für die Praxis gleich wichtige völkerrechtliche Quellenmaterial nach einheitlichem Plan und System zu durchforschen und die gesamten in diesem Material enthaltenen rechtlichen und politischen allgemeinen Grundsätze, Einzelregeln und Einzelentscheidungen in systematisch geordneter Form der allgemeinen Benutzung zur Verfügung zu stellen“. Nicht weniger meisterlich als die Festlegung der Ziele der neuen Schöpfung war es, wie Bruns seine Mitarbeiter gewann und ihren Kreis teils festhielt, teils erweiterte, wie er die jüngeren Kräfte der Anstalt für ihre Arbeit zu erziehen und zu begeistern verstand, wie er die Beziehungen des Instituts zu hohen Behörden des Reichs, aber auch zu Männern und Instituten der Wissenschaft des Auslandes zu pflegen wußte. Das Ansehen, das dem Institut schon nach wenigen Jahren innerhalb und außerhalb der deutschen Grenzen zuteil geworden ist - es diente sogar bald ausländischen Gründungen zum Vorbilde -, beruht zu allermeist auf der Persönlichkeit seines Gründers und ersten Direktors.

Von der wissenschaftlichen Arbeit, die im Institut geleistet worden ist, legen die großen allesamt Bruns' Initiative entsprungenen und unter seiner obersten Leitung vollendeten Publikationen aus zwei Jahrzehnten Zeugnis ab: von unserer Zeitschrift abgesehen, in erster Reihe die unter dem Namen „Fontes Iuris Gentium“ zusammengefaßten vielbändigen Sammlungen diplomatischer Aktenstücke und völkerrechtlicher Entscheidungen von Gerichtshöfen, Schiedshöfen und Schiedsgerichten; übrigens enthalten die von Bruns verfaßten Vorreden zu mehreren Serien der Fontes interessante und für seine Grundauffassung höchst charakteristische Ausführungen über das Wesen des Völkerrechts, dessen Quellen und die Methode der Rechtsfindung auf diesem Gebiete. Ferner gehören hierhin die bisher auf drei Bände angewachsene Sammlung der politischen Verträge, die aus sechsundzwanzig Bänden bestehenden „Beiträge zum ausländischen öffentlichen Recht und Völkerrecht" und die zehn in Verbindung mit der Fédération internationale herausgegebenen Hefte der „Preßgesetze des Erdballs“. Auch der jetzt 150 Jahre alte, von G. F. v. Martens begründete Recueil de Traités hat seit längerer Zeit unter dem Dache des Instituts eine Heimstätte gefunden: Daß alle diese Arbeit durch eine sinnreich ange- 
legte und vortrefflich geleitete, allmählich zu erstaunlich großem Umfange gediehene Bibliothek wesentlich gefördert worden ist, bedarf besonderer Hervorhebung.

So ist es ein von Mühe und Arbeit erfülltes, aber auch mit Erfolg reich gesegnetes Gelehrtenleben gewesen, dem der Tod jetzt ein noch zu frühes Ende bereitet hat. Allein dieses Leben hatte neben den wissenschaftlichen auch anderen, namentlich künstlerischen Interessen Raum gelassen. Bruns hatte sein schönes Heim in Zehlendorf, in Gemeinschaft mit seiner ihm geistesverwandten treuen Lebensgefährtin, einer Tochter von Wilhelm v. Bode, mit vornehmem Geschmacke eingerichtet. Und er wußte sein Haus in gesunden Tagen seinen Freunden zu einer Stätte edler Geselligkeit zu machen. Die behäbige Ruhe seines Wesens, das durchaus die Züge des echten Schwaben trug, die Weite seines Gesichtskreises und sein feiner Humor machten ihn zu einem liebenswerten Gesellschafter. Mehr als dies aber waren es die Güte seines Herzens, das Wohlwollen, mit dem er jeden berechtigten Wunsch entgegennahm, die verständnisvolle Teilnahme, mit der er jede ehrliche Arbeit Mitstrebender verfolgte, nicht zuletzt sein hervorragendes taktisches Geschick in der Behandlung von Menschen und Dingen, was den Gewinn seiner Freundschaft als Geschenk erscheinen ließ. Alle, die ihm bei seinem Werke helfen durften, werden in Dankbarkeit und Treue das Andenken an den Gelehrten und Menschen Viktor Bruns bis ans Ende ihrer Tage in ihrem Herzen bewahren. Wer ihn gekannt hat, wird den Schmerz ermessen können, der den Verfasser dieses Nachrufs bewegt. Denn ihm war Bruns seit dessen Jugendzeit vertraut, er hat seinen Aufstieg mit stetigem warmen Anteil begleitet und muß es nun als alter Mann - ach, nicht zum ersten Male! - erleben, daß ihm ein hochbegabter und anhänglicher Schüler im Tode vorangeht. 


\section{Text 17 \\ [Vom Stil des Rechts. Schlusskapitel] ${ }^{1}$}

Es scheint mir keinem Zweifel zu unterliegen, daß sich der juristische Laie den in unserer Abhandlung ${ }^{2}$ aufgeworfenen Fragen völlig anders gegenüberstellt als der mit der Rechtsordnung vertraute Jurist. Der Laie, der vielfach mit dem Rechte nur dann in Berührung kommt, wenn ihn die unangenehmen Seiten des Lebens dazu führen, der sogar manchmal, wie ich habe beobachten können, in Strafrecht und Strafprozeß das Ganze des Rechts beschlossen glaubt, wird schon die Fragestellung unseres Buches, die auf das Vorhandensein ästhetischer Reize des Rechts hinweist, und die Anwendung des Stilbegriffs auf das Rechtliche mit Verblüffung hinnehmen. Aber selbst der Jurist wird sich nicht anders verhalten, solange er nicht mit dem Geiste einer Rechtsordnung in ganz intime Fühlung gekommen ist. Erst wenn dies geschehen ist, kann sich ihm die Tatsache erschließen, daß auch der Formenbau einer Rechtsordnung das Beiwort „schön“ verdienen kann und ästhetische Bewunderung, ja Begeisterung zu erwecken vermag. Wem von uns in seiner Jugend das Glück zuteil geworden ist, unter dem Katheder großer Rechtslehrer zu sitzen, der wird sich leicht daran erinnern, welchen Eindruck es auf ihn machte, wenn ein hervorragend Kundiger von den Reizen des Stoffes sprach, den er behandelte. So scheint mir im Gebiete des Rechts die Rangfolge von Schönheit und Wahrheit anders zu sein als auf anderen Gebieten, wenigstens, wenn wir hier Schillers Ästhetik zugrunde legen wollen. Dieser rief, wie wir früher erwähnt haben, ${ }^{3}$ in den „Künstlern“ aus:

\section{„Nur durch das Morgentor des Schönen \\ Drangst Du in der Erkenntnis Land“.}

Aber im Bereich des Rechtlichen steht es wohl gerade umgekehrt, so, daß man nur durch das Morgentor der Erkenntnis in das Land des Schönen einzudringen vermag.

1 [In: Heinrich Triepel, Vom Stil des Rechts. Beiträge zu einer Ästhetik, Heidelberg 1947, S. 149-153].

2 [Vom Stil des Rechts].

3 [Vom Stil des Rechts, S. 34, vgl. 25 ff.]. 
Freilich hat es die Ästhetik bekanntlich auch mit dem Häßlichen zu tun. Und auch im Gebiete des Rechtlichen gibt es und gab es, wie wir schon im Vorübergehen gelegentlich gesehen haben, da und dort etwas Häßliches. Gewiß, wie eine Abweichung vom Normalen auch durch Steigerung seiner guten Eigenschaften ein Objekt noch nicht schön macht, so bewirkt auch eine sich sozusagen nach unten vollziehende Normenwidrigkeit eines rechtlichen Tatbestandes noch nicht, daß man ihn als häßlich bezeichnen darf. Um dies zu bewirken, muß die Normenwidrigkeit einen so hohen Grad erreicht haben, daß unser ästhetisches Gefühl in besonders starkem Maße abgestoßen, mit Ekel, mit Abscheu erfüllt wird. Und wie es in der Begriffswelt des Schönen ein Zusatz von der Seite des Sittlichen war, der einem Rechtsakte die Bezeichnung „schön“ verlieh, so ist hier, wo es sich um das Häßliche handelt, ein starker Mangel an Sittlichkeit oder ein hohes Maß von Unsittlichkeit notwendig, um es zu rechtfertigen, daß wir einem Akt, insbesondere einem Rechtsakt, die Eigenschaft, häßlich zu sein, zusprechen. Auch in dieser Beziehung wird das Urteil des Laien von dem des Rechtskundigen leicht abweichen. Nur so ist es zu erklären, daß ein großer Teil der Volksgenossen vieles Häßliche in der Rechtspflege zur Zeit des Nationalsozialismus mit geringerer Erregung hingenommen hat, als sie bei den Männern sich einstellte, die von den empörenden Rechtswidrigkeiten erfuhren, die sich ein in die Irre gehender Parteigeist auf dem Boden der deutschen Rechtspflege hat zuschulden kommen lassen ${ }^{4}$. Es wurde ja auch dafür gesorgt, daß außer den nächstbetroffenen Personen, seien es die Prozeßparteien, Anwälte oder Richter, nur selten jemand von jenen Ungerechtigkeiten, außer vom Hörensagen, erfuhr. In der Tat aber gibt es wohl keine Periode der Rechtsgeschichte, in der sich der Staat oder der Personenkreis, der sich als Staat ausgab, oder der sich ihn zu beherrschen vermaß, so sehr mit der Vornahme von Akten befleckt hat, die als häßlich anzusehen sind, wie die Zeit des Nationalsozialismus in Deutschland, des Faschismus in Italien. Beispiele lassen sich zur Genüge anführen. Sie sind sowohl im Bereiche der Gesetzgebung wie insbesondere in dem der Rechtspflege, der Justiz zu finden, wo es eine widernatürliche Vermischung von Verwaltung und Rechtspflege den Gewalthabern möglich machte, die Unabhängigkeit des Richtertums zu vernichten und unter dem Schein eines rechtlichen Verfahrens für politische Herrschaft auch für Rachegelüste einen Betätigungsraum zu schaffen. Die Gesetzgebung, die sich gegen Person und Eigentum der Juden richtete, und wie sich später

4 S. zum Folgenden F. v. Hippel, Die nationalsozialistische Herrschaftsordnung als Warnung und Lehre (1946). 
gezeigt hat, vielfach der Bereicherung von „Parteibonzen“ diente, ist ein Beispiel dafür, daß es auch häßliche Gesetze geben kann. Besondere Gesetze sorgten dafür, daß sogar offenkundige Widerrechtlichkeiten mit dem Mantel der Liebe zugedeckt werden konnten. Wenn zum Beispiel das Gesetz über Gewährung von Straffreiheit vom 7. August 1934 (RGBl. I S. 769) $)^{5}$ bestimmte: „Straftaten, zu denen sich der Täter durch Übereifer im Kampfe für den nationalsozialistischen Gedanken" habe hinreißen lassen, sowie „sonstige Beleidigungen und Körperverletzungen im politischen Meinungsstreit" hätten straffrei zu bleiben, so war dies ein bequemes Mittel für die Gewalthaber und ihre Gehilfen, selbst flagrante Amtsvergehen, an politischen Gegnern begangen, straflos zu machen. Am abstoßendsten vielleicht wirkt das von Adolf Hitler unterzeichnete Regierungsgesetz vom 3. Juli 1934 (RGBl. I S. 529), wodurch die von einigen Parteigenossen vorgenommene Auflehnung gegen die Partei und ihren Führer als Hoch- und Landesverrat und die dagegen am 30. Juni 1934 und an den folgenden Tagen vorgenommenen „Maßnahmen“ - in Wirklichkeit waren es gemeine, aus Rachsucht verübte Verbrechen - zur berechtigten ,Staatsnotwehr“ gestempelt wurden. Es ist wohl in der Rechtsgeschichte einzig dastehend gewesen, daß ein Mörder, der zur Zeit gerade Regierungschef war, die von ihm und seinen Gehilfen verübten Missetaten auf „legalem“ Wege der Bestrafung entzog, durch ein Gesetz, dessen ungeheuerliche Unsittlichkeiten und innere Unmöglichkeit dazu angetan waren, es von Anfang an als null und nichtig erscheinen zu lassen. Auch konnte es damals einem Parteihäuptling leicht gelingen, ein gegen einen Parteigenossen ergangenes Zivilurteil durch einen Einspruch der Vollstreckung zu entziehen oder einen Parteigenossen, der sich eine strafbare Handlung hatte zuschulden kommen lassen, durch einen Druck auf Staatsanwalt oder Richter der verdienten Strafe zu entwinden. Dabei war der Terror, der dem Richter gegenüber angewandt wurde, um ihn geradeswegs zu einer Rechtsbeugung zu zwingen, so stark, daß ihm mit Mühe Widerstand geleistet werden konnte. Es ist vorgekommen, daß ein Parteigewaltiger die Fortführung einer Strafgerichtsverhandlung mit einem Faustschlage auf den Gerichtstisch unmöglich machte, und daß es der Richter nicht wagte, die Verhandlung fortzusetzen und - was ihm sofort sein Amt gekostet haben würde - den Störenfried mit einer Ordnungshaftstrafe zu belegen. Auch andere Häßlichkeiten verunstalten das Bild der Strafrechtspflege dieser Zeit. Es war ein widerwärtiges Gegenstück zu einer ,,vornehmen“ Verhandlungsleitung, daß sich der Vorsitzende in der Verhandlung, die vor

5 [„Gesetz über die Staatsnotwehr“]. 
dem Volksgerichtshof gegen die Attentäter des 20. Juli 1944 stattfand, die rohesten Beschimpfungen der Angeklagten, die ihm gegenüber wehrlos waren, zuschulden kommen ließ. Daß man sich nicht scheute, den Vorgang der Strafvollstreckung in diesem Verfahren, nämlich die Vollziehung der Hinrichtungen durch Erhängen, kinematographisch aufzunehmen, um durch wiederholte Vorführung des Films der Rachgier des „Führers“ Genüge zu leisten, gehört wohl zu den hässlichsten Vorkommnissen der deutschen Strafrechtsgeschichte. Und daß man der Witwe und Erbin eines wegen politischer Vergehen erhängten „Volksschädlings“ auf Anweisung der Reichsanwaltschaft beim Volksgerichtshof als der Vollstreckungsbehörde durch die Gerichtskasse eine spezifizierte Gebühren- und Kostenrechnung über die Vollziehung des Urteils zustellen ließ, war nicht bloß ein ins grotesk-lächerliche gesteigerter Formalismus, sondern eine abscheuliche Roheit. Alles dies ließe sich leider durch viele Einzelheiten über die an Untersuchungsgefangenen vorgenommenen Folterungen ergänzen, die von dem Opfer ein Geständnis oder die Nennung von angeblich Mitschuldigen erpressen sollten. Die Massenhaftigkeit der Amtsverbrechen und die Tatsache, daß manche in dieser Periode ergangenen Strafurteile schwerlich anders denn als Justizmorde bezeichnet werden können, macht das Bild dieser "Strafrechtspflege“ nur noch abscheulicher.

Es ist für einen deutschen Juristen beschämend, daß er genötigt ist, dieses Kapitel der Rechtsgeschichte des eigenen Vaterlandes zu schreiben. Diese Aufgabe wird nur etwas erträglicher, wenn man mit ihr die Arbeit vergleicht, die Voltaire im 18. Jahrhundert zur Schilderung von häßlichen Vorkommnissen der französischen Rechtspflege aufwenden mußte. Auf alle Fälle zwingt uns die Gerechtigkeit, auch über das Hässliche, das die unglücklichste Zeit der deutschen Geschichte im Rechtsleben hervorgebracht hat, zu berichten. Wir müssen uns damit trösten, daß gerade das deutsche Recht, wenn es von der ästhetischen Seite her gesehen wird, so viel des Schönen bietet - wir haben es durch die verschiedensten Stilperioden, die der Gotik, der Renaissance, des Barock, des Rokoko und des Biedermeier verfolgen können -, daß daneben die häßlichen Flecken, die in der jüngsten Vergangenheit aufgetreten sind, einigermaßen verblassen. 


\section{Text 18 \\ Zweierlei Föderalismus ${ }^{1}$}

Der Sinn, in dem wir das Wort „Föderalismus“ verstehen, ist im allgemeinen klar. Wir denken dabei an eine Richtung des politischen Lebens einer Gesamtnation, bei der sich die als gesonderte politische Körper, d. h. als Staaten organisierten Teile des Ganzen zueinander wie Glieder eines Bundes verhalten.

Allein, man soll dabei nicht übersehen, daß dieser Föderalismus in mehreren Färbungen erscheint. Ihr Unterschied besteht in der Verschiedenheit der Stärke, in der sie auf die Einheit des Ganzen gerichtet sind. In der einen Färbung kann man den Föderalismus als zentripetalen, in der anderen als zentrifugalen bezeichnen. Vielleicht könnte man auch einerseits von positivem, andererseits von negativem Föderalismus sprechen. Bei jenem ist die Richtung auf die politische Einheit der Gesamtnation stark, bei diesem ist sie nur schwach betont; vielmehr ist hier der Nachdruck auf die politische Selbständigkeit der einzelnen Teile des Gesamtkörpers gelegt. Rechtlich am schärfsten ausgeprägt erscheint der zentripetale Förderalismus beim sogenannten Bundesstaate, d. h. bei einer Staatsbildung, bei der eine Reihe von Einzelstaaten wieder zu einem sie zur Einheit zusammenfassenden Gesamtstaate mit einer Herrschaft nicht nur über die Bundesglieder, sondern auch über die Angehörigen der Einzelstaaten vereinigt ist, wie in der Nordamerikanischen Union, in der Schweizer Eidgenossenschaft seit 1848, im Deutschen Reiche nach der Verfassung von 1871, aber auch nach der Weimarer Reichsverfassung von 1919. Der zentrifugale Föderalismus ist am stärksten verwirklicht beim „bloßen“ Staatenbunde, d. h. bei einer Staatenbildung, bei welcher der Zusammenschluss mehrer Staaten „nur“ die Gestalt eines vertragsmäßig durch einen völkerrechtlichen

1 [In: Süddeutsche Juristen-Zeitung 2 (1947), S. 150-151; der Abdruck enthält die redaktionelle Fußnote: „Der nachstehende Beitrag ist die letzte staatsrechtliche Äußerung des Verstorbenen, die uns kurze Zeit vor seinem Tode zuging. Der Nachruf auf den Verfasser, den ein im Ausland lebender Schüler des Verstorbenen übernommen hat, hoffen wir im nächsten Heft veröffentlichen zu können." Triepel zog sich in den letzten Kriegs- und Lebensjahren fast erblindet aus Berlin in sein oberbayerisches Ferienhaus nach Grainau zurück. Seine Arbeitsmöglichkeiten waren stark eingeschränkt. Der vorliegende Text gibt einen ungefähren Eindruck von Triepels verfassungspolitischer Wahrnehmung der ersten Nachkriegszeit.]. 
Akt gebildeten Vereins von Staaten mit bloßer Vereinsgewalt über dessen Mitglieder erhalten hat, und nicht bis zur Zusammenfassung in einem neuen Gesamtstaate gediehen ist. In einem weiten Sinne genommen steht mithin Föderalismus nicht im Gegensatz zur Erscheinung des Bundesstaats, umfasst vielmehr sowohl den Bundesstaat als auch den Staatenbund, wie denn die Amerikaner von Anfang an bis heute die Form ihres Bundesstaats immer wieder als "federal“ government und die Anhänger dieser Staatsform Föderalisten genannt haben.

In der deutschen Staatsrechtslehre hat man sich freilich mehr und mehr daran gewöhnt, den Ausdruck „Föderalismus“ auf das zu beschränken, was im Staatenbunde verkörpert ist und sich als Gegensatz dazu nicht nur den Bundesstaat, sondern den Einheitsstaat zu denken, also als Gegensatz zu föderalistisch unitarisch zu nehmen. Insbesondere ist dies nach dem Vorbilde von Constantin Frantz, diesem fanatischen Gegner des nach seiner Meinung dem Einheitsstaate zusteuernden Deutschen Reichs Bismarckscher Prägung geschehen.

Macht man sich von dieser Gegensatzbildung unabhängig, und lässt die Trennlinie zwischen zentripetal und zentrifugal sich nicht mit der zwischen Bundesstaat und Staatenbund verlaufenden decken, so kann der Unterschied zwischen zentripetal und zentrifugal, positiv und negativ auch innerhalb der Elemente sowohl des Bundesstaats, wie auch des Staatenbundes erscheinen. Anders ausgedrückt: der Bundesstaat kann mit staatenbündischen, der Staatenbund mit bundesstaatlichen Elementen durchsetzt werden. Wenn z. B. in den Vereinigten Staaten von Amerika die am schärfsten von Calhoun gepredigte Theorie der Nullifikation und Sezession für die Nordamerikanische Union Recht behalten hätte, - was durch den Ausgang des Bürgerkriegs von 1861-1865 endgültig verhindert worden ist - das heißt eine Lehre, wonach sich ein in die Minderheit gedrängter Einzelstaat weigern kann, ein Bundesgesetz durch die Aufnahme in das Landesrecht gültig zu machen, ja sogar aus dem Bundesverhältnis ausscheiden darf, so wäre das Zentrifugale über das Zentripetale Herr geworden. Umgekehrt wäre innerhalb des deutschen Bundes von 1815, eines typischen Staatenbundes, der in den Reformplänen in der Mitte des Jahrhunderts aufgetretene Gedanke, die Bundesorganisation durch ein gesamtdeutsches Parlament zu ergänzen, verwirklicht worden, so hätte man die Einrichtung des Bundes - was in der Tat die Absicht war - durch Einfügung eines zentripetalen Elements wesentlich verschoben.

Es ergibt sich aus dem bisher Gesagten ohne weiteres, daß die Antwort auf die Frage nach der künftigen Verfassung Deutschlands unvollständig ist, wenn sie lediglich aus dem Worte Föderalismus oder föderalistisch be- 
steht. Es kommt entscheidend darauf an, in welcher der beiden Richtungen, zentripetal oder zentrifugal, dieser Föderalismus verlaufen wird. Die Entscheidung wird wesentlich davon abhängen, welchem Subjekte die Feststellung der Verfassung überlassen werden wird. Erfolgt sie nur über einen Vertrag zwischen den Länderregierungen, so ist zu erwarten, daß das zentrifugale Element angesichts der hier zu erwartenden Abneigung gegenüber der hier zulande übertriebenen Zentralisation des letzten Jahrzehnts und die verständliche Neigung zu einer politischen Selbständigkeit der Einzelstaaten zu einer starken Betonung des bloß Vertragsmäßigen, im schlimmsten Fall zur Einführung von Nullifikation und der Möglichkeit von Sezession, also zu einer Löslichkeit des über die Verfassung abgeschlossenen Vertrages, führen wird. Legt man dagegen die Feststellung der Verfassung, was hoffentlich geschehen wird, in die Hand des deutschen Gesamtvolkes, so ist anzunehmen, daß das Einheitsbedürfnis der Nation, in erster Linie auf dem Gebiet der Wirtschaft und des Rechts, das zentripetale Element in den Vordergrund schieben wird. Es wird also darauf ankommen, ob der Eingang der künftigen Verfassung dem entsprechend lauten wird, was in den Verfassungen des Norddeutschen Bundes von 1867 und des Deutschen Reiches von 1871 gesagt worden war: Die deutschen Länderregierungen schließen einen ewigen Bund zu folgenden Zwecken, oder ob er lauten kann wie in der Verfassung von Weimar: „Das deutsche Volk, einig in seinen Stämmen, ........ hat sich die folgende Verfassung gegeben." Eine Verfassung, die von einer Vertretung des gesamtendeutschen Volkes festgestellt ist, wird naturgemäß als Zentralorgan Deutschlands einen auf der breiten Grundlage des Volkes ruhenden Reichstag einführen, neben dem ein aus Delegierten der Länderregierungen zusammengesetzter Länderrat ein zwar wichtiges, aber doch auch erst in zweiter Linie entscheidendes Organ sein wird. Es wird sich wiederholen, was in der Verfassungsgeschichte der letzten 150 Jahre in Europa und Amerika immer geschehen ist: der, aus dessen Willen eine neue Verfassung geflossen ist, hat immer dafür gesorgt, daß in der Organisation des Staates ein ihm wesensgleicher Erbe als Hauptorgan vorhanden ist. Eine von einem Monarchen "oktroyierte“ Verfassung stellt den Monarchen als entscheidend in den Mittelpunkt, während die mit einer Volksvertretung vereinbarte oder die von ihr einseitig oder die durch ein Plebiszit geschaffene Verfassung einem Parlament oder Volksentscheidungen die Hauptrolle zuweist. Eine Volksabstimmung, der die künftige Verfassung ihre Geltung verdankt, wird mithin eine Gewähr für eine zentripetale Richtung des deutschen Föderalismus sein. Dies wird sich, wie in der Gestalt der Reichsorganisation, so in der Abgrenzung der Zuständigkeiten zwischen Reich und Ländern auf 
dem letzteren Gebiete in einer verhältnismäßig ansehnlichen Ausstattung des Reichs mit Kompetenzen zu Gesetzgebung, Rechtsprechung und Verwaltung zeigen. Daß man darin nicht zu weit gehen wird, dafür wird auch der im Volke und in den Parteien verbreitete Widerwille gegen die durch den Nationalsozialismus hochgezüchtete Zentralisation und die jahrhundertelange Gewöhnung an eine Vielheit selbständiger deutscher Länder Sorge tragen. 


\section{Bibliographische Nachweise}

1. In: Daheim. Ein deutsches Familienblatt mit Illustrationen 55 (1918/19), Nr. 2 vom 12. Oktober 1918, S. 8-9

2. In: Großdeutsch oder Kleindeutsch? Reden über den Anschluss Deutsch-Österreichs an die Deutsche Republik, Berlin 1919, S. 32-39

3. In: Daheim. Ein deutsches Familienblatt mit Illustrationen 55 (1918/19), Nr. 16 vom 18. Januar 1919, S. 9-10

4. In: Deutsche Politik. Wochenschrift 4 (1919), S. 299-305

5. In: Deutsche Juristen-Zeitung 24 (1919), Sp. 366-374

6. In: Schmollers Jahrbuch 43 (1919), S. 459-510

7. In: Deutsche Allgemeine Zeitung. Reichsausgabe 62 (1923), Nr. $184 / 185$, S. 1-2

8. In: Deutsche Juristen-Zeitung 29 (1924), Sp. 2-7

9. In: Zeitschrift für Politik 14 (1924), S. 193-230

10. Beiträge zum ausländischen öffentlichen Recht und Völkerrecht, Heft 1, Berlin und Leipzig 1927

11. Öffentlich-rechtliche Anhandlungen, Heft 10, Berlin 1928

12. In: VVDStRL 5, Berlin und Leipzig 1929, S. $2-29$

13. In: Deutsche Juristen-Zeitung 37 (1932), Sp. 1501-1508

14. In: Deutsche Allgemeine Zeitung. Ausgabe Groß-Berlin 72 (1933), Nr. 157 vom 2. April 1933, S. 1-2 
15. In: Archiv des öffentlichen Rechts 63 (1934), S. 1-2

16. In: Zeitschrift für ausländisches öffentliches Recht und Völkerrecht 11 (1942), S. 324a-324d

17. In: Heinrich Triepel, Vom Stil des Rechts. Beiträge zu einer Ästhetik, Heidelberg 1947, S. 149-153

18. In: Süddeutsche Juristen-Zeitung 2 (1947), S. 150-152 